\title{
ASSESSMENT OF COAL LIQUIDS AS REFINERY FEEDSTOCKS
}

\author{
Prepared for \\ U.S. Department of Energy \\ Pittsburgh Energy Technology Center
}

Originally Prepared by

P. Zhou and S.N. Rao November 1990

\author{
Revised by \\ P. Zhou \\ Burns and Roe Services Corporation
}

February 1992 


\section{EXECUTIVE SUMMARY}

The R\&D of direct coal liquefaction has reached such a stage that current twostage processes can produce coal liquids with high yields and improved quality at a reasonable cost. To fully realize the potential value, these coal liquids should be refined into high-value liquid transportation fuels. The purpose of this study is to assess coal liquids as feedstocks to be processed by modern petroleum refining technologies.

After the introduction, Section 2.0 summarizes ASTM specifications for major transportation fuels: gasoline, jet fuel, and diesel fuel, which serve as a target for coal-liquid refining. A concise description of modern refining processes follows with an emphasis on the requirements for the raw materials. These provide criteria to judge the quality of coal liquids as a refinery feedstock for the production of marketable liquid fuels.

Section 3.0 surveys the properties of coal liquids produced by various liquefaction processes. Compared with typical petroleum oils, the current two-stage coal liquids are:

- light in boiling range and free of resids and metals

- very low in sulfur but relatively high in oxygen

- relatively low in hydrogen and high in cyclics content

- essentially toxicologically inactive when end point is lower than $650^{\circ} \mathrm{F}$, particularly after hydroprocessing.

Despite these characteristics, the coal liquids are basically similar to petroleum. The modern refining technology is capable of processing coal liquids into transportation fuels meeting al! specifications, and hydroprocessing is obviously the major tool. The 
important point is the determination of a reasonable product slate and an appropriate refining scheme.

The research results on coal-liquid refining documented ir the past two decades were thoroughly reviewed and classified into three refining schemes as discussed in Sections 4.0 through 7.0. They are:

- Refining of coal liquid fractions after they are distilled from the crude coal Liquid.

- Hydrotreating of total coal liquids, and then distilling them into products.

- Hydrocracking of total coal liquids and separating them into products.

Most of the studies were done on coal liquids obtained from early stages of liquefaction process development. However, major conclusions drawn from these studies are applicable at least qualitatively to the refining of current two-stage liquids, since all coal-derived liquids bear fundamental similarity in composition and property.

Based on the experimental and test results accumulated to date, the quality of the liquid fuels that can be obtained from coal liquids is as follows:

Gasoline. The naphtha yield from two-stage coal liquids ranges from $20 \mathrm{wt} \%$ to $28 \mathrm{wt} \%$. The raw naphtha contains $50-68$ vol\% of napthenes and $7-22$ vol\% of aromatics. It has an octane number in the range of 70-83, and is an excellent source for gasoline production. Its high oxygen and nitrogen content is the major cause of fuel instability, and mild hydrotreating is required to produce a premium gasoline component for a refinery gasoline pool. After hydrotreatment, the coal naphtha is also a superior reformer feedstock to make high octane (95-100) gasoline with high reformate yields and a net production of hydrogen. Gasoline appears to be the most 
profitable fuel product from coal liquids, and its yield can be maximized by hydrocracking coal-derived distillates heavier than naphtha (so called all-gasoline-mode of operation).

Jet Fuels. The kerosene fraction of two-stage coal liquids contains around 4050 vol\% of aromatics, and the low API gravity ( $\sim 25)$ and smoke point ( 10 mm) are two major obstacles for jet fuel production. High-severity hydrotreating is necessary for manufacturing coal-derived jet-fuels, and the success depends on the selection of suitable feedstocks and process parameters. Hydrocracking a proper coal distillate with an appropriate recycle cut point seems to be an efficient way to maximize jet fuel production. The coal-derived jet fuels are characterized by excellent cold-weather property and high volumetric heat value.

Diesel Fuels. The middle distillates from two-stage liquids contain high percentages of aromatics (up to $80 \mathrm{vol} \%$ ), which are reflected in low cetane numbers ( 20-25). The heteroatoms are the cause of instability. A distillate of proper boiling range, after hydrotreating under medium-to-moderate severity and with the assistance of appropriate additives, can meet the specifications for light diesel fuels.

The gasoline-diesel product slate and all-gasoline-mode of production appear to be two realistic strategies for coal liquid refining. The manufacture of jet fuels from coal liquids is a difficult task and more investigation is needed. Tailoring the coalderived jet fuels either as high-density jet-fuels or as a high-volumetric-heating-value range-extender component for jet-fuel blending, is advisable.

Regarding the three refining schemes mentioned above, total-coal-liquid hydrotreating is not recommended due to: 
- difficulty in hydrotreating. The high end point of the total coal liquid makes its hydrotreating much more difficult and less efficient then hydrotreating of individual fractions.

- lack of selectivity and flexibility. The total coal liquid has to be hydrotreated under the highest severity required by one specific fraction and other fractions are thus over-hydrogentated, or vie versa.

- lower product quality. The multi-ring aromatics in the total coal liquid, which are outside the range of jet fuel or diesel fuel fractions, are also hydrogenated. The resultant cyclic compounds, which have lower boiling points than their precursors, enter the product fractions, thus lowering the fuel quality.

Hydrocracking of total coal liquids has similar disadvantages, but perhaps to a lesser extent. Therefore, separate refining of raw (or straight-run) coal-liquid fractions -- as petroleum has been processed in refineries for decades -- is the preferred scheme. This refining scheme has flexibility in product slate composition, selectivity in processing severity for different products, and better product quality.

Recommendations are made in Section $\mathbf{8 . 0}$ for systematic refining studies on two-stage coal liquids, paying special attention to the cut points of various coal liquid fractions, including an oxygen-rich fraction $\left(350-450^{\circ} \mathrm{F}\right)$ for phenolics extraction. Engine tests for coal-derived gasoline and diesel fuel products are suggested. Economic studies on coal-liquid refining schemes, product slates, and refining process viabilities are strongly recommended. Further studies on physical and thermodynamic properties to develop specific correlations for coal liquids are highly justified. 
TABLE OF CONTENTS

Page

EXECUTIVE SUMMARY

1.0 INTRODUCTION $\ldots \ldots \ldots \ldots \ldots \ldots \ldots \ldots \ldots \ldots \ldots \ldots$

1.1 Background $\ldots \ldots \ldots \ldots \ldots \ldots \ldots \ldots \ldots \ldots \ldots$

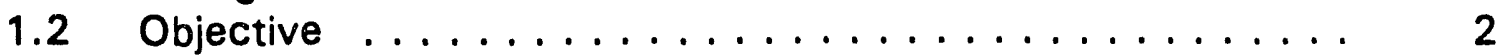

2.0 PETROLEUM REFINING PROCESSES AND PRODUCT

REQUIREMENTS $\ldots \ldots \ldots \ldots \ldots \ldots \ldots \ldots \ldots \ldots \ldots \ldots$

2.1 Product Specifications $\ldots \ldots \ldots \ldots \ldots \ldots \ldots \ldots \ldots$

2.1.1 Automotive Gasoline ............... 4

2.1.2 Aviation Gasoline . . . . . . . . . . . . . 4

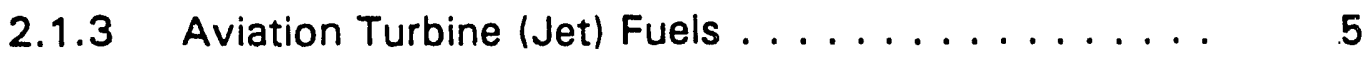

2.1.4 Diesel Fuel Oils ................. 6

2.1 .5 Fuel Oils ................... 6

2.1.6 Gas Turbine Fuel Oils . . . . . . . . . . . . 7

2.2 Related Licensed Refining Processes . . . . . . . . . . . . 8

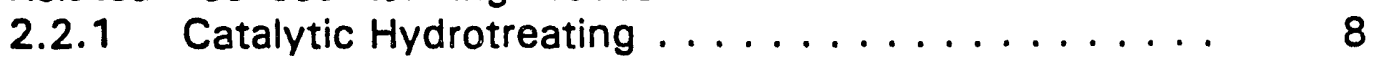

2.2.2 Catalytic Hydrocracking . . . . . . . . . . . 9

2.2.3 Catalytic Reforming ................ 12

2.2.4 Catalytic Cracking . . . . . . . . . . . . . 13

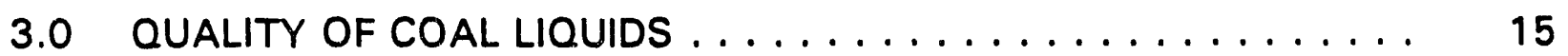

3.1 Composition and Properties of Coal Liquids . . . . . . . . 15

3.2 Heteroatoms in Coal Liquids ................ 18

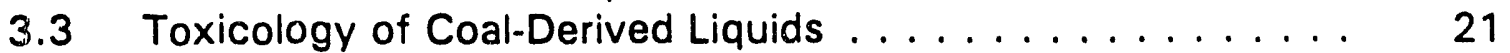

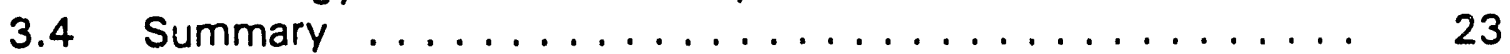

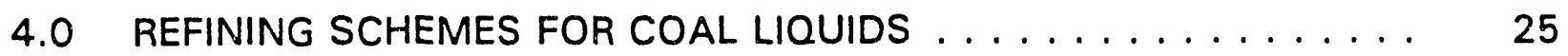

5.0 REFINING OF RAW COAL LIQUID FRACTIONS $\ldots \ldots \ldots \ldots . \ldots 28$

$5.1 \quad$ Light Naphtha $\ldots \ldots \ldots \ldots \ldots \ldots \ldots \ldots \ldots \ldots \ldots \ldots$

5.2 Naphtha . . . . . . . . . . . . . . . . . 29

5.3 Kerosene Fraction $\ldots \ldots \ldots \ldots \ldots \ldots \ldots \ldots \ldots \ldots$

5.4 Diesel Fuel Fraction $\ldots \ldots \ldots \ldots \ldots \ldots \ldots \ldots \ldots \ldots . \ldots . \ldots . \ldots$

5.5 Heavy Distillates . . . . . . . . . . . . . . 43

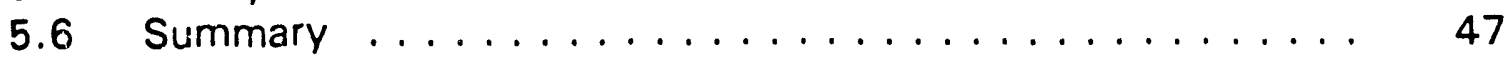




\section{TABLE OF CONTENTS \\ continued}

Page

6.0 HYDROTREATING OF TOTAL COAL LIQUIDS . . . . . . . . . . 49

6.1 Naphtha from Hydrotreated Coal Liquids . . . . . . . . . . 53

6.2 Jet Fuel Fraction from Hydrotreated Coal Liquids . . . . . . . 55

6.3 Diesel Fuel Fraction from Hydrotreated Coal Liquids . . . . . 58

6.4 Fuel Oil Fraction from Hydrotreated Coal Liquids . . . . . . . . 60

6.5 Two-Step Hydrotreating of High End-Point Coal Liquids . . . . 61

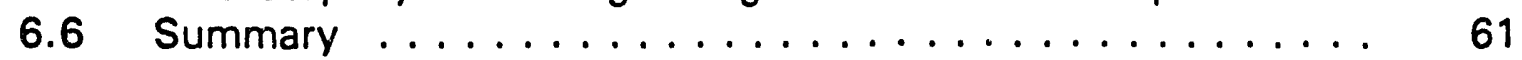

7.0 HYDROCRACKING OF TOTAL COAL LIOUIDS . . . . . . . . . . 64

8.0 CONCLUSIONS AND RECOMMENDATIONS $\ldots \ldots \ldots \ldots$

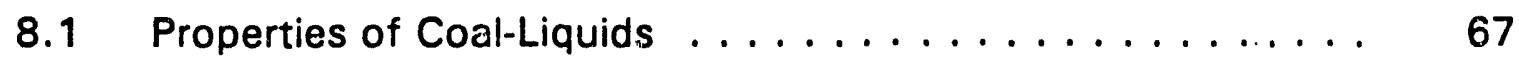

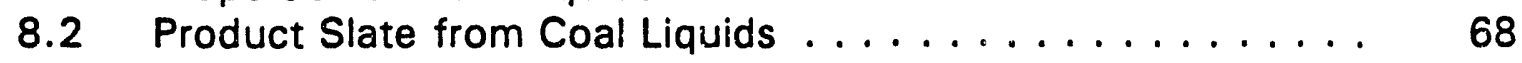

8.3 Coal-Liquid Refining Technologies . . . . . . . . . . . 69

8.4 Refining Scheme for Coal Liquids . . . . . . . . . . . 70

8.5 Research Recommendations . . . . . . . . . . 72

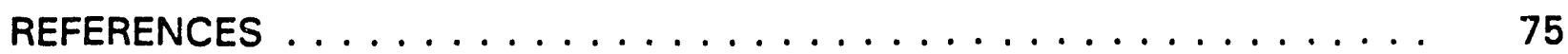




\section{LIST OF TABLES}

Page

Table 1. Detailed Requirements for Gasoline . . . . . . . . . . . . . . 86

Table 2. Gasoline Antiknock Indexes and Their Application . . . . . . 87

Table 3. Detailed Requirements for Aviation Gasolines . . . . . . . . . . . . 88

Table 4. Detailed Requirements for Aviation Turbine Fuels . . . . . . . . 90

Table 5. Primary Military Aviation Fuel Specification Requirements . . 92

Table 6. Average Jet Fuel Properties in the United States . . . . . . . 93

Table 7. Detailed Requirements for Diesel Fuel Oils . . . . . . . . . . . 94

Table 8. Detailed Requirements for Fuel Oils . . . . . . . . . . . . . . 95

Table 9. Detailed Requirements for Gas Turbine Fuel Oils . . . . . . . . 97

Table 10. Trace Metal Limits of Fuel Entering Turbine Combustors . . . 99

Table 11. Residua and Heavy Oils Hydrotreating Processes . . . . . . . 100

Table 12. Distillate Hydrotreating Processes . . . . . . . . . . . . . . . 101

Table 13. Hydrocracking Processes . . . . . . . . . . . . . . . . . 102

Table 14. Catalytic Reforming Processes . . . . . . . . . . . . . . . . . 104

Table 15. Catalytic Cracking Processes . . . . . . . . . . . . . . . . 105

Table 16A. Properties of Coal Liquids from Single-Stage Processes . . . 107

Table 16B. Properties of Coal Liquids from Two-Stage Processes . . . . 109

Table 17. Properties of Crude Petroleum and Shale Oil . . . . . . . . . . 114

Table 18. Comparison of Elemental Composition of H-Coal Fractions

from Illinois No. 6 with Petroleum Fractions . . . . . . . . . 115

Table 19. Comparison of Typical Petroleum Fractions with

Wilsonville Fractions . . . . . . . . . . . . . . . . 115

Table 20. Light Naphtha from Illinois No. 6 ITSL . . . . . . . . . . . . . 116

Table 21. Properties of Raw Naphtha Fractions from Single-Stage

Liquefaction Coal Liquids . . . . . . . . . . . . . . 117

Table 22A. Properties of Raw Naphtha Fractions from Two-Stage

Liquefaction Coal Liquids . . . . . . . . . . . . . . . 119

Table 22B. Properties of Straight-Run Naphthas from Recent

Wilsonville CC-ITSL Runs . . . . . . . . . . . . . . . . 120

Table 23. Compositional Analyses of Coal-Derived Naphthas . . . . . . 121

Table 24. Hydrotreating of H-Coal Naphtha . . . . . . . . . . . . 122

Table 25A. Properties of Raw Kerosene Fraction from Coal Liquids . . . . 123

Table 25B. Properties of Jet Fuel Fraction from Two-Stage Coal

Liquid . . . . . . . . . . . . . . . . . . . . . 124

Table 26. Properties of the $250^{\circ} \mathrm{F}-600^{\circ} \mathrm{F}$ Jet Fuels from Hydrotreated

$600^{\circ} \mathrm{F}$. Redistilled Texas Lignite EDS Coal Liquids . . . . . . 125

Table 27. Gas Turbine Test Fuels . . . . . . . . . . . . . . . . . 126

Table 28A. Properties of Raw Middle Distillates from Coal Liquids . . . . 127

Table 28B. Properties of Diesel Fuel Fractions from Coal Liquids of

Recent CC-ITSL Process . . . . . . . . . . . . . 


\section{LIST OF TABLES \\ continued}

Page

Table 28C. Hydrotreating of Coal-Derived Middle Distillate . . . . . . . . 129

Table 29. Properties of Raw Heavy Distillates from Coal Liquids . . . . . 130

Table 30. Hydrocracking of H-Coal Gas Oil . . . . . . . . . . . . . 131

Table 31. Hydrotreating Tests of Coal Liquids . . . . . . . . . . . 132

Table 32. Hydroupgrading of SRC-II Coal Liquid . . . . . . . . . . 133

Table 33. High Severity Hydrotreating Yields and Hydrogen

Consumptions ..................... 134

Table 34. High Severity Hydrotreating Product Inspections . . . . . . . . 134

Table 35. Typical Naphthas from Hydrotreating of Coal-Derived Oils . . 135

Table 36. Properties of Selected Naphthas Derived from Shale Oil and Wyodak H-Coal . . . . . . . . . . . . . . . . . 135

Table 37. Properties of Naphtha Products from SRC-II Liquids

Hydrotreated at Intermediate and High Severities . . . . . 136

Table 38. Composition of Naphtha Fractions from Eight Upgraded Coal Liquids . . . . . . . . . . . . . . . . . . . 137

Table 39. Comparison of Kerosene Jet Fuel Products from Severely Hydrotreated Coal-Derived Oils with ASTM Jet A Specifications ...................... 138

Table 40. Representative $250^{\circ} \mathrm{F}-550^{\circ} \mathrm{F}$ Jet Fuels from Hydrotreated Coal Liquids . . . . . . . . . . . . . . . . . . . . . . 139

Table 41. Properties of Selected Jet Fuels Derived from Shale Oil and Wyodak H-Coal . . . . . . . . . . . . . . . . . . 139

Table 42. Jet Fuels from Hydrotreating and Hydrocracking Illinois ITSL Oil . . . . . . . . . . . . . . . . . . . . . . . . 140

Table 43. Detailed Analyses of Narrow-Boiling Fractions of Jet Fuel from Hydrotreated Wyodak ITSL Oil . . . . . . . . . . . 141

Table 44. Detailed Analyses of Narrow-Boiling Fractions of Jet Fuel from Hydrotreated Wyodak CTSL Oil . . . . . . . . . . . 142

Table 45. Group Analysis of Distillates from Upgraded TSL Coal Liquids . . . . . . . . . . . . . . . . . . . . . . 143

Table 46. Comparison of Severely Hydrotreated Coal Products with ASTM Diesel Fuel Specifications . . . . . . . . . . . . 144

Table 47. Properties of Selected Diesel Fuels Derived from Shale Oil and Wyodak H-Coal . . . . . . . . . . . . . 145

Table 48. Properties of $250^{\circ} \mathrm{F}+$ Fractions from ITSL Liquids . . . . . . 146

Table 49. Comparison of Moderately Hydrotreated Coal Oil Products with ASTM Specifications for Heating Fuel . . . . . . . . .

Table 50. Detailed Analyses of Narrow-Boiling Fractions of Jet Fuel from Hydrotreated Illinois ITSL Oil . . . . . . . . . . . . 148

Table 51. Detailed Analyses of Narrow-Boiling Fractions of Jet Fuel from Hydrocracking of Hydrotreated Illinois ITSL Oil . . . . 149 


\section{LIST OF FIGURES}

Page

Figure 1. TBP Distillations for Arabian Light Crude, Shale Oil and Coal-Derived Liquids . . . . . . . . . . . . . . . . 150

Figure 2. TBP Distillations of Arabian Crudes and Coal-Derived Liquids . . . . . . . . . . . . . . . . . . 151

Figure 3. TBP Distillations of Coal Liquids . . . . . . . . . . . 152

Figure 4. TBP Distillations of Coa! Liquids . . . . . . . . . . . . . 153

Figure 5. Hydrogen Content of Coal Liquid Fractions vs

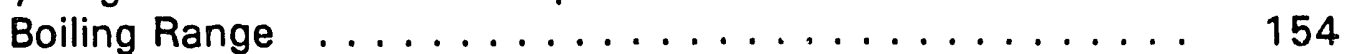

Figure 6. Distribution of Heteroatom Content in H-Coal Fractions . . . . 155

Figure 7. Direct Oxygen Content vs Average Cut Temperature of Coal Liquids from Two Liquefaction Stages . . . . . . . . . 156

Figure 8. Sulfur Level vs Average Cut Temperature of Coal Liquids from Two Liquefaction Stages . . . . . . . . . . . . . . 157

Figure 9. Total Nitrogen Content vs Average Cut Temperature of Coal Liquids ......................... 158

Figure 10. Basic Nitrogen Level vs Average Cut Temperature of Coal Liquids . . . . . . . . . . . . . . . . 159

Figure 11. Oxygen Distribution in CC-ITSL Coal Liquids . . . . . . . . . 160

Figure 12. Hydrogen and Liquid Yield vs Octane for Upgraded Illinois No. 6 H-Coal Naphtha . . . . . . . . . . . . . . 161

Figure 13. Hydrogen and Liquid Yield vs Octane for Upgraded Illinois No. 6 SRC-II Naphtha . . . . . . . . . . . . . . . 162

Figure 14. Hydrogen Consumption vs EDS Naphtha API Gravity Increase 163

Figure 15. $\quad \mathrm{C}_{5}{ }^{+}$Reformate Yield vs Octane Level for EDS Naphtha . . . . 164

Figure 16. Hydrogen Yield vs Octane Level for EDS Naphtha Reforming 165

Figure 17. Hydrotreating of Illinois No. 6 EDS Middle Distillate . . . . . 166

Figure 18. Relationships of Cetane Number, Aromatics Concentration, and hydrogen Content of Coal-Derived Middle Distillates . . 167

Figure 19. Effect of Feedstock Hydrogen Content on Response to Fluid Catalytic Cracking (H-Coal Gas Oil) . . . . . . . . . 168

Figure 20. Effect of Feedstock Hydrogen Content on Response to Fluid Catalytic Cracking (EDS Gas Oil) . . . . . . . . . . . 169

Figure 21. $\quad \mathrm{C}_{5}{ }^{+}$Yield vs Product Aromatic Content . . . . . . . . . . 170

Figure 22. Product Nitrogen vs Hydrogen Consumption for Four Coal Liquids . . . . . . . . . . . . . . . . . . . . . . 171

Figure 23. Product Aromatic Content vs Hydrogen Consumption for Four Coal Liquids . . . . . . . . . . . . . . . . . . . . . 172

Figure 24. Effect of Feed End Point on Catalyst Temperature for Hydrodenitrogenation of ITSL Oils . . . . . . . . . . 173

Figure 25. Effect of Aromatics on Smoke Point of Jet Fuels from Hydrotreated Coal-Derived Feed . . . . . . . . . . . . . . 174

Figure 26. Smoke Point of $250^{\circ} \mathrm{F}+$ Jet Fuels from Different Hydrotreating Schemes ................ 


\section{LIST OF FIGURES}

continued

Page

Figure 27. Effect of Aromatics on the Cetane Number of Diesel Fuels from Hydrotreated Coal-Derived Oils . . . . . . . . . . . . 176

Figure 28. Effect of Octyl Nitrate Cetane Number Improver on Two Coal-Derived Diesel Fuels . . . . . . . . . . . . . . . . . 177

Figure 29. Yield-Octane Curve for $\mathrm{H}$-Coal Hydrocrackate Platforming ........................ 178

Figure 30. Hydrocracking of Hydrotreated ITSL Oil-Effect of Recycle Cut Point on Yield and Smoke Point of $250^{\circ} \mathrm{F}+$ Jet Fuel Fraction . . . . . . . . . . . . . . . . . . . . 179

Figure 31. Effect of Boiling Range on Smoke Point of NarrowBoiling Fractions of Hydrocracked ITSL Oil . . . . . . . . . . . 180

Figure 32. Refining Scheme for Coal Liquids . . . . . . . . . . . . 181 


\section{ASSESSMENT OF COAL LIOUIDS AS REFINERY FEEDSTOCKS}

\subsection{INTRODUCTION}

\subsection{Background}

The production of liquid fuels from coal is one of the lead missions of the Pittsburgh Energy Technology Center. R\&D in the direct liquefaction of coal has progressed steadily and has decreased the cost of production of coal-derived liquid fuels remarkably in the 1980 s.

In the early stages of coal liquefaction technology development coal-derived liquids were considered potential boiler fuels. It was soon realized that in order to attain their full value, products from direct liquefaction would have to be refined and upgraded to quality liquid fuels for both transportation and home heating uses. The coal liquefaction products soon became candidates as refinery feedstocks [1]. In the meantime, substantial irnprovements were achieved in soal liquefaction technology through two-stage liquefaction processes. This resulted in the prenduction of coal liquids with virtually no resid or metals and low sulfur and nitrogen content, which make them prospective refinery feedstocks.

The petroleum industry has undergone tremendous expansion and changes in the past few decades. Enormous increases in the size of process units, new catalytic processes, shifting product demands, and new sources of feedstocks from tar sands, heavy oils, and oil shales have made present-day technology and economics of petroleum refining very complex and sophisticated. Theoretically, modern refining technology is capable of processing almost any liquid hydrocarbon feedstock to yield desired products. Coal liquids, when needed to supplement crude oil supplies, will be processed in units similar to those in petroleum refineries. The basic requirement, however, is the cost-effectiveness of manufacturing products that meet market 
demand and strict specifications for commercial liquid fuels. As a result, the coal liquids produced by state-of-the-art coal liquefaction technology must be assessed relative to the specifications for marketable fuel products and to the requirements for feedstocks to vaılous units in present-day refineries.

\subsection{Objective}

The objective of this report is to evaluate the quality and properties of liquid products from direct liquefaction processes relative to the specifications for petroleum fuel products and to the feed requirements for refinery processes that can be used to upgrade coal liquids. The report will attempt to determine the refinability of coal liquids and the suitability of various existing refining processes to produce commercial products from coal liquids. These processes include hydrotreating, hydrocracking, catalytic crackirig, and naphtha reforming. 


\subsection{PETROLEUM REFINING PROCESSES AND PRODUCT REQUIREMENTS}

Modern direct liq' 'lefaction processes are designed to produce coal liquids to be refined eventually to make transportation fuels inat are currently manufactured primarily from petroleum. These fuels from coal liquids must meet market demand and quality requirements set forth by stringent product specifications. A detailed analysis of these specifications is therefore of vital importance to determine the gap between product quality requirements and the coal liquid properties. Thus, related fuel specifications and pertinent refining processes are reviewed in following subsections.

\subsection{Product Specifications}

The American Petroleum Institute conducted a survey of petroleum refineries and petrochemical plants, which revealed that over 2,000 products are made to meet a huge variety of specifications $[2,3]$. Generally, the products that dictate refinery design are relatively few in number, and the fundamental refinery processes are based on the large-quantity products such as gasoline, jet fuel, and ciesel fuel.

Although lubricating oils and greases are very high-value products, they represent only a small fraction in terms of volume of refinery products. Moreover, based on available analytical data, coal-derived liquids are not suitable for the manufacture of lube oils. Therefore, only transportation fuels and home heating fuels, as a replacement for petroleum products, are considered as reasonable products to be manufactured from coal liquids. Since kerosene is an obsolete product with little chance of revival, discussion on kerosene is limited to its use as a jet fuel fraction. 


\subsubsection{Automotive Gasoline (ASTM Designation: D439-88b)}

Detailed requirements for automotive gasoline are listed in Table 1 . These standard specifications are a guide in wstablishing the requirements of gasoline for ground vehicles equipped with spark-ignition engines. A specification that encompasses all fuels for automotive spark-ignition engines, including blends of gasoline with oxygenates such as alcohols and ethers, is under development, and appears as Specification D4814.

The major performance requirements for gasoline are the following:

1) Volatility is varied for seasonal climatic changes by providing five volatility classes of gasoline, which correspond to seasonal and geographical distributions. This requirement is usually met by blending of light ends, which are always available in the refinery.

2) Antiknock index levels, defined as the average of the Research Octane Number (RON) and Motor Octane Number (MON), and their application are set forth in Table 2. For gasolines derived from coal liquids, especially after reforming, this requirement can be met very easily.

\subsubsection{Aviation Gasoline (ASTM Designation: D910-88a)}

This specification defines specific types of aviation gasoline for civil use. Three grades of aviation gasoline are provided, known as Grade 80, 100, and 100LL. Aviation gasoline grades are also identified by two numbers separated by a hyphen $(-)$ or sometimes a slant line (/). The first number is called the "lean mixture rating" and the second the "rich mixture rating": $80-87$ (80/87), 100-130 (100/130), and 100-130LL (100/130LL). Numbers below 100 are octane numbers, while numbers above 100 are performance numbers. At 100, octane number and performance 
number are equal. The detailed requirements for aviation gasoline are listed in Table 3.

\subsubsection{Aviation Turbine (Jet) Fuels tâSTM Designation: D1655-88a)}

Aviation gas turbine fuels, or jet fuels, are the most critical products, in terms of quality, produced by the refining industry, although they represent only about $7 \%$ of the refinery products in the U.S.

Standard Specification D1655-88a defines the specific types of aviation turbine fuels for civil use. It does not include all fuels suitable for aviation turbine engines. Certain equipment or conditions of use may permit a wider or require a narrower range of characteristics than is shown in Table 4.

Aviation turbine fuet, except as otherwise specified herein, shall consist of blends of refined hydrocarbons derived from petroleum, natural gasoline, or blends thereof with synthetic hydrocarbons.

Three types of aviation turbine fuels are provided for civil use:

Jet $A$ and Jet $A-1$ represent two grades of high flash point kerosene-type jet fuels that differ in freezing point. Jet $A-1$ requires a freezing point $7^{\circ} \mathrm{C}$ lower than Jet $A$. Jet $B$ is a relatively wide boiling range volatile distillate, which is characterized with a boiling range between $150^{\circ} \mathrm{F}$ and $480^{\circ} \mathrm{F}$.

The aviation turbine fuel shall be free of undissolved water, sediment, and suspended matter. The odor of the fuel should not be nauseating or irritating. No substance of known dangerous toxicity under usual conditions of handling and use can be present, except as permitted herein. 
In 1951, the U.S. Air Force standardized aircraft operation on JP-4 jet fuel to optimize performance and availability. This fuel can be characterized as a "wide-cut" fuel. Some of the most important chemical and physical properties of JP-4 are depicted in Table 5. The -ommercial specification for the wide-cut fuel is designated as Jet $B$ and is similar, with a few minor exceptions, to JP-4. The properties of JP-4 are required for high-altitude operations and low-ambient-temperature conditions at certain air bases. For operations where JP-4 may not be available, a kerosene-type jet fuel, Specification JP-8, may be used. The commercial equivalent for JP-8 is Jet A-1. The basic differences between Jet A-1 and JP-8 are the additives required for military operations. The Navy fuel specification is JP-5, which is identical to JP-8, except for a minimum flash point of $140^{\circ} \mathrm{F}$, for safety on aircraft carriers. Table 6 carries the average jet fuel properties in the U.S.

The possibility of modifying jet fuel specification has been the objective of various research efforts over the years. Allowing the jet fuels to become more cyclic, thereby increasing fuel density, offers promise as a range extender for aircraft. This so-called high-density jet fuel is often referred to as JP-8X. It has the same volatility as JP-8 and Jet A-1, essentially a kerosene. Comparing the volumetric heating value of JP. $8 \mathrm{X}$ with that of conventional JP-4, the energy increase could be more than $10 \%$.

\subsubsection{Diesel Fuel Oils (ASTM Designation: D975-88)}

This specification covers three grades of diesel fuel oils suitable for various types of diesel engines.

Standard Specification D975 (Table 7) is intended as a statement of permissible limits of significant fuel properties used for specifying the wide variety of commercially available diesel fuel oils. The properties of these commercial fuel oils depend upon the refining practices employed and the nature of the crude oils from 
which they are made. Distillate fuel oils, for example, may be produced within the boiling range of $150^{\circ} \mathrm{C}$ and $400^{\circ} \mathrm{C}\left(300^{\circ} \mathrm{F}\right.$ and $\left.755^{\circ} \mathrm{F}\right)$, with many possible combinations of various properties such as volatility, ignition quality, viscosity, and other characteristics.

\subsubsection{Fuel Oils (ASTM Designation: D396-86)}

This specification covers grades of fuel oil intended for use in various types of fuel-oil-burning equipment under various climatic and operating conditions. Standard Specification D396 divides fuel oils into grades based upon the types of burners for which they are suitable. It places limiting values on several of the properties of the oils in each grade, as shown in Table 8.

The grades of fuel oil specified herein shall be homogeneous hydrocarbon oil, free from inorganic acid, and free from excessive amounts of solids or fibrous foreign matter likely to make frequent cleaning of suitable strainers necessary. All grades containing residual components shall remain uniform in normal storage and not separate by gravity into light and heavy oil components outside the viscosity limits for the grade.

\subsubsection{Gas Turbine Fuel Oils (ASTM Designation: D2880-88)}

This specification covers the selection of fuels for gas turbines, except those used in aircraft.

The various grades of gas turbine fuel oil shall conform to the limiting requirements shown in Table 9. As noted in the supplementary footnotes to this table, the requirements for Grade Nos. 1-GT and 2-GT conform in most respects to corresponding Grade Nos. 1 and 2 fuels in Specification D396 (fuel oils), and to Grade Nos. 1-D and 2-D in Specification D975 (diesel fuels). The viscosity range of Grade 
Nos. 3-GT and 4-GT fuels brackets the Grade Nos. 4, 5, and 6 of D396 and Grade No. 4-D of D975. It is the intention that fuels meeting Specification D396 and D975 requirements may also be listed under these specifications provided they meet the requirements listed in Table 9.

The particular significance of trace metals in gas turbine fuels is noted and upper limits of trace metals are recommended for various grades of gas turbine fuels (Table 10).

\subsection{Related Licensed Refining Processes}

Based on the information regarding coal liquid property and coal liquid refining accumulated in the past two decades, it is predictable that various hydroprocessing techniques will be principal refining tools for coal liquids derived from direct liquefaction. Pertinent technologies are described as follows.

\subsubsection{Catalytic Hydrotreating}

Hydrotreating or hydrorefining is applied to a wide range of feedstocks, from naphtha to reduced crude, in petroleum refineries. Objectionable elements removed by hydrotreating include sulfur, nitrogen, oxygen, halides, and trace metals. When the process is used specifically for sulfur removal, one of the main concerns in petroleum refineries, it is usually called hydrodesulfurization or HDS. Under certain circumstances, hydrogenation of unsaturated hydrocarbons may be another objective.

If nitrogen removal is a significant consideration, catalysts composed of nickelcobalt-molybdenum or nickel-molybdenum compounds supported on alumina are more efficient. Nitrogen is generally more difficult to remove from hydrocarbon streams than is sulfur and any treatment that reduces nitrogen concentration to a satisfactory level will effectively eliminate excess sulfur. Nickel-containing catalysts usually 
require activation by presulfiding with disulfide, mercaptans, or dimethyl sulfide before bringing them up to reaction temperature.

Although about 30 hydrotreating processes are available for licensing [4], most of them have essentially the same process flow for a given application. Some confusion may exist because of the many alternative processes that are available and because of the nomenclature that has been employed by the licensors.

The tcchnical literature contains many references to processes that are reported to be suitable for the hydrodesulfurization of heavy oils and residue (Table 11) [5-18] as well as for distillates (Table 12) [19-28].

As shown in Tables 11 and 12, hydrotreating units designed for resids can handle feedstocks as heavy as $1050^{\circ} \mathrm{F}+$, with Conradson carbon up to $28 \mathrm{wt} \%$, sulfur up to $6 \mathrm{wt} \%$ and metals over $400 \mathrm{ppm}$. Distillate hydrotreating processes treat a wide variety of distillate feedstocks that may contain sulfur up to $3.6 \mathrm{wt} \%$ and nitrogen as high as $0.6 \mathrm{wt} \%$. Two-stage coal liquefaction liquids can meet these standards easily. There are no clear limits on oxygen content for hydrotreating feedstocks, which merit close attention as far as coal liquids are concerned.

\subsubsection{Catalytic Hydrocracking}

The hydrocracking process was commercially developed by I.G. Farben Industrie in 1927 for converting lignite into gasoline and was brought to this country by ER\&E in the early 1930s for use in upgrading petroleum feedstocks and products. Improved catalysts have been developed that permit operation at relatively low pressures, and a shift in demand has necessitated conversion of higher boiling petroleum materials to gasoline and jet fuels. Relatively few operations offer the versatility of catalytic hydrocracking. 
In a modern refinery, catalytic cracking and hydrocracking work as a team. The catalytic cracker takes the more easily cracked straight-run gas oils as charge stocks, while the hydrocracker uses cycle oils and coker distillates as feed [29]. Highly aromatic feeds (such as cycle stou.. from catalytic cracking) are very refractory, and using them as a component for fuel blending is limited as they burn with a smoky flame. But they make excellent feedstocks for hydrocracking.

In addition to middle distillates and cycle oils used as feed for hydrocracking units, it is also possible to process residual stocks and reduced crude by hydrocracking. This usually requires a different technology such as ebullated-bed technology. Thus, the hydrocracking operations can be broken into two general types of processes: those which process distillate feeds and those which process residual materials. These processes are similar and some of the licensed processes can be adapted to operate on both types of feedstocks. There is a major difference, however, between the two processes in regard to the type of catalyst and operating conditions.

A number of hydrocracking processes are available for licensing, as described in Table 13 [30-51].

Most of the hydrocracking catalysts consist of a crystalline mixture of silicaalumina, which serves as the cracking base, with a small amount of uniformly distributed transition metals contained within the crystalline lattice. The metals vary with the manufacturer. Those in most common use are platinum, palladium, tungsten oxide, and nickel [30], as well as molybdenum.

Different hydrocracking catalysts are susceptible, to a different extent, to poisoning by metallic salts, oxygen-, nitrogen-, and sulfur-compounds in the feedstock. The feedstock is first hydrotreated to saturate the olefins and remove the sulfur, nitrogen, and oxygen compounds. Certain metals are retained on the catalyst. 
An increase in organic nitrogen content of the feed causes a decrease in conversion. For some types of hydrocracking catalysts, the presence of hydrogen sulfide in low concentrations inhibits the saturation of aromatic rings. This is beneficial when maximizing gasoline production as it conserves hydrogen and pruduces a higher octane product. However, hydrocracking in the presence of a small amount of hydrogen sulfide normally produces a low smoke point jet fuel. At high sulfide levels, corrosion of the equipment becomes important and the cracking activity of the catalyst is also affected adversely.

Many feedstocks have been processed successfully, such as vacuum gas oils (VGO's) of moderate to heavy qualities (50-70 wt\% aromatics, 2-4 wt \% S, 0.1-0.35 $w t \% N$ ), and nun-virgin feedstocks like pretreated pyrolysis fuel oil (>98 wt \% polyaromatics). For some processes, a limit is set on the asphaltene content not to exceed $0.5 \mathrm{wt} \%$. For some catalysts, run time may be decreased by irreversible poisoning caused by vanadium content in the feedstock, and therefore vanadium should be kept below $2.5 \mathrm{ppm}$ for the Linde hydroconverter catalyst. Within the above limits, practically any feedstock can be fed [50].

In addition to the removal of the nitrogen and sulfur compounds and metals, it is also necessary to reduce the water content of the feed streams to less than 25 ppm. At the temperatures required for hydrocracking, steam causes the collapse of crystalline structure of the catalyst and the agglomeration of dispersed rare-earth atoms. The feed oxygen content may also be considered to affect the catalyst in a similar way. An exception to this is the Unicracking/JHC process, which can tolerate water contents as high as 400 to 500 ppm [42]. According to Unocal [52], the oxygen level of $2.7 \%$ in the Great Plains tar oil would be borderline acceptable, and the maximum allowable nitrogen level to the hydrocracker is about 5,000 ppm. If the oxygen level is too high, the resulting partial pressure of water vapor is deleterious and destroys the catalyst support. Unocal also specifies maximum particulates concentration in the $2-5 \mathrm{ppm}$ range for its fixed bed operations. 


\subsubsection{Catalytic Reforming}

The typical feedstocks to catalytic reforming are heavy straight-run naphthas $\left(180^{\circ} \mathrm{F}-375^{\circ} \mathrm{F}\right)$, which have the following PONA analysis 130 ]:

\begin{tabular}{lcc} 
& \multicolumn{2}{c}{ Vol\% } \\
\cline { 3 - 4 } Component & Feed & Product \\
Paraffins & $15-55$ & $30-50$ \\
Olefins & $0-2$ & 0 \\
Naphthenes & $30-40$ & $5-10$ \\
Aromatics & $5-10$ & $45-60$
\end{tabular}

The active material in most reforming catalysts is platinum. Certain metals, hydrogen sulfide, ammonia, and organic nitrogen and sulfur compounds will deactivate the catalyst. Reformer catalysts require less than $0.5 \mathrm{wppm}$ sulfur in the feed, or even lower into the range of $10 \mathrm{wppb}$. Not only sulfur but other contaminants such as water, nitrogen, oxygen, silica, phosphorus, and metals like copper, arsenic, and lead must be removed or reduced to very low levels in reformer reactor charge [53]. Normally, feeds are well hydrodesulfurized and stripped free of sulfur [54]. Fifty to $75 \mathrm{ppm}$ of nitrogen in the naphtha feed would be the upper limit that most refineries could handle, and only when well blended with a more typical naphtha.

The process by which contaminants are reduced to acceptable concentrations in reformer feed is hydrotreating. The hydrotreater employs a cobalt-molybdenum catalyst to convert organic sulfur and nitrogen compounds to hydrogen sulfide and ammonia, which are then removed from the system with the unreacted hydrogen. The metals in the feed are retained by the hydrotreater catalyst acting as a guard bed for the reformer catalyst. Refiners consider it better to sacrifice a cobalt-moly or nickel-moly hydrotreating catalyst rather than to poison a bimetallic reforming catalyst. 
Several major reforming processes are in use today as depicted in Table 14 [5462]. Also available are some other commercial reformers, such as Rexforming (combination of Platforming and aromatics extraction), Hydroforming, Catforming, Ultraforming (licensed by Standard Oil of Indiana), Houdriforming and Iso-Plus Houdriforming (Houdry), Selectoforming, Hyperforming (moving bed), Thermofor Catalytic Reforming (Mobil, moving bed), and fluid-bed reforming $[4,63]$.

\subsubsection{Catalytic Cracking}

This is the most important and widely used petroleum refining process for converting heavy oils into valuable gasoline and lighter products, with almost one million tons of oil processed per day in the U.S. [64].

The Thermofor Catalytic Cracking process (TCC) is representative of the moving-bed units and the Fluid Catalytic Cracker (FCC) is representative of the fluidized-bed units. Models II, III, and VI Fluid Catalytic Cracking units have long been known, and commercial catalytic processes are summarized in Table 15 [65-79].

Catalytic cracking of distillate feedstocks (gas oils usually have an average boiling point around $800^{\circ} \mathrm{F}$ ) is the most common operation and has been practiced for a long time. However, the use of crackers for resids and asphalt-containing feedstocks increased dramatically in the early 1980s. The 1987 survey reported about $40 \%$ of U.S. FCC capacity to be resid cracking, with resid defined as as containing over $5 \mathrm{LV} \%$ of $1000^{\circ} \mathrm{F}+[80]$. Conradson carbon of a few percent is usual and feedstocks with a conradson carbon as high as $18 \%$ can be handled in resid cracking units.

There were not many units processing desulfurized feedstocks in the late $1970 \mathrm{~s}$ and early 1980s, since then, however, desulfurization of high sulfur feeds, such as using hydrocracked feedstocks, has become common practice. In general, removing 
$65 \%$ to $75 \%$ of the sulfur does not profoundly improve the product yield pattern, and only deep desulfurization in combination with saturation of polyaromatic nuclei will significantly increase gasoline yield and reduce coke make [69,81]. The catalysts can tolerate feedstocks with a sulfur content $-p$ to $3 \%$, and nitrogen contents ranging from $0.2 \%$ to $0.76 \%$ are not unusual. Metals content of a couple of hundred ppm is permissible for residue-processing crackers, while distillate crackers limit the metals content to a few ppm. 


\subsection{QUALITY OF COAL LIQUIDS}

\subsection{Composition and Properties of Coal Liquids}

Properties of coal liquids derived from direct liquefaction were collected and summarized in Table 16A (single-stage processes [82-87]) and Table 16B (two-stage processes $[85,87-95]$ ), including data obtained from recent two-stage runs at Wilsonville facility.

Since none of the liquefaction processes has yet been applied commercially, properties of the liquefaction products may change as each process is developed and optimized. Moreover, for each process, yields and product distribution can vary appreciably depending on coal rank, operating conditions, distillation cut points, and amount of bottoms recycled. However, representative data were sought and gathered so that the data can be analyzed and trends can be reasorrably assessed.

The coal liquids data in Tables $16 \mathrm{~A}$ and $\mathrm{B}$ represent liquefaction products from different processes at different development stages. SRC-I contains essentially no distillate and can be regarded as a deashed, partially desulfurized coal rather than a coal oil. The other coal liquids are quite low-boiling. These coal liquids were obtained in various fairly well-developed processes, and they boil primarily in the naphtha and middle distillate range. Only a small portion boils above $700^{\circ} \mathrm{F}$ with virtually no resids $\left(1000^{\circ} \mathrm{F}+\right)$.

The SRC-II, H-Coal, and EDS process liquids are representative of single-stage liquefaction products and are all quite similar. The few major differences that are observed could be due to any combination of the following factors: (1) differences in the liquefaction processes themselves, (2) differences among the feed coals, (3) differences in the distillation procedures, and (4) differences in storage and handling of the coal liquids. 
The surcessful development of two-stage liquefaction (TSL) has been showing significant imprnvements in process efficiency, including increased distillate yield, reduced hydrogen consumption, and lower heteroatom content in liquid products. Data for Wilsonville two-stage coal liquids shown in Table $1 € 3$ lupresent the recent achievernents.

For comparison, properties of some crude petroleum and shale oils are listed in Table $17[83,96,97]$.

Statistically, the proportions of the elements in petroleum vary over the following limits, compared with the ranges that modern two-stage coal lic sids fall in:

\begin{tabular}{|c|c|c|}
\hline & Petroleum & $\begin{array}{r}\text { Wilsonville Two-S } \\
\text { Liquefaction Coal L } \\
\text { (After Run 25 }\end{array}$ \\
\hline Gravity, ${ }^{\circ} \mathrm{API}$ & $11-33$ & $16-36$ \\
\hline \multicolumn{3}{|l|}{ Elemental analysis, } \\
\hline Carbon & $83-87$ & $85.5-87.5$ \\
\hline Hydrogen & $10-14$ & $11.1-12.2$ \\
\hline Sulfur & $0.05-6.0$ & $0.01-0.10$ \\
\hline Oxygen & $0.05-1.5$ & $0.2-2.5$ \\
\hline Nitrogen & $0.1-2.0$ & $0.1-0.5$ \\
\hline $\mathrm{H} / \mathrm{C}$ Atom Ratio & $1.4-2.0$ & $1.54-1.7$ \\
\hline Metals, ppm & $3-1000+$ & $<10$ \\
\hline Resid $\left(1000^{\circ} \mathrm{F}+1, \omega \div \%\right.$ & $16-58$ & 0 \\
\hline
\end{tabular}

The above ccmparison shows that the gravity and elemental compositions of coal liquids are comparable to those of petroleum, except for somewhat higher carbon content and lower hydrogen content. The heteroatom contents of the coal liquids are 
well within the ranges for petroleum and in fact are close to the lower limits, except for oxygen. Specifically, comparing the data in Tables 16 and 17, coal liquids contain larger quantities of nitrogen and oxygen and less hydrogen than does Arabian light crude. However, the sulfur contents of these coal liquids (ariu shale oil also) are low compared to typical Middle Eastern crudes. In other words, when compared with typical sour petroleum, the coal liquids are light in boiling range, lower in sulfur, but slightly higher in nitrogen and oxygen. When compared with shale oil, coal liquid is lower boiling and contains about one-half of the nitrogen. A major difference between coal liquid and petroleum is the highly aromatic structure of the former and the abserice of long paraffinic structures. Current coal liquids have $\mathrm{H} / \mathrm{C}$ atom ratios of 1.5-1.7, which is significantly better than the $H / C$ ratio of 1.0-1.2 reported for earlier processes [98].

Distillation curves of some coal liquids, crude petroleum, and shale oil are presented in Figures 1 and 2 [83,84]. The coal liquids contain very little high-boiling material compared with petroleum and shale oil because most of the high boilers are typically recycled in the liquefaction process and ultimately converted to lower-boiling products.

Although coal liquids are virtually alike, there are some significant quantitative differences among different coal liquids, particularly between the two-stage liquefaction products and the others. In general, the two-stage coal liquids contain a much larger middle distillate fraction (60-76 LV\% 400- $700^{\circ} \mathrm{F}$ fraction) and less naphtha than single-stage liquids ( $45 \mathrm{LV} \% 400-700^{\circ} \mathrm{F}$ fraction).

Coal rank also makes a difference. The coal liquids from subbituminous coals generally show a higher oxygen level, as compared with the bituminous coal liquids. They are also less cyclic and contain more $\mathrm{N}$ in the naphtha fraction. For instance, the subbituminous Clovis Point coal naphtha contains $32.6 \%$ paraffins, $50.5 \%$ naphthenes, and $17.0 \%$ aromatics, whereas the bituminous Illinois No. 6 naphtha 
contains $15.9 \%$ paraffins, $60.7 \%$ naphthenes, and $23.4 \%$ aromatics. This result is indicative of the more paraffinic nature of subbituminous coal. The total distillates and gas-oil fractions for I (integrated) TSL liquids from Illinois No. 6 and Clovis Point coals are similar. The elemental analysis, rams , rbon, and refractive indices are nearly the same for similar fractions of these two ITSL liquids [88]. It is the naphtha fractions of these two liquids that show considerable compositional difference and may have significant impact on naphtha refining.

The distillation curves for $\mathrm{H}$-Coal and TSL liquids for Illinois No. 6 and Wyodak coals are plotted in Figure 3 [87]. Coal liquids designated " $A$ " have higher end points as noted in Table 16. The GLC simulated true-boiling-point (TBP) distillation curves for Ireland Mine coal and Black Thunder coal obtained in Wilsonville Runs $259 \mathrm{G}$ and 260D, respectively, are depicted in Figure 4. These are samples representative of current two-stage liquefaction products, which are relatively lighter in distillation.

Current two-stage coal liquids contain considerably more hydrogen than singlestage coal liquids. Figure 5 [87] shows that within a given boiling range, the twostage product has higher hydrogen content than comparable $\mathrm{H}$-Coal liquids. The $\mathrm{H}$ Coal liquids may contain more of the comparatively $\mathrm{H}$-rich low-boiling components than the two-stage liquids, probably as a result of the higher severity required for the single-stage process.

\subsection{Heteroatoms in Coal Liquids}

The heteroatoms content in the coal liquids has been an important concern, since it affects the upgrading performance of the coal liquids and the quality of the products derived therefrom.

Inferred from data in Table 16A, coal liquids from single-stage liquefaction contain heteroatoms in the following ranges $(w t \%)$ : $0.025-0.89$ sulfur (generally 
around 0.2 ), 0.15-2.04 total nitrogen (generally around 0.4$), 0.13-0.70$ basic nitrogen, and 0.67-4.52 oxygen (generally around 2.0 ).

The distribution of heteroatoms in single-stage coal liquids can be represented by Figure 6, a plot of S, N, and $\mathrm{O}$ contents for Illinois No. $6 \mathrm{H}$-coal liquids [99]. Oxygen, being the most abundant heteroatom, shows a high peak content around $400^{\circ} \mathrm{F}$ boiling point, another peak in $620-720^{\circ} \mathrm{F}$ range, and an increasing level in heavy ends. The sulfur and nitrogen contents increase with increasing boiling point somewhat monotonically.

As a whole, the two-stage coal liquids contain much less heteroatoms than do the single-stage liquids. Data in Table 16B demonstrate that the heteroatom contents of two-stage liquids fall in the following ranges (wt\%): $0.01-0.23$ sulfur (generally 0.01-0.05), 0.07-0.50 total nitrogen, and 0.14-3.52 oxygen. The reduced heteroatoms content in tiwo-stage liquids reflects one of the important achievements in the process development of two-stage coal liquefaction.

The heteroatoms distribution in two-stage coal liquids analyzed by Amoco [88] shows the oxygen (direct determination) distribution in coal liquids (Figure 7) from the two liquefaction stages of Wilsonville Run 246 . Direct oxygen is : sually about $0.5 \%$ higher than oxygen by difference. This plot reveals a predominate oxygen peak in the $300^{\circ} \mathrm{F}-600^{\circ} \mathrm{F}$ range of the first-stage product. $\mathrm{NaOH}$ extraction experiments prove that a large fraction of the oxygen compounds in first-stage product comprises phenols. Two sulfur peaks are observed (Figure 8 ) for the first-stage product, which are largely due to thiophenic sulfur. The second-stage coal liquid is low in sulfur, generally less than $0.1 \mathrm{wt} \%$; however, the first cut from it has an unexpectedly high sulfur (between $300^{\circ} \mathrm{F}$ and $400^{\circ} \mathrm{F}$ ) level $(2.58 \mathrm{wt} \%$ ). Only $20 \%$ of this sulfur is found to be thiophenic. The nitrogen content increases with increasing boiling range, while the basic nitrogen demonstrates a peak between $400^{\circ} \mathrm{F}$ and $500^{\circ} \mathrm{F}$, for coal liquids 
from both stages (Figures 9 and 10). The nitrogen level of the second-stage product is lower than that of the first-stage liquid.

The advanced CC (close-coupled)-ITSL process yields products wich relatively low heteroatoms content. The three CC-ITSL liquids in Table 16B, all derived from subbituminous coals, contain $<0.1 \mathrm{wt} \% \mathrm{~S}, 0.23-0.50 \mathrm{wt} \% \mathrm{~N}$, and $1.13-2.49 \mathrm{wt} \%$ 0 . The distribution pattern of the heteroatoms in these three coal liquids is generally similar to that in other TSL liquids. The sulfur content decreases with increasing boiling point, and is predominantly in the naphtha fraction. The nitrogen level increases with increasing boiling point, and predominates in the vacuum gas oil fraction $\left(650-1000^{\circ} \mathrm{F}\right)$. The oxygen distribution again shows a peak in the $350-450^{\circ} \mathrm{F}$ fraction, which consists mostly of phenolic compounds [92]. The nitrogen and oxygen contents of the coal liquid samples obtained from most recent Wilsonville runs (No. 259-261) are even lower (Table 16B).

Liquids derived from lower rank coals usually have higher oxygen contents than higher rank coal liquids. For instance, in Wilsonville ITSL Run 246 the Clovis Point (subbituminous) coal produced a liquid product containing $3.52 \mathrm{wt} \%$ oxygen, while in ITSL Run 244 the Illinois No. 6 coal liquid has only 1.92 wt\% oxygen (both by direct method) [88]. As far as subbituminous and other low-rank coal liquids are concerned, recovery and utilization of oxygen compounds are therefore of more importance.

For Clovis Point coal liquid (Run 246), the yields of naphtha (IBP- $360^{\circ} \mathrm{F}$ ) and $360-450^{\circ} \mathrm{F}$ fraction are 19.4 and $20.4 \mathrm{wt} \%$, and the oxygen contents for these two fractions are 3.71 and $6.20 \mathrm{wt} \%$, respectively [88]. The amounts of oxygen compounds in these fractions are roughly estimated to be 5 and $12 \mathrm{wt} \%$ of total coal liquid, respectively. For Illinois No. 6 ITSL liquid (Run 244), the oxygen compounds in the naphtha (IBP-360 $0^{\circ} \mathrm{F}$ ) and $360-450^{\circ} \mathrm{F}$ fractions constitute about 2 and $5 \mathrm{wt} \%$ of total liquid product. With this appreciable quantity, recovery is worth considering. 
The oxygen compounds in the naphtha fraction and light distillate are mostly phenols. In Illinois No. 6 and Wyodak CC-ITSL liquids, most of the extractable phenols are concentrated in the same boiling range of $350-600^{\circ} \mathrm{F}$ with a peak level at $446^{\circ} \mathrm{F}$ as shown in Figure 11 . They chiefly consist of four types of ring structures: phenols, idanols, naphthanols, and biphenylols. Essentially all of these compounds are alkyl substituted with short chains $\left(C_{1}\right.$ to $\left.C_{4}\right)[100]$.

When the naphtha and kerosene fractions of Black Thunder coal liquid (obtained from Wilsonville Run 260D) were caustic washed, phenolic species were selectively extracted. The results are given below [101]:

Run 260D Fraction

Naphtha $\left(<380^{\circ} \mathrm{F}\right)$

Kerosene $\left(380-510^{\circ} \mathrm{F}\right)$

Gas Oil (510-650\%)
Phenolic $-\mathrm{OH}$ Concentration by FTIR $\mathrm{meq} / \mathrm{g}$ Sample

\begin{tabular}{cc}
\hline Before Caustic Wash & After Caustic Wash \\
0.40 & 0.02 \\
0.92 & 0.07 \\
0.52 & 0.27
\end{tabular}

The data demonstrate that about $3.6 \mathrm{wt} \%$ of the naphtha fraction and $10 \mathrm{wt} \%$ of the kerosene fraction are phenolic compounds and can be easily recovered.

With this appreciable quantity of phenolics in coal liquids, a study of their recovery and utilization, as well as an assessment of their market value, will be very meaningful.

\subsection{Toxicology of Coal-Derived Liquids}

Major health/environmental concerns have been related to the toxicological activity of coal derived liquids, and a large amount of research has been performed. 
It is beyond the scope of this study, and readers are referred to an excellent comprehensive review edited by Gray et al. [102] for detailed information. A summary of major conclusions from this reference is provided below:

1. Although some quantitative differences exist, the chemical classes responsible for toxicological activity in coal-conversion materials are qualitatively the same regardless of the coal conversion process used to produce the material.

2. The chemical classes primarily responsible for mutagenic and carcinogenic activity of coal liquids and tars are high-molecular weight, polycyclic aromatic hydrocarbons (PAHs). Amino-PAHs are also prevalent and are a major source of mutagenic activity.

3. Toxicological activity of coal conversion materials can be predicted from their $95 \%$ distillation temperatures and their aromaticity. Toxicological activity is concentrated in those highly aromatic components boiling above $650^{\circ} \mathrm{F}$ and having hydrogen: carbon $(\mathrm{H} / \mathrm{C})$ ratios below 1.5. For a wide variety of materials studied, distillates with a boiling range above $700^{\circ} \mathrm{F}$ were toxicologically active, while those with a boiling range below $650^{\circ} \mathrm{F}$ were essentially inactive. Therefore distillation can be used to separate carcinogenic and mutagenic components of coal-derived liquids from those components that do not show toxicological activity.

4. Mild to moderate hydrotreatment decreases the mutagenic activity of coal-conversion products by reduction of primary amino functionalities and, to a lesser extent, by dearomatization of PAH structures through saturation and/or C-C bond cleavage. More severe hydrotreatment significantly decreases skin carcinogenicity of these materials, primarily from hydro-dearomatization of four- to six-ring PAH structures. Hence, hydrogenation can be used to reduce the adverse toxicological effects of coal liquids. 
5. Efficient distillation of coal liquids, heavy-ends process recycle, and catalytic hydrotreating, singly or in combination, can effectively reduce toxicological activity through control of product boiling point and aromaticity.

6. The information available, although limited for gasification, suggests that suitable engineering controls, combined with good industrial- hygiene practices and medical surveillance, have effectively protected the health of workers in this industry [102].

A study on hydrotreatment of SRC-II liquid shows that the mutagenic activity of this coal liquid was reduced by an order of magnitude by $35 \%$ removal of nitrogen and $52 \%$ removal of oxygen. Liquid product with $67 \%$ nitrogen removal and $82 \%$ oxygen removal shows no distinguishable mutagenic activity [103].

Present day two-stage liquefaction technology recycles heavy distillates and resids to extinction, has high conversion efficiency, and produces coal liquids of much improved quality, including low end point and reduced heteroatoms content. This should greatly reduce the concentration of toxicological components in liquefaction products. The transportation fuels to be manufactured from coal liquids are gasoline, jet fuel, and diesel fuel, which would have been hydrorefined and have end points lower than $600^{\circ} \mathrm{F}$. They should show no toxicological activity based on the above conclusions.

\subsection{Summary}

1. The successful development of two-stage liquefaction has shown remarkable improvements in process efficiency and liquid product properties, which are comparable to those of petroleum, except for somewhat lower hydrogen and higher oxygen contents. Present coal liquids are low-boiling, low in sulfur, and essentially free of residues and metals, which are superior to those of petroleum. 
The naphtha fraction from subbituminous coal liquids contain more paraffins and less aromatics than that from the bituminous coal liquids, which is indicative of the more paraffinic nature of subbituminous coal.

2. The distribution pattern of the heteroatoms is generally similar with all TSL liquids. The sulfur content decreases with increasing boiling point and is predominantly contained in the naphtha fraction. The nitrogen level increases with increasing boiling point, and predominates in the VGO fraction. The oxygen distribution shows a peak in the $350-450^{\circ} \mathrm{F}$ fraction. The extractable phenols are concentrated in the $350-600^{\circ} \mathrm{F}$ boiling range with a peak level around $450^{\circ} \mathrm{F}$.

Liquids derived from low-rank coals contain much more oxygen compound than high-rank coal liquids. Consequently, recovery and utilization of these oxygen compounds will be an important contribution to coal liquefaction economics.

3. The chemical classes primarily responsible for mutagenic and carcinogenic activity of coal liquids are high-molecular-weight polycyclic aromatic hydrocarbons (PAHs) and amino-PAHs. Distillates with a boiling range above $700^{\circ} \mathrm{F}$ are toxicologically active, while those with a boiling range below $650^{\circ} \mathrm{F}$ are essentially inactive. Hence, proper hydrotreating and efficient distillation of coal liquids can produce $<650^{\circ} \mathrm{F}$ distillates essentially free of toxicological activity. Recycling of heavy distillates and resids to extinction during liquefaction is therefore necessary and beneficial not only for maximizing the light distillate yield but also for improving the product quality. 


\subsection{REFINING SCHEMES FOR COAL LIOUIDS}

A number of earlier studies were made of the use of raw coal liquids in various applications where a high degree of refinement is not necessary. Combustion cests of SRC-I and SRC-II products have been conducted under the sponsorship of the Electric Power Research Institute, and tests of SRC-II distillates as stationary turbine fuels have been performed under a program carried out by the NASA Lewis Research Center [104]. An evaluation of SRC-Il distillate as a low-speed diesel fuel has been made by Sulzer Brothers, Ltd. [105]. Raw coal naphthas have been found to have poor stability [106].

Current two-stage coal liquids are of much better quality, which suggests that high-value fuel products of better quality can be expected from their refining. Coal liquids from Wilsonville ITSL operations have been evaluated through the use of standard petroleum tests on several occasions $[85,88,107,108]$, including the most recent work on coal-liquid products from Wilsonville Runs 259 and $260[94,109]$. The studies show that the present day coal liquids, although much superior in quality than before, still have to be refined to meet stringent specifications for high-value liquid fuel products.

Representative distillation cuts from two typical coal liquids, one from singlestage and another from two-stage liquefaction, both from Illinois No. 6 coal, are compared with their petroleum counterparts in Tables 18 and $19[85,110]$. In fact, coal-liquid fractions bear many similarities to petroleum streams of comparable boiling range. They do have lower API gravity and lower H/C ratio, reflecting higher proportions of aromatics, while the non-aromatic compounds tend to be naphthenic rather than paraffinic. They also contain considerable amounts of highly polar compounds, principally $\mathrm{O}$ - and $\mathrm{N}$-containing compounds, whereas sulfur is not really a problem. 
Modern refining processes are well developed to modify the characteristics of hydrocarbon feed streams of varying quality. Therefore, with appropriate processing, coal-derived liquids could be refined into specification fuels so that there is no inherent barrier to the use of coal-derived liquids as refinery feedstocks. Conventional refineries would be able to accept the coal liquids as feedstock if they were blended down to low concentrations or properly upgraded, either at the liquefaction plant or in the refinery.

It is generally recognized that the best refining strategy involves the use of each potential feedstock and fraction in a way in which it can most easily and efficiently be tailored to meet the market needs. The hydrogen content of coal liquids is close to the hydrogen level found in a high octane gasoline. Consequently, coal liquid naphtha is best suited for the gasoline market [111]. The diesel and jet fuel fractions require much higher levels of hydrogen to meet specifications, therefore the high aromaticity of coal liquids would have to be modified for these applications. Stability of transportation fuels is another important concern, which usually results in the need for thorough removal of nitrogen and oxygen.

Therefore, the coal liquefaction plant has to produce either finished fuel products meeting all the specifications and market requirements, or a product stream as refinery feed to be processed to required specifications [1]. The former would involve significant additional capital requirement for the liquefaction plant. The latter assures utilizing existing refineries with existing markets and minor modifications either in liquefaction or in the refinery. The present task focuses attention on the latter.

Blending coal liquids with petroleum as a supplementary source of refinery crude is a possible refining strategy, especially if they are blended with paraffinic crude oil. Incompatibility is unlikely with modern coal liquids. However, information 
about refining coal liquid-petroleum mixtures is not yet available, and the discussion in this report focuses solely on the refining of coal-derived liquids.

Basically three refining routes may be considered when coal liquids are processed in the refinery:

1. The coal liquid is distilled to some straight-run fractions, which are refined or upgraded by whatever means necessary. One fraction may only need a caustic wash, another a mild hydrotreating, the third a severe hydrorefining, and the fourth may be subjected to destructive processing, like cracking or coking, etc.

2. The whole coal liquid is hydrotreated to a certain degree so that, after fractionation, the distillates could meet the product specifications or qualify as feed to a hydrocracker or catalytic cracker.

3. The whole coal liquid may be hydrocracked and then distilled into fractions, some of which may or may not need further treating to turn into refinery blending stocks, while some of them may be improved quality feedstocks for units like catalytic cracking or hydrocracking.

As a universal practice, refineries rarely make fuel products from one single stream. They always blend a number of stocks for a specific fuel, both for operational flexibility and refinery balancing. Blending of coal liquid fractions with petroleumderived stocks is an important topic that needs to be studied. As a fundamental study for coal-liquid refining, the discussion here is based on producing various fuels entirely from coal liquids, mainly for the purpose of exploring the coal-liquid potential. 


\subsection{REFINING OF RAW COAL LIQU!U FRACTIONS}

The conventional way of petroleum refining in existing refineries is to first fractionate the crude petroleum, after desalting and dewatering, in an atmospheric and vacuum distillation unit into various fractions. These fractions are then processed in different refining units into a variety of product streams, which are finally blended into specification fuel products.

One of the refining schemes for coal liquids follows the routine petroleum refining procedure. Straight-run distillation of coal liquids is considered a preliminary step to prepare various cuts for further refining. Relevant information is discussed below, in the order of increasing boiling range of individual fractions.

\subsection{Light Naphtha}

A sample of light naphtha (IBP- $285^{\circ} \mathrm{F}$ ) was obtained by fractionation of a Wilsonville sample from Run 244, Illinois No. 6 ITSL, $8.3 \%$ of total liquefaction liquid. This clear, water-white liquid met many of the aviation gasoline specifications (Table 20) including freezing point, sulfur content, Reid vapor pressure (RVP), coppercorrosion, etc. However, it failed the D86 $10 \%$ point, heat of combustion, octane number, and potential gum specification [85].

The sample may have suffered some light end loss during shipment, so that failure to meet D86 10\% point and minimum vapor pressure is not considered to be serious and can be remedied without difficulty. The octane number and heat of combustion, which are a little lower than required, are not a problem for a blending stock. The only thing of concern is the stability (potential gum), which is most likely caused by nitrogen and oxygen compounds. It is reasonable to expect this light naphtha, after hydrotreating, to be a good blending stock for aviation gasoline blending. 


\subsection{Naphtha}

Properties of some naphthas from raw coal liquids derived from different coals by both single-stage and two-stage liquefaction processes are documented in Tables 21 [110-113], 22A and $B$ [85,88, $5^{\circ}-94$ ]. For all the 400 ${ }^{\circ}$ F-fractions obtained from $\mathrm{H}$-Coal and EDS raw coal liquids, most of the distillation specifications are not met probably due to the loss of light ends during handling, which can be remedied by blending with light components and/or redistillation. The existent gum exceeds the limit implying instability, which is most likely attributed to the existence of abundant hetero-compounds and emphasizes the necessity of hydrotreating. Storage stability tests were conducted for the $\mathrm{H}$-Coal naphtha over a one-year period. For all three samples, insolubles, gum, and total acidity increased substantially with time. The main component of the Illinois coal naphtha is ammonium sulfate, and the gums from Illinois and Wyodak naphtha have much higher $N, 0$, and $S$ contents but lower hydrogen levels than original liquids [110]. This is direct proof that the heterocompounds are the main course for instability. The two-stage coal liquefaction yields naphtha fractions with lower heteroatom content, especially the recent CC-ITSL runs, which give the naphtha very low sulfur level and much reduced nitrogen content. However, the total heteroatom level is still high relative to petroleum-derived naphtha.

The motor octane numbers for these naphthas range from 70 to 83 except for Wyodak naphtha. Based on the data in these tables, it seems that the EDS and $H$. Coal naphthas possess more aromatics (30-50\%) and the ITSL naphthas more naphtheries (50-68\%). The ITSL naphthas correspondingly have higher hydrogen content than do the single-stage naphthas, while the CC-ITSL naphthas have the highest hydrogen percentage (13.6-14.1 wt\%, H/C atom ratio 1.94-2.01) and contain the largest amount of saturated hydrocarbons $(87-88$ vol\%).

Any of the coal-derived naphthas makes an excellent source for gasoline production, especially the naphtha fraction from current CC-ITSL process, which 
meets most of the gasoline specifications except stability (Table 22B). This is certainly related to its relatively high heteroatom content, which dictates the necessity of hydrotreating the naphtha to produce gasoline product.

Single-stage liquefaction processes yield more naphtha fraction $(30 \%-45 \%)$, prcsably due to high liquefaction severity. With the Wyodak $\mathrm{H}$-Coal naphtha yield as high as $74.4 \%$ was obtained, due partly to the higher cut point $\left(400^{\circ} \mathrm{F}\right)$. Naphtha yields from TSL liquids are in the range of $20-28 w t \%$.

The cutpoint for TSL naphtha has usually been around $350^{\circ} \mathrm{F}$. A higher cut point up to $380-400^{\circ} \mathrm{F}$ may be necessary to maximize gasoline production. As a consequence, the naphtila fraction will contain an appreciable amount of oxygen compounds, almosi exclusively phenolics, as illustrated in Table 23 [86]. Raising the naphtha end point also increases the relative amount of aromatics in the hydrocarbon portion. To determine a $p$ iper cut point between naphtha and the next higher-boiling fraction (jet or diesell, a refining plan for the total coal liquid has to be considered.

The purpose of hydrntreating the coal-derived naphtha can be:

1) to generate a gasoline blending stock with improved stability and with an octane number in the approximate range of $70-80$, or

2) to make a feedstock for catalytic reforming to produce a gasoline component of very high octane.

To date, research has been mostly conducted on the latter. H-Coal naphthas were hydrotreated to bring the hetero-compounds content within acceptable limits for reformer feed [114]. The IBP- $400^{\circ} \mathrm{F}$ coal naphtha was first rerun and then hydrotreated over a commercial hydrotreating catalyst in a bench-scale continuous unit. The target levels of $30 \mathrm{wppm}$ oxygen and $<1 \mathrm{wppm}$ nitrogen were reached at 
moderate severity of operation. Test results are summarized in Table 24. Only a trace amount of gas $\left(\mathrm{C}_{1}-\mathrm{C}_{4}\right)$ was produced and the yield of upgraded naphtha was almost $100 \%$. The total hydrogen consumption was $480 \mathrm{SCF} / \mathrm{bbl}$, of which $13.8 \%$ was required for the reduction of heteroatoms content to acceptable levels. As might be expected, a major portion (60\%) of this amount of hydrogen was used in oxygen removal. The bulk of the total hydrogen consumed resulted in an increase in hydrogen content from $12.8 \%$ to $13.6 \%$ and, correspondingly, in an increase in saturates content from $70.1 \%$ to $81.1 \%$ and a decrease in aromatics content from $24.7 \%$ to $18.9 \%$. The latter caused a reduction in RON from 80.3 to 66.8 . However, the hydrogen consumed in saturation is "recoverable" and the octane number can be greatly improved via reforming.

The amount of hydrogen used in heteroatom elimination, however, is not recoverable. Therefore, extraction and recovery of these oxygen compounds as a byproduct, instead of removing them by hydrogenation, is fave ed both technically and economically.

Since the hydrotreated coal naphthas are high naphthene feedstocks, the required temperatures for their reforming are relatively low, and high space velocity can be employed. At these low-severity conditions the yield of gasoline of a given octane number is generally very high. When an upgraded Illinois No. $6 \mathrm{H}$-Coal naphtha (properties shown in Table 24) was reformed over a commercial Platforming catalyst in bench-scale continuous units under $\mathbf{4 5 0}$ psig over a range of temperatures, a yield-octane curve was obtained as depicted in Figure 12, which shows that the reformate has a RON ranging from 94 to 102 (clear). The $C_{5}+$ yield ranges from $88 \%$ to $92.5 \%$, while the hydrogen produced by reforming is 125 J to $1750 \mathrm{SCF} / \mathrm{bbl}$, with a net hydrogen yield of 800 to $1250 \mathrm{SCF} / \mathrm{bbl}$ (480 SCF/bbl lsed for upgrading). The product distribution data obtained from MS analyses illustrate that, at mojerate temperature, the aromatics in the reformates increased solel, at the expense of 
naphthenes. While at the highest temperature used in the tests, dehydrocyclization of the $\mathrm{C}_{9}+$ paraffins became significant [114].

In the case of Illinois No. 6 upgraded SRC-II naphtha (Figure 13), the upgrading required $560 \mathrm{SCF} / \mathrm{bbl}$ of hydrogen. The reforming product has a research cctane ranging from 88 to 100 with a $C_{5}+$ yield of 88 to $92 \mathrm{wt} \%$, and the hydrogen produced ranges from 1200 to 1550 SCF/bbl, which results in a net hydrogen production between 650 and $1000 \mathrm{SCF} / \mathrm{bbl}[115]$. All these results point to a successful reforming of the coal-derived naphtha.

Similar results are recorded in several EDS project reports $[113,114,116]$. An Illinois No. 6 raw EDS naphtha, and a Wyodak raw EDS naphtha, before and after caustic washing, were hydrotreated to make reformer feedstocks. It was found that:

1. Reformer feed qualities can be met with all four naphtha feedstocks by h:yourotreating in a conventional, single-stage hydrotreater.

2. Minimum conditions required to meet reforming specifications were set by product nitrogen level. When a product target of $<1 \mathrm{wppm}$ is met, sulfur and Bromine No. are sufficiently low to permit reforming with either platinum or bi-metallic catalyst.

3. Both raw naphthas exhibited the same effect of caustic washing to remove phenolics: slightly more than a two-fold increase in space velocity along with a $50 \%$ reduction in hydrogen consumption for the washed naphtha.

Due to data scatter, hydrogen consumption was reported as a trend-line of hydic, gen uptake versus API gravity increase (Figure 14). The hydrotreated naphthas were redistilled and blended to obtain reformer feedstocks with different end points. 
Reforming results are exhibited in Figures 15 and 16 with Arabian Light naphtha as a reference, and corresponding conclusions were drawn [117-119]:

1. Because of their high cyclics content, coal naphthas reform much more readily than petroleum naphthas. At an equivalent octane (100 RON clear) a 600 to $700 \%$ increase in reformability (relative space velocity) and approximately $16 \%$ increase in reformate yield were observed with Wyodak naphtha $\left(370^{\circ} \mathrm{F}\right.$ EP) vs Arabian Light $\left(360^{\circ} \mathrm{F} \mathrm{EP}\right)$.

2. Naphthas from different coals, but having similar end points, have essentially the same reformability. Lowering the end point of coal naphtha facilitates reforming. A $25 \%$ increase in reformability was observed by lowering feed end point from $395^{\circ} \mathrm{F}$ to $340^{\circ} \mathrm{F}$.

3. The abundant cyclic compounds in coal naphthas lead to high hydrogen yields and low yields of $\mathrm{C}_{4}{ }_{4}$ gases during reforming. Hydrogen yields in excess of $2000 \mathrm{SCF} / \mathrm{bbl}$ are twice as much as typical yields from petroleum naphthas, and light gas yields of less than $4 w t \%$ are only $20 \%$ to $25 \%$ of what was obtained from petroleum feedstocks.

4. Coal naphthas contain significantly higher levels of condensed naphthenes and indanes compared with petroleum naphthas. These compounds increase catalyst deactivation rates and condensed aromatics content of the reformate. With a bimetallic reforming catalyst, a twofold increase in deactivation rate was observed with coal naphthas relative to comparable petroleum naphtha. However, by taking advantage of the high reformability of coal naphthas and thus a lower reforming temperature to achieve the same product octane, the deactivation rate is reduced to approximately one-half that encountered with petroleum naphthas. 
5. The condensed aromatics impact engine performance. Nevertheless, by reducing feed end point and/or by operating at milder severity, condensed aromatics content could be limited to no higher than that obtained in petroleum reformates.

6. Coal naphtha reformates contain high levels of BTX, making them attractive chemical feedstocks. Depending on feed endpoint, benzene, toluene, and xylene yields fall in the following ranges: $7-12,19-25$, and $17-23$ wt $\%$, respectively.

7. Reforming admixtures of coal and virgin petroleum naphthas has no synergistic effects on reformate yield or catalyst deactivation.

Attention has been focused on the cut point of coal naphtha as reformer stock. Chevron used a cut point close to $325^{\circ} \mathrm{F}$ [118], apparently based on the amount of dinaphthenes in the reformer feedstock and on concerns about the end point of the reformate. Later work has indicated that, with modern reforming catalysts, feedstock end points as high as $350^{\circ} \mathrm{F}$ are feasible and economically preferable for gasoline production [104]. The EDS workers used a $350^{\circ} \mathrm{F}$ cut point for their reformer feedstock because the $350^{\circ} \mathrm{F}$ to $370^{\circ} \mathrm{F}$ fraction of the EDS naphtha, when reformed, produced enough condensed aromatics to adversely affect engine performance [113]. UOP employed $400^{\circ} \mathrm{F}$ end-point naphtha for hydrotreating and subsequent reforming. Plugging at the preheating section of the hydrotreating reactor was once encountered and attributed to the presence of gum in the feed, but no significant pressure drop across the reactor was observed in the later run with fresh catalyst and with preheater packings replaced [114].

In short, coal-derived naphthas are readily hydrotreated and the hydro-upgraded naphthas are excellent reformer feedstocks to make high-octane gasoline with very high yield. The hydrotreating and reforming of the naphtha fraction from current CCITSL coal liquids, although not studied, should be similar to or even better than the results described above. 
The coal-naphtha reformate does have a very high octane number due to its high aromatics content, possibly $70-80 \%$. However, the increasing concern about the aromatics content in gasoline makes coal naphtha reforming not so attractive as before. The more realistic way of coal-naphtha refining is mild hydrotreating to eliminate its heteroatoms thus improving its stability. The high saturates content (86$88 \%$ ) and the relatively low aromatics content (usually less than $15 \%$ ) of the naphtha fraction obtained from current two-stage coal liquids should be maintained. Studies on coal-naphtha hydrotreating with the sole purpose of stability improvement are very much required.

\subsection{Kerosene Fraction}

The naturally occurring hydrocarbons in petroleum can be fractionated with little additional processing to produce highly stable jet fuels. In petroleum refineries, jet fuel stocks may sometimes need mild hydrotreating to remove sulfur, but chemical conversion processes have not been necessary most of the time. This is not true with coal-derived jet fuel fractions. Properties of some coal liquid fractions in, the jet fuel range are shown in Table 25A. Properties of the jet fuel fraction $\left(380-510^{\circ} \mathrm{F}\right)$ obtained from the coal liquid produced in a recent Wilsonville Run No. 259G (Pittsburgh seam coal) are listed in Table 25B in comparison with the ASTM specifications [109].

The coal-derived kerosene fractions have lower hydrogen content than do naphthas from the same source, following the general trend that hydrogen content decreases with increasing boiling point. Kerosene fractions from CC-ITSL liquids are somewhat richer in hydrogen than ITSL counterparts, however, their hydrogen content is still low compared with that of petroleum-derived jet fuels $(\mathrm{H} 13.5-14.0 \mathrm{wt} \%)$. This low hydrogen level is reflected in their high aromatics content, typically around $50 \%$, which makes the API gravity and the smoke point, two major properties for jet fuels, much lower than required. 
Regarding the heteroatom content, the coal-derived kerosene fractions are loaded with hetero-compounds, especially oxygen-containing, when the initial boiling point is around $350^{\circ} \mathrm{F}$. The hetero-compounds are believed to be responsible for the instability (failure of JFTOT test and very high gum content) of the coal-derived jet fuel fractions.

The low H/C ratio and high heteroatom level of the coal-derived kerosene fractions exclude the possibility of producing jet fuel by simple fractionation of coal liquids. Hydrotreating is absolutely necessary to saturate the aromatics and to remove the heteroatoms to manufacture quality jet fuel products.

Chevron prepared a $600^{\circ} \mathrm{F}$ - distillate by redistilling a Big Brown lignite EDS liquid product and hydrotreated over Chevron ICR 106 catalyst at a variety of conditions to make jet fuel [115]. The redistilled stocks are easy to hydrotreat in comparison to the whole crude, and all the heteroatoms are removed at the mildest severity studied: 1.5 LHSV, 1800 psig total pressure, and $700^{\circ} \mathrm{F}$ catalyst temperature. The $250^{\circ} \mathrm{F}-600^{\circ} \mathrm{F}$ jet fuel fraction contains $5 \mathrm{ppm}$ nitrogen (Table 26). The smoke point of the jet fuels depends heavily upon the aromatics content and, in turn, upon the hydrogen partial pressure during hydrotreatment. It is inferred from Table 26 that jet fuels with smoke points of at least $20 \mathrm{~mm}$ can be made when the hydrogen partial pressure is about 1700 psia or greater. Similar work was done by Southwest Research Institute on EDS middle distillates [120]. Phenolic compounds were first removed from the feedstock by caustic extraction, and the raffinate was then hydrotreated under three levels of severity. The three hydrogenated coal distillates were redistilled to obtain three jet fuel fractions with a boiling range of $374-527^{\circ} \mathrm{F}$. The aromatics content of the jet fuel fractions from mild-, medium-, and high-severity hydrotreating are 39.6, 20.7, and 10.4 vol\%, respectively. The medium- and high-severity products passed the thermal stability test (JFTOT). However, both the API gravity and smoke point of all three samples are higher than specification. This is not in agreement with Chevron results 
mentioned above [115]. Additional work, especially on CC-ITSL. coal liquids, would be constructive.

The jet fuel fractions obtained from high rank coal liquids, containing much more aromatics than lignite kerosene fractions, need hydrotreating with higher severity to meet the specifications. However, related data are not available.

More work on the manufacture of coal-derived jet fuels has concentrated on hydrotreating the total liquefaction liquid product rather than hydrotreating proper fractions from raw coal liquids. Special discussion will be given in Section 6.0.

\subsection{Diesel Fuel Fraction (Middle Distillates)}

The direct use of middle distillates from early versions of coal liquefaction process was studied a long time ago. A number of middle distillates from different coal liquids were tested in an EPRI-sponsored stationary turbine test program conducted by Westinghouse, Inc., and their properties are summarized in Table 27 [114]. Analytical data, except for the EDS fuel, were obtained by Mobil. General observations and conclusions achieved in this program are as follows:

1) The lighter cuts of most coal-derived liquids are usable in current gas turbine power plants with only small modifications. Boiling point is not a basic limitation but correlates loosely with fuel-bound nitrogen and hydrogen contents. For fuels containing $<0.25 \mathrm{wt} \% \mathrm{~N}$, combustors with water injection are probably capable of meeting EPA standards. The lower limit of hydrogen content is likely due to combustor wall temperatures, smoke emissions, etc.; while some heavier and most lighter test fuels are comparable to No. 2 fuel oil as far as smoke emission is concerned. The major problem is that none of these coal-derived middle distillates meets the gravity specification for No. 2 fuel oil and No. 2 GT gas turbine fuel. 
2) These coal-derived mid-distillates mix very well with petroleum No. 2 fuel oil. Corrosion tests were promising but long-term testing would be required for definitive conclusions.

3) Combustion tests of a $350-650^{\circ} \mathrm{F}$ distillate fraction from Illinois No. 6 EDS coal liquids were conducted in a conventional $1 \mathrm{gal} / \mathrm{h}$ home heating oil burner unit. This distillate contains aromatics $68.6 \mathrm{LV} \%$, sulfur $0.79 \mathrm{wt} \%$, and nitrogen $0.67 \mathrm{wt} \%$. The tests demonstrated that this oil is operable in home heating oil burners. The smoke emission is comparable to petroleum No. 2 fuel oil, but $\mathrm{NO}_{x}$ emissions are roughly three times higher than typical petroleum No. 2 fuel oil, unless the coal-derived distillate is hydrotreated to less than $200 \mathrm{ppm} \mathrm{N} \mathrm{[110].} \mathrm{In} \mathrm{a} \mathrm{storage}$ stability test with EDS Wyodak distillate $\left(350-650^{\circ} \mathrm{F}\right)$, no changes were detected after three months storage at $150^{\circ} \mathrm{F}$ or after one month at $210^{\circ} \mathrm{F}$ but further testing is necessary [113].

4) Regarding storage stability of the test fuels of the above two programs, hydrotreating may be required prior to storage. Severe hydrotreating is indeed necessary to meet the petroleum-based gravity specifications for ASTM No. 2 fuel oil for domestic heating and for ASTM No. 2 GT gas turbine fuel. Hydrotreating results are demonstrated in Figure 17. To obtain an acceptable ASTM No. 2 fuel oil, approximately $2500 \mathrm{SCF} / \mathrm{bbl}$ of hydrogen must be invested to reduce the aromatics level (from $>80 \mathrm{LV} \%$ to $\sim 20 \mathrm{LV} \%$ ) in order to achieve a minimum specification value of $30^{\circ} \mathrm{API}$ [116]. No information is available for No. 2 fuel oil and gas turbine fuel production from TSL coal liquids.

Table 28A presents property data for a number of straight-run middle distillates or light gas oils from $\mathrm{H}$-Coal, Wilsonville ITSL, and CC-ITSL coal liquids, derived from both bituminous and subbituminous coals. Their starting boiling points are somewhat different, but the end points are the same. Properties of diesel fuel fractions distilled 
from coal liquid products of recent Wilsonville Runs 259 G and 260D, in comparison with ASTM No. 1 diesel fuel specifications, are listed in Table 28B $[93,94,109]$.

Generally, these middle distillates have less hydrogen than lighter distillates. They show very low cetane index, 20-21 for ITSL distillates in Table 28A. A higher IBP helps improve the cetane number to some extent, such as $\sim 27$ for diesel fuel fractions in Table 28B, but the number is still low compared with normal values of 3550. Also, the viscosity is too high and $90 \%$ distillation point needs to be reduced.

The nitrogen content in these middle distillates increases compared with naphtha and kerosene fractions, while sulfur declines as boiling range goes up. Oxygen content is lower for fractions with IBP higher than $400^{\circ} \mathrm{F}$, compared with the peak in the $350^{\circ} \mathrm{F}$ to $450^{\circ} \mathrm{F}$ fraction. There are not enough data to judge the stability of these fractions.

If the coal-derived middle distillates (or diesel fuel fractions) are intended to be refined to high-grade diesel fuels, gas turbine fuels, and fuis! oils, hydrotreating is necessary to improve their combustion quality and emission performance.

Hydrotreating of the middle distillate of Wilsonville Run 254 product (Ohio No. 6 coal) was studied at Southwest Research Institute (SwRI) [108]. A maximum nitrogen concentration of $400 \mathrm{ppm}$ was adopted as a guide for a stable diesel fuel product, and the minimum ignition quality was marked for 31.0 cetane number (before the addition of ignition improver) at which a production diesel engine might start unassisted. Preliminary tests showed that stability was the more restrictive product property than ignition quality. The hydrotreater feed and products obtained at two levels of operating severity are reported in Table $28 \mathrm{C}$.

Data in Table $28 \mathrm{C}$ show that the wide-boiling feedstock $\left(412-823^{\circ} \mathrm{F}\right)$ has a high density and low cetane number (21.3), which are consistent with the high proportion 
(81.7 vol\%) of aromatic hydrocarbons and low hydrogen content $(10.4 \mathrm{wt} \%)$. Its viscosity is outside the range of 1.9-4.1 cSt specified for No. 2 diesel fuel. After being hydrotreated under high operating severity, the product has a reduced aromatics content (42.2 vol\%) and a cetane number of 35.4. Relationships of cetane number, aromatics concentration, and hydrogen content of Wilsonville and EDS coal liquids are depicted in Figure 18 [108]. The viscosity of the high-severity product is just below the maximum allowable, while the result of accelerated stability test $(1.60 \mathrm{mg} / 100 \mathrm{ml})$ is still marginally high compared with the $1.5 \mathrm{mg} / 100 \mathrm{ml}$ allowed in the federal specification for diesel fuel [121]. It is, therefore, advisable to treat this diesel fraction with a multipurpose additive combining antioxidant, dispersant, corrosion inhibitor, and metal deactivator, in addition to an ignition improver additive.

Another refining route explored for coal-derived middle distillates is catalytic cracking. Coal-derived mid-distillates have been catalytically cracked to increase the yields of light fuels. Among the earliest work on catalytic cracking of coal liquids is a study on coal-tar fractions from low-temperature carbonization [122], where low conversion, low naphtha yield, and high coke make were observed. Polynuclear aromatics, the $C_{7}$ insolubles, gum, and high molecular-weight oxygenates are coke precursors. The poisoning effect of basic nitrogen compounds on active sites of cracking catalysts has also been investigated and reviewed [123], while coal liquids contain a significant amount of basic nitrogen. These are the disadvantages for coal liquid catalytic cracking.

Distillates from SRC-II liquids provided by Pittsburg and Midway Coal Refining Company [124] and from H-Coal atmospheric still bottoms obtained by UOP at Des Plaines, with and without hydrotreatment, were subjected to fluid-bed catalytic cracking over a commercial zeolite catalyst at UOP $[125,126]$. The results are as follows: 


\section{H-Coal Gas Oil}

The $\mathrm{H}$-Coal gas oil has a boiling range from $415^{\circ} \mathrm{F}$ to $769^{\circ} \mathrm{F}$, with hydrogen, sulfur, nitrogen and oxygen contents of 9.14, 0.08, 0.41, and $0.52 \mathrm{wt} \%$, respectively. Catalytic cracking of this gas oil results in low conversion (31-42 LV\%), low gasoline yield (15.5-20.0 LV\%) and high carbon yield (11.1-13.4 wt\%). After different levels of hydrotreatment, the hydrogen content of this gas oil was increased to 10.68 and $12.88 w t \%$, respectively, with corresponding reductions in $\mathrm{S}, \mathrm{N}$, and $O$ levels. The cracking behavior of these two hydrotreated gas oils were considerably improved, and the results are plotted in Figure 19 [125].

\section{SRC-II Gas Oil}

Similar results were obtained in the catalytic cracking of SRC-II gas oil, which has a boiling range of $421^{\circ} \mathrm{F}-738^{\circ} \mathrm{F}$, with $\mathrm{H}, \mathrm{S}, \mathrm{N}$, and $\mathrm{O}$ contents of $8.89,0.29$, 0.995 , and $2.28 w t \%$, respectively. Two additional gas oils from the same source, but hydrotreated at different severities, have about the same boiling ranges as the raw gas oil, but with increased hydrogen and reduced heteroatoms contents. Catalytic cracking of the raw gas oil gives low conversion (45.3-51.6 LV\%), low gasoline yield (25-28 LV\%), and high carbon yield (12.2-13.9 wt\%), while hydrotreated gas oils yield better results in parallel with their increased hydrogen content. The yields and product quality from SRC-II gas oils are compared below with data from a West Coast refinery feed hydrotreated to different hydrogen levels [124]. The latter was chosen for comparison because California crudes contain appreciable amounts of nitrogen. 


\begin{tabular}{|c|c|c|c|c|c|c|c|c|}
\hline \multirow[b]{2}{*}{ Food $H$ content, wt\% } & \multicolumn{4}{|c|}{ SRC-II Gas Oil } & \multicolumn{4}{|c|}{ West Coast Refinery Foed } \\
\hline & 8.66 & 8.89 & 9.98 & 10.59 & 11.78 & 12.46 & 12.50 & 13.47 \\
\hline Conversion, LV\% & 44.8 & 45.3 & 49.2 & 61.9 & 67.8 & 74.6 & 78.9 & 87.2 \\
\hline $\mathrm{C}_{\mathrm{b}}{ }^{+}$Gaoolino, LV\% & 23.9 & 25.1 & 35.3 & 46.9 & 50.9 & 59.0 & 61.8 & 71.0 \\
\hline$c_{i} \therefore w t \%$ & 5.3 & 5.0 & 8.4 & 13.5 & 15.2 & 16.5 & 18.9 & 21.2 \\
\hline Carbon, wt\% & 11.6 & 12.2 & 7.3 & 3.9 & 7.4 & 5.7 & 5.5 & 4.8 \\
\hline RON Clear & - & 106.7 & 101.8 & 97.5 & - & $\cdots$ & $\ldots$ & $\cdots$ \\
\hline
\end{tabular}

\section{EDS Gas Oil and Others}

Figure 20 shows data patterns, similar to the above two cases, with an EDS gas oil and a West Coast refinery feedstock [127,128].

These correlations for the coal and petroleum gas oils are reasonably consistent in their general trends. As the hydrogen content of the feed increases, the catalytic cracking conversion and gasoline yield also increase, and the coke production decreases. If $C_{3}$ and $C_{4}$ in the cracked gas are to be alkylated, with severely hydrotreated coal-derived cracker feed, additional $10 \mathrm{wt} \%$ (based on cracker feed) of high octane gasoline component $\left(C_{b}+\right.$ alkylate $)$ is roughly estimated.

Based on the above information, it can be concluded that with proper hydrotreatment, the coal-derived gas oils can be processed via FCC and alkylation into a high-octane and high-quality gasoline with fairly good yield.

Obviously, the effect of coal-oil catalytic cracking depend on the extent of hydrotreating and associated hydrogen consumption. For the $\mathrm{H}$-Coal gas oil, when its hydrogen content was brought up from 9.14 to $10.68 \mathrm{wt} \%$ by moderate hydroupgrading, the total hydrogen consumed was $1130 \mathrm{SCF} / \mathrm{bbl}$. Of this amount of hydrogen, $8.0 \%$ is involved in denitrogenation, desulfurization, and deoxygenation. The bulk $(90.5 \%)$ of the total hydrogen consumed (1.6 wt \% of raw gas oil feed) 
increases the hydrogen content mainly in saturating the aromatic rings. When hydrotreating was carried out at severe conditions, the hydrogen consumption was $5.6 \mathrm{wt} \%$ of the feed ( $3640 \mathrm{SCF} / \mathrm{bbl})$, which caused an increase in gas oil hydrogen content to $13.75 \mathrm{wt} \%$ and a reduction of aromatics from 90.2 to $7.2 \mathrm{LV} \%$. Under severe conditions, hydrocracking also became very significant. UOP suggested that the optimum hydrotreating level is around 11.5-12.0 wt\% hydrogen of the cracker feed [111].

Hydrotreatment plus catalytic cracking of middle distillates is a way of producing more gasoline from coal liquids. All the feedstocks (gas oils) used in the above-mentioned studies have a higher end point $\left(\sim 750^{\circ} \mathrm{F}\right)$ than that of diesel fuel fraction. For a coal-derived distillate with a lower end point (say $650^{\circ} \mathrm{F}$ ), it might be more beneficial to produce diesel fuel simply by hydrotreatment.

\subsection{Heavy Distillates}

Heavy distillates $\left(650^{\circ} \mathrm{F}+1\right.$, sometimes called vacuum gas oils (VGOs), obtained from coal liquids have even higher levels of aromatic and heteroatom compounds and pose additional problems in their utilization, such as toxicological activity and incompatibility with petroleum stocks.

Table 29 compiles data for some heavy distillates from EDS, H-Coal, and TSL liquid products. Yield of the heavy distillate varies over a wide range depending on liquefaction conditions, especially the recycle ratio. The heavy distillates from twostage liquefaction are significantly richer in hydrogen than those obtained from singlestage processes. More $\mathrm{S}$ - and $\mathrm{N}$ - compounds are concentrated in VGO than in either naphtha, kerosene, or middle distillates. The two-stage VGOs have less heteroatoms content than the single-stage counterparts. VGOs from ITSL processes can have negligibly small amounts of sulfur and heavy metals. 
The heavy distillates from coal liquids can be used as heavy fuel oils. H-Coal heavy distillate could be sold without further upgrading as a heavy industrial fuel oil (No. 6 fuel o:1) [112]. Nevertheless, when the coal-derived VGOs are blerided with Fuiroleum products, incompatibility may become a problem. As ari example, an EDS VGO $\left(650-1000^{\circ} \mathrm{F}\right)$ is reported to be incompatible with petroleum No. 2 and heavier fuel oils [113].

Storage instability is another concern with heavy distillates. After one month of storage at $210^{\circ} \mathrm{F}$, a viscosity increase was observed with EDS Wyodak fuel-oil blends $\left(350-1000^{\circ} \mathrm{F}\right)$. When stored below $150^{\circ} \mathrm{F}$, EDS fuel oil did not form wall deposits; however, at $200^{\circ} \mathrm{F}$ the fuel oil showed very high levels of deposits, indicating a strong effect of temperature on deposit formation [113]. In Mobil's storage stability tests on $\mathrm{H}$-Coal fuel oils $\left(400-975^{\circ} \mathrm{F}\right)$ derived from lllinois No. 6 , Wyodak, and West Kentucky coals over a one-year period, it was found that insolubles and gum formed in all three fuel oils and increased appreciably with time. The same is true for the total acid numbers, while changes in gravity and viscosity were relatively minor [110]. No comparable data are available ff: TSL products.

Combustion studies were conducted on a wide-boiling EDS fuel-oil product in a pilot-scale 50 HP Cleaver-Brooks boiler. Illinois and Wyodak fuel-oil blends were prepared with boiling ranges of $400-1000^{\circ} \mathrm{F}$ and $350-1000^{\circ} \mathrm{F}$, respectively. The coal liquid blends burn easily with smoke emissions equal to or lower than petroleum fuel oils at all levels of excess air. $\mathrm{NO}_{x}$ emissions are consistently higher relative to petroleum fuel oils, reflecting their higher fuel-bound nitrogen content. Particulate emissions are even lower than those obtained from petroleum fuel oil and are roughly equivalent to ash content. However, the coal fuel oils contain and emit significantly higher levels of polynuclear aromatics (PNA) [116].

Due to the incompatibility of coal vacuum gas oil with petroleum-derived industrial fuel oils, studies were performed at an Exxon R\&D Laboratory to determine 
the fersibility of hydrotreating as a means of upgrading. Although nitrogen is not a current resid fuel specification, it is anticipated that levels exceeding $0.2 \mathrm{wt} \%$ may be prohibited in certain applications (e.g., gas turbine fuel). To achieve this target, a high severity-hydrotreating would be required [116], and this may not be economical for the production of a low-value product like heavy industrial fuel oils.

Besides the elevated levels of hetero-compounds, the very high aromatics content of the coal-liquid heavy distillates is the primary difficulty encountered in refining. For instance, the heavy oils from the above-mentioned two ITSL runs (244 and 246) have extremely high concentrations of aromatics $\left(C_{A}\right)(46$ and 51.2, respectively) determined by ${ }^{13} \mathrm{C}$ NMR (Table 29). The aromatics content in singlestage VGOs is even higher. Typical petroleum gas oils have $C_{A}$ values between 8 and 26. The very high $C_{A}$ value with the coal-derived raw vacuum ges oils, especially when it is related to heavy polynuclear aromatics, makes the coal-derived VGOs extremely refractory and highly coke-producing during catalytic cracking.

Hydrocracking is a reasonable choice for refining this coal heavy distillat ?. Generally, two-stage hydrocracking is suitable for feedstocks that are high in heterocompounds and/or aromatics. Typically, the first-stage reactor is essentially a hydrotreating-hydrocracking system where heteroatom removal takes place so that nitrogen content is reduced to a level tolerable to the second-stage where hydrocracking is completed to extinction of the feed.

In a study conducted by UOP, first-stage hydrocracking of a rerun $\mathrm{H}$-Coal gas oil $\left(435^{\circ} \mathrm{F}-850^{\circ} \mathrm{F}\right)$ was done in a once-through operation over a UOP-DCA catalyst in bench-scale continuous units. Under suitable conditions, nitrogen conversions of $99.9+\%$ can be achieved. Inspection of the feedstock and the first-stage product to be used as feedstock for second-stage hydrocracking is summarized in Table 30 [129]. Hydrogen consumption is a little over $2 w t \%$ of feed, and the liquid yield exceeds $100 \%$, representing hydrogen added to the feed and low gas yield. 
Second-stage hydrocracking studies were carried out at maximum gasoline yield mode over a UOP-HCA catalyst, and the $375^{\circ} \mathrm{F}+$ stream was recycled to extinction (Table 30). At conditions studied, gasoline with reasonably high octane number (RON, clear 92.1-93.6) was obtained at high liquid yields (92.42-97.38 LV\%). At 3820-4400 SCF/bbl hydrogen consumption, the high rate of heat generation by saturation of polycyclics may exceed the heat transfer capacity of a second-stage reactor. It is therefore suggested that there can be a number of arrangements of different catalysts in several reactors for multistage hydrocracking.

Single-stage hydrocracking of the rerun $\mathrm{H}$-Coal atmospheric still bottoms to No. 2 fuel oil, with $600^{\circ} \mathrm{F}+$ product recycled to extinction over the UOP-DCA catalyst, can be performed under ve: $f$ severe conditions. But that may not be commercially practical. Two-stage hydrocracking to fuel oil is more flexible, and conditions can be less severe. The gasoline $\left(\mathrm{C}_{5}-375^{\circ} \mathrm{F}\right)$ yield is $15.3 \mathrm{LV} \%, \mathrm{C}_{4}$ - yield is $4-5 \mathrm{wt} \%$, and No. 2 fuel oil $\left(375^{\circ} \mathrm{F}-600^{\circ} \mathrm{F}\right)$ yield is $90.2-91.2 \mathrm{LV} \%$. Overall hydrogen consumption is about $1600 \mathrm{SCF} / \mathrm{bbl}$.

UOP estimated the hydrogen balance for two-stage hydrocracking of the above feedstock to gasoline. Reforming of the hydrocracker naphtha and steam reforming of $C_{1}-C_{3}$ could provide only $55 \%$ of total hydrogen consumed. UOP workers believe that including $\mathrm{C}_{4}$ in the steam reformer feed should result in a hydrogen balance [129].

The yield of liquid product $\left(C_{5}+\right)$ is almost linearly correlated with the product aromatic content (Figure 21), which in turn dictates the chemical hydrogen consumption. The naphthenes in naphtha are eventually dehydrogenated during reforming; a naphthene content in hydrocrackate higher than required for $375^{\circ} \mathrm{F}^{+}$ extinction operation is therefore not necessary. This could lead to overload of both the hydrocracking and reforming reactors. 
Hydrocracking of an EDS coal oil was also investigated by UOP. The hydrocracking feedstocks had an IBP around $400^{\circ} \mathrm{F}$ and a $90 \%$ point around $900^{\circ} \mathrm{F}$. The volumetric yields of $\mathrm{C}_{5}+$ gasoline and butanes from the gasoline mode operation ranged from $105 \%$ to $115.5 \%$ and $18 \%$ to $26 \%$, respectively. The octane number of the $C_{5}+$ gasoline ranged from 75 to 83 RON clear. The overall hydrogen consumption ran from 3300 to $4200 \mathrm{SCF} / \mathrm{bbl}$. In the fuel oil mode, yield of environmentally acceptable distillate was about $88 \%$, which was obtained principally in the first stage. The overall hydrogen consumption was about 1650 SCF/bbl [130].

\subsection{Summary}

1. The naphtha fraction from coal liquids is rich in aromatics and naphthenes, high in octane rating, and therefore is an excellent source for gasoline production. It makes a superior reformer feedstock, and it is also a premium gasoline blending stock. In either case, hydrotreating is required. The heteroatom levels, especially oxygen level, of coal-derived naphthas are high and heteroatom removal by either hydrotreating or extraction is necessary.

2. A kerosene fraction distilled from Texas lignite EDS liquid was hydrotreated by Chevron to make jet fuels with smoke points of at least $20 \mathrm{~mm}$ under a hydrogen partial pressure of 1500 psia or higher. However, similar work done by Southwest Research Institute indicates that even the jet-fuel obtained by high-severity hydrotreating did not meet the specifications on API gravity and smoke point. Information on jet fuels from fractions of higher rank coal liquids is not available.

3. Due to its elevated aromatics content, the coal-derived diesel fuel has a very low cetane index, and it must be hydrogenated under a severity high enough to improve its combustion quality as well as its stability. 
4. Tests with coal-derived middle distillates on a stationary turbine and a home heating oil burner showed that the smoke emissions are comparable to No. 2 fuel oil. The distillates can not meet the gravity specification for No. 2 fuel oil and No. 2 GT ys turbine fuel due to high aromatics content, and $\mathrm{NO}_{\mathrm{x}}$ emissions are much higher than those of petroleum No. 2 fuel oil. Therefore, hydrotreating is required to make No. 2 fuel oil from coal-derived middle distillates.

5. Coal-derived middle distillates must be hydrotreated to be a good catalytic cracker feed. The optimum hydrotreating level is suggested by UOP to be 11.5-12.0 wt\% hydrogen of the cracker feed, which is comparable to petroleum feedstocks in catalytic cracking performance. It may be more beneficial to produce diesel fuel from middle distillates simply by hydrotreatment.

6. The heavy distillates $\left(650^{\circ} \mathrm{F}+\right)$ from coal liquids may be incompatible with petroleum counterparts to make heavy fuel oil blends. It is highly recommended that the coal-derived heavy distillates be converted to lighter distillates for producing more valuable transportation fuels. Two-stage hydrocracking of coal-derived heavy distillates can either produce high quality gasoline with high yields, or environmentally acceptable No. 2 fuel oil. If maximum gasoline yield is required, the hydrogen consumption would be as high as $3300-4400$ SCF/bbl and the heat transfer capacity of the second-stage reactor may be exceeded. Recycling the $650^{\circ} \mathrm{F}+\mathrm{VGO}$ to extinction during liquefaction seems to be preferable.

7. A considerable portion of the hydrogen consumption during hydrotreating is attributed to oxygen elimination. The oxygen compounds in the peak region $\left(350^{\circ} \mathrm{F}\right.$ $450^{\circ} \mathrm{F}$ ) are mostly phenolics, and recovery of the phenolics as a by-product can reduce hydrogen consumption and increase product value. 


\subsection{HYDROTREATING OF TOTAL COAL LIQUIDS}

Straight-run distillation and then refining individual fractions separately according to the product slate, as discussed in the previous section, is the conventional refinery schedule. As an alternative, the total coal liquid can be hydrotreated as a whole and then fractionated to various, supposedly finished products. This is discussed in the present section.

Chevron has done hydrotreating pilot plant studies on coal liquids with the goal of either making specification jet fuel or diesel fuel and a naphtha suitable for catalytic reforming in a single hydrotreating step, or making a product suitable for hydrocracking in a second step [87]. Coal liquids from five different liquefaction processes (SRC-II, EDS, H-Coal, ITSL, and CTSL) were catalytically hydrotreated in laboratory pilot plants. The two-stage coal liquids are: 1. Illinois No. 6 ITSL liquid. produced by LCI in its ITSL pilot plant designated as LC-Fining Run 3LCF9 [131]; 2. Wyodak ITSL oil product by LCI [132]; and 3. Wyodak CTSL oil made by HRI in its CTSL pilot plant in Lawrenceville, N.J. [133]. The hydrotreated liquids were distilled to obtain different fractions. In some cases, the oil boiling above the jet fuel range was hydrocracked to extinction in a second catalytic stage to maximize jet fuel production. Test results are summarized in Table 31 . The tests were made at $750^{\circ} \mathrm{F}$ average catalyst temperature, on a single commercial hydrotreating catalyst, Chevron's ICR 106 [84].

To meet either goal, almost all of the heteroatom contaminants had to be removed by hydrotreatment. Typically, the control target for product nitrogen content was $<0.5 \mathrm{ppm}$. Sulfur is relatively easy to remove compared with nitrogen and, therefore, was of little concern in Chevron's study. Oxygen-containing compounds can be at least as hard to remove as nitrogen compounds; however, when the nitrogen was reduced to $0.5 \mathrm{ppm}$, organic oxygen content was also reduced to less than 5-10 ppm (based on limited analytic results). The relationship between product 
nitrogen and hydrogen consumption for three coal liquids is depicted in Figure 22 with a shale oil for reference. More hydrogen is required for shale oil denitrogenation since the shale oil has a higher nitrogen content and its higher boiling range results in more cracking of the high-boilers during hydroprocessing [83].

In addition to the removal of heteroatoms, it is necessary to hydrogenate most of the aromatics in these fractions if finished jet or diesel fuel is to be the main product from a single hydrotreating step. Figure 23 is a comparison of the hydrogen consumption for the four coal liquids required to make products at a given aromatics concentration. The results reasonably conform to their hydrogen and heteroatom contents [83]. This information also indicates that the prime factors in process design and cost estimate for coal liquids refining can be based upon inspections of the coal liquids, without much knowledge of the coal source or the liquefaction process employed $[134,135]$.

Full-boiling-range coal liquids require relatively high hydrotreating severities to remove the heteroatoms and increase the hydrogen content. Of these four singlestage total coal oils, the Wyodak $\mathrm{H}$-Coal oil is the easiest to upgrade, probably because of its high hydrogen content and low average boiling range. For a given boiling range, coal liquids from two-stage liquefaction are easier to upgrade than those made in single-stage processes, due to the effect of the higher hydrogen and lower heteroatom content of two-stage liquids. For coal liquids from a given liquefaction process, a relatively small increase in end point can make the liquid much harder to upgrade. Distilled coal liquid fractions, especially fractions with end points lower than $600^{\circ} \mathrm{F}$, are very easy to hydrotreat in comparison to the whole coal liquid [115]. A $900^{\circ} \mathrm{F}$ end-point Wyodak ITSL oil is much harder to process than $800^{\circ} \mathrm{F}$ end-point Illinois No. 6 ITSL liquids. The differences are believed to be the result of a higher end point of this Wyodak oil, rather than differences in coal properties [136]. A roughly linear correlation was found [84] between required catalyst temperature and coal-oil end point for a group of ITSL liquids, regardless of coal source (Figure 24). Moreover, 
a lower average boiling range also makes processing easier. These are very important observations with respect to coal-liquid hydroprocessing.

If transportation fuels igasoline, jet, and diesel fuel) are desired products, relatively high severities are required; for example, hydrogen pressure ranging from 1750-2300 psia, temperatures in the range of $750^{\circ} \mathrm{F}-800^{\circ} \mathrm{F}$, and LHSV of 0.5-1.5 $\mathrm{vol}$. feed $/ \mathrm{vol}$. catalyst $/ \mathrm{hr}$. With the feed end points of $<750^{\circ} \mathrm{F}$, the catalyst is very stable, and catalyst lives of several years can be predicted. In spite of the relatively severe hydroprocessing conditions, there is little cracking to light gases for coal liquids with end points below $800^{\circ} \mathrm{F}$. Liquid volume yields are typically higher than those obtained when hydrotreating petroleum, because of the higher hydrogen input [134136].

The extent of upgrading is an important factor in final coal liquid composition. Work on Wyodak coal liquid hydroupgrading reveals that the more extensive the upgrading, the higher the yields of low-ring-number compounds produced. The possible causes are heteroatomic ring opening and breaking of alkyl linkages between rings, both contributing to formation of hydrocarbons with less ring numbers [137140].

The coal rank seems to be another factor in determining the upgrading effect and the composition of upgraded product. For instance, under the same upgrading conditions, the extent of denitrogenation is greater for subbituminous Wyodak coal oil than for the higher-rank Illinois No. 6 coal liquid, and significantly higher yields of low-ring-number compound types were identified for the former. However, for coal liquids from different coal sources upgraded to about the same nitrogen content, no clear trend in terms of ring number distribution as a function of coal rank was evidenced [137]. 
After hydrotreating, products of similar boiling ranges from different liquefaction processes and different coals were quite similar. The products mainly comprise cyclic hydrocarbons, since heteroatom compounds have been removed. The hydrotreating severity determi..\&d the amount of hydrogenation of aromatics to naphthenes. Products from subbituminous coals contained more paraffins than those from bituminous coals. The hydrogen consumption needed for a given product quality from these coal liquids depends on their hydrogen content and heteroatom contents. The hydrogen required in coal-liquid hydrotreating is higher than that usually needed in petroleum hydrotreating [138-140].

An EDS coal-oil blend and an H-Coal oil blend from Illinois No. 6 coal, as well as a $400^{\circ} \mathrm{F}+$ SRC-II oil derived from Pittsburgh Seam coal, were hydrotreated under different severities to obtain coal-liquid samples with different nitrogen contents: 5000, 2000, $500 \mathrm{ppm}$, and acceptable levels for $30^{\circ} \mathrm{API}$ fuel-oil product, for biological studies at Oak Ridge National Laboratory [141,142]. By adjusting the operating conditions and hence the severities, heteroatom removal and aromatics saturation can be realized to certain extents almost at will. As the hydroupgrading severity and hydrogen consumption increase, the heteroatoms contents and aromatics level are reduced while hydrogen content and $\mathrm{H} / \mathrm{C}$ atom ratio increase. Some data are compiled in Table 32. If severity is high enough, all the heteroatoms can eventually be removed to beyond the detection of certain analytical techniques, most of the aromatics can be hydrogenated, and the product is water-white in appearance [143]. When hydrogen content of SRC-II liquid is increased from 8.4 to 12.24 wt\%, essentially $100 \%$ of the nitrogen and $95 \%$ of the oxygen have been removed. Calculated hydrogen consumptions for this range of conditions varies from 970 to $2880 \mathrm{SCF} / \mathrm{bbl}$, which is within the range reported by other workers $[144,145]$.

High severity hydrotreating of total liquids is required under most circumstances to produce quality transportation fuels, especially jet and diesel fuels. Tables 33 and 
34 summarize the yields, hydrogen consumptions, and product inspections achieved by hydrotreating four coal liquids at high severities [104].

Properties of various products obtained from the total coal liquids, hydrotreated as a whole, are discussed in the following subsections.

\subsection{Naphtha from Hydrotreated Coal Liquids}

Properties of naphthas prepared by hydrotreating single-stage coal liquefaction oils are shown in Table 35. The naphthas are quite similar except that naphthas from low-rank coals are more paraffinic than naphthas derived from bituminous coals. $\mathrm{H}$ Coal naphthas have a somewhat higher paraffin content than two-stage naphthas from the same coal, as revealed by the following data:

\section{Parrafin Contents of Typical $150^{\circ} \mathrm{F}-350^{\circ} \mathrm{F}$ Naphthas \\ from \\ Hydrotreated Coal Liquids}

\begin{tabular}{cc} 
Feed Source & Parraffin, LV\% \\
\hline Wyodak H-Coal & 23 \\
Wyodak CTSL & 18 \\
Illinois H-Coal & 11 \\
Illinois ITSL & 7
\end{tabular}

All the hydrotreated coal naphthas have a high content of cyclic compounds. Compared with naphthas from shale oil, the naphthas from hydrotreated Wyodak $\mathrm{H}$ Coal oil have higher octane ratings as a result of their high ring content (Table 36) [83]. 
At higher hydrotreating severities, almost all the aromatics in the naphtha fraction are saturated, and virtually no heteroatoms are left. They can be fed directly to the second stage of a catalytic reformer. Much of the hydrogen consumed in the pric. :yydrotreating step can be recovered in the reforming stage. Reforming yields will be high, as it is reported that with a given octane reformate, the liquid yields from EDS naphtha are at least 10 vol\% higher than the expected yields for Arabian light naphtha [146].

Table 37 shows properties of the naphtha products obtained from SRC-II liquids hydrotreated at high and intermediate severities, with hydrogen consumption of $>2750$ and 1750-2750 SCF/bbl, respectively [144]. At lower severity hydrotreating, the naphtha will require further hydrorefining in a conventional hydrotreater to remove the remaining heteroatoms before being sent to the reformer.

Analytical results of naphtha samples $\left(<392^{\circ} \mathrm{F}\right)$ derived from eight upgraded coal liquids are listed in Table 38. Obviously, these naphthas have high contents of cyclic compounds, especially cycloparaffins, which make them very suitable for reforming. No olefins were detected from these hydrotreated naphthas [137].

If the refining goal is mainly gasoline, then the portion of hydrotreated total coal liquid heavier than naphtha needs to be hydrocracked to maximize gasoline production. In the all-gasoline mode, the RONs of $\mathrm{C}_{5}-180^{\circ} \mathrm{F}$ and $180^{\circ} \mathrm{F}+$ naphthas from hydrocracking Illinois and Wyodak H-Coal and SRC-II liquids (denitrified) are 88-90 and 69-75, respectively [147]. The hydrocracked naphtha can also be combined with the hydrotreated naphtha and the blend can then be reformed.

For the production of transportation fuels as primary products, there is an opinion that hydrotreating the naphtha and heavier distillates separately holds no particular advantage [83]. However, the total coal liquid must be hydrotreated at high severity to reduce the heteroatoms to very low levels ( $\mathrm{N}<1 \mathrm{ppm}$ in Chevron's work) 
for the naphtha to be acceptable to the reforming catalyst. Under such a high severity hydrotreatment (with hydrogen consumption $>2750 \mathrm{SCF} /$ bbl), essentially all the aromatics in the naphtha are hydrogenated into naphthenes, which in turn are dehydrogenated back to aromatics during subsequent reforming. Referring to Section 5.2 , hydrotreating an $\mathrm{IBP}-400^{\circ} \mathrm{F}$ raw naphtha cut from an $\mathrm{H}$-Coal liquid to reformer stock can be achieved at moderate severity of operation with a hydrogen consumption of only $480 \mathrm{SCF} / \mathrm{bbl}$. Moreover, fractions heavier than naphtha may not need a very high severity in hydrotreatment. Hydrotreating the coal-derived fractions separately is a definite advantage even if the naphtha is to be reformed.

\subsection{Jet Fuel Fraction from Hydrotreated Coal Liquids}

After the heteroatom contents have been reduced to acceptable levels, the critical point for jet fuel from coal-derived liquids is the aromatics content. To meet the ASTM smoke-point specification (20 mm, min), most of the aromatics in the fraction had to be hydrogenated. Figure 25 is a plot of smoke point data vs. aromatics content of kerosene-type jet fuels from various hydrotreated coal liquids. At a given aromatics content, those from Wyodak (subbituminous) coal have smoke points $2-3 \mathrm{~mm}$ higher than those from Illinois No. 6 (bituminous) coal, a consequence of the higher Wyodak paraffin content. The Illinois jet fuels meet the smoke specification of $20 \mathrm{~mm}$ at $10 \mathrm{LV} \%$ aromatics or lower, while the Wyodak jet fuels meet the specification at about $15 \mathrm{LV} \%$ aromatics [148].

Except for restrictions on aromatics and olefins (for stability consideration), the proportions of hydrocarbon types are not directly controlled. The requirements on density, energy content, and freezing point favor isoparaffinic and naphthenic composition. The hydrocarbon constituents of most JP-4 fuels are primarily normal and iso-paraffins (50-70 LV\%) and cycloparaffins $(20-40 \mathrm{LV} \%)$, with alkyl benzenes less than $20 \mathrm{LV} \%$. Refiners usually produce JP-4 from a blend of $60 \%-70 \%$ naphtha and $30 \%-40 \%$ kerosene fraction from petroleum. 
Polycyclic naphthenes are considered to be ideal components for high-energy jet fuels. Regarding the heat of combustion, bicyclic naphthenes average about $135,000 \mathrm{Btu} / \mathrm{gal}$, tricyclic naphthenes average about 145,000 Btu/gal, and four-ring naphthenes approach 150, $30 \mathrm{Btu} / \mathrm{gal}$ [149]. In comparison, conventional jet fuels range from about 120,000 to $127,000 \mathrm{Btu} / \mathrm{gal}$. Catalytic cracking cycle oils could be hydrogenated to high-energy jet fuels due to their high cyclic contents [150]. Naphthenes with two or three rings are believed to give the best compromise among various properties required for jet fuels: high volumetric heating value, satisfactory gravimetric heating value, acceptable thermal stability, very low freezing point, acceptable low-temperature viscosity, low volatility, high flash point, and acceptable flame characteristics (smoke point, etc.). No other hydrocarbons in the jet fuel range have all of these properties. The high cyclics contents of coal-derived liquids makes them a very promising feedstock for making high-energy jet fuels.

Severe hydrotreating of single-stage coal liquefaction liquids yields $75-87 \mathrm{LV} \%$ jet-fuel fraction (TBP $250^{\circ} \mathrm{F}-600^{\circ} \mathrm{F}$ ). These fractions meet almost all of the specifications for kerosene-type Jet $A$ fuel (Table 39). The only property that was not met consistently was the API gravity, for example, the SRC-II jet-fuel fraction in Table 39. The API gravity of these fractions could be met by adjusting the end point from $600^{\circ} \mathrm{F}$ to $550^{\circ} \mathrm{F}$ [83]. Representative jet fuels $\left(250^{\circ} \mathrm{F}-550^{\circ} \mathrm{F}\right)$ made from hydrotreated coal liquids meet all ASTM Jet A specifications, as evidenced by the test data listed in Table 40 [148]. These coal liquids were obtained from Illinois No. 6 , Wyodak, and Texas Big Brown coals by single-stage liquefaction processes. Table 41 is a comparison between jet fuels from different sources with Jet A specifications. Jet fuels produced from these hydrotreated coal liquids easily passed the very stringent thermal oxidation stability test (JFTOT) whenever the specifications for aromatics and smoke point were met. Severe stability requirements mean that heteroatom content must be very low, and usually the nitrogen content is less than $10 \mathrm{ppm}$ for petroleum-derived jet fuel [83]. 
Properties of two sets of jet fuels from hydrotreated two-stage Illinois No. 6 coal liquids are shown in Table 42; the first set from hydrotreating alone, the second from hydrotreating plus hydrocracking of the total coal liquids. The first sample in each set boils between $230-550^{\circ} \mathrm{F}$, the second between $350^{\circ} \mathrm{F}$ and $550^{\circ} \mathrm{F}$. The jet fuel fractions from hydrotreated ITSL liquids meet Jet $A$ specifications except those for gravity and viscosity [148]. Changing the initial point from $350^{\circ} \mathrm{F}$ to $250^{\circ} \mathrm{F}$ had little effect because ITSL liquids contain relatively little $250-350^{\circ} \mathrm{F}$ material, and little cracking occurred during hydrotreatment. This may indicate that coal-derived jet fuels should contain adequate amout of front-ends $\left(250-350^{\circ} \mathrm{F}\right)$ to meet gravity and viscosity requirements.

Group analysis data for hydrotreated Wyodak ITSL and CTSL liquids are shown in Tables $\mathbf{4 3}$ and 44 . Jet fuels from hydrotreated Wyodak coal liquids have somewhat higher paraffin contents, and products from CTSL processes have even higher concentration of paraffins than those obtained from ITSL process. Products from ITSL bituminous coal liquids have the lowest paraffin contents and the highest densities of any of the coal liquids studied [148].

Figure 26 plots the smoke point versus aromatics content for jet fuel obtained by hydrotreating a distillate from raw EDS liquid and by hydrotreating whole EDS liquid and then distilling. Obviously, the jet fuels obtained by hydrotreating the raw distillate cut have significantly higher smoke points than the jet fuels distilled from hydrotreated total coal oil. The smoke point advantage increased from zero, when both jet fuels contain about $40 \%$ aromatics, to $5 \mathrm{~mm}$, when all the aromatics are saturated. The main reason for this difference is that for the total coal-oil hydrotreating, some heavy aromatics (which boil above $600^{\circ} \mathrm{F}$ ) are saturated and the resultant polycyclic naphthenes boil below $600^{\circ} \mathrm{F}$. These polycyclic naphthlenes therefore enter into the jet fuel range. The polycyclic naphthenes have relatively low hydrogen content and low smoke point, and therefore lower the smoke point of the 
jet fuel. Their presence also increases the average ring number per molecule, which is supported by analytical data [119].

Hence, it is clear that total coal-liquid hydrotreating produces a jet fuel with lower quality, and consequently separate hydrotreatment of different fractions is preferred when jet fuel is the main product.

\subsection{Diesel Fuel Fraction from Hydrotreated Coal Liquids}

Diesel fuel fractions from coal liquids are also characterized by high aromatics content. Group anå. $y s i s$ data for $392-617^{\circ} \mathrm{F}$ fractions from eight upgraded TSL coal liquids are shown in Table 45 . In most cases, the aromatics content is $50 \%$ or more [137]. According to Chevro:'s work, diesel products from both single-stage and two-stage liquefaction liquids meet typical ASTM specifications, provided a relatively high degree of hydrogenation of the total coal liquid is undertaken to satisfy the minimum cetane-number requirement of $\mathbf{4 0}$ for the diesel fuel cut [87].

The $250^{\circ} \mathrm{F}+$ fractions from the hydrotreated coal liquids, at the conditions ernployed to prepare jet fuel, also meet all specifications for No. 1 diesel fuel within experimental error, as shown in Table 46. Comparison of diesel fuels from different sources is presented in Table 47. Heteroatoms must be removed to a certain level as required for stability, however, this level is not known for coal-derived diesel fuels. For petroleum diesel fuels, nitrogen level is usually 500 ppm or below [83], and Sullivan et al. [151] found that 400 ppm nitrogen was the maximum concentration at which hydrotreated shale oil products remained stable.

Table 48 lists some data for $250^{\circ} \mathrm{F}+$ fractions from hydrotreated ITSL coal liquids $[132,152]$. These fractions do not meet smoke point specifications for jet fuel, but their cetane numbers qualified them for diesel fuels. Adjustments can be made to modify their boiling range and viscosity, etc. 
No. 1-D fuel is used in small engines that require frequent speed or load adjustments. Diesel fuel No. 2-D is more widely used in engines for heavy mobile or industrial service, which requires a higher flash point of $125^{\circ} \mathrm{F}(\mathrm{min})$. If the $300^{\circ} \mathrm{F}+$ fraction is cut, then the flash point requirement for No. 2-D fuel can ke satisfied. For diesel fuel used in typical climates, the initial points could be adjusted further upward to meet viscosity and D86 $90 \%$ point requirements. These diesel fuels also passed accelerated oxidation and thermal stability tests [83].

Figure 27 dernonstrates the relationship of cetane number versus aromatics content for products from single-stage and two-stage processes. With the two-stage oils, the specification was met with an aromatics content of about $20 \mathrm{LV} \%$, while an aromatics content of less than $10 \mathrm{LV} \%$ is required with a single-stage liquid. These differences, however, may be due to the differences in boiling ranges of the diesel fuels rather than the differences in processing (single stage vs. two stage). For instance, the following table compares pairs of samples of different boiling ranges, with essentially the same paraffin and aromatics contents within a given pair. For each pair, the higher boiling sample has the higher cetane number. Of course, more paraffinic diesel fuels have higher cetane numbers, with otherwise equal properties.

Effect of Boiling Range on Cetane Number [87]

\begin{tabular}{|c|c|c|c|c|c|}
\hline Source & $\begin{array}{c}\text { Initial, }{ }^{\circ} \mathbf{F} \\
\text { TBP }\end{array}$ & $\begin{array}{l}\text { Midpoint, } \\
\text { 'F (TBP) }\end{array}$ & $\begin{array}{c}\text { Cotane } \\
\text { No. }\end{array}$ & $\begin{array}{c}\text { Aromatics, } \\
\text { LV\% }\end{array}$ & $\begin{array}{c}\text { Paraffins, } \\
\text { LV\% }\end{array}$ \\
\hline \multirow[t]{2}{*}{ Wyodak CTSL } & 250 & 414 & 44.2 & 3.9 & 9.5 \\
\hline & 350 & 454 & 48.7 & 4.6 & 7.7 \\
\hline \multirow[t]{2}{*}{ Illinois ITSL } & 250 & 520 & 43.1 & 9.8 & $<1$ \\
\hline & 350 & 538 & 4.3 & 11.7 & $<1$ \\
\hline \multirow[t]{2}{*}{ Illinois H-Coal } & 250 & 393 & 35.9 & 15.6 & 3.6 \\
\hline & 350 & 438 & 37.7 & 18.5 & 3.7 \\
\hline
\end{tabular}


As with the jet fuels described before, the hydrotreated coal-derived diesel fuels have excellent cold-weather properties and high volumetric energy contents, since they are essentially all cyclics, especially naphthenes.

Coal-derived liquids respond well to certain cetane improvers. Because of the high cost of hydrogen, it may be cost-effective to substitute cetane improvers for hydrotreating severity to some extent. For instance, adding $0.3 \mathrm{LV} \%$ octyl nitrate, a commercial cetane improver, to diesel fuels from hydrotreated Wyodak $\mathrm{H}$-Coal oil was shown (Figure 28 ) to increase the cetane number by $6-8$ points [83].

It is also reported that the calculated cetane indices for twelve coal-derived diesel fuels are lower than measured cetane numbers by an average of about eight units. This means that the cetane index (ASTM D976-66) method should not be used to predict cetane numbers for coal-derived diesel fuels without correction [83].

\subsection{Fuel Oil Fraction from Hydrotreated Coal Liquids}

No. 2 fuel oil equivalent product can be obtained from coal liquids by hydrotreatment. Table 49 lists properties of $250^{\circ} \mathrm{F}+$ fractions from moderately hydrotreated single-stage coal liquids in comparison with ASTM No. 2 fuel oil specifications [83]. These fractions have about 50-60 LV\% of aromatics and show very low pour points; they all have viscosities just below the ASTM minimum of 1.8$2.0 \mathrm{cSt}$. The gravities are below ASTM minimum of $30^{\circ} \mathrm{API}$. Viscosity and gravity specifications could be met by increasing hydrotreating severity. For instance, hydrotreated at 2000 psig, the Texas lignite total liquid has an API gravity of 32.8 , and its $600^{\circ} \mathrm{F}$ - distillate has an API gravity of 34.7 [153]. 


\subsection{Two-Stage Hydrotreating of High End-Point Coal Liquids}

The coal liquids with end points below $775^{\circ} \mathrm{F}$ can produce specification jet and diesel fuels after hydrotreatment under relatively severe conditions. However, with high end-point coal liquids, even after hydrotreating under severe conditions, the jet and diesel fuels produced have marginal properties and are too aromatic to meet specifications directly. Perhaps this is the reason why SwRI did not obtain a diesel fuel meeting all the specifications, since their feedstock has a high end point of $823^{\circ} \mathrm{F}$ [108]. Hence, for high end-point coal liquids, two-step hydrotreating was investigated by Chevron. The two steps are: 1 , hydrotreating at relatively high temperatures to remove most of the heteroatoms, and 2 . further hydrogenation at lower temperatures for more aromatics saturation under favorable conditions, since hydrogenation of some of the high-boiling polycyclic-aromatic compounds is thermodynamically favored at lower temperatures [87]. Experimental results show that two-stage hydrotreating with a second-stage temperature of $650^{\circ} \mathrm{F}$ reduced the aromatics content to $12 \mathrm{LV} \%$. The jet and diesel fractions from hydrotreated coal liquids readily met and even exceeded smoke point and cetane number specifications. End-point reduction was also remarkable with less than $5 \%$ of the hydrotreated coal liquid boiling above the diesel range. Chevron suggested the two-step hydrotreating as an alternative to the hydrotreating/hydrocracking route for upgrading high end-point coal liquids, provided diesel fuel is a desired end product [87].

\subsection{Summary}

As an alternative refining scheme for coal liquids, the total coal liquid can be hydrotreated and then fractionated into various products.

1. Coal liquids from two-stage liquefaction processes are easier to upgrade than single-stage liquids with comparable boiling range due to lower $\mathrm{N}$ and $\mathrm{O}$ contents. Relatively small increases (viz. $750^{\circ} \mathrm{F}$ vs $650^{\circ} \mathrm{F}$ ) in end points make the coal 
liquids much harder to upgrade. After hydrotreatment, coal liquids of comparable boiling ranges from different liquefaction processes and different coals are quite similar. The hydrotreated coal liquids consist mainly of cyclic hydrocarbons. Hydrotreated coal liqu.ds from subbituminous coals contain more paraffins than those from bituminous coals.

2. Products obtained from hydrotreated coal liquids have the following properties:

Naphtha -

Jet Fuel -

Diesel Fuel -
The total coal liquid must be hydrotreated at a relatively high severity to yield a naphtha fraction acceptable as a reformer feedstock.

The $250-550^{\circ} \mathrm{F}$ fraction obtained from severely hydrotreated single-stage coal liquids meet all ASTM specifications for kerosene-type Jet $A$ fuel. The jet fuel fractions from hydrotreated ITSL liquids meet most of Jet A specifications except gravity and viscosity. Hydrotreating the total coal liquid does not appear to be a reasonable scheme to produce jet fuel from two-stage coal liquids.

Diesel fuels from both single-stage and two-stage liquids meet typical ASTM specifications, including the minimum cetane number requirement of 40 , provided a relatively high degree of hydrogenation of the total coal liquid is undertaken. Coal-derived diesel fuels respond well to certain cetane improvers, such as octyl nitrate. The calculated cetane index for coal-derived diesel fuels 
are lower than measured cetane numbers by an average of about 8 units.

Fuel Oil - $\quad$ Coal-liquid product equivaient to No. 2 fuel oil can be obtained by hydrotreating total coal liquids with medium severity.

3. The major disadvantage to hydrotreating the total liquids as a refining scheme is the difficulty posed by their wide boiling range and high end points. High severity is required for the total coal liquid hydrotreatment to make specification jet fuel or diesel fuel and a reformer feedstock. Almost all of the heterocompounds had to be removed; consequently, an essential part of the aromatics was saturated. This results in a much higher hydrogen consumption compared with the hydrogen consumption for moderate-severity hydrotreatment of a raw naphtha cut from coal liquids. An operation of saturating all the aromatics in naphtha by hydrotreating and then dehydrogenating them by reforming is a wasteful combination.

4. Another disadvantage to hydrotreating the total coal liquids is that the jet fuel fraction thus obtained has lower quality, particularly a lower smoke point, compared with hydrotreating the kerosene fraction from the same coal liquid under the same severity.

5. The operation of total-coal-liquid hydrotreating excludes the possibility of separating the $350-450^{\circ} \mathrm{F}$ fraction, which contains valuable chemicals such as phenols and cresols. The hydrogen consumed in converting oxygen to water lowers the hydrogen efficiency in hydrotreatment.

6. The total-coal-liquid hydrotreating scheme is therefore not recommended for coal-liquid refining due to the difficulty in hydrotreating, lack of process selectivity and flexibility, and lower product quality. 


\subsection{HYDROCRACKING OF TOTAL COAL LIQUIDS}

When a relatively hydrogen-deficient, heteroatom-rich heavy coal liquid is to be converted to higher value, lighter fuel prouucts with reduced heteroatom content, hydrocracking is a major tool. Hydrocracking is a versatile process that can be varied to make naphtha only, or a combination of naphtha and middle distillate. Similar to hydrotreating, hydrocracking may also be practiced in two ways: hydrocracking of heavy raw coal liquid distillates as described in Section 5.0; or hydrocracking the total coal liquid and then distilling into various fuel products, as will be discussed here.

Chevron studied hydrocracking of SRC-II, H-Coal, and ITSL liquids in its pilot plant. The results for recycle hydrocracking of some denitrified coal liquids in an "All Gasoline Mode" are summarized below [147].

\begin{tabular}{|c|c|c|c|c|}
\hline \multirow[b]{2}{*}{ Feodstock } & \multicolumn{2}{|c|}{$\begin{array}{c}\text { Chemical } \mathrm{H}_{2} \text { Consumption } \\
\text { (SCF/bbl) of Food }\end{array}$} & \multicolumn{2}{|c|}{ Yields, LV\% } \\
\hline & $\begin{array}{l}\text { Hydrocracker } \\
\text { only }\end{array}$ & $\begin{array}{l}\text { Hydrocracker + } \\
\text { Hydrotroater }\end{array}$ & $\begin{array}{l}\mathrm{C}_{\mathrm{b}^{+}}^{+} \\
\text {Total }\end{array}$ & $\begin{array}{r}180- \\
315^{\circ} \mathrm{F}\end{array}$ \\
\hline 350"F+ HDN Illinois H-Coal & 1400 & 3100 & 92.8 & 62.1 \\
\hline $\begin{array}{l}350^{\circ} F^{+} \text {HDN Wyodak } H \text { - } \\
\text { Coal }\end{array}$ & 2450 & $1850^{\circ}$ & 93.1 & 56.6 \\
\hline $350^{\circ} \mathrm{F}+$ HDN SRC- 11 & 2250 & 3850 & 95.9 & 62.2 \\
\hline
\end{tabular}

The yield of total naphtha from the hydrocracker is excellent, between 93 and $96 \mathrm{LV} \%$. The naphthá yield can be increased by $3 \mathrm{LV} \%$ if the recycle cut point (RCP) is raised to $350^{\circ} \mathrm{F}$; and correspondingly, the hydrogen consumed can be reduced by $100-300 \mathrm{SCF} / \mathrm{bbl}$. Total cyclics content in the $\mathrm{C}_{5}-180^{\circ} \mathrm{F}$ cut is above $40 \mathrm{LV} \%$, and for $180^{\circ} \mathrm{F}-315^{\circ} \mathrm{F}$, cut it ranges from 85 to $89 \mathrm{LV} \%$. The RON for the $\mathrm{C}_{5}-180^{\circ} \mathrm{F}$ cut is $88-90$, and that for $180-315^{\circ} \mathrm{F}$ naphtha is between $70-75$. 
Hydrocracked coal naphthas are superior reforming feedstocks. Two naphthas obtained by hydrocracking H-Coal gas oil were reformed over a commercial Platforming catalyst by UOP [114]. Since these feeds are highly naphthenic, reforming temperature requirement is relatively low. The yield-octane correlation for $400^{\circ} \mathrm{F}$ EP naphtha reforming is illustrated in Figure 29. The naphthas from the hydrotreater and from the extinction recycle hydrocracker can also be severely reformed to produce BTX precursor compounds $\left(C_{8}, C_{7}\right.$, and $C_{8}$ cyclics) with a yield of 52.5-58.9\%.

The total coal liquids may be hydrotreated before hydrocracking. If the nitrogen is removed to less than $0.5 \mathrm{ppm}$ in the whole coal-liquid hydrotreater, a first-stage hydiocracker is not necessary; the hydrocracker can be a single second-stage [154].

A hydrocracking pilot-plant test was also conducted on hydrotreated full-boilingrange ITSL liquids from Lummus to make both naphtha and jet fuel products. Particular interest was on the smoke point and yield of the jet fuel fractions, which are depicted in Figure 30 [119]. At a 550 $\mathrm{F}$ recycle cut point, the jet fuel meets the ASTM smoke point specification of $20 \mathrm{~mm}$. The yield is $84 \mathrm{LV} \%$ based on fresh feed to the first-stage hydrotreater. When recycle cut points (RCP) are lower, the smoke points exceed the specification but the yields are lower. Figure 31 demonstrates the smoke points of narrow boiling fractions as a function of mid-boiling points. The fractions with a mid-boiling point below $450^{\circ} \mathrm{F}$ have a smoke point $>20 \mathrm{~mm}$. The jet fuel gravity specification of $37^{\circ} \mathrm{API}$ is fulfilled at recycle cut points up to $525^{\circ} \mathrm{F}$. At $550^{\circ} \mathrm{F}$ cut point, the gravity of the fraction is $34.4^{\circ} \mathrm{API}$, well below the current specification.

Therefore, by controlling the recycle cut point during coal-liquid hydrocracking, both the smoke point and gravity of the jet fuel obtained can meet or exceed the ASTM specifications. These two requirements are difficult to be satisfied by the jet fuel fraction obtained from total liquid-hydrotreating. Chevron workers concluded that 
hydrocracking is an excellent way to maximize jet fuel production from two-stage liquefaction coal oils [119].

As discussed in Sectio. 6.2, the jet-fuel fractions from hydrotreated two-stage liquids do not meet gravity and viscosity requirements, even if the smoke point is marginally satisfied. This is probably due to the lack of light-ends $\left(250-350^{\circ} \mathrm{F}\right)$. To meet gravity specifications, hydrocracking is necessary for jet fuels to be produced from hydrotreated two-stage coal liquids. Since hydrocracking converts high-boiling fractions into lighter fractions, $250-550^{\circ} \mathrm{F}$ jet fuel fraction of hydrocracked ITSL liquids easily meet the viscosity specification, and the smoke point was above specification (Table 42). The gravimetric heats of combustion of these samples by ASTM D1405 were all about $18,400 \mathrm{Btu} / \mathrm{lb}$, just meeting the ASTM specification. The API gravity can be adjusted further by controlling the RCP in hydrocracking.

Table 42 also lists group type composition for these fractions. It is evident that hydrocracking increased the naphthene content in the fraction and caused a shift in naphthene distributions to more rings per average molecule at a given boiling point. The jet fuel from hydrocracked coal liquids has a significant quantity of four-ring naphthenes, whereas the jet fuel from hydrotreated coal liquids does not. The former also has less alkyl substitution on the cyclics than the latter and can be explained by paring reaction and/or new ring formation. These phenomena are further proved by detailed analyses of narrow fractions in the jet-fuel range from hydrotreated and hydrotreated plus hydrocracked Illinois No. 6 ITSL liquids as reported in Tables 50 and 51 [148]. This suggests that in order to produce quality jet fuels, especially from two-stage coal liquids, hydrocracking the middle distillate but not the total coal liquid may be the best way. 


\subsection{CONCLUSIONS AND RECOMMENDATIONS}

A number of studies on properties and refining of coal liquids, mostly obtained from liquefaction processes at earlier development stages, provide information which is principally applicable to the refining of coal liquids from current two stage liquefaction processes.

Modern refining technology is capable of processing coal liquids into various transportation fuels meeting all requirements. The major tool is hydroprocessing. The main task is to determine a reasonable product slate and the most cost-efficient refining scheme.

\subsection{Properties of Coal Liquids}

1. The liquid products from today's direct liquefaction processes are much lighter both in gravity and in boiling range, and contain much less hetero-compounds than before. They are essentially metal and resid-free and very low in sulfur. Their nitrogen content is comparable to petroleum, and their oxygen content is within the petroleum oxygen range but at the higher end. Coal liquids bear fundamental similarities with petroleum, but are characterized by their elevated cyclics content and relatively high oxygen level.

2. Coal liquids derived from different coals and different liquefaction processes are basically alike and differ only quantitatively in component content and distribution. Coals of lower ranks, viz. subbituminous coals and lignites, yield liquid products containing more paraffins and oxygen compounds than liquid products from high-rank coals. These features should be considered when cheaper coals with high liquid yields are sought for liquefaction as a cost-reduction measure as recently suggested [155]. 


\subsection{Product Slate from Coal-Liquids}

1. Coal liquids are an excellent source of gasoline production because of the high cyclics content $(68-85 \%)$ in the naphtha fractiun. The motor octane number (MON) of raw coal naphthas ranges from 70 to 83 . Gasoline can be readily obtained by mildly hydrotreating a straight-run coal naphtha. Coal-derived naphthas are also superior reforming stocks. Gasoline production can be maximized by hydrocracking or catalytic cracking of hydrotreated middle distillates from coal liquids.

2. Although specification jet-fuels were obtained in certain cases, it is difficult in general to produce jet fuels meeting the smoke point and density specifications even if high-severity hydrotreatment is applied to coal liquids. Low-rank coal liquids may be an easier feedstock, and hydrocracking seems to be a better technology for jet fuel production from two-stage coal liquids. Coal-derived jet fuels have an excellent cold-weather performance and a high volumetric heat of combustion.

3. The coal-derived diesel fuel must be hydrogenated under a severity high enough to improve its combustion quality (cetane number) as well as stability. However, the diesel fuel is easier to produce from coal liquids than the jet fuel, and its good response to additives (such as cetane number improver) mitigates the severity required on hydrotreatment.

4. The recovery of phenolic compounds concentrated in the $350-450^{\circ} \mathrm{F}$ fraction of coal liquids may provide a valuable by-product and reduce hydrogen consumption, and therefore merits consideration.

5. A gasoline-diesel fuel product slate (by hydrotreating the coal-derived naphtha and middle distillate) and an "All-Gasoline" product slate (by hydrotreating the 
naphtha and hydrocracking the distillate) are two realistic production schemes for coal-liquid refining.

\subsection{Coal Liquid Refinirig Technologies}

1. Various licensed hyürotreating processes are available for feedstocks with various levels of heteroatoms and Conradson carbon content. Hydrotreating of coalderived liquids and their fractions is technically feasible, as confirmed by numerous experimental studies.

2. Reforming feedstocks are subject to stringent restrictions on sulfur (less than $10 \mathrm{ppm}$ ), nitrogen (usually less than $1 \mathrm{ppm}$ ) and oxygen (not exceeding $30 \mathrm{ppm}$ ); therefore, hydro-upgrading of coal naphtha before reforming is mandatory.

3. Hydrocracking is an efficient way to produce specification jet fuels and diesel fucls or to maximize gasoline production from coal liquids. However, coal-liquid hydrocrackers must be specifically designed and reactors properly arranged to take care of the reaction heat related to higher hydrogen consumption.

4. Coal liquids must be upgraded to higher hydrogen content to improve the conversion and gasoline yield and reduce coke make during catalytic cracking. The heteroatoms level will be significantly reduced during hydro-upgrading and poses no problem for the cracking catalysts.

In short, coal liquids can be processed by existing refining techniques and no extraordinary pretreatments are necessary. 


\subsection{Refining Scheme for Coal Liquids}

1. Among the three refining schemes discussed in Sections 5.0,6.0, and 7.0, the total-coal-liquid hydrotreating uperation is not recommended because 1) it has to be conducted under the highest severity dictated by the most difficult product to make, 2) the heavy ends in the total coal liquid make the hydrotreating considerably less cost-effective, and 3) the quality of the jet fuel obtained in this scheme is significantly lower.

2. The simplest and most economical refining scheme is to distill the coal liquid into naphtha and diesel fuel fraction, then hydrotreating them separately to make a gasoline and diesel fuel (or blending stocks). Catalytic reforming of hydrotreated coal naphthas may not be a good way in view of the trend toward reduction of aromatics content in gasoline.

3. Based on coal-liquids characterization, maximizing gasoline production up to an all-gasoline mode of operation may be the most profitable refining strategy for coal liquids. This can be realized by hydrocracking or hydrotreating plus catalytic cracking of the $350^{\circ} \mathrm{F}^{+}$fraction of coal liquids, and hydrocracking is probably a better way to manufacture gasoline with less aromatics content.

4. Jet fuel production from coal liquids is a difficult task as far as gravity and smoke-point requirements are concerned. The success in making jet fuels by hydrotreatment of coal liquid fractions needs further verification. Hydrocracking of coal-derived middle distillates, possibly including some ring-opening reactions, appears to be an effective way to maximize specification jet-fuel production.

5. The oxygen peak in the $350-450^{\circ} \mathrm{F}$ boiling range strongly suggests the separation of this fraction. Phenolics can be recovered by certain means such as 
extraction. This will appreciably reduce hydrogen consumption and may improve the liquefaction economics.

6. A simplified block flowsheet, based on the refining scheme involving separate refining of coal-liquid fractions, is suggested (Figure 32). It also includes the recovery of oxygen compounds in the $350-450^{\circ} \mathrm{F}$ fraction. It is a flexible flowsheet that can be adjusted to different operating modes:

a) For a simple operation of gasoline-diesel fuel production, the crude coal liquid is fractionated into naphtha, 350-450 $\mathrm{F}$ fraction, and a $450^{\circ} \mathrm{F}+$ fraction. The naphtha fraction is hydrotreated into a gasoline blending stock. The $350-450^{\circ} \mathrm{F}$ fraction is extracted to recover phenolics, and its raffinate joins the $450^{\circ} \mathrm{F}+$ fraction, which is then hydrotreated to make diesel fuel. A small amount of fuel oil may be produced to maintain a proper end point of diesel fuel and can be used as process fuel;

b) For an all-gasoline mode of operation, the raffinate of the 350$450^{\circ} \mathrm{F}$ fraction combines with the $450^{\circ} \mathrm{F}+$ fraction and the blend is then hydrocracked. Either the hydrotreated naphtha or the hydrocracked naphtha, or their combination, can be reformed if so desired; and

c) If jet fuel is the desired product, then the hydrocracker is operated at a recycle cut point suitable for jet fuel production.

In operating modes b) and c), no fuel oil is produced due to recycle hydrocracking.

This transportation-fuel type refinery comprises only five refining units: crude distillation, naphtha hydrotreating, reforming, phenolics recovery, and distillate 
hydrotreating or hydrocrackirig. These units are available, except for phenolics extraction, in almost any petroleum refinery.

\subsection{Research Recommendations}

On the basis of research accomplishments accumulated to date, further research needs, especially on refining of modern two-stage coal liquids, are delineated as follows:

1) Gasoline Production.

Hydrotreatment of straight-run coal naphthas with different end points to make quality gasoline blending stocks should be thoroughl:; investigated. Oxidation stability is the major concern. Optimum cut point, hydrotreating severity and hydrogen consumption need to be determined.

The all-gasoline-mode hydrocracking of various coal-derived distillates (light, middle, heavy and w' de-boiling) should be studied. The target is to define the optimal conditions to achieve highest gasoline yield with minimum hydrogen consumption.

Another route for all-gasoline operation is to hydrotreat the coal distillate plus catalytic cracking. The oxidation stability of the cracked gasoline must be studied to determine the necessity of product hydrorefining. An economic comparison between hydrocracking and hydrotreating plus ceralytic cracking is necessary.

The determination of blending octane number of coal-derived gasoline (hydrotreated, cracked, and hydrocracked) could provide information not available in the literature. Engine tests for coal-derived gasoline, singly and blended with gasoline 
components from other sources, such as petroleum and Fischer-Tropsch products, are appropriate at this stage of coal liquefaction development.

2) Diesel Fuel Production.

A reasonable route for manufacturing coal-derived diesel fuels is to hydrotreat coal distillates of proper boiling ranges with the addition of suitable additives. Studies are needed to determine the optimal boiling range and additives so that the lowest hydrotreating severity is required to produce specification diesel fuels. Hydrotreating a wide-boiling distillate with a very high end point is not justified, either technically or economically.

3) Jet Fuel Manufacture.

The major difficulty in jet fuel manufacture from coal liquids is to meet density and smoke-point specification. However, coal liquid hydrorefining can yield highly-naphthenic light distillates with high volumetric heating values. Tailoring the coal-derived light distillate as a high-density jet-fuel range-extender is advisable. To make jet fuels via hydrotreating, the critical point is to select a feedstock, either kerosene or a wide-boiling cut, with an appropriate boiling range. The same is true with hydrocracking a coal distillate to maximize jet-fuel production. In both cases, it is recommended that research eftorts be concentrated on the selection of suitable feedstocks, and high end poin î must be avoided. Low-rank coal distillates seem easier to refine into jet fuels, a point that needs further verification.

\section{4) Oxygen Compounds}

It is recommended that studies on the separation and recovery of phenolic compounus from the $350-450^{\circ} \mathrm{F}$ fraction be conducted, and the extracts be identified. A market survey for phenolic by-products is needed. 
Recovery and utilization of oxygen compounds as octane enhancers and cetane improvers is beyond the scope of this review. Substituted phenols have long been known to possess antiknock activity. Creosote, a phenolic mixture with high xylenol content, displays an antiknock activity similar to MTBE. Benzofuran, whose derivatives constitute the second largest oxygen-containing group in coal liquids, was also found to be characterized by significant antiknock capability [156]. This area merits further investigation.

\section{5) Economic Studies}

Economic studies are strongly recommended for coal-liquid refining, which include techno-economic comparison of different refining schemes; evaluation of refining technologies, such as hydrocracking vs. hydrotreating plus catalytic cracking of coal distillates; and naphtha hydrotreating vs. hydrotreating plus reforming. The economic viability of phenolics extraction also needs to be assessed.

\section{6) Physical Properties and Thermodynamic Data}

Due to the highly cyclic nature anc high heteroatom content of coal liquids, application of traditional correlations for predicting physical and thermodynamic p.operties of petroleum and its fractions to coal liquids leads to substantial errors. Specific correlations for coal liquids are urgently' needed, and continued research in this area is clearly justified. 


\section{REFERENCES}

1. Rao, S.N.; Schin Jler, H.D.; McGurl, G.V.; and Hickey, R. "Direct Liquefaction Program - Development Status and Future," presented at 15th International Conference on Coal \& Slurry Technology, Apr. 23-26, 1990, Clearwater, FL.

2. American Petroleum Institute. Inform. Bull. No. 11. Philadelphia, PA. 1958.

3. Annual Book of ASTM Standards, Section 5, "Petroleum Products, Lubricants and Fossil Fuels." 1989.

4. Hengstebek, R.J. "Petroleum Processing," McGraw-Hill, New York, 1959.

5. Hydrocarbon Processing, 63 (9), 88 (1984).

6. Hood, R.L., et al. API Refining Meeting, May 11-14, 1981. Chicago, IL.

7. Hydrocarbon Processing, $\underline{56}$ (5), 97 (1977); 63 (9), 87 (1984).

8. $\underline{59}(6), 73$ (1980); 63 (9), 85 (1984).

9. $67(9), 78(1988)$

10. Reynolds, et al. "Chevron's Pascagoula Residuum Hydrotreater Demonstrates Versatility," NPRA Annual Meeting, March 24-26, 1985. San Antonio, Texas.

11. Hydrocarbon Processing, 63 (9), 91 (1984).

12. Linsay, D.A., et al. API Meeting, May 16, 1984. New Orleans, LA.

13. Hydrocarbon Processing, 67 (9), 78 (1988).

14. Third Conference on Heavy Crude and Tar Sands, July 22-31, 1985. Long Beach, CA.

15. Hydrocarbon Processing, 63 (9), 77 (1984).

16. "Design and Process Modeling of a Heavy Gas Oil Hydrotreater," Third Iranian Congress of Chem. Eng., Autumn 1977.

17. Hydrocarbon Processing, $\underline{63}$ (9), 74 (1984); $\underline{58}$ (5), 103 (1979).

18. $63(9), 75$ (1984); 52 (9), 131 (1973). 
19. , 63 (9), 71 (1984).

20. , 63 (9), 90 (1984).

21. , 63 (9), 89 (1984).

22. , 58 (9), 136 (1979); 63 (9), 79 (1984).

23. . 63 (9), 84 (1984).

24. , 63 (9), 70 (1984).

25. , 67 (9), 79 (1988).

26. Baron, K., et al. Ketjen Catalyst Symposium, May 27-30, 1984. Amsterdam, The Netherlands.

27. Hydrocarbon Processing, 63 (9), 78 (1984).

28. Petroleum Engineer, 28 (3), C37 (1956).

29. Murphy, J.R.; Smith, M.R.; and Viens, C.H. Oil \& Gas J. 88 (23), 108 (1970).

30. Gary, J.H. and Handwerk, G.E. "Petroleum Refining," Marcel Dekker, New York, 1959.

31. McFatter, W.; Meaux, E.; Mounce, W.; and Van Driesen, R. Oil \& Gas J. 67 (27), 119 (1969).

32. Hydrocarbon Processing, 67 (9), 70 (1988).

33. Van Driesen, R.P., et al. "Technique for High Conversion Residual Hydrocracking Demonstrated," AlChE National Meeting, April 7, 1986.

33a. Beaton, W.I., et al. "Operating Experience with Amoco's LC-Fining Resid Crackers," presented at the 1986 NPRA Annual Meeting, March 23- 25, 1986, Los Angeles, CA.

33b. Van Driesen, R.P., et al. "Upgrading Heavy Oil to Pipeline Quality," presented at API Mid-Year Refining Meeting, May 14-17, 1979. San Francisco, CA.

34. Hydrocarbon Processing, $\underline{67}$ (9), 71 (1988). 
35. Sue, H., et al. "Mild Resid Hydrocracking for Heavy Oil Upgrading," presented at UNITAR International Conference on Heavy Crude and Tar Sands, Aug. 7-12, 1988. Edmonton, Alberta, Canada.

36. Oil \& Gas J., 82, March 26, 1984.

37. Hydrocarbon Processing, $\underline{63}$ (9), 101 (1984).

$38 . \quad 67$ (9), 71 (1988).

39. Paper AM-84-35. NPRA Meeting, March 25-27, 1984.

40. Watkins, C.H. and Jacobs, W.L. Hydiocarbon Process. 45 (5), 164 (1966).

41. Craig, R.G.; White, E.A.; Henke, A.M.; and Kwolek, S.J. Hydrocarbon Process. 45 (5), 159 (1966).

42. Ward, J.W.; Hansford, R.C.; Reichle, A.D.; and Sosnowski, J. Oil \& Gas J. 71 (22), 69 (1973).

43. Hydrocarbon Processing, 67 (9), 73 (1988).

44. Oil \& Gas J., 79 (22), 102 (1981).

45. Hydrocarbon Processing, 57 (5), 117 (1978); 67 (9), 73 (1988).

46. "New Hydrocracking Catalysts for High Quality Distillate Production," NPRA Annual Meeting, 1987. San Antonio, Texas.

47. Hydrocarbon Processing, 67 (9), 69 (1988).

48. Laity, et al. "Maximizing Hydrocracking Flexibility Using Chevron Technology," Third Refinery Technology Conference, March 7-9, 1988. Visakhapatnam, India.

49. Hydrocarbon Processing, $\underline{63}$ (9), 98 (1984).

50. , 59 (10), 137 (1979); 67 (9), 72 (1988).

51. Frye, C.G.; Muffat, D.L.; and McAninch, H.W. Oil \& Gas J. $\underline{68}$ (20), 69 (1970).

52. J.E. Sinor Consultants, Inc. "Market Assessment for Liquid By-Products from the Great Plains Gasification Plant," April, 1987. 
53. Little, D.M. "Cdalytic Reforming," Penn Well Books, Tulsa, OK. 1985.

54. Nevison, J.A.; Obaditch, C.J.; and Dalson, M.H. "Magnaforming Units Compared," Hydrocarbon Process., 53 (6), 111 (1974).

55. Hydrocarbon Processing, $\underline{67}$ (9), 81 (1988).

56. 67 (9), 80 (1988).

57. Carter, J.L., et al. ACS Meeting, March 28, 1982. Las Vegas, Nevada.

58. Hydrocarbon Processing, $67,(9), 80$ (1988).

59. 67 (9), 79 (1988).

60. "Recent Catalyst and Process Improvements in Commercial Rheniforming," presented at NPRA Annual Meeting, March 23-25, 1980. New Orleans, LA.

61. Hydrocarbon Processing, 67 (9), 81 (1988).

62. Oil \& Gas J., 74 (3), 48 (1976).

63. Speight, J.G. "The Chemistry and Technology of Petroleum," Marcel Dekker, Inc., NY, 1980.

64. Thomas, C.L. "Catalytic Processes and Proven Catalysts," Acadernic Press, New York, 1970.

65. Oil \& Gas J., 71 (45), 79 (1973).

66. Hydrocarbon Processing, 67 (9), 68 (1988).

67. 63 (9), 106 (1984).

68. 67 (9), 67 (1988).

69. Murcia, A.A.; Soudek, M.; Quinn, G.P.; and D'Souza, G.J. "Add Flexibility to FCC's," Hydrocarbon Processing, 58 (9), 131 (1979).

70. Hydrocarbon Processing, 67 (9), 66 (1988).

71. , 63 (9), 105 (1984).

72. 67 (9), 68 (1988). 
73. Dean, R., et al. "Crude Oil Upgrading Utilizing Residual Oil Fluid Catalytic Cracking," presented at Katalistik's Eighth Annual FCC Symposium, 1987. Budapest, Hungary.

74. Oil \& Gas J., 80 (12), 92 (1982).

75. Hydrocarbon Processing, $\underline{63}$ (9), 109 (1984).

76. , 63 (9), 110 (1984).

77. Oil \& Gas J., 82 (22), 79 (1984).

78. "Modern Residue Upgrading by ART," presented at NPRA Annual Meeting, March 23-25, 1986.

79. Hydrocarbon Processing, 67 (9), 67 (1988).

80. Avidan, A.A.; Edwards, M.; and Owen, H. "Innovative Improvements Highlight FCC's Past and Future," Oil \& Gas J., 88, Jan. 8, 36 (1990).

81. McCulloch, D.C. "Feed Hydrotreating Improves FCCU Performance," Oil \& Gas J., 73, July 21, 53 (1975).

82. Sullivan, R.F. "Refining and Upgrading of Synfuels from Coal and Oil Shales by Advanced Catalytic Processes," Final Report, prepared for U.S. DOE, Contract No. DE-AC22-76ET10532, May, 1987.

83. Sullivan, R.F.; O'Rear, D.J.; and Frumkin, H.A. "Converting Syncrudes to Transportation Fuels, " presented at 1981 Fuels and Lubricants Meeting, NPRA, November 5-6, 1981, Houston, Texas.

84. Sullivan, R.F., and Frumkin, H.A. "Refining Coal Liquids: Where We Stand," presented at 191st ACS National Meeting, April 13-18, 1986. New York.

85. Kowalski, T.L. and, Basu, A. "Wilsonville Product Evaluation, lllinois No. 6, ITSL Run 244," Amoco, EPRI Contract No. RP1604-5, June, 1984.

86. Nowaski, P. "Coal Liquefaction Process," Noyes Data Corp., NJ, 1979.

87. Sullivan, R.F. "Refining Comparisons: CTSL, ITSL, and H-Coal Syncrudes," presented at Direct Liquefaction Contractors' Review Meeting, Oct. 20-22, 1986. Monroeville, PA. 
88. Amoco. "Subbituminous Synthetic Crude and Product Evaluations, Wilsonville Run 246, Draft Report," March 12, 1985.

89. Gray, D.; Tomlinson, G.; and El Sawy, A.E. "A Comparative Techno- Economic Analysis of HRI Co-Processing, Catalytic Two-Stage Liquefaction, and H-Oil," MITRE, Proceedings of Direct Liquefaction Contractors' Review Meeting, October 2-4, 1989, Pittsburgh, PA.

90. Comolli, A.G.; Johanson, E.S.; McLean, J B.; and Smith, T.O. "Low- Severity Catalytic Trvo-Stage Liquefaction Process," HRI, DOE Contract No. DE-AC2285PC80002, September, 1988.

91. Wilsonville Report for Run 257.

92. Wilsonville Report for Run 258.

93. Winschel, R.A., and Zhou, P. "Inspection of Integrated Two-Stage Liquefaction Products by Petroleum Assay," presented at the 16th Annual EPRI Fuel Science Conference, June 18-20, 1991, Palo Alto, CA.

94. Kramer, R.L. Conoco Research Report No. 6210-0003-T000-1-91, Aug. 20, 1991.

95. Vimalchand, P.; Lee, J.M.; and Gollakota, S.V. "Recent Developments in Coal Liquefaction at the Wilsonville Facility," presented at the 16th EPRI Fuel Science Conference, June 18-20, 1991, Palo Alto, CA.

96. Rosenthal, J.W.; Dahlberg, A.J.; Kuehler, C.W.; and Shiun, J.H. "The Chevron Co-Refining Process," presented at 49th Midyear Refining Meeting Session on Heavy Oils Processing, May 16, 1984, New Orleans, LA.

97. Oil \& Gas J. 67 (40), 91 (1969); 69 (20) 124 (1971).

98. Energy Engineering Board, Assembly of Engineering. "Refining Synthetic Liquids from Coal and Shale," National Academy Fress, Washington, D.C. 1980.

99. Wilson, B.W.; Later, D.W.; Wright, C.W.; and Steward, D.L. "Chemical Analysis and Mutational Assay of Distilled Oils from the $\mathrm{H}$-Coal Direct Liquefaction Process: A Status Report," Battelle, DOE Contract DE-AC0676RL01830, January, 1985. 
100. Pauls, R.E.; Bambacht, M.E.; Bradley, C.; and Cronauer, D.C. "Distribution and Characterization of Phenolics in Distillates Derived from Two-Stage Coal Liquefaction," Amoco Research Center, 1988.

101. Burke, F.P.; Winschel, R.A.; Robbing, G.A.; and Brandes, S.D. Projert Status Report under DOE Contract DE-AC22-89PC89883, November 6, 1991.

102. Gray, R.H.; Drucker, H.; and Massey, M.J. "Toxicology of Coal Conversion Processing," John Wiley \& Sons, New York, 1988.

103. Sutterfield, D., and Lanning, W.C. "Hydrotreatment and Biological Test of SRC"Coal Liquid," Chap. 5 in 'Upgrading Coal Liquids' (R.F. Sullivan, ed.), ACS Symposium Series 156, ACS, Washington, D.C., 1981.

104. Salmon, R. "Direct Liquefaction Technology Assessment. Task 1. Technical Readiness of the Developing Plant Functions," Appendix I, ORNL/TM-9181, September, 1985.

105. Pittsburg and Midway Coal Mining Co. "Solvent Refined Coal Process," Final Report, DOE/ET/10104-46, 2, May, 1982.

106. deRosset, A.J.; Tan, J.; and Hiffman, L. "Upgrade Coal-Derived Distillates," Hydrocarbon Processing, 58 (5), 152 (1979).

107. Bernier, E.J. "Wilsonville Synthetic Crude and Product Evaluations in Integrated Two-Stage Liquefaction of Subbituminous Coal," Southern Company Services, Inc. EPRI Report No. AP-5222, June, 1987.

108. Sefer, N.R., and Erwin, J. "Hydroprocessing of Direct Coal Liquefaction Product for Diesel Engine Fuel," SEA Paper No. 892131, September 1989.

109. Winschel, R.A.; Burke, F.P.; and Zhou, P. "Inspection of Integrated Two-Stage Liquefaction Products as Petroleum Refining Feedstocks," presented at 1991 International Conference on Coal Science, September 16-21, 1991, Newcastle, U.K.

110. Becker, M., et al. "Analytical Siudies for the H-Coal Process," Mobil, Final Report, DOE Contract No. DE-AC05-77ET10112, July, 1982.

111. Fischer, R.H., and Hildebrand, R.E. "Refining of Coal-Derived Syncrudes," in 'Upgrading Coal Liquids', Chap. 12, ACS Symp. Series 156, ACS, Washington, DC, 1981. 
112. MacArthur, J.B.; Duddy, J.E.; and Moonijy, A.V. "H-Coal Process Liquids Upgrading Options for Fuels Production," presented at 1982 NPRA Annual Meeting, March 21-23, 1982, San Antonio, Texas.

113. ER\&E. "EDS Coal Liquefaction Process Development, Phare V," Interim Report, DOE/ET/10069-T5, March, 1981.

114. Tan, G., and deRossett, A.G. "Hydrotreating and Reforming H-Coal ProcessDerived Naphtha," DOE Report, FE-2566-12, March, 1978.

115. UOP. "Hydrotreating and Reforming SRC-II Naphtha," DOE Report, FE- 256627, June, 1979.

116. Epperly, W.R. "EDS Coal Liquefaction Process Development, Phase V, EDS Product Quality Final Report," FE-2893-97, Sept., 1982.

117. Fant, B.T., and Barton, W.J. "Refining Coal Liquids," presented at API Refining Dept. 43rd Midyear Meeting, May 10, 1978. Toronto, Canada.

118. Sullivan, R.F., and O'Rear, D.J. "Refining and Upgrading of Synfuels from Coal and Oil Shales by Advanced Catalytic Processes," Quarterly Report, JanuaryMarch, 1980, FE-2315-52.

119. Sullivan, R.F., and O'Rear, D.J. "Refining and Upgrading of Synfueis from Coal and Oil Shales by Advanced Catalytic Processes," Monthly Report, DOE Contract No. DE-AC22-76ET10532, February, 1982.

120. Erwin, J., and Sefer, N.R. "Synthetic Fuels from Coal-Derived Distillate as Jet Fuels for High Mach Aircraft," presented at ACS Meeting, Div. Petrol. Chem., September 10-15, 1989. Miami Beach, FL.

121. Federal Specification VF-800D, Fuel Oil, Diesel, October 27, 1987.

122. Zhou, P.Z.; Zhang, Y.Z.; Wu, Z.H.; Wang, J.E.; and Ruam, J.Z. "Catalytic Cracking of Low-Temperature Carbonization Coal Tar Fractions," Chemical Bulletin (China), (1), 1 (1959).

123. Zhou, P.Z., and Wu, C. "Kinetics of Catalytic Cracking of Cumene and Poisoning of Silica-Alumina Catalysts," Acta Focalia Sinica, 4 (1), 1 (1959).

124. Riedl, F.J., and deRosset, A.J. "Hydrotreating and Fluid Catalytic Cracking of SRC-II Process Derived Gas Oils," UOP, Interim Report, DOE Contract No. EF77-C-01-2566, July, 1980. 
125. Tan, G., and deRosset, A.J. "Hydrotreating and Fluid Catalytic Cracking of HCoal Process-Derived Gas Oils, " UOP, Interim Report, DOE Contract No. EF-77C-01-2566, August, 1978.

126. UOP. "Hydrotreating of H-Coal Gas Oil," DOE Report, FE-2566-33, November, 1978.

127. UOP. "Hydrotreating and Fluid Catalytic Cracking of EDS Gas Oil," DOE Report, FE-2566-30, August, 1979.

128. UOP. "Hydrotreating of EDS Gas Oil," DOE Report, FE-2566-33, November, 1979.

129. Tan, G., and deRosset, A.J. "Hydrocracking of H-Coal Process Derived Gas Oils," UOP, Interim Report, DOE Contract No. EF-77-C-01-2566, November, 1978.

130. Riedl, F.J., and deRosset, A.J. "Hydrocracking of EDS Process Derived Gas Oil," UOP, Interim Report, DOE Contract No. EF-77-C-01-2566, November, 1979.

131. Sullivan, R.F. "Processing of Illinois ITSL Oils: Experimental Studies, "Eleventh Interim Report, DOE Contract No. DE-AC22- 76ET10532, May, 1985.

132. Sullivan, R.F. "Processing of Wyodak and Illinois No. 6 ITSL Oils: Experimental Studies," Twelfth Interim Report, DOE Contract No. DE- AC22-76ET10532, November, 1985.

133. Sullivan, R.F. "Processing of Wyodak CTSL Oil and Related Experimental Studies," Fourteenth Interim Report, DOE Contract No. DE-AC22- 76ET10532, August, 1986.

134. Chevron Research Co. "Refining and Upgrading of Synfuels from Coal and Oil Shales by Advanced Catalytic Processes," DOE Report DOE/ET10532 Series, NTIS, U.S. Dept. of Commerce, Springfield, VA, 1987.

135. Chevron Research Co. "Processing of SRC-II," DOE Report FE-2345-47, May, 1980.

136. Sullivan, R.F. "Refining and Upgrading of Synfuels from Coal and Oil Shales by Advanced Catalytic Processes," Chevron, Quarterly Report, DOE Contract No. DE-AC22-76ET10532, November, 1984. 
137. Sturm, Jr., G.P.; Dooley, J.E.; Thomson, J.S.; Woodward, P.W.; and Vogh, J.W. "The Composition of Coal Liquids from Coals of Different Ranks," in 'Upgrading Coal Liquids' (R.F. Sullivan ed.), Chap. 1, ACS Symposium Series 156, ACS, Washington, D.C, 1981.

138. Wiser, W.H.; Singh, S.; Oader, S.A.; and Hill, G.R. "Catalytic Hydrogenation of Multi-ring Aromatic Coal Tar Constituents," Ind. Eng. Chem. Prod. Res. Develop. 9 (3), 350 (1970).

139. Wu, W., and Haynes, Jr., H.W. "Hydrocracking Condensed-Ring Aromatics Over Non-Acidic Catalysts," Preprints, ACS Div. Petrol. Chem. 20 (2), 446 (1975).

140. Zielke, C.W.; Stuck, R.T.; Evans, J.M.; Constanza, C.P.; and Gorin, E. "Molten Salt Catalysts for Hydrocracking of Polynuclear Hydrocarbons," Ind. Eng. Chem. Proc. Dec. Develop. 5 (3), 151 (1966).

141. Sullivan, R.F. "Hydrotreating of EDS and H-Coal Blends for Biological Studies," Chevron, Interim Report, DOE Contract No. DE-AC22-76ET10532, January, 1983.

142. Sullivan, R.F. "Hydrotreating $400^{\circ} F^{+}$SRC-1l Oil for Biolngical Studies," Chevron, Interim Report, DOE Contract No. DE-AC22-75ET10532, April, 1982.

143. Frumkin, H.A.; Sullivan, R.F.; and Stangeland, B.E. "Catalytic Upgrading of SRC-II Syncrude," Chap. 3 in 'Upgrading Coal Liquids' (R.F. Sullivan, ed.), ACS Symposium Series 156, ACS, Washington, D.C, 1981.

144. Frumkin, H.A.; Sullivan, R.F.; and Stangeland, B.E. "Converting SRC-II Process Product to Transportation Fuels," presented at the 87th National Meeting of AlChE, August 20, 1979, Boston, MA,.

145. Lanning, W.C. "The Refining of Synthetic Crude Oils," BETC/IC-76/2, July, 1976.

146. Zaczepinski, S.; Kamienski, P.W.; Toups, H.J.; Smith, R.S.; and Turner, D.W. "Upgrading of Coal Liquids," Proceedings, Refining Department, 44th Midyear Meeting, May 14-17, 1979, San Francisco, CA.

147. Sullivan, R.F.; O'Rear, D.J.; and Frumkin, H.A. "Processing of H-Coal Syncrude," Chevron, Fifth Interim Report, DOE Contract No. DE-AC2276ET10532, September, 1981. 
148. Sullivan, R.F. "High-Density Jet Fuels from Coal Syncrudes," Symposium on Structure of Future Jet Fuels, presented at the Div. Petroleum Chemistry, ACS, April 5-10, 1987. Denver, CO.

149. Beverly, J.B., and Marschner, R.F. Preprints Div. Petrol. Chem., ACS, 4 (2), B-41 (1959).

150. Zimmerschied, W.J.; Mickel, B.L.; Hunt, R.A.; and DerHerder, M.J. Preprints Div. Petrol. Chem., ACS, 4 (2), B-47 (1959).

151. Sullivan R.F.; Stangeland, B.E.; Rudy, C.E.; Green, D.C.; and Frumkin, H.A. "Refining and Upgrading of Synfuels from Coal and Oil Shales by Advanced Catalytic Processes - First Interim Report, Processing of Paraho Shale Oil," Chevron Research Co., DOE Report FE-2315-25, April 1978.

152. Sullivan, R.F. "Refining and Upgrading of Synfuels from Coal and Oil Shales by Advanced Catalytic Processes," Chevron, Quarterly Report for period AprilJune, 1983, DOE Contract No. DE-AC22-76ET10532, September, 1983.

153. Sullivan, R.F.; O'Rear, D.J.; and Frumkin, H.A. "Refining and Upgrading of Synfuels from Coal and Oil Shales by Advanced Catalytic Processes," Chevron, Ninth Interim Report, DEO Contract No. DE-AC22-76ET10532, August, 1984.

154. Sullivan, R.F., and Frumkin, H.A. "Refining and Upgrading of Synfuels form Coal and Oil Shales by Advanced Catalytic Processes," Chevron, Third Interim Report, DOE Contract No. DE-AC22-76ET10532, November, 1982.

155. Lumpkin, R.E. "Recent Progress in the Direct Liquefaction of Coal," Science, 239 873 (1988).

156. Stournas, S.; Lois, E.; and Polyssis, P. "Performance Assessment of Novel Substitute Gasoline Components," Prep. 199th ACS National Meeting, Div. Fuel Chem. 35 (1), 258, April 22-27, 1990. Boston, MA. 
TABLES 


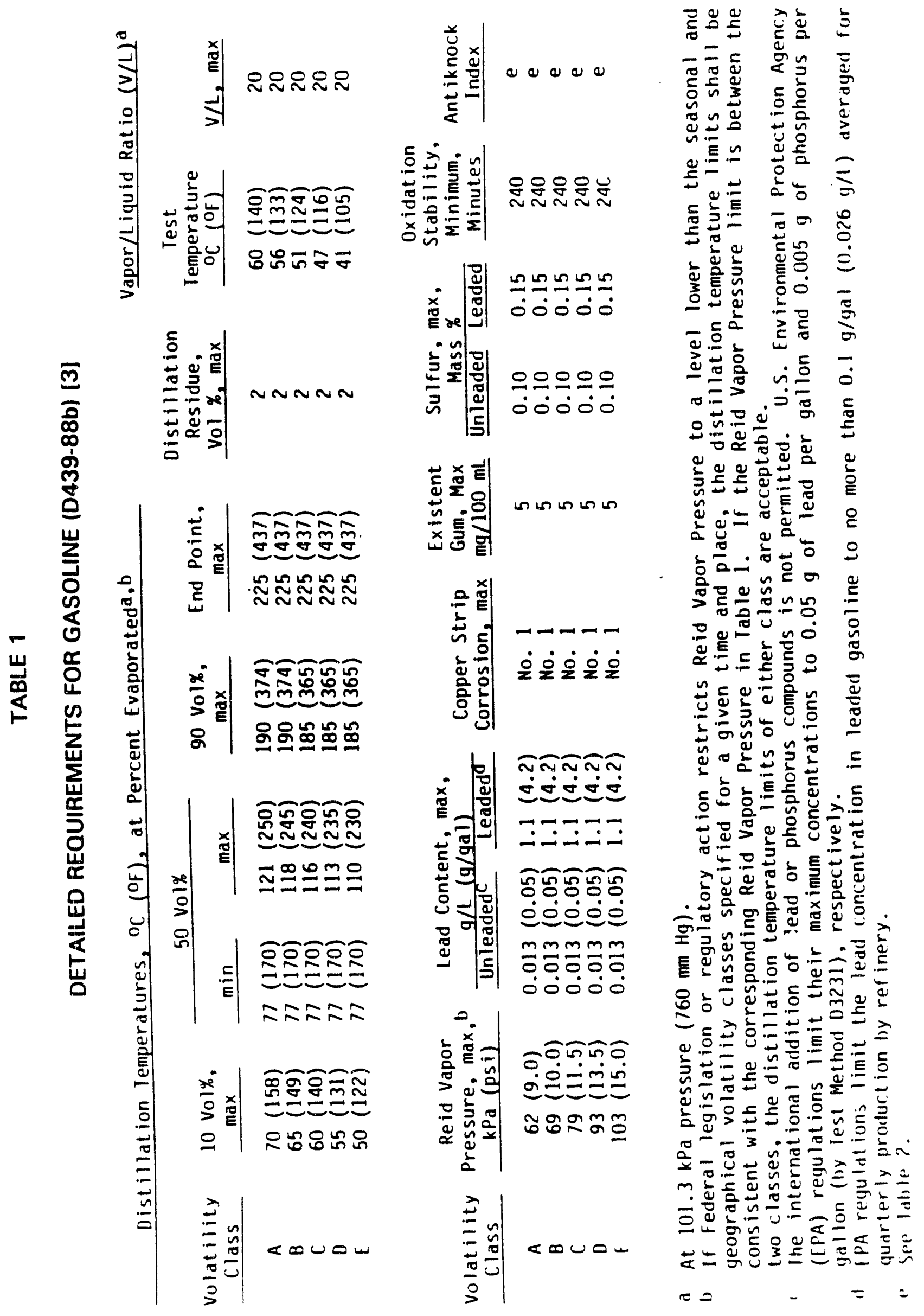




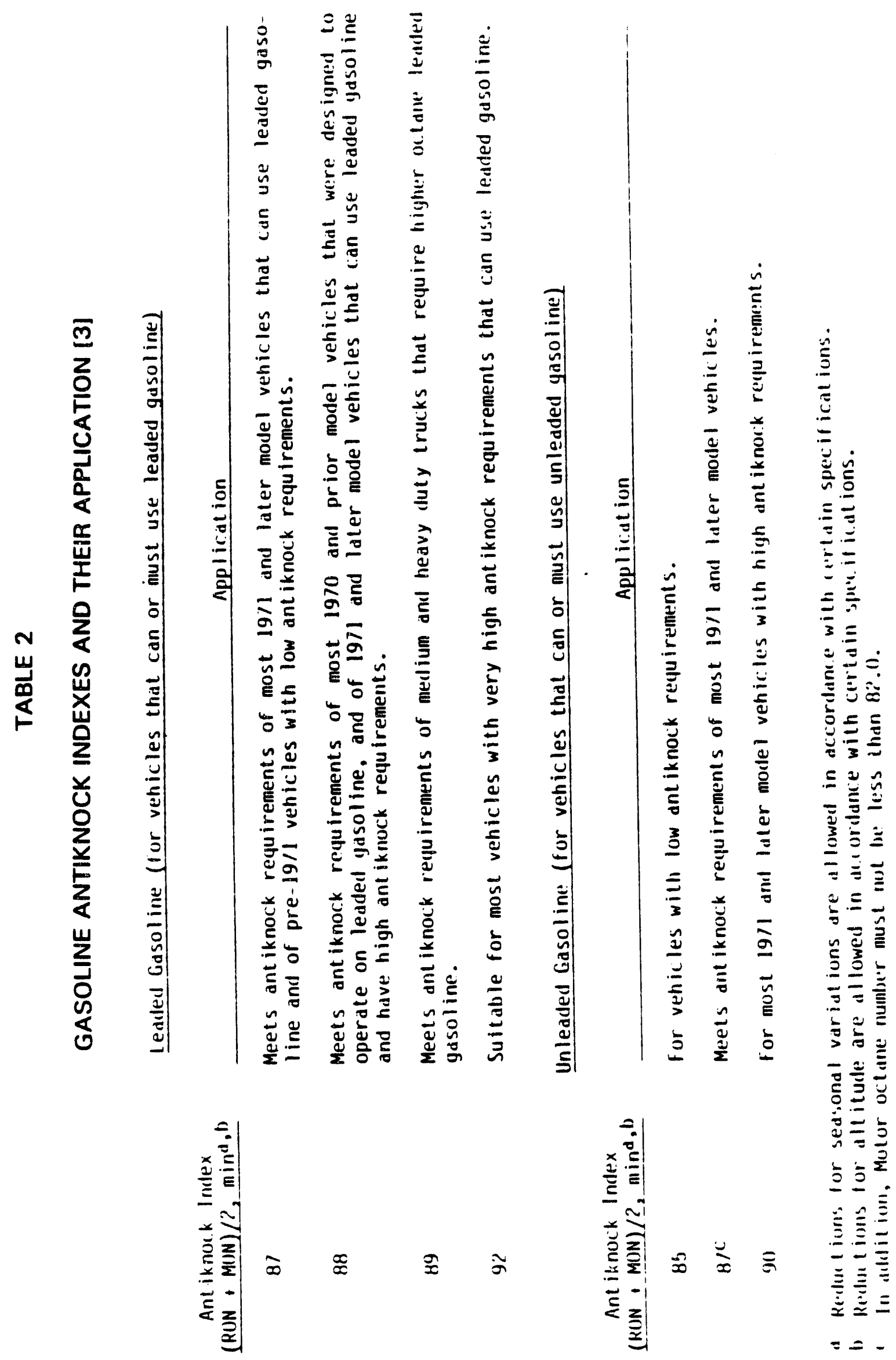



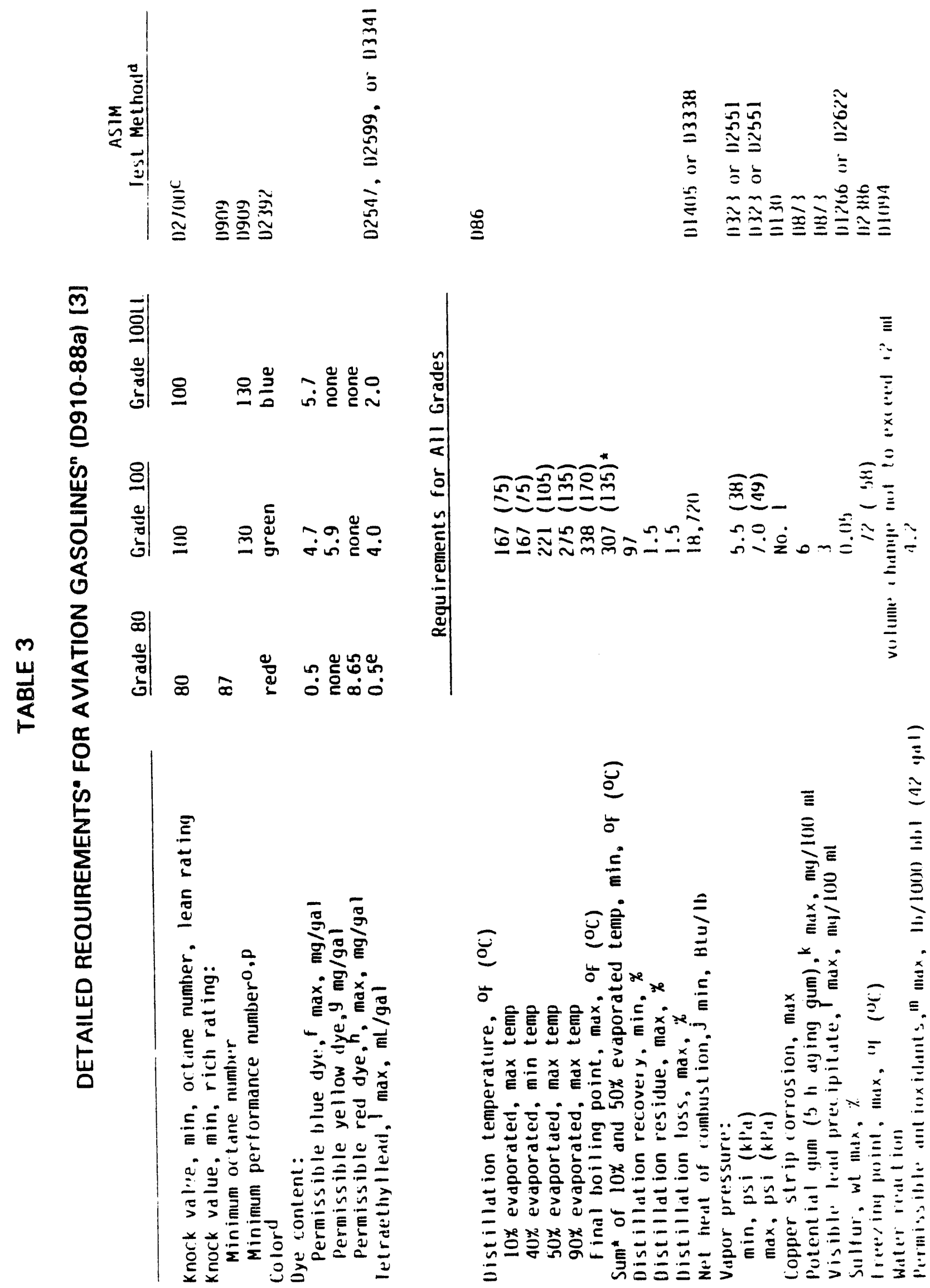


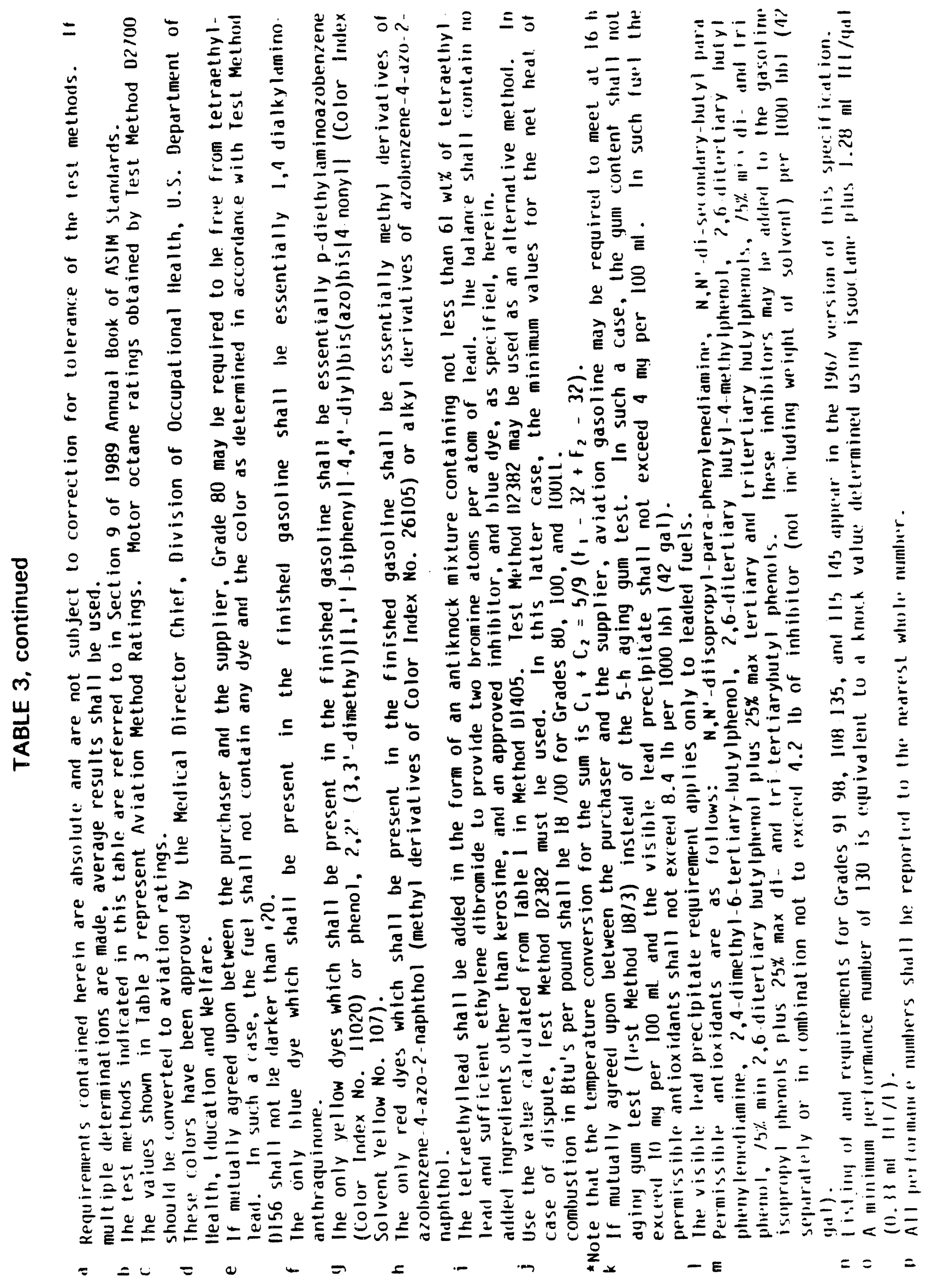




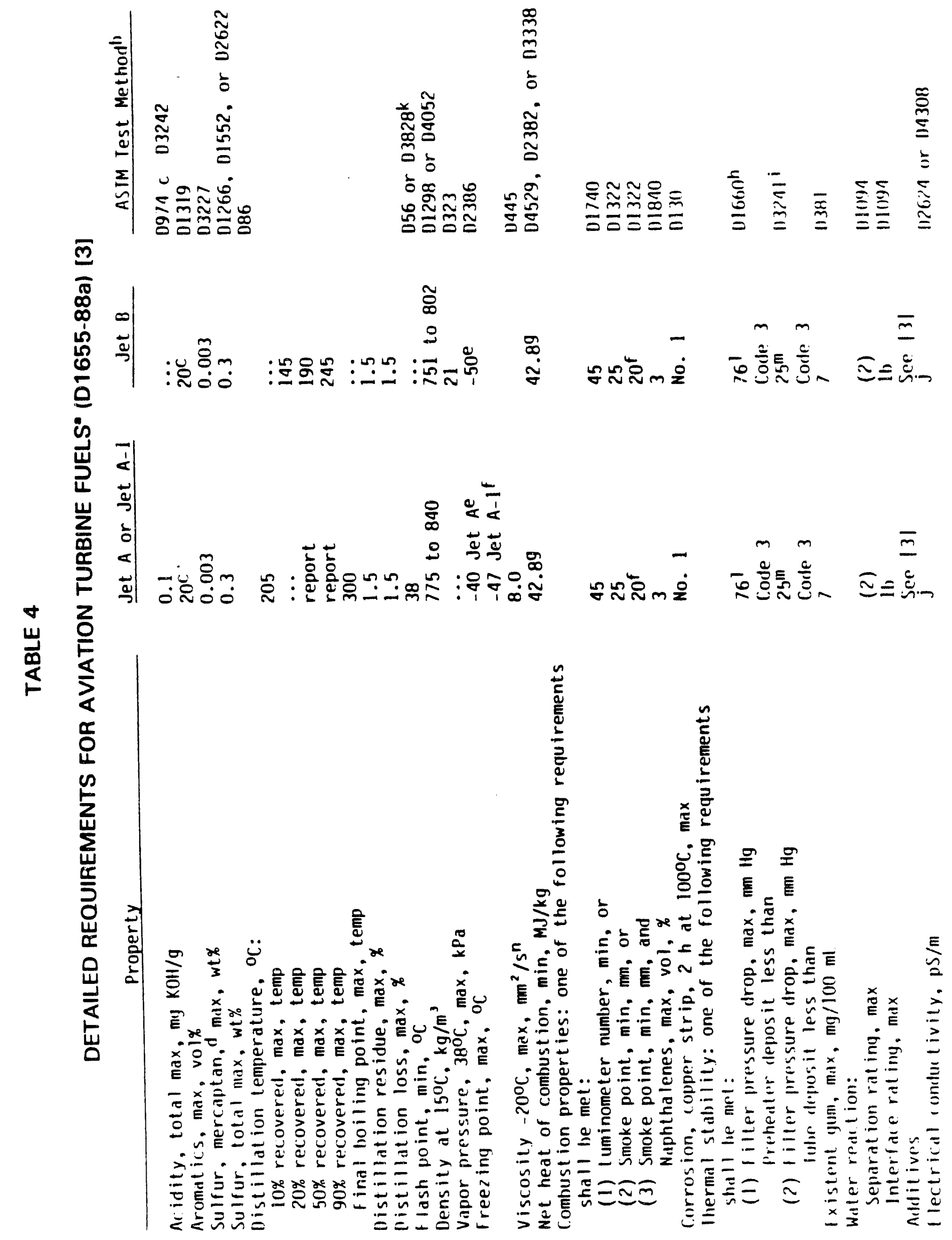




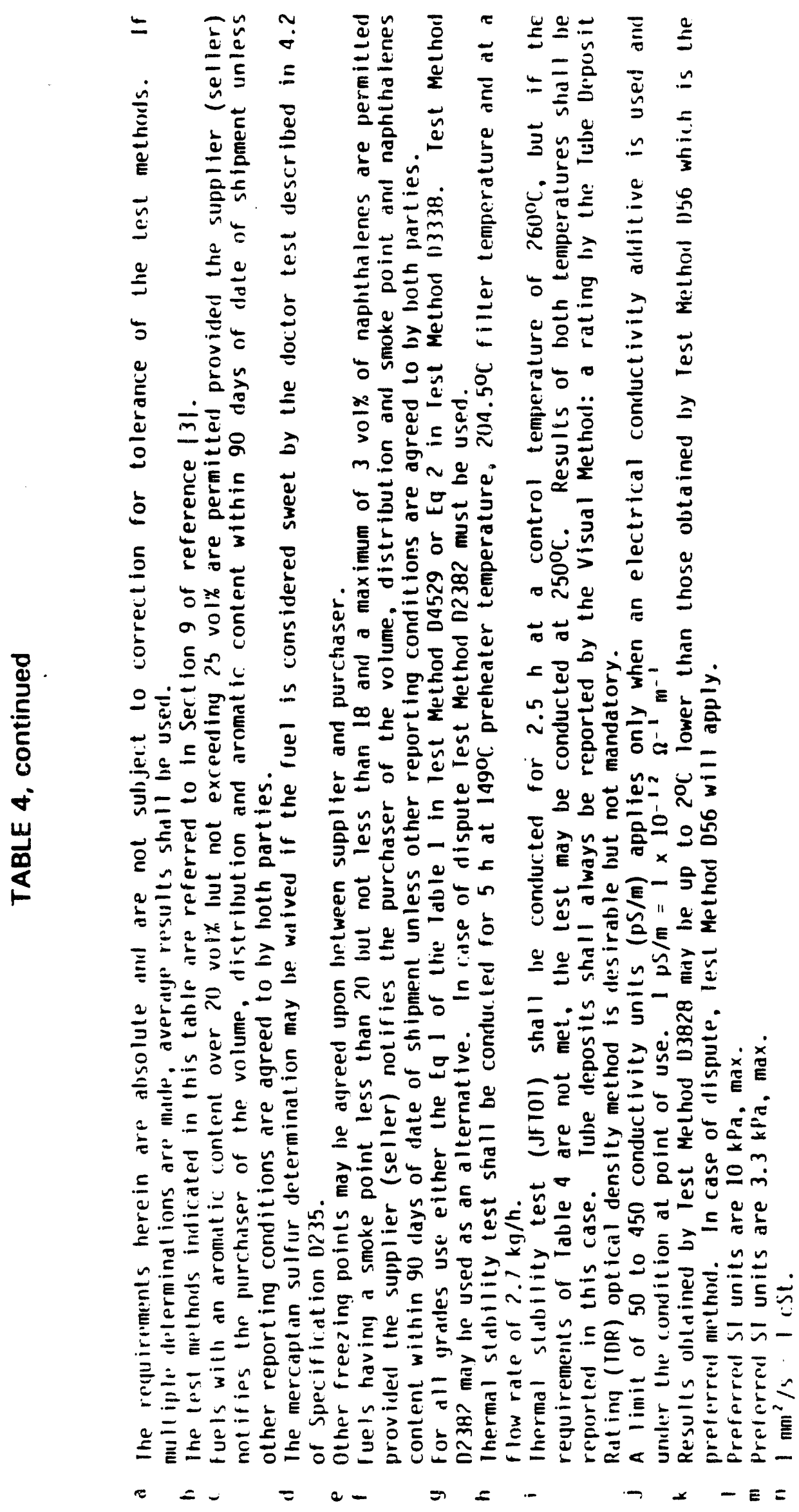


TABLE 5

PRIMARY MILITARY AVIATION FUEL SPECIFICATION REQUIREMENTS

\begin{tabular}{|c|c|c|}
\hline & $\begin{array}{l}J P-4 \text { (Jet B) } \\
M I L-T-5624 L \\
\end{array}$ & $\begin{array}{l}\text { JP-8 (Jet A-1) } \\
\text { MIL-T-83133A }\end{array}$ \\
\hline $\begin{array}{l}\text { Specific Gravity, } 600 \mathrm{~F} \\
\text { Gravity, API \& } 600 \mathrm{~F}\end{array}$ & $\begin{array}{c}0.751-0.802 \\
45-57\end{array}$ & $\begin{array}{l}0.775-0.840 \\
37-51\end{array}$ \\
\hline $\begin{array}{l}\text { 10\% Recovered } \\
\text { 10\% Re }\end{array}$ & -- & -- \\
\hline $20 \%$ Recovered & 293 & 401 \\
\hline 50\% Recovered & 374 & -- \\
\hline 90\% Recovered & 473 & $--\overline{-1}$ \\
\hline $\begin{array}{l}\text { Final Boiling Poing } \\
\text { Freezing Point, Of }\end{array}$ & $-72^{518}(-58)$ & $\begin{array}{l}572 \\
-54\end{array}$ \\
\hline $\begin{array}{l}\text { Viscosity, Centistokes }-400 \mathrm{~F} \text {, max } \\
\text { Aromatics, vol\%, max }\end{array}$ & $25.0(20.0)$ & $25.0^{8.0}(20.0)$ \\
\hline $\begin{array}{l}\text { Olefins, vol\%, max } \\
\text { Sulfur, wt\%, max }\end{array}$ & $0.40^{5.0}(0.30)$ & $0.40^{5.0}(0.30)$ \\
\hline $\begin{array}{l}\text { Net Heat of Combustion, Btu/lb, min } \\
\text { Hydrogen Content, wt\%, min } \\
\text { Thermal Stability, JFToT }\end{array}$ & $\begin{array}{c}18,400 \\
13.6\end{array}$ & $\begin{array}{l}18,400 \\
13.6\end{array}$ \\
\hline Pressure Drop, mm Hg, max & 25 & 25 \\
\hline Tube Deposit, max & 3 & 3 \\
\hline Flash Point, OF, min & --- & 100 \\
\hline Vapor Pressure, Reid, psi & $2-3$ & -- \\
\hline
\end{tabular}


TABLE 6

AVERAGE JET FUEL PROPERTIES IN THE UNITED STATES [52]

Type

Gravity, OAPI

RVP, psi

Freezing Point, of

ASTM D86 Distillation \% Overhead

$10 \%$

$50 \%$

$90 \%$

Aromatic Content, vol\%

Olef in Content, vol\%

Heat of Combustion, Net, Btu/lb
$\frac{J P-4}{\text { Naphtha }}$

54.7

2.6

$-82$

195

277

378

12.3

0.8

18,706 $\frac{\text { JET A }}{\text { Kerosene }}$

42.2

---

$-50$

369

414

472

17.8

1.1

18,698

18,504

Source: Bartlesville Energy Technology Center, 1986 


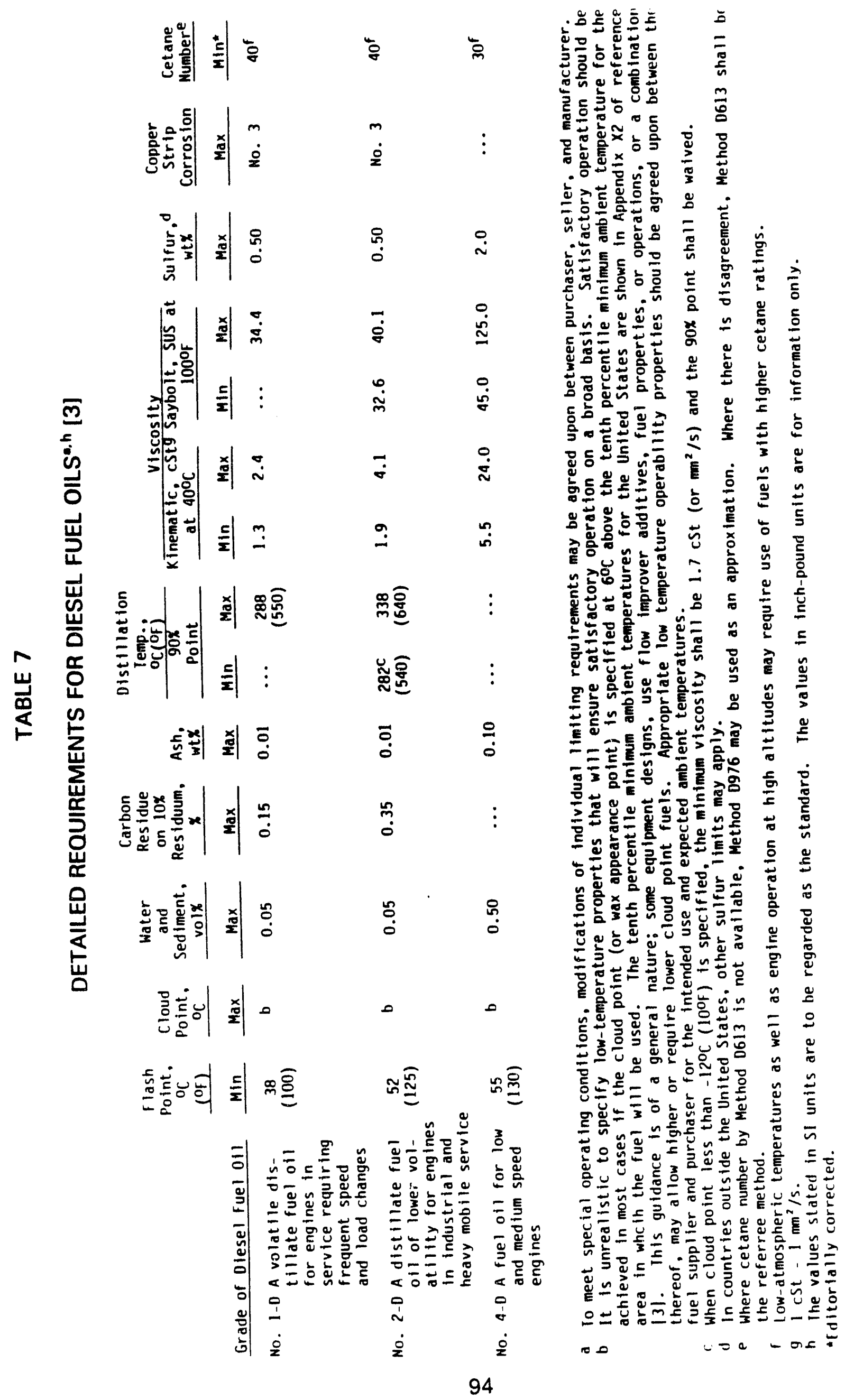




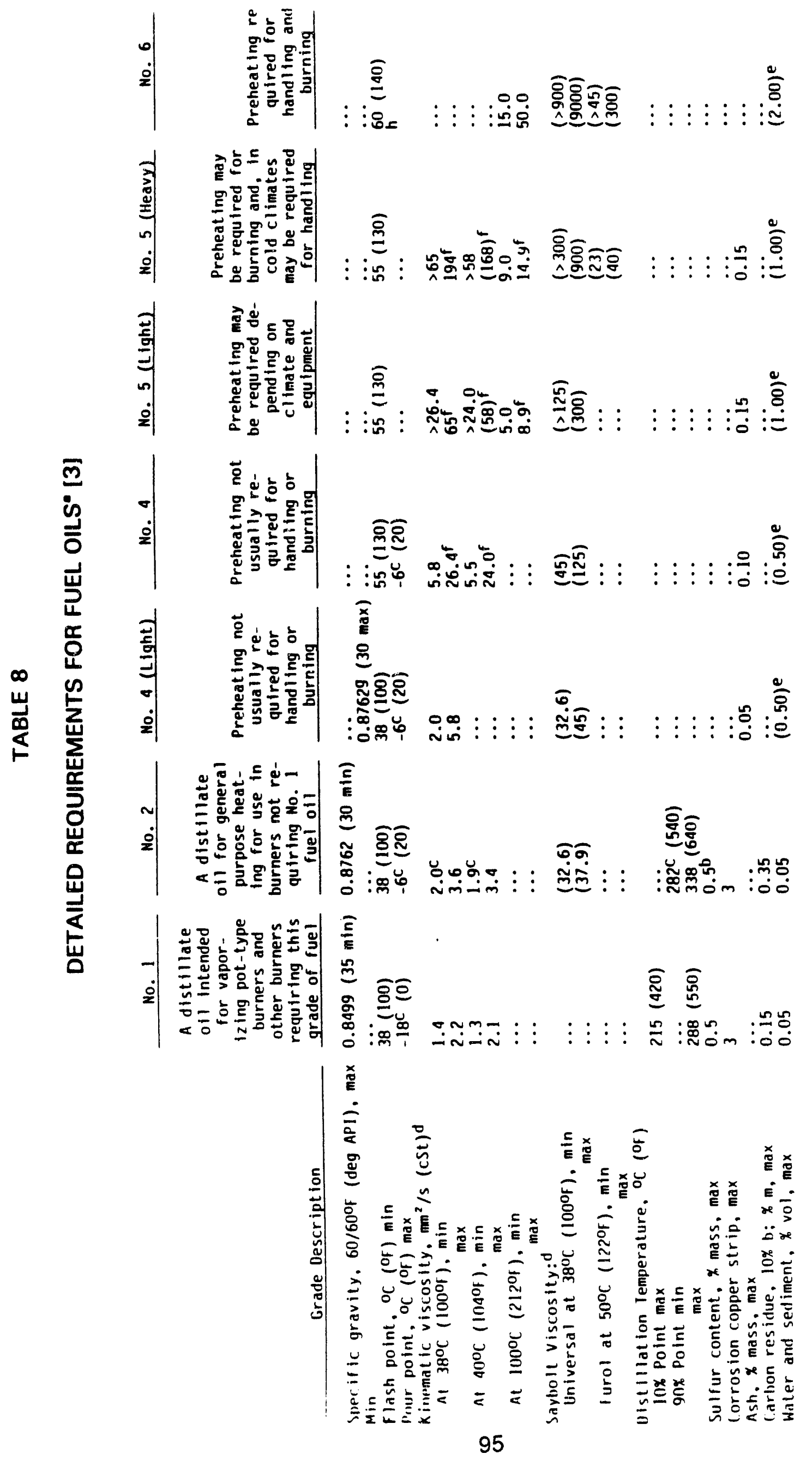




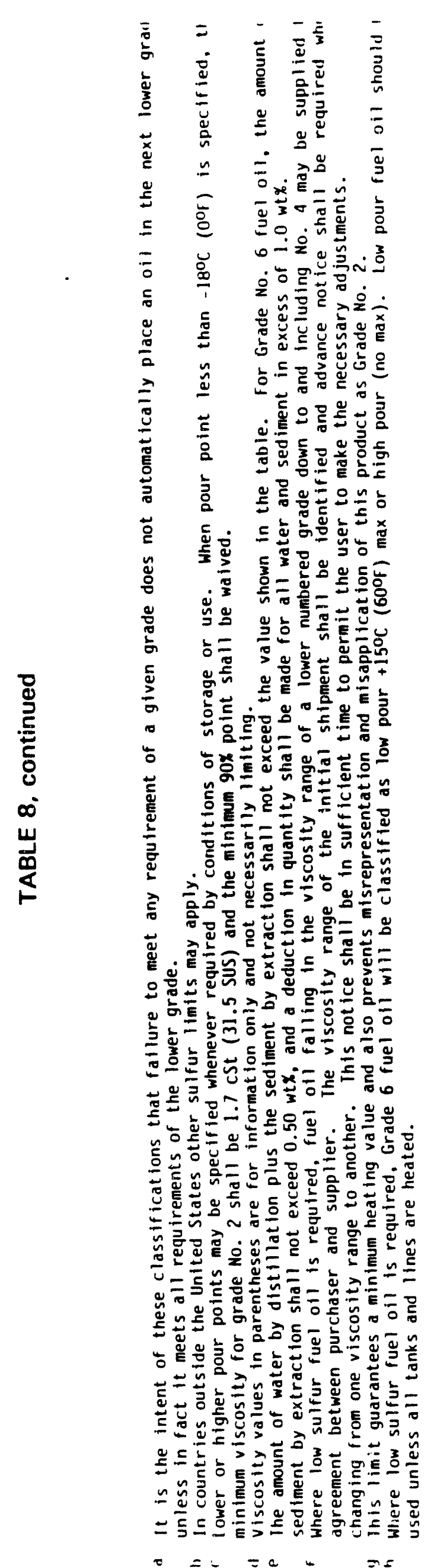




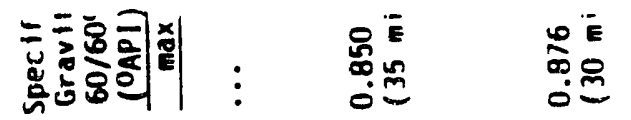
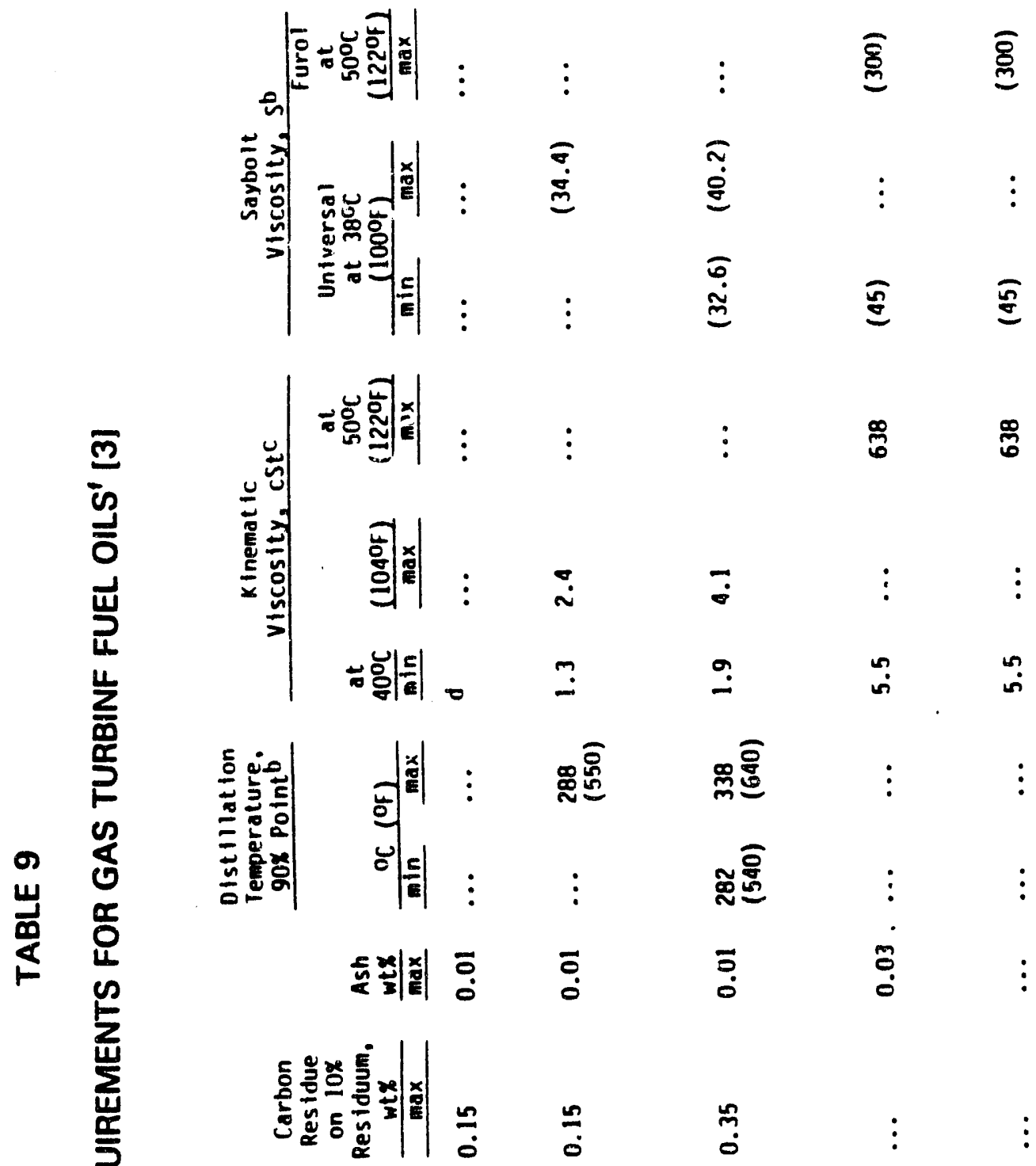

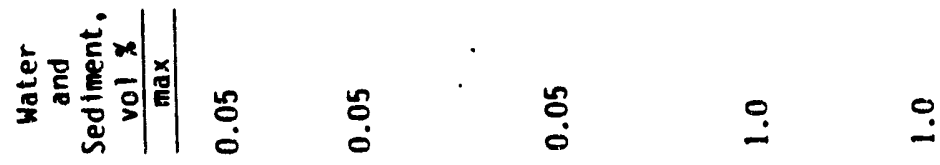

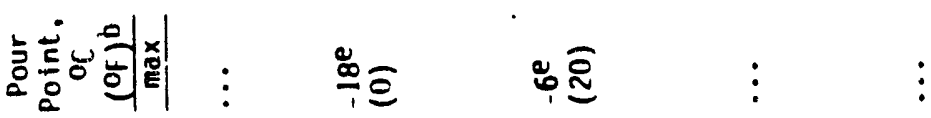

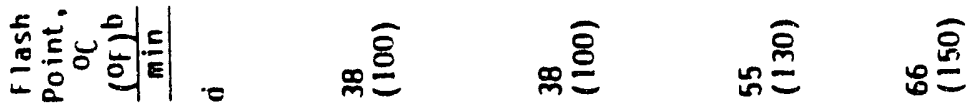

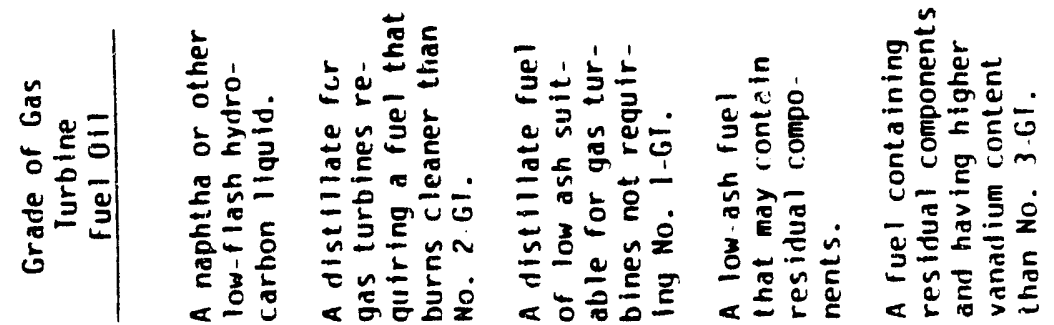

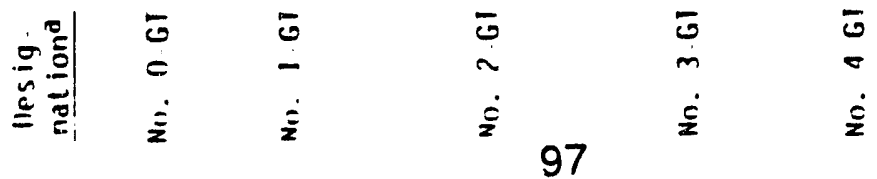




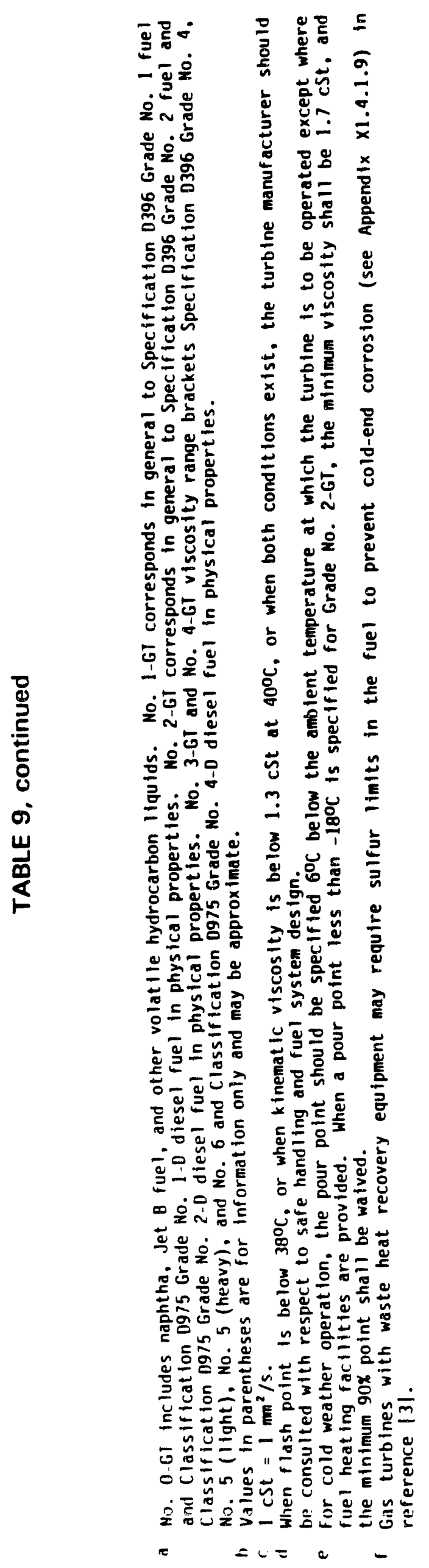


TABLE 10

TRACE METAL LIMITS OF FUEL ENTERING TURBINE COMBUSTOR(S)" [3]

Trace Metal Limits, ppm by weight, (max)

\begin{tabular}{lcccc} 
Designation & $\begin{array}{c}\text { Vanadium } \\
(V)\end{array}$ & $\begin{array}{c}\text { Sodium plus } \\
\text { Potassium } \\
(\mathrm{Na}+\mathrm{K})\end{array}$ & $\begin{array}{c}\text { Calcium } \\
(\mathrm{Ca})\end{array}$ & $\begin{array}{c}\text { Lead } \\
(\mathrm{Pb})\end{array}$ \\
\cline { 2 - 2 } & 0.5 & 0.5 & 0.5 & 0.5 \\
No. 1-GT & 0.5 & 0.5 & 0.5 & 0.5 \\
No. 2-GT & 0.5 & 0.5 & 0.5 & 0.5 \\
No. 3-GT & 0.5 & 0.5 & 0.5 & 0.5 \\
No. 4-GT & & (Consult turbine manufacturers) &
\end{tabular}

A Test Method 03605 may be used for determination of vanadium, sodium, calcium, and lead. 


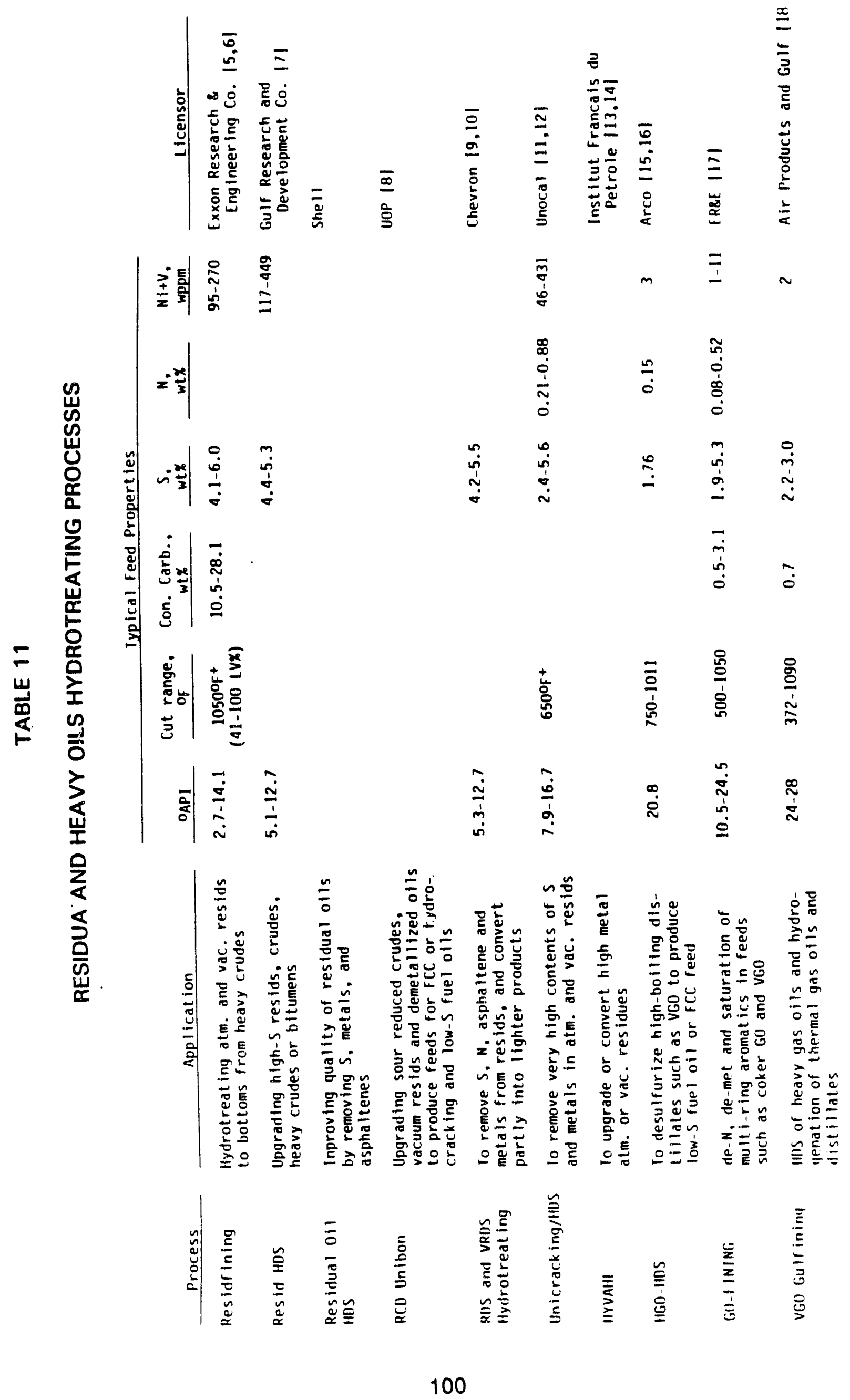




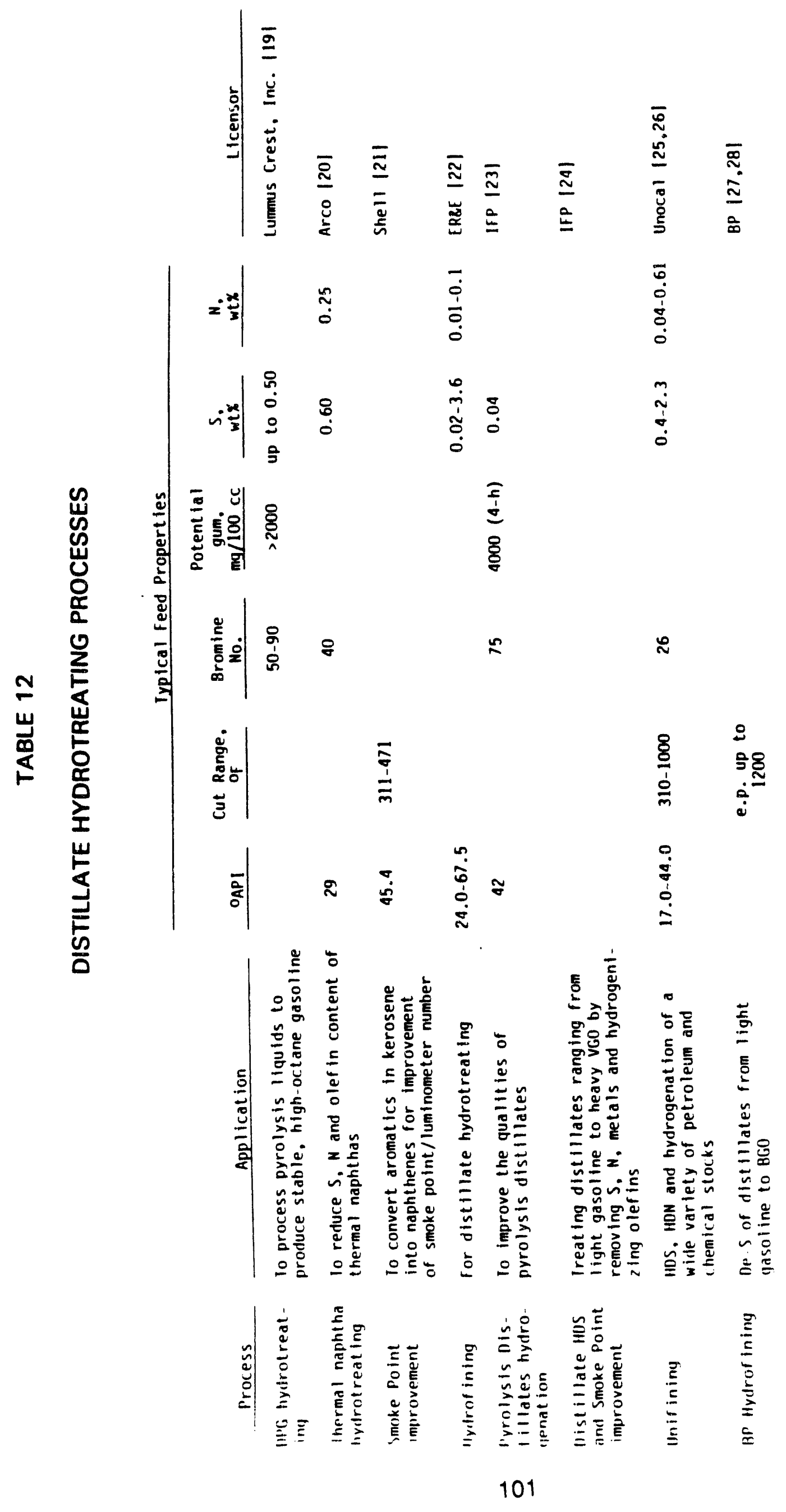




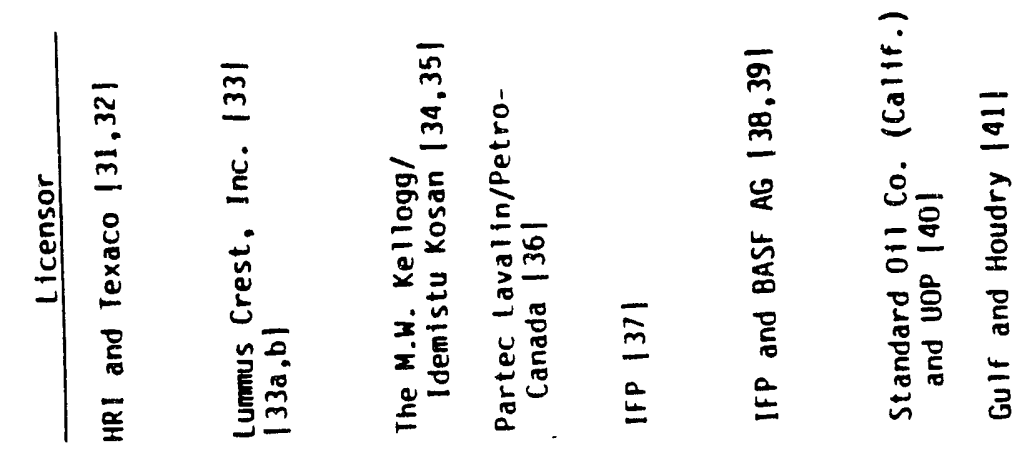

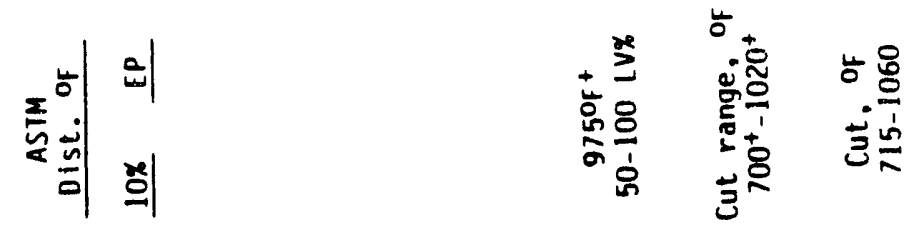

$$
\begin{aligned}
& \text { : }
\end{aligned}
$$

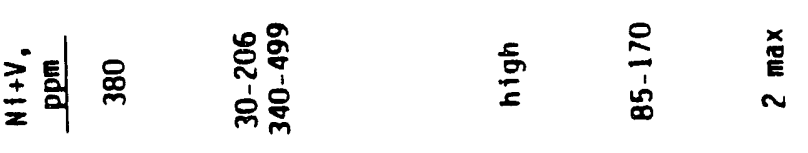

$$
\begin{aligned}
& \text { *ํำ }
\end{aligned}
$$

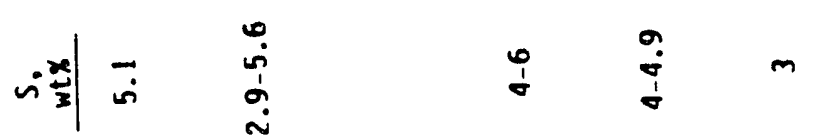

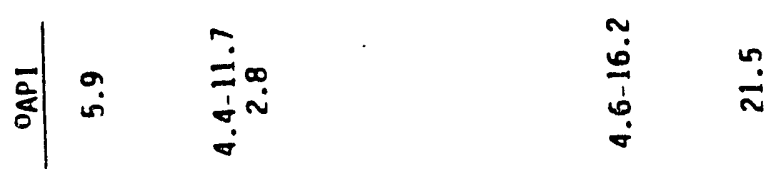

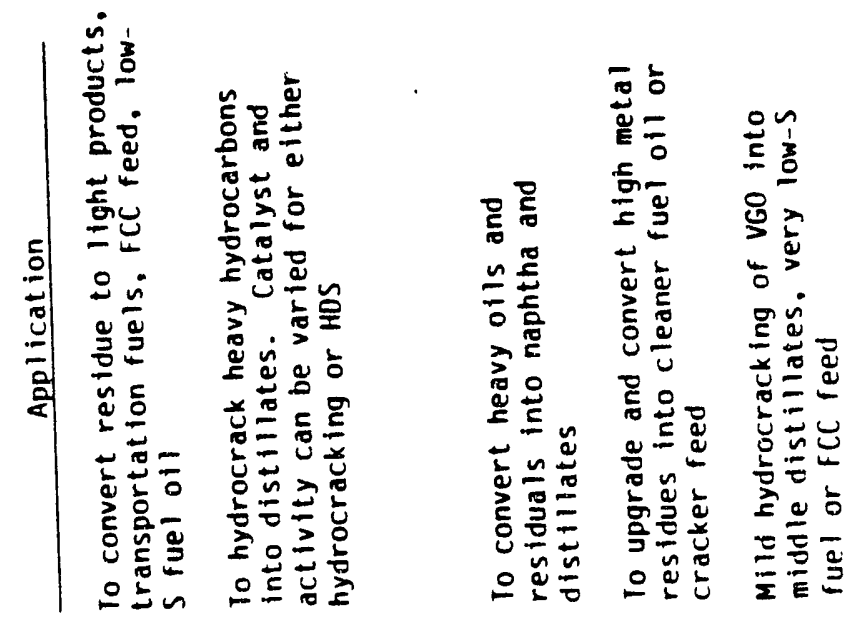

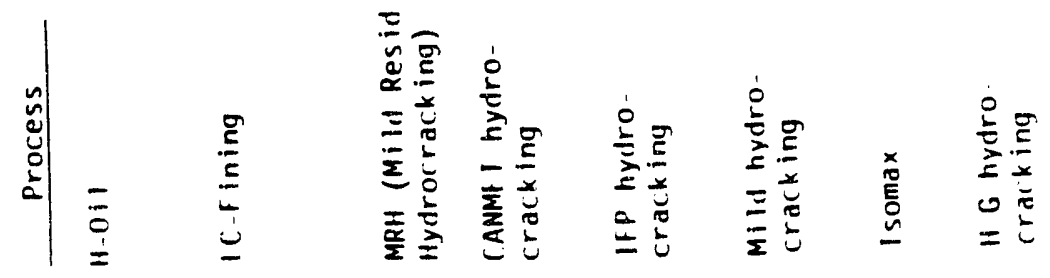




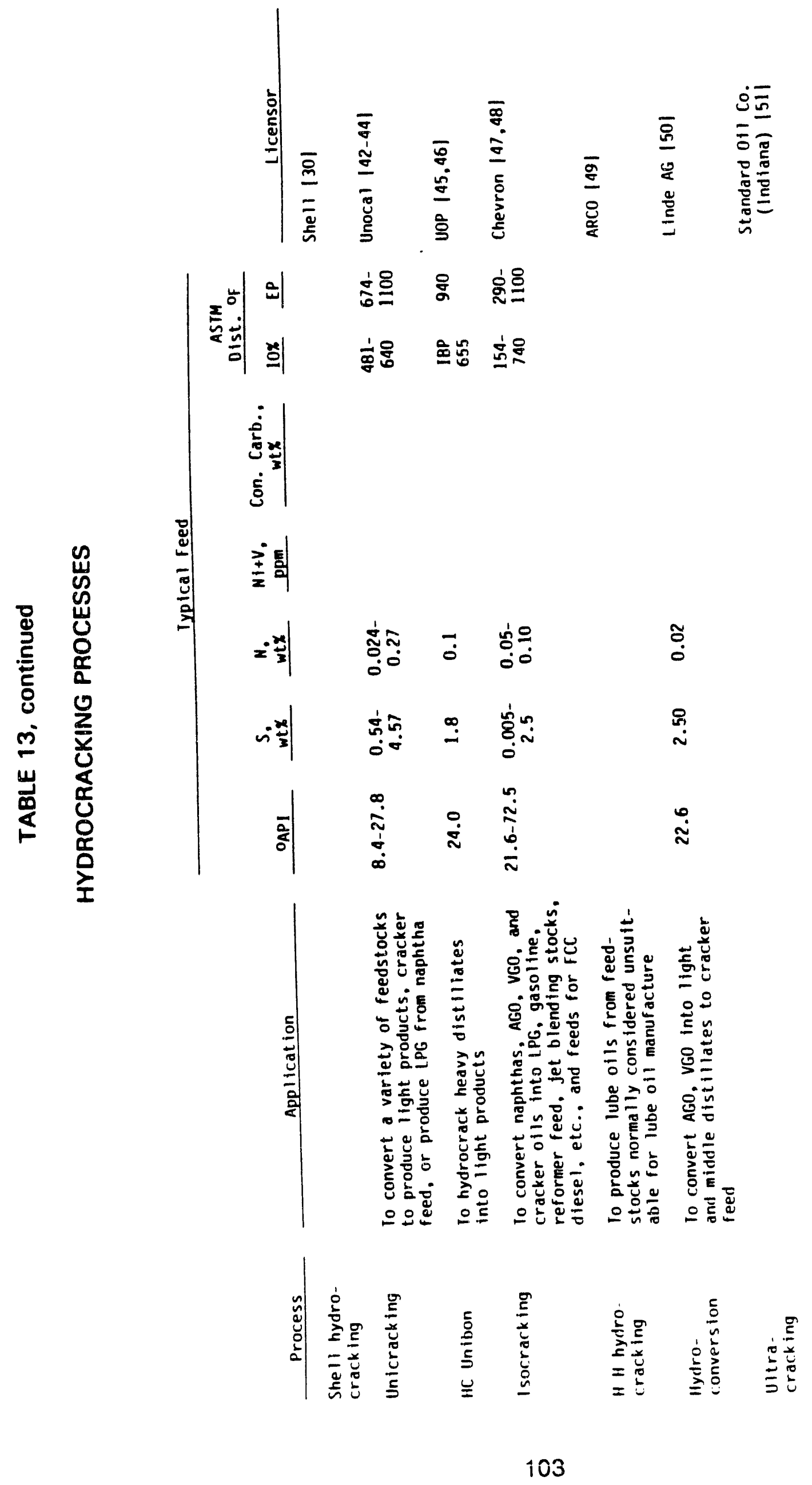




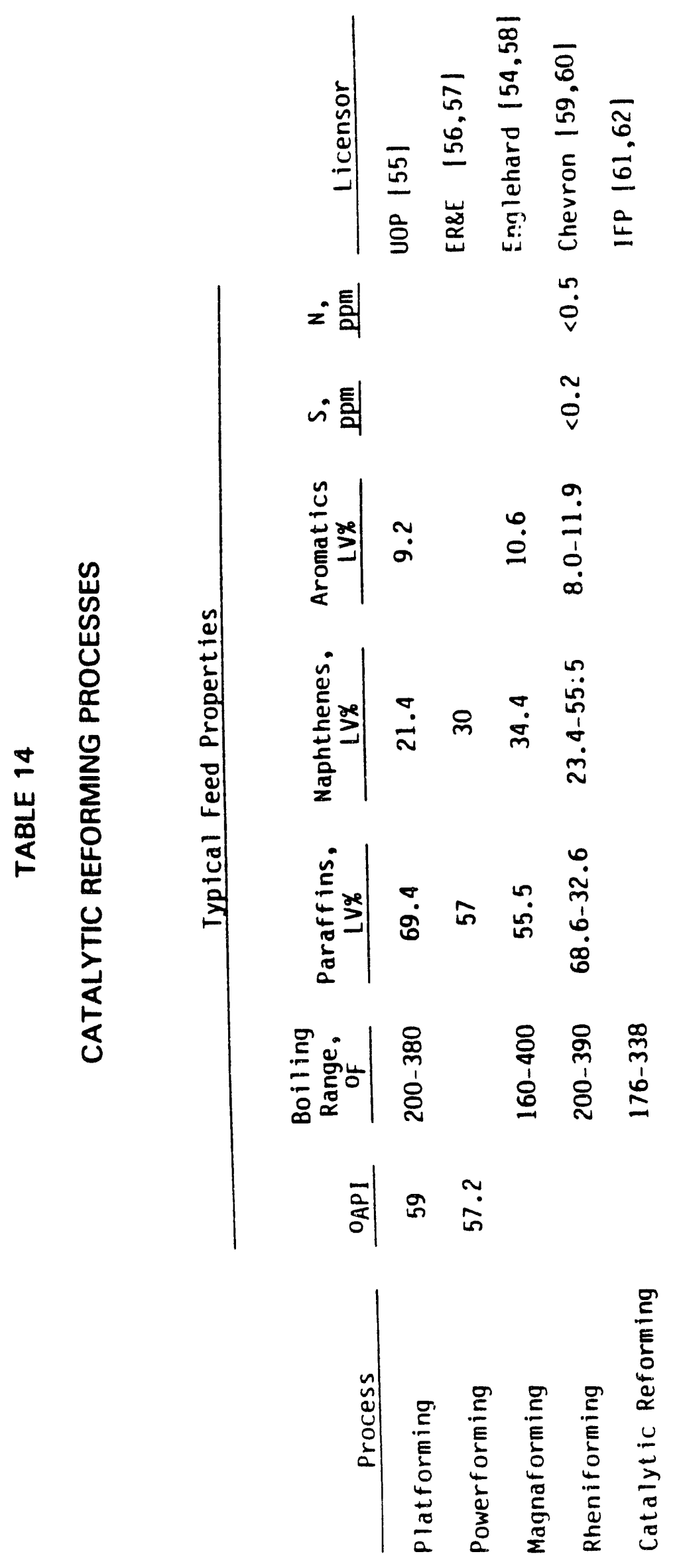




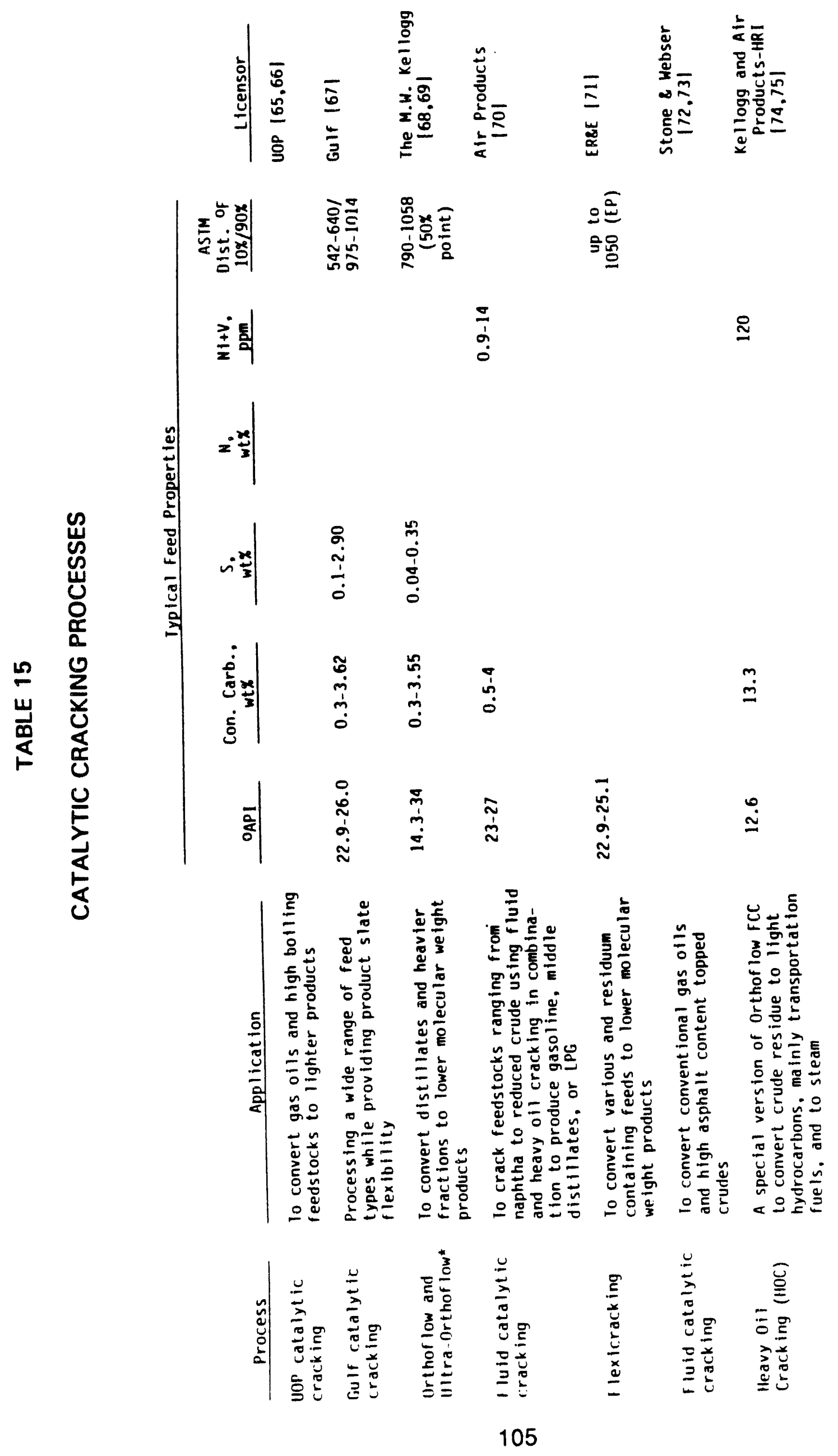




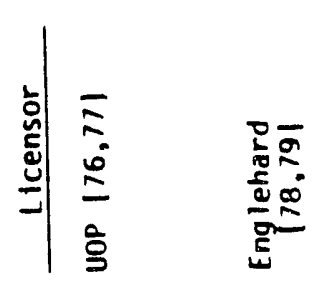

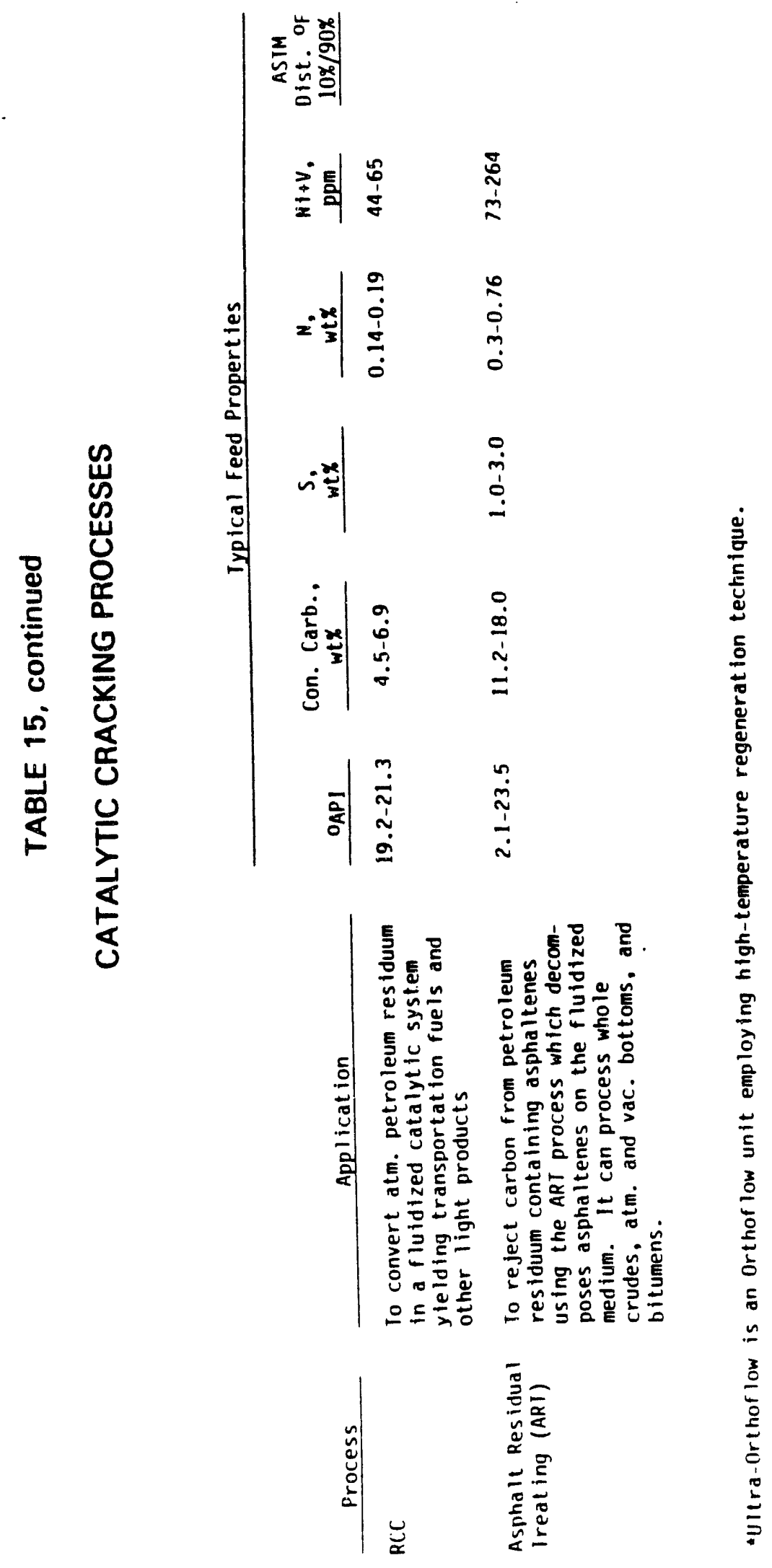


TABLE 16A

PROPERTIES OF COAL LIQUIDS FROM SINGLE-STAGE PROCESSES

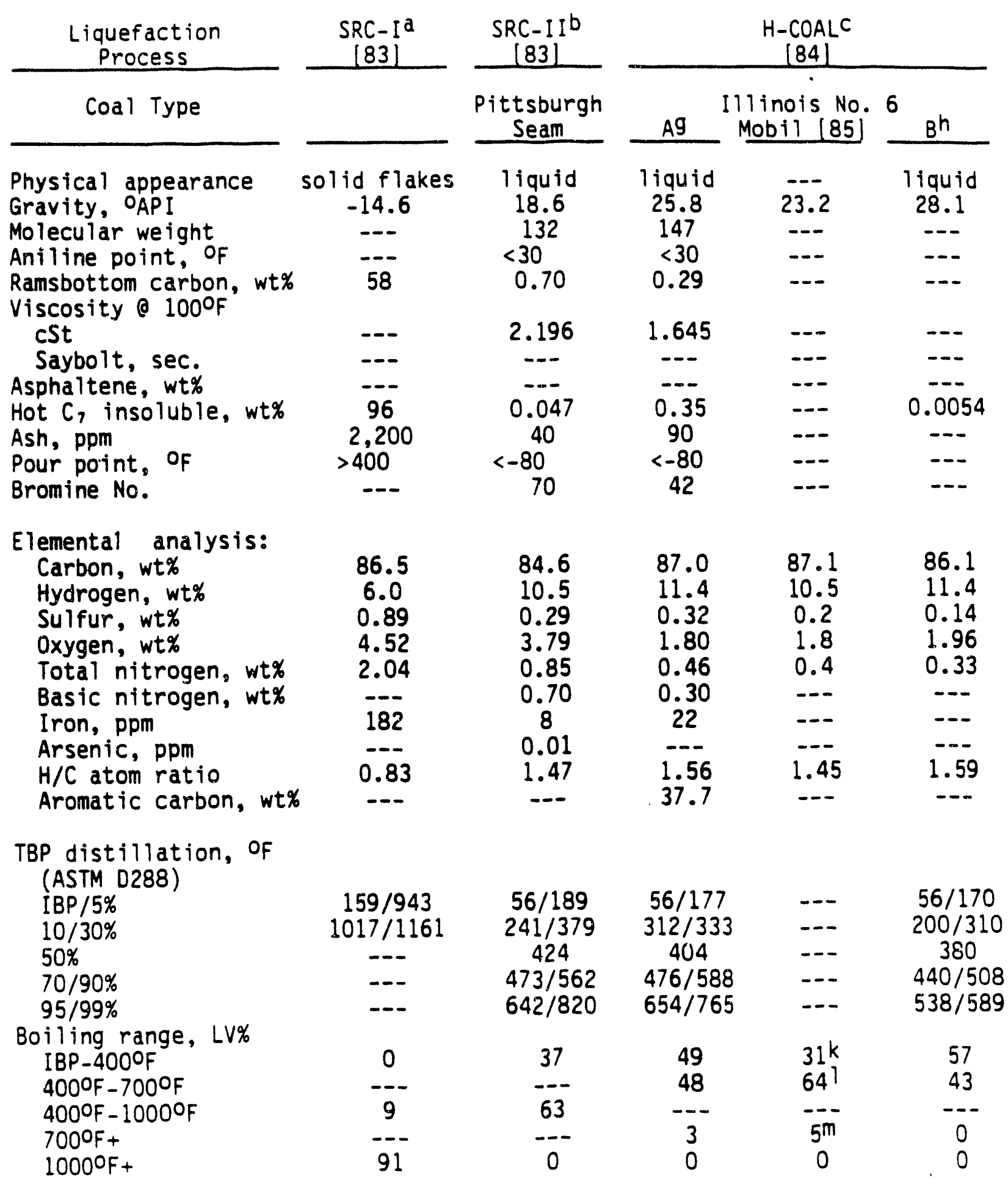


TABLE 16A, continued

PROPERTIES OF COAL LIOUIDS FROM SINGLE-STAGE PROCESSES

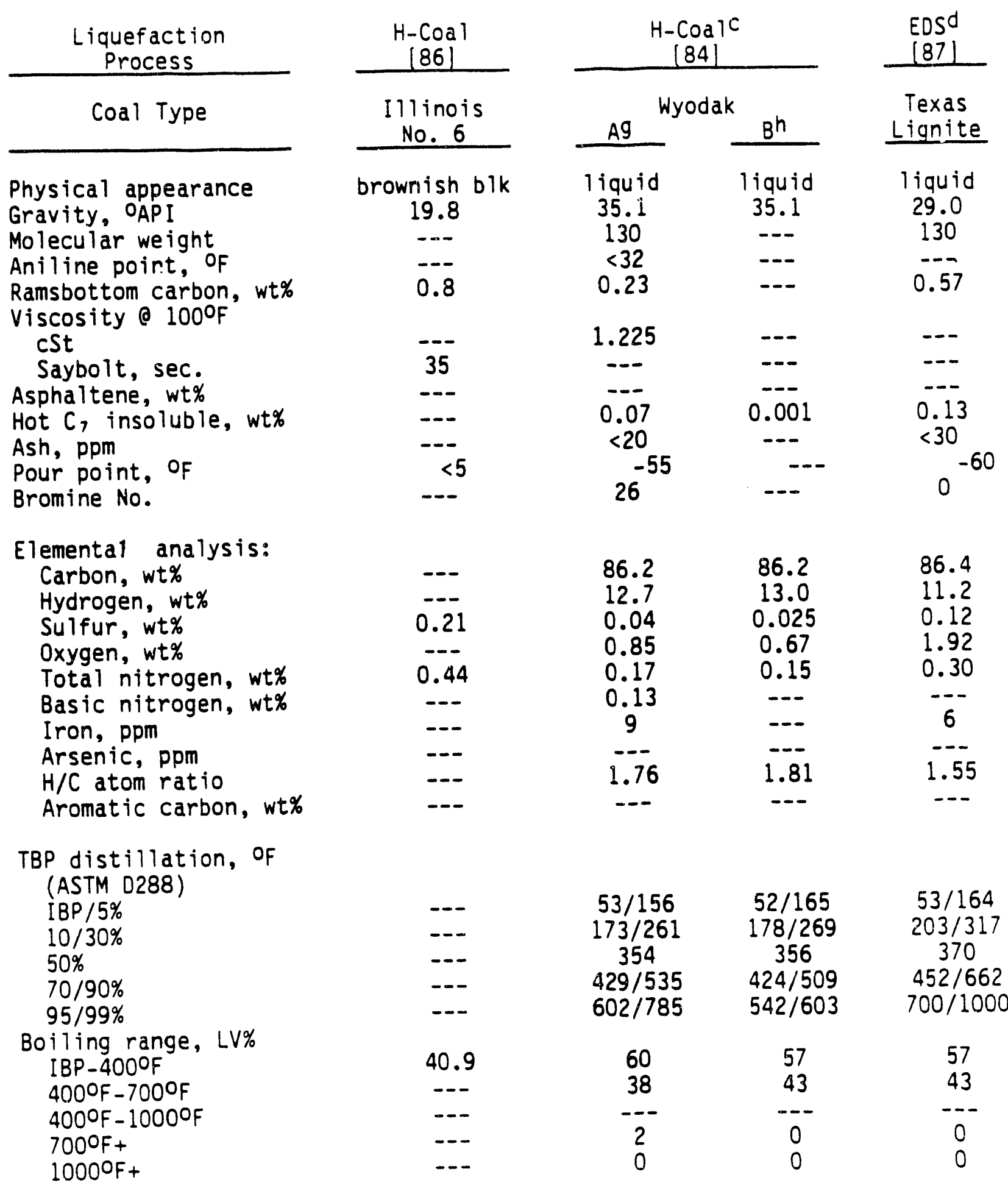


TABLE $16 B$

PROPERTIES OF COAL LIQUIDS FROM TWO-STAGE PROCESSES

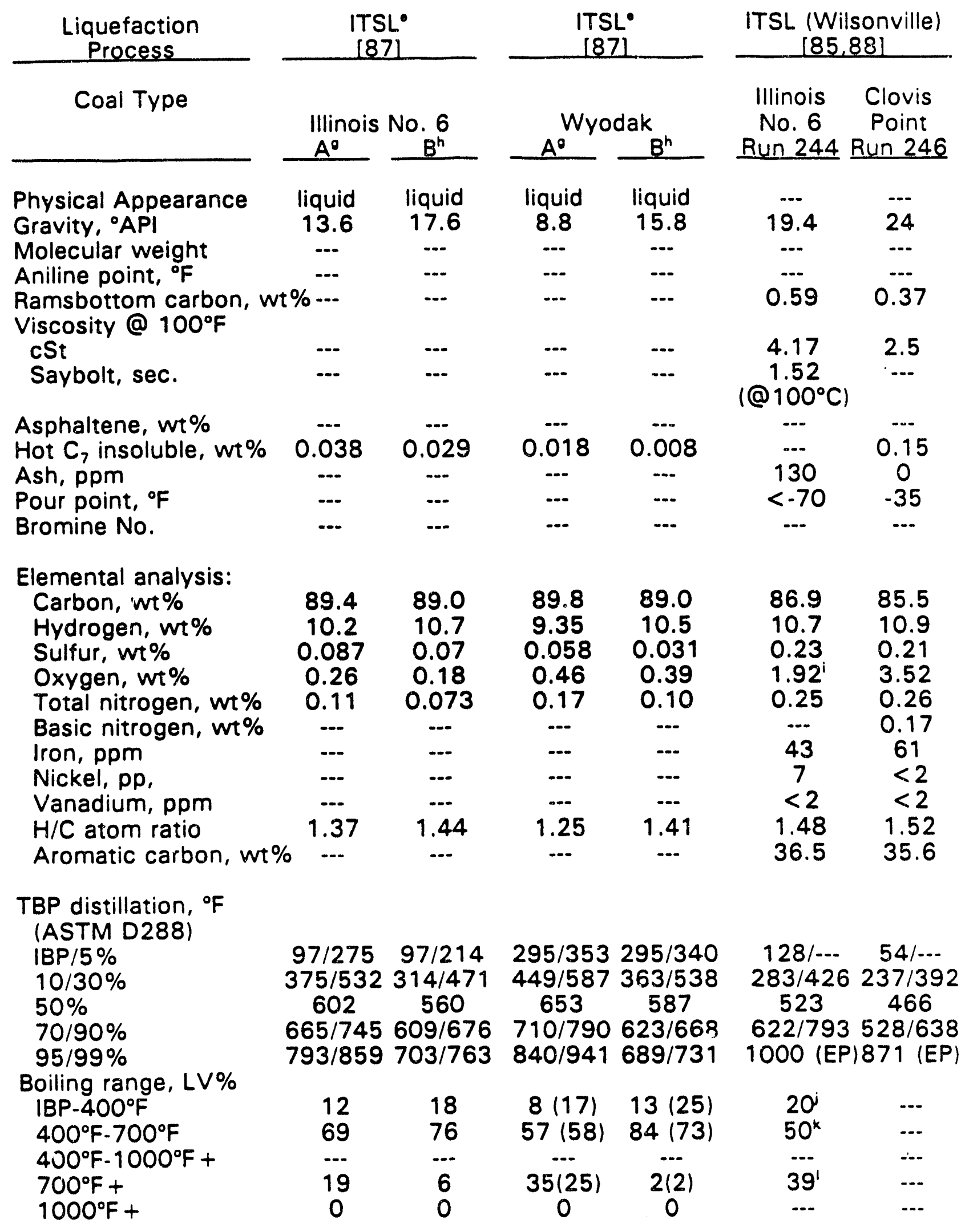


TABLE 16B, continued

PROPERTIES OF COAL LIQUIDS FROM TWO-STAGE PROCESSES

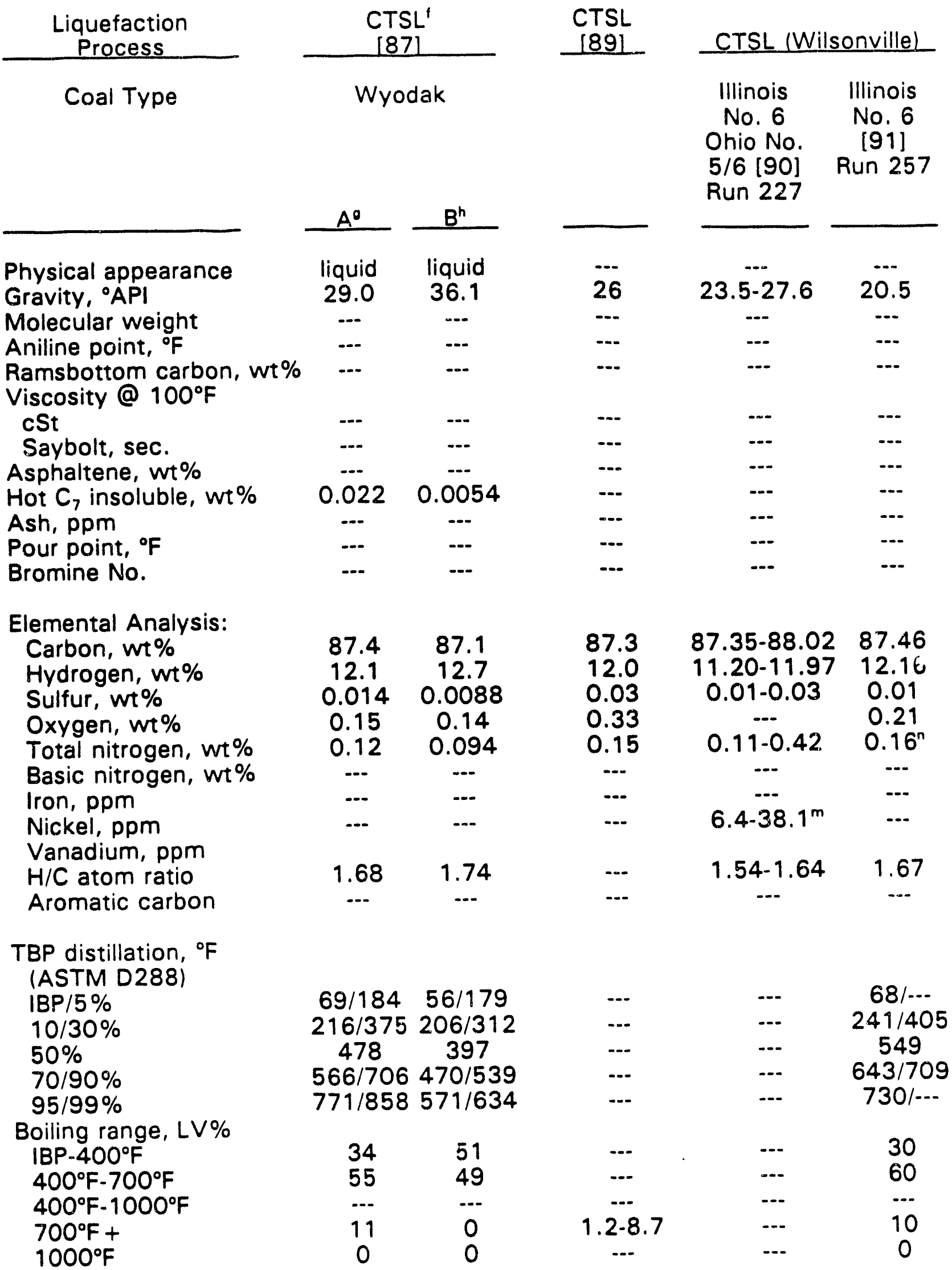


TABLE 168 , continued

PROPERTIES OF COAL LIQUIDS FROM TWO-STAGE PROCESSES

Liquefaction Process

Coal Type

Fhysical Appearance Gravity, ${ }^{\circ} \mathrm{API}$ Molecular weigni Aniline point, ${ }^{\circ} \mathrm{F}$

Ramsbottom carbon, wt \% Viscosity @ $100^{\circ} \mathrm{F}$

cSt

Saybolt, sec.

Asphaltene, wt $\%$

Hot $\mathrm{C}_{7}$ insoluble, wt \%

Ash, ppm

Pour point, ' $\mathrm{F}$

Bromine No.

Elemental analysis:

Carbon, wt \%

Hydrogen, wt \%

Sulfur, wt $\%$

Oxygen, wt \%

Total nitrogen, wt \%

Basic nitrogen, wt \%

Iron, ppm

Nickel, ppm

Vanadium, ppm

$H / C$. atom ratio

Aromatic carbon

GC sim. ditstillation, ${ }^{\circ} \mathrm{F}$

(ASTM D288)

IBP $/ 5 \%$

$10 / 30 \%$

435

$50 \%$

$70 / 90 \%$

671

EP (by dist.)

Boiling range, LV\%

IBP-350

$350^{\circ} \mathrm{F}-450^{\circ} \mathrm{F}$

$450^{\prime \prime} \mathrm{F}-650^{\circ} \mathrm{F}$

$650^{\circ} \mathrm{F}-\mathrm{EF}$

Close-Coupled ITSL (Wilsonville) [92]

b:yodak

Subbituminous

Run 251-11B

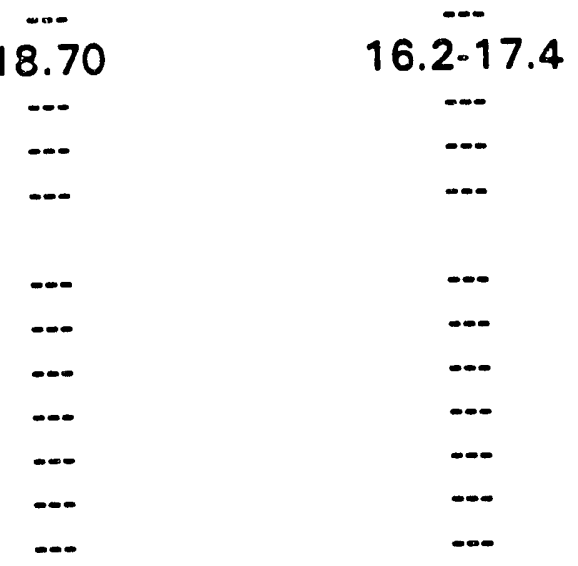

บ6.4

12.2

0.05

1.13

0.23

-..

-..

-..

1.70

$--$

$\cdots$

--.

-..

-..

-.

28.5

20.4

37.1

14.1
Spring Creek

Subbituminous

Run 258 B-F

$16.2-17.4$

86.2-86.9

$11.1-11.3$

0.05-0.10

1.36-2.21

$0.40-0.45$

---

-.-

1.54-1.58

-..

47-104/..-

245-301/354-514

555-627

$636-722 / 697-778$

$685-750$

16.3-18.8

11.7-13.7

45.2-57.1

12.1-25.3
Black Thunder

Subbituminous

Run 258-H-M

18.3-19.5

-.-

$--$

$\cdots$

$\cdots$
$\cdots$
$\cdots$
$\cdots$
$\cdots$

85.5-86.6

11.2-11.9

0.05-0.06

1.41-2.49

$0.37-0.50$

-..

--.

-.-

$1.56-1.66$

$88-97 / \ldots$

209-246/343-

474-531

568-606/638-

630-667

20.3-24:3

13.5-16.9

52.0-63.8

0.5 .2 
TABLE 16B, continued

PROPERTIES OF COAL LIQUIDS FROM TWO-STAGE PROCESSES

Liquefaction Process

Coal Type

Physical appearance Gravity, ${ }^{\circ} \mathrm{API}$

Molecular weight

Aniline point, ${ }^{\circ} \mathrm{F}$

Ramsbottom carbon, wt \%

Viscosity @ $100^{\circ} \mathrm{F}$

cSt

Saybolt, sec.

Asphaltene, wt \%

Hot $\mathrm{C}_{7}$ insoluble, wt \%

Ash, ppm

Pour point, ${ }^{\circ} \mathrm{F}$

Bromine No.

Elemental analysis:

Carbon, wt \%

Hydrogen, wt \%

Sulfur, wt \%

Cxygen, wt \% (diff.)

Total nitrogen, wt \%

Basic nitrogen, wt \%

Iron, ppm

Nickel, ppm

Vanadium, ppm

$\mathrm{H} / \mathrm{C}$ atom ratio

Aromatic carbon, wt \%

GC sim. distillation, ${ }^{\circ} \mathrm{F}$
(ASTM D288)
IBP $/ 5 \%$
$10 / 30 \%$
$50 \%$
$70 / 90 \%$
EP (by dist.)

Boiling range, LV\%

IBP-350 $\mathrm{F}$

$350^{\circ}-450^{\circ} \mathrm{F}$

$450^{\circ} \mathrm{F}-650^{\circ} \mathrm{F}$

$650^{\circ} \mathrm{F}$-EP

Close-Coupied ITSL (Wilsonville)

\section{Pittsburgh No. 8 \\ Bituminous \\ Run 259G [93]}

Black Thunder

Subbituminous

Run 260D [94]
Illinois No. 6

Bituminous

Run 261C [95]

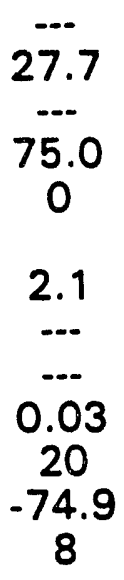

86.9

11.55

0.05

1.40

0.1

0.078

2.5

$<0.5$

$<1$

1.59
23.9

-.-

$\overline{0}$

3.1

-..

0.5

100

$-15$

4

87.4

11.2

0.05

1.05

0.3

0.18

23

$<0.5$

$<1$

1.54

-.-
87.2

11.8

0.02

0.78

0.22

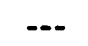

..-

-..

1.62

---/155

$215 / 371$

488

$554 / 652$

23.6

14.9

51.5

10

\section{$---/ 177$ \\ $207 / 417$ \\ 518 \\ $606 / 689$}

25.0

34.2

45.8

20.0
22.3

16.7

43.0

18.0 
TABLES $16 A$ and $B$, continued

\section{Notes to Tables $16 \mathrm{~A}$ and $\mathrm{B}$}

a SRC-I, produced from bituminous coal and supplied by Pittsburg and Midway Coal Mining Company.

b SRC-II, produced by same company as SRC-I and derived from bituminous from Pittsburgh seam (Blacksville No. 2 mine) in West Virginia.

c H-COAL oils, supplied by HRI and derived from (1) Illinois No. 6, Burning Star mine, and (2) Wyodak, subbituminous.

d EDS oil, made from Big Brown Texas lignite by Exxon.

e ITSL oils, derived from (1) Illinois No. 6 Burning Star mine, and (2) Wyodak, subbituminous, much of the front end (500 $\mathrm{F}_{-}$) was missing ( 38 LVX) for this oil, numbers in parentheses were corrected for the missing part.

$f$ CTSL, from Wyodak coal by HRI.

9 A - blended from components in ratios to represent, as close as possible, "net whole-liquid products" from these processes.

$h$ B - redistilled A with recovery of LV\%: 87 (IIlinois No. $6 \mathrm{H}-\mathrm{Coa}$ ), 96 (Wyodak H-COal), 69 (Illinios No. 6 ITSL), 52 (Wyodak ITSL), 62 (Wyodak CTSL).

$i$ Direct determination.

j IBP $-360^{\circ} \mathrm{F}$.

k $360^{\circ} \mathrm{F}-650^{\circ} \mathrm{F}$.

$1650 \mathrm{FF}^{+}$.

in $\mathrm{Ni}+\mathrm{V}$ in $975^{\circ} \mathrm{F}^{+}$residuum.

$n \quad 0.11$ by $\mathrm{Kjeldah} 1$. 


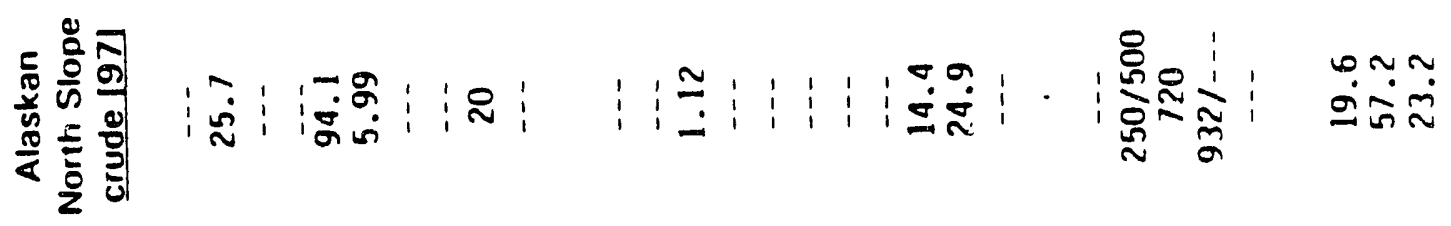

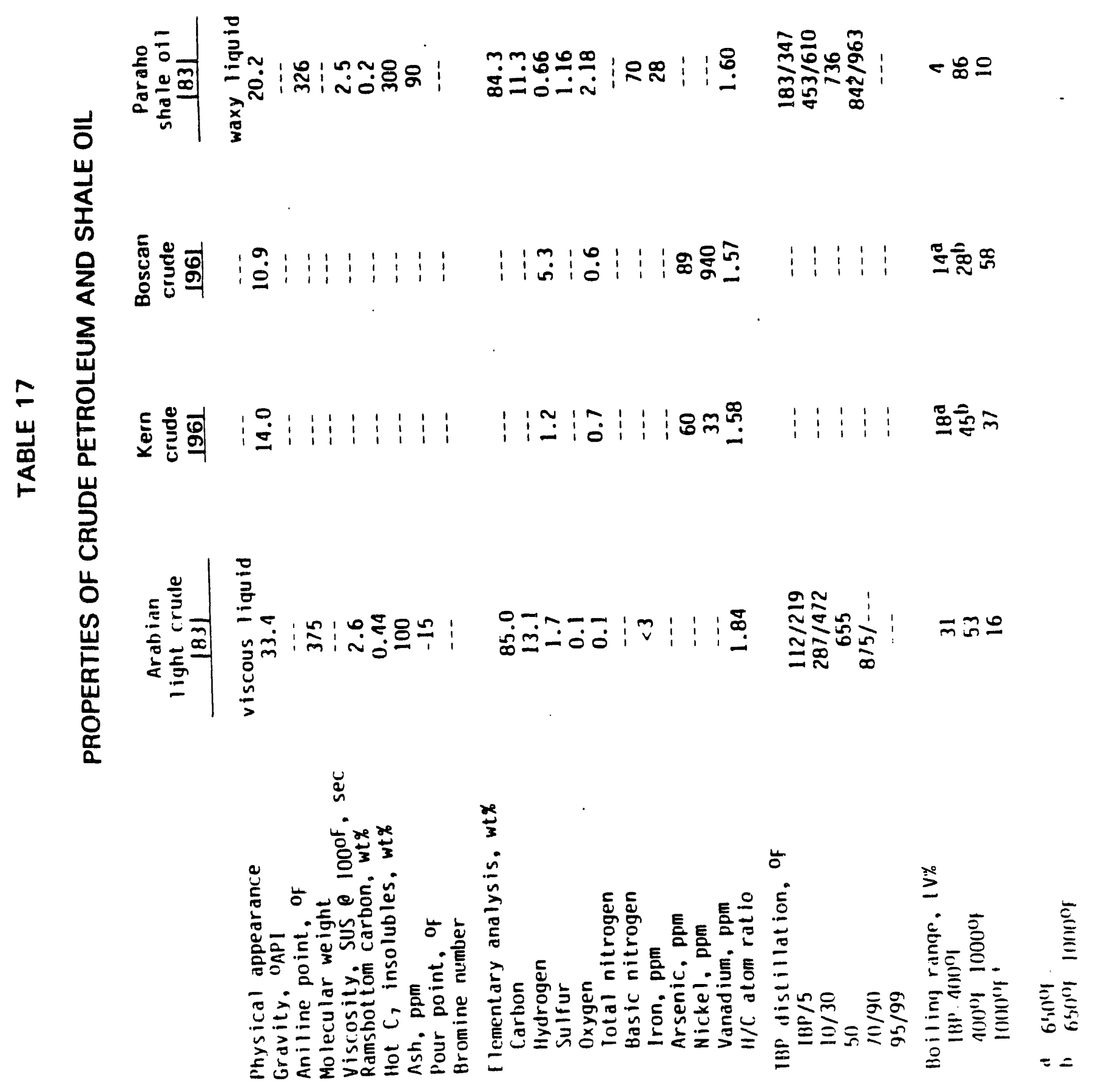



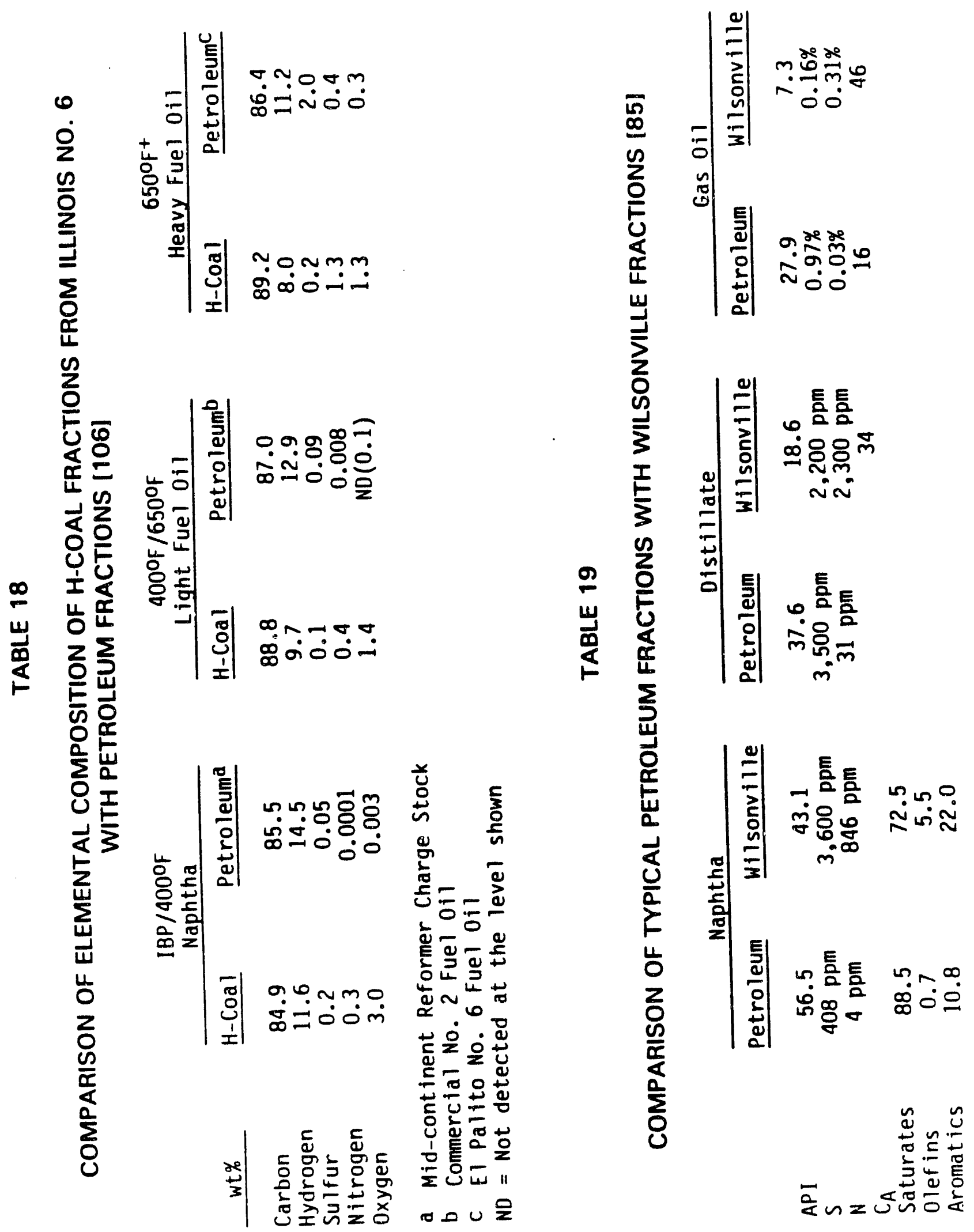
TABLE 20

LIGHT NAPHTHA (IBP- $285^{\circ}$ F) FROM ILLINOIS NO. 6 ITSL (RUN 244) [85]

Run 244

IBP-2850F Cut

Specification

Remarks

Distillation temperature, of

IBP

$10 \%$ evaporated

$40 \%$ evaporated

$50 \%$ evaporated

$90 \%$ evaporated

FBP

Sum of $10 \%$ and $50 \%$ evap. temp.

Distillation recovery, \%

Distillation residue, \%

Distillation loss, \%

Net heat of combustion, Btu/1b

Reid vapor pressure, psi

Copper strip corrosion

Potential gum, mg/100 ml

Sulfur, wt\%

Freezing point, of

Octane no., lean rating

Elementary analysis, \%

C

H

$S$

N

FIA, \%

Aromatic

Olefin

Saturates

API gravity

Aniline point
171

198

208

212

242

287

410

98.1

0.8

1.1

18,313

2.9

la

10.4

0.0027

$-112$

74

86.85

13.15

0.0027

0.0058

24.5

1.5

74.0

48.1

64.9

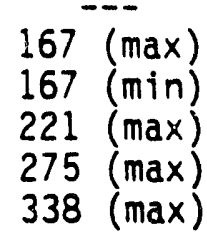

Fail

Fail

$\mathrm{Fail}$

Fail

$6(\max )$

0.05 (max)

-72 (max)

80 (Grade $80 \mathrm{~min}$ ) Fail 


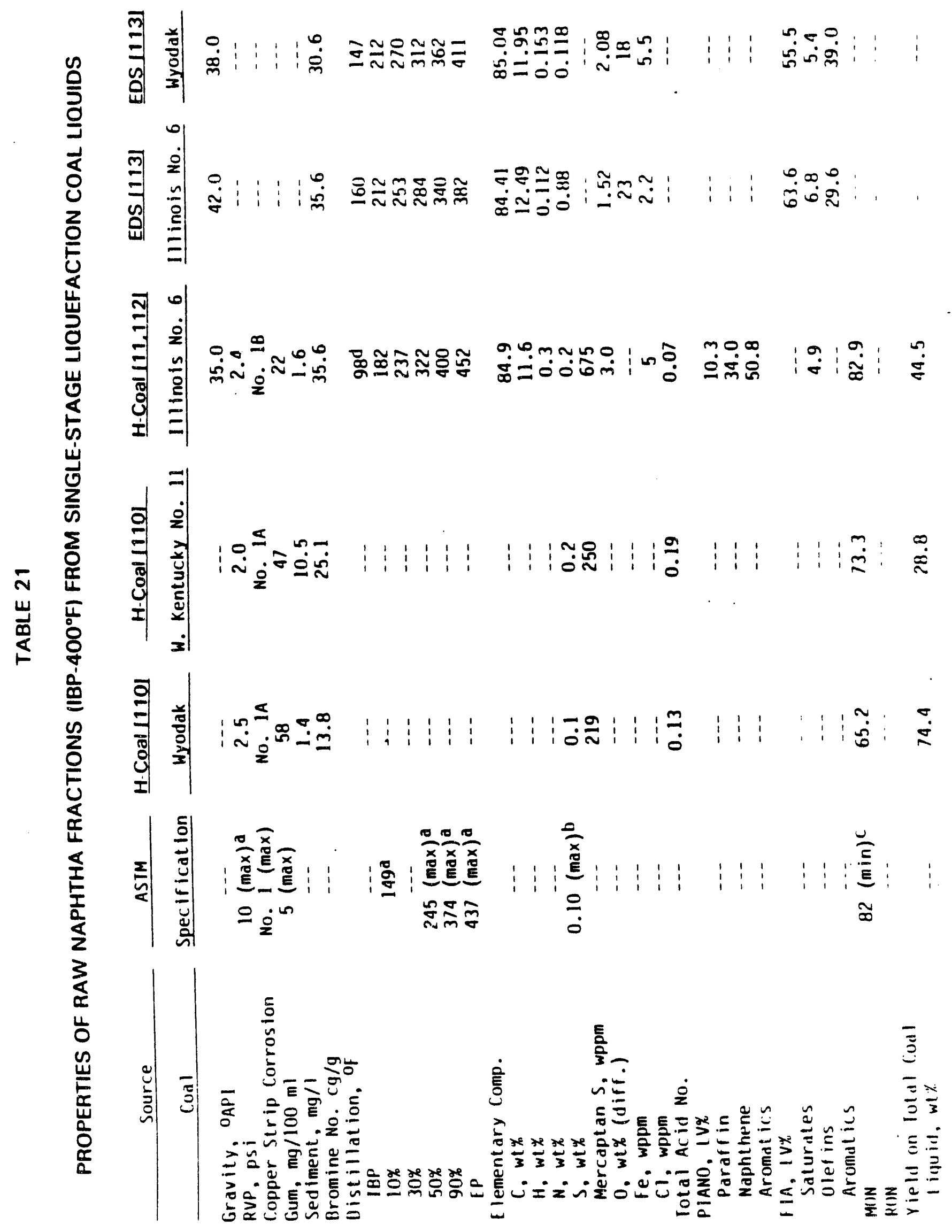



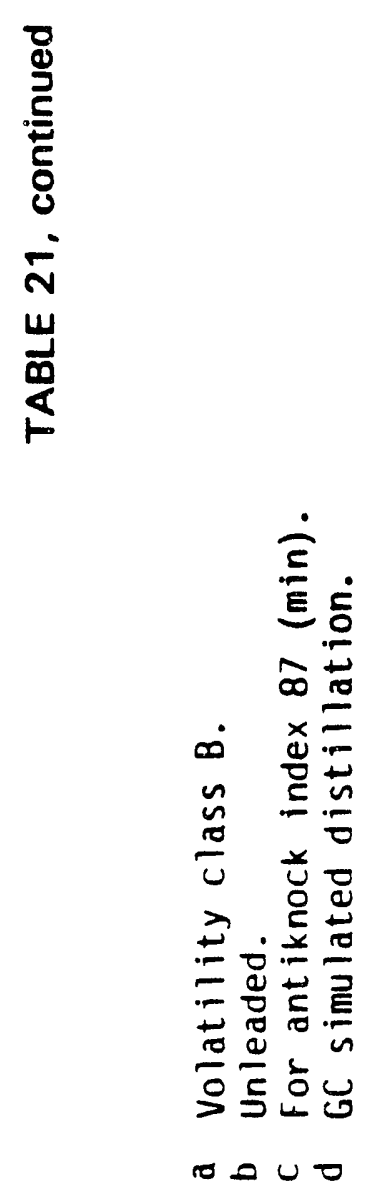


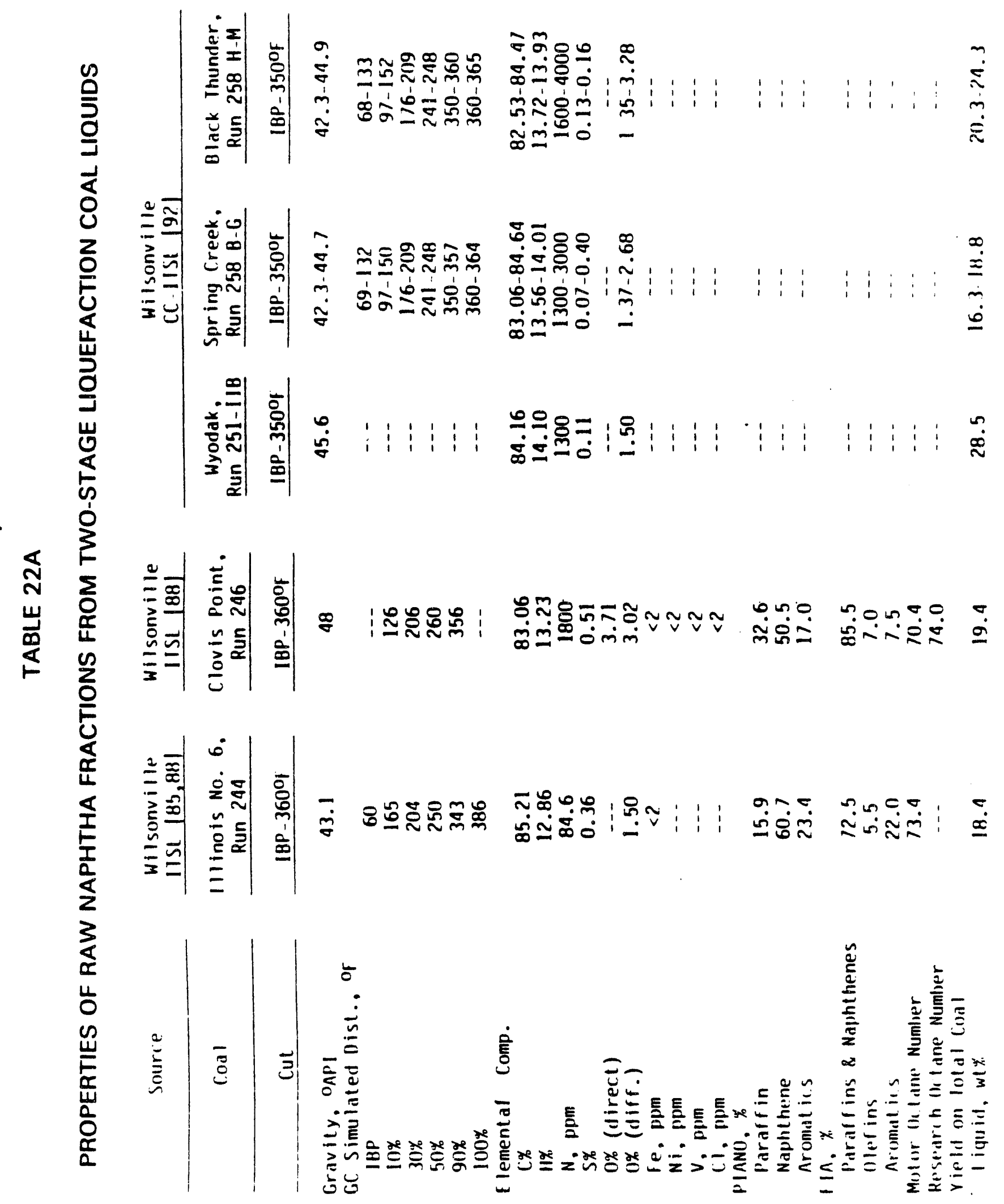


PROPERTIES OF STRAIGHT-RUN NAPHTHAS FROM RECENT WILSONVILLE CC-ITSL RUNS

\begin{tabular}{|c|c|c|}
\hline $\begin{array}{l}\text { Coal } \\
\text { Run No. }\end{array}$ & $\begin{array}{c}\text { Pittsburgh Seam } \\
259 G[93] \\
\end{array}$ & $\begin{array}{r}\text { Black Thund } \\
2600[94] \\
\end{array}$ \\
\hline Boiling range, ${ }^{\circ} \mathrm{F}$ & IBP-380 & IBP-380 \\
\hline $\begin{array}{l}\text { Yield, wt } \% \text { of total } \\
\text { distillate }\end{array}$ & 26.72 & 23.65 \\
\hline \multicolumn{3}{|l|}{ Properties } \\
\hline Gravity, ${ }^{\circ} \mathrm{API}$ & 48.9 & 50.9 \\
\hline $\begin{array}{l}\text { Elemental analysis, wt\% } \\
\text { Carbon } \\
\text { Hydrogen } \\
\text { Sulfur } \\
\text { Nitrogen } \\
\text { Basic nitrogen } \\
\text { Oxygen (by diff.) }\end{array}$ & $\begin{array}{c}85.3 \\
13.3 \\
0.05 \\
<0.1 \\
0.028 \\
1.25\end{array}$ & $\begin{array}{c}84.3 \\
13.6 \\
0.08 \\
0.1 \\
0.046 \\
1.92\end{array}$ \\
\hline $\begin{array}{l}\text { Group analysis, vol\% } \\
\text { Paraffins } \\
\text { Naphthenes }\end{array}$ & $\begin{array}{l}19.3 \\
67.5\end{array}$ & 88.0 \\
\hline $\begin{array}{l}\text { Olefins } \\
\text { Aromatics }\end{array}$ & 13.2 & $\begin{array}{l}5.0 \\
7.0\end{array}$ \\
\hline Bromine number & $-\cdots$ & 16 \\
\hline Octane number (by GC) & 86.5 & 87.1 \\
\hline Reid vapor pressure, Psia & 2.8 & 3.1 \\
\hline Copper strip corrosion & $1 \mathrm{~A}$ & $1 \mathrm{~A}$ \\
\hline Existent gum, $\mathrm{mg} / 100 \mathrm{ml}$ & 26.2 & 56.2 \\
\hline $\begin{array}{l}\text { Oxidation stability (held } \\
100 \text { psi for } 5 \mathrm{~h} @ 212^{\circ} \mathrm{F} \text { ) }\end{array}$ & Pass & Pass \\
\hline Acidity, $\mathrm{mg} \mathrm{KOH} / \mathrm{g}$ & --- & 0.38 \\
\hline Phenolic $-\mathrm{OH}$ conc., meq/g & 0.18 & 0.40 \\
\hline $\begin{array}{l}\text { ASTM distillation, }{ }^{\circ} \mathrm{F} \\
\text { IBP } \\
10 \% \\
50 \% \\
90 \% \\
\text { EP }\end{array}$ & $\begin{array}{l}109 \\
196 \\
258 \\
341 \\
368\end{array}$ & $\begin{array}{c}-- \\
176 \\
240 \\
340 \\
399\end{array}$ \\
\hline
\end{tabular}


TABLE 23

COMPOSITIONAL ANALYSES OF COAL-DERIVED NAPHTHAS (BERC/RI-76/10)

Naphtha Cut

Chemical Class Type, wt\%
Acids
Bases
Pyridines
Anilines
Total Bases
Hydrocarbons
Saturates
Olefins
Monoaromatics
Diaromatics
Total hydrocarbons
Loss

IBP-3970F

22.3

0.19

0.88

1.07

33.9

5.9

34.2

Trace

74.0

2.6
IBP-3870F

14.5

0.1

0.7

0.8

42.6

3.6

31.4

0.2

77.8

6.85 
TABLE 24

HYDROTREATING OF H-COAL NAPHTHA [114]

property

\begin{tabular}{l} 
Property \\
\hline Gravity, OAPI \\
D86 Distillation, of \\
IBP \\
$10 \%$ \\
$30 \%$ \\
$50 \%$ \\
$70 \%$ \\
$90 \%$ \\
EP \\
Elementary Composition \\
C, wt\% \\
H, wt\% \\
S, wppm \\
N, wppm \\
O, wppm \\
Ci, wppm \\
FIA, LV\% \\
Aromatics \\
Olef ins \\
Saturates \\
MS Hydrocarbon Types, LV\% \\
Aromatics \\
Naphthenes \\
Paraffins \\
N Jet Gum, mg/100 ml \\
RON, Clear
\end{tabular}

Rerun Naphtha

43.7

132

189

233

260

312

396

85.90

12.80

1389

1930

5944

23

24.7

5.2

70.1

18.6

$55.5^{\mathrm{a}}$

16.2

40.0

80.3
Upgraded Naphtha

46.8

153

199

231

263

306

352

393

86.45

13.59

3.9

0.63

34

4

18.9

0.0

81.1

17.6

63.4

19.0

66.8

a LV\% of polars and olefins are 4.2 and 5.5 , respectively. 


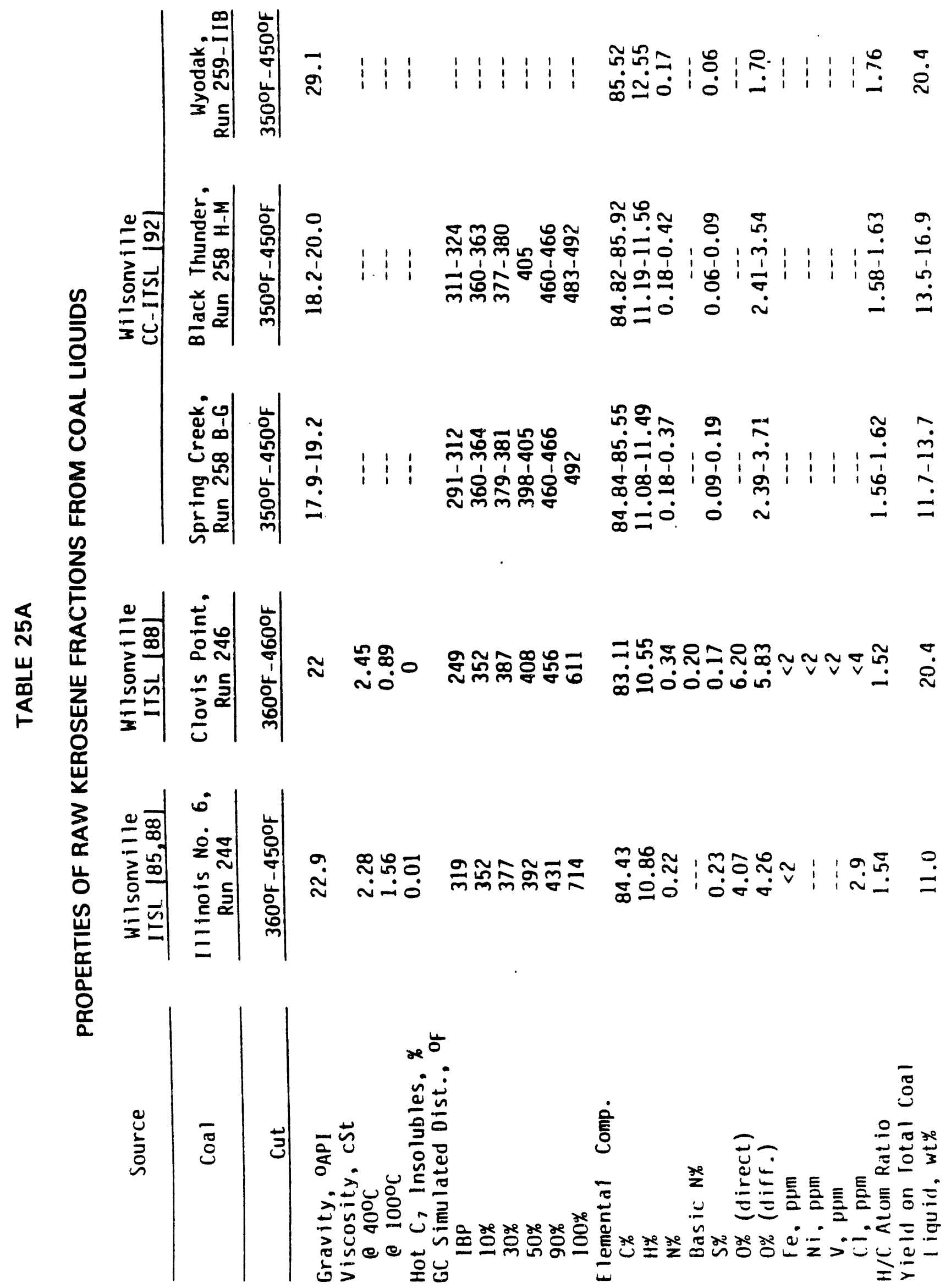


PROPERTIES OF JET FUEL FRACTION FROM TWO-STAGE COAL LIOUID (WILSONVILLE RUN 259G, PITTSBURGH SEAM COAL)

\begin{tabular}{|c|c|c|}
\hline Property & Actual & $\begin{array}{c}\text { Jet A-1 } \\
\text { Specification } \\
\end{array}$ \\
\hline Gravity, ${ }^{\circ} \mathrm{API}$ & 25.9 & $37-51$ \\
\hline 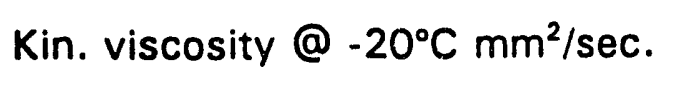 & 1.75 & $8 \max$ \\
\hline Freezing pt., ${ }^{\circ} \mathrm{C}$ & -53.5 & $-47 \max$ \\
\hline Reid vapor pressure, $\mathrm{kPa}$ & 1.4 & $20.7 \max ^{(a)}$ \\
\hline Flash pt., ${ }^{\circ} \mathrm{C}$ & 76.1 & $38 \mathrm{~min}$ \\
\hline Sulfur, wt $\%$ & 0.04 & $0.30 \max$ \\
\hline Mercaptan sulfur, wt $\%$ & 0.003 & $0.003 \max$ \\
\hline Smoke pt, $\mathrm{mm}$ & 10.8 & $25 \min$ \\
\hline Aromatics, vol\% & 44.0 & $25 \max$ \\
\hline Olefins, vol\% & 3.0 & $5 \max ^{(a)}$ \\
\hline JFTOT & Fail & $25 / 3 \mathrm{~min}$ \\
\hline Cu strip corrosion & $1 \mathrm{~A}$ & $1 \max$ \\
\hline Existent gum, $\mathrm{mg} / 100 \mathrm{ml}$ & 69.0 & $7 \max$ \\
\hline Acidity, mg KOH/g & 0.05 & $0.1 \max$ \\
\hline Net heat value, $\mathrm{MJ} / \mathrm{kg}$ & $42.2^{(b)}$ & $42.8 \mathrm{~min}$ \\
\hline $\begin{array}{l}\text { Distillation, }{ }^{\circ} \mathrm{C} \\
10 \% \\
\text { FBP }\end{array}$ & $\begin{array}{l}219.6 \\
263.3\end{array}$ & $\begin{array}{l}205 \max \\
300 \max \end{array}$ \\
\hline
\end{tabular}

(a) Applicable to Jet B, not Jet A or Jet A-1.

(b) Calculated (ASTM D-1405) 


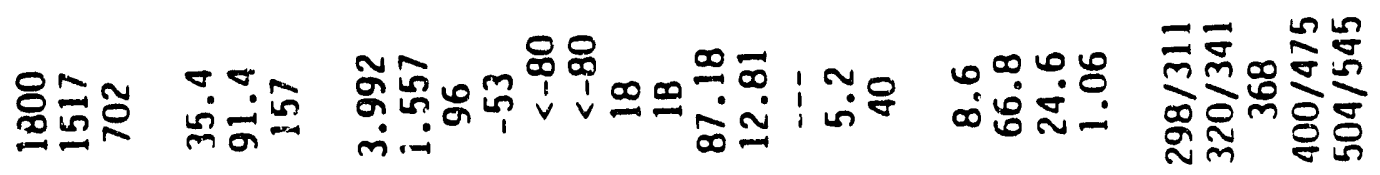

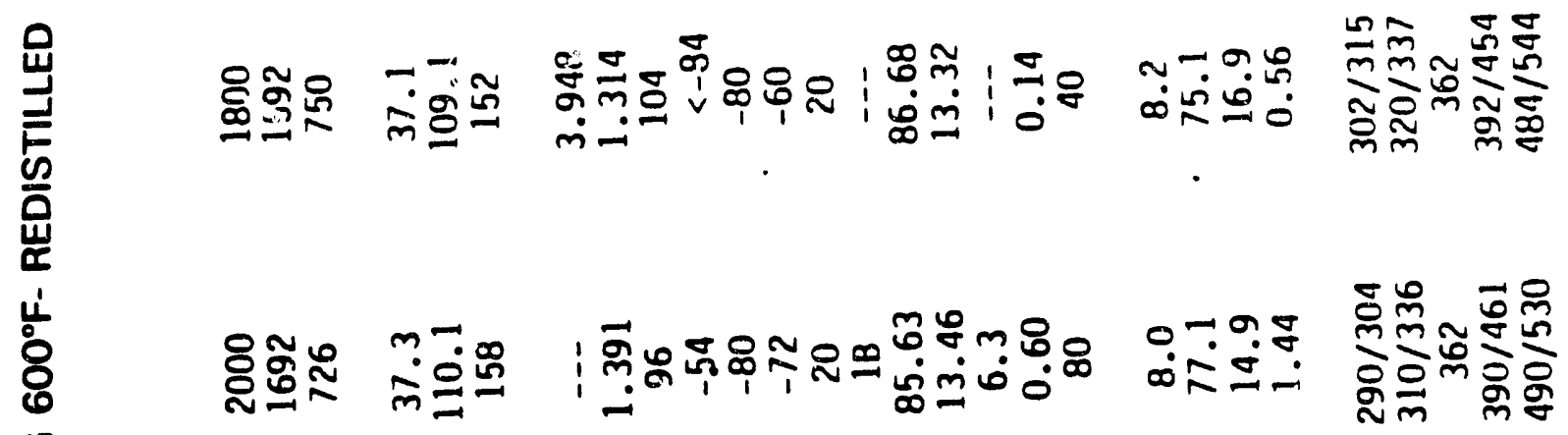

窟

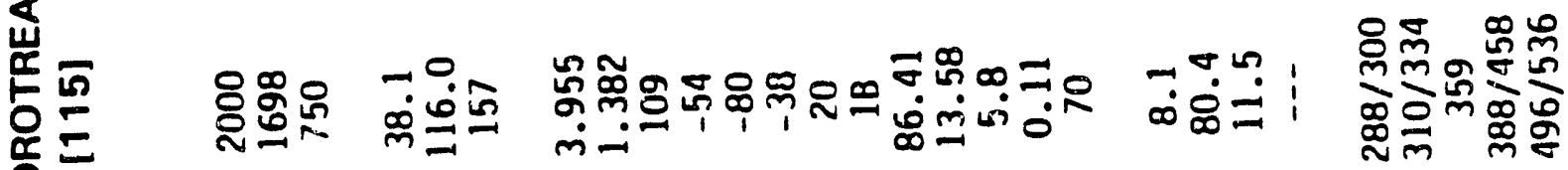

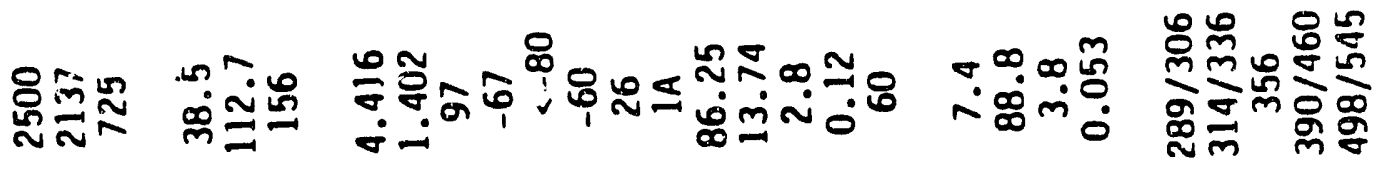

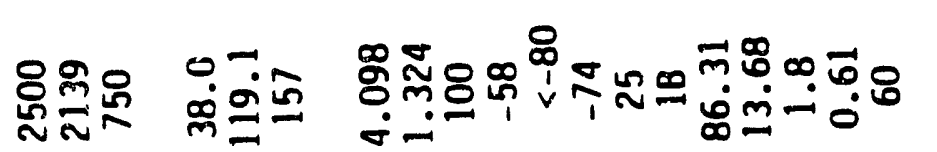

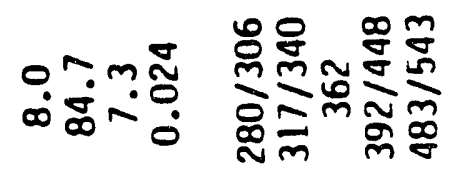

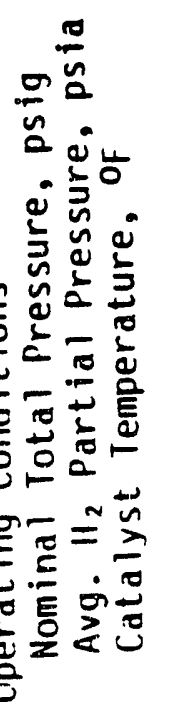
$\begin{array}{ll} & \\ & \end{array}$ 


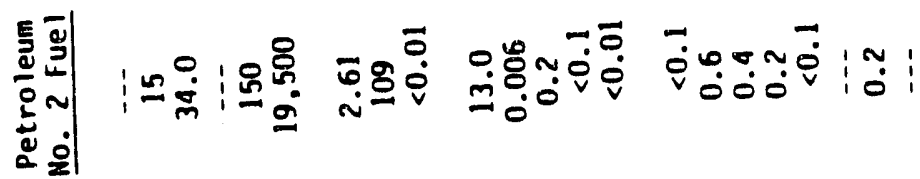

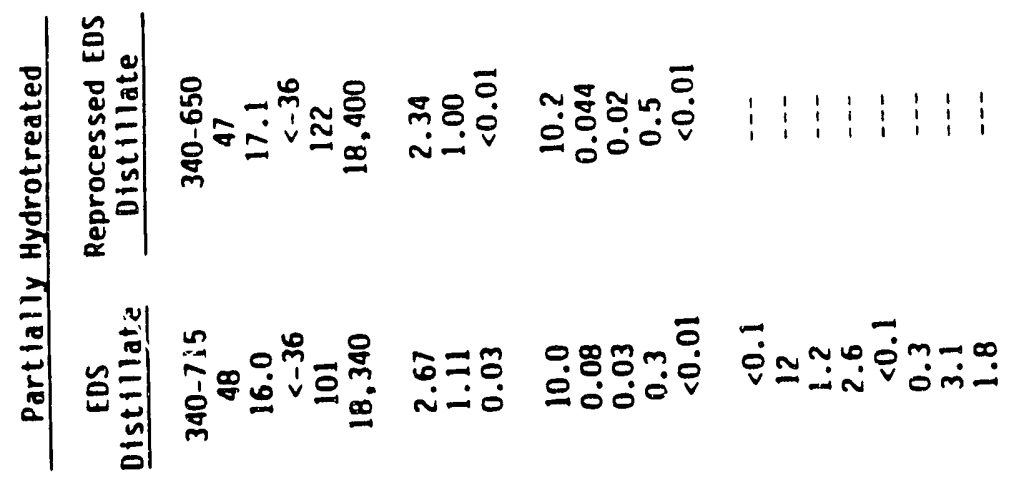

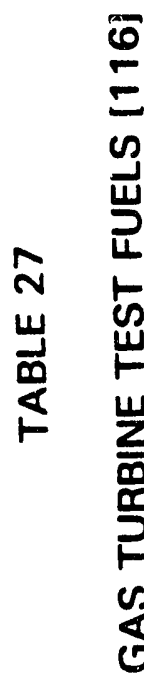

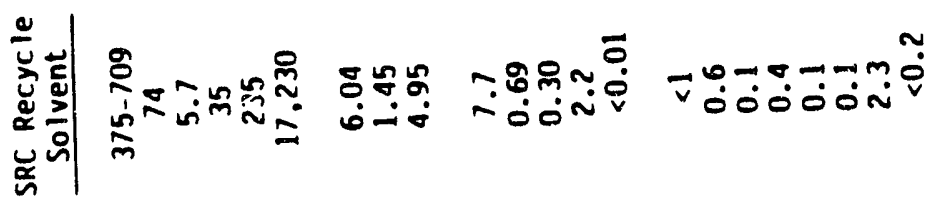

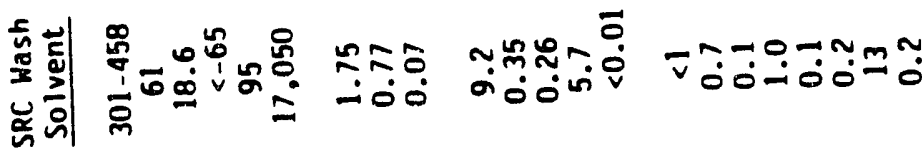

志营|

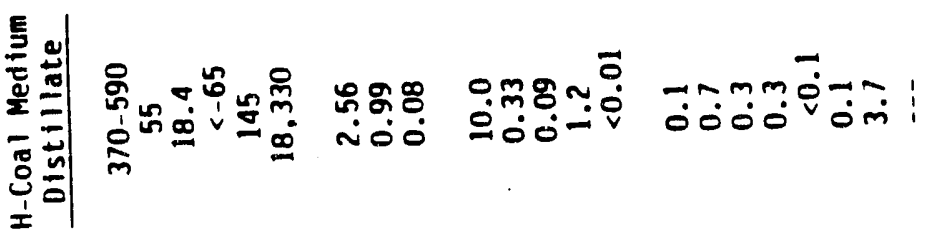

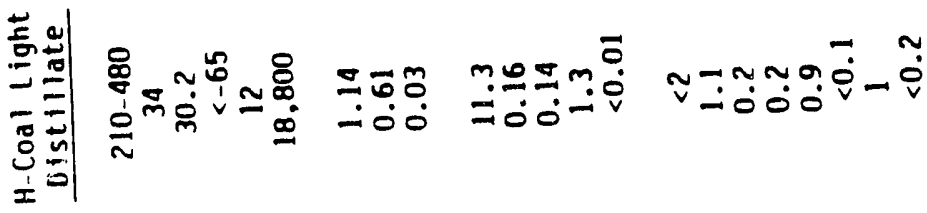

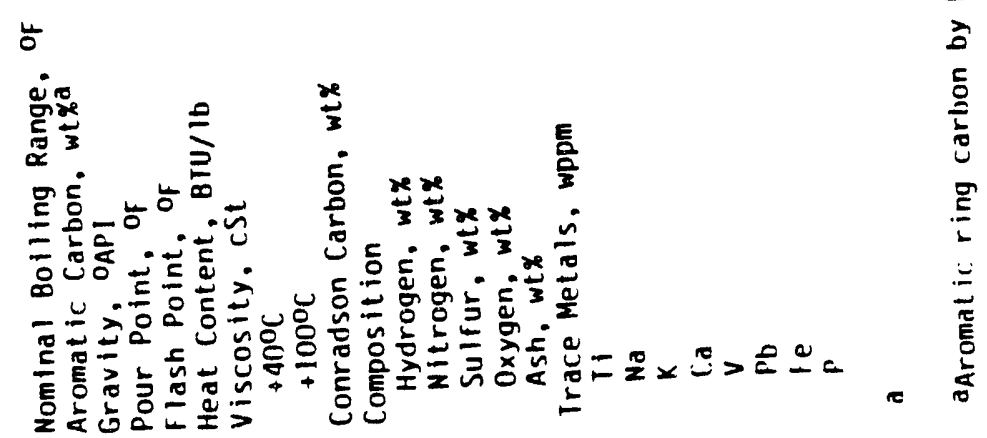




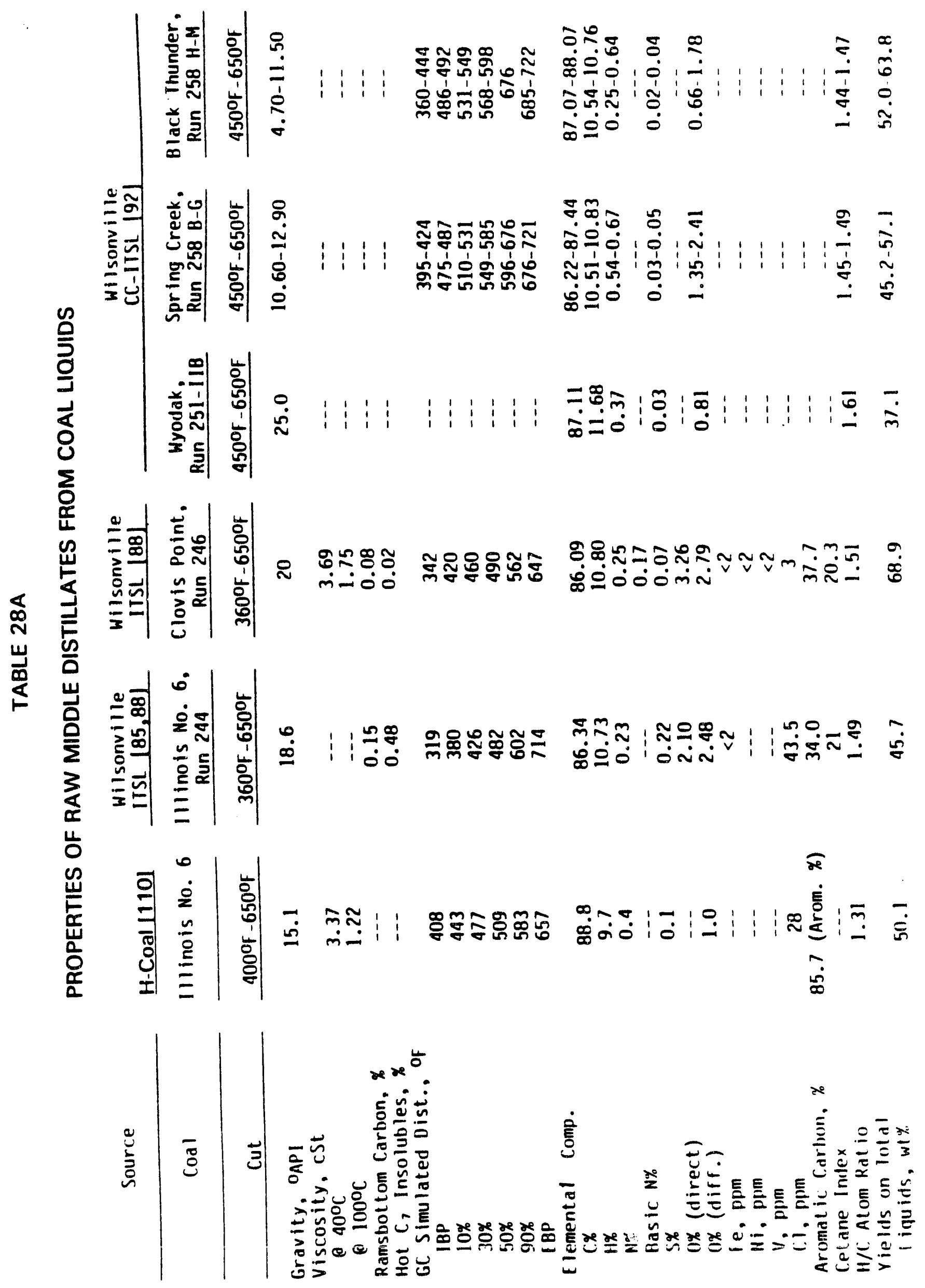


TABLE 28B

PROPERTIES OF DIESEL FUEL FRACTIONS FROM COAL LIQUIDS

OF RECENT CC-ITSL PROCESS

- Run No.

Coal

Boiling range, ${ }^{\circ} \mathrm{F}$

Properties

Gravity, ${ }^{\circ} \mathrm{API}$

Elemental, wt\%

C

H

$\mathrm{S}$

N

Bromine number, $\mathrm{g} / 100 \mathrm{~g}$

Kin. viscosity @ $100^{\circ} \mathrm{F}, \mathrm{cSt}$

Ash, wt\%

Copper strip corrosion

Acidity, $\mathrm{mg} \mathrm{KOH} / \mathrm{g}$

Flash pt, ${ }^{\circ} \mathrm{F}$

Cetane number

$90 \%$ off, ${ }^{\circ} \mathrm{F}$
16.3

88.4

10.5

0.04

0.1 .

7.4

8.97

0.02

$1 \mathrm{~A}$

$\cdots$

-..

$26.5^{(0)}$

$689^{(b)}$
Diesel Fuel No. 1 Specifications
$0.50 \max$
0.3

17

6.2

1.3-2.4

0.00

$0.01 \max$

$1 \mathrm{~A}$

0.14

255

$27.7^{(6)}$

$610^{(b)}$
$100 \mathrm{~min}$ $40 \mathrm{~min}$

$550 \max$

(a) Cetane index by ASTM D976.

(b) GC simulated. 
TABLE 28C

HYDROTREATING OF COAL-DERIVED MIDDLE DISTILLATE [108]

\begin{tabular}{|c|c|c|c|c|}
\hline Property & $\begin{array}{l}\text { ASTM } \\
\text { Method }\end{array}$ & $\begin{array}{l}\text { Hydrotreater } \\
\text { Feed } \\
\end{array}$ & $\frac{P}{\text { Low Severitt }}$ & $\frac{\text { ducts }}{\text { High Severity }}$ \\
\hline Gravity, ${ }^{\circ} \mathrm{API}$ & & 15.3 & 21.7 & 23.7 \\
\hline $\begin{array}{l}\text { Distillation, F } \\
\text { IBP/5 } \\
10 / 20 \\
30 / 40 \\
50 / 60 \\
70 / 80 \\
90 / F B P\end{array}$ & D86 & $\begin{array}{l}412 / 445 \\
463 / 496 \\
530 / 565 \\
600 / 629 \\
675 / 722 \\
785 / 823\end{array}$ & $\begin{array}{l}348 / 402 \\
422 / 464 \\
492 / 524 \\
560 / 592 \\
624 / 670 \\
740 / 788\end{array}$ & $\begin{array}{l}356 / 407 \\
427 / 459 \\
490 / 520 \\
548 / 578 \\
610 / 652 \\
708 / 794\end{array}$ \\
\hline Cetane number & D613 & 21.3 & 30.1 & 35.4 \\
\hline Cetane index & D976 & 28.2 & 32.9 & 34.4 \\
\hline Cetane index & D4737 & 24.4 & 30.7 & 32.6 \\
\hline $\begin{array}{l}\text { Hydrocarbon type, V\% } \\
\text { Aromatics } \\
\text { Olefins } \\
\text { Saturates }\end{array}$ & D1319 & $\begin{array}{c}81.7 \\
0 \\
18.3\end{array}$ & $\begin{array}{c}67.6 \\
0 \\
32.4\end{array}$ & $\begin{array}{c}42.2 \\
0 \\
57.8\end{array}$ \\
\hline $\begin{array}{l}\text { Aromatic carbon, M\% } \\
\text { Monocyclic } \\
\text { Dicyclic } \\
\text { Tricyclic }\end{array}$ & UV & $\begin{array}{c}16.22 \\
10.51 \\
3.52\end{array}$ & $\begin{array}{c}17.24 \\
5.37 \\
1.16\end{array}$ & $\begin{array}{c}11.87 \\
3.02 \\
0.67\end{array}$ \\
\hline $\begin{array}{l}\text { Elemental Analysis, M\% } \\
\text { Carbon } \\
\text { Hydrogen } \\
\text { Sulfur } \\
\text { Nitrogen }\end{array}$ & $\begin{array}{l}\text { D1378 } \\
\text { MOD } \\
\text { D2622 } \\
\text { D4629 }\end{array}$ & $\begin{array}{l}89.19 \\
10.39 \\
0.05 \\
0.394\end{array}$ & $\begin{array}{l}88.15 \\
11.64 \\
0.04 \\
0.008\end{array}$ & $\begin{array}{l}87.27 \\
12.00 \\
<0.01 \\
0.002\end{array}$ \\
\hline Viscosity, cSt @ $40^{\circ} \mathrm{C}$ & D445 & 6.72 & 4.47 & 3.95 \\
\hline Accel. Stab., $\mathrm{mg} / 100 \mathrm{ml}$ & D2274 & --. & 3.26 & 1.60 \\
\hline
\end{tabular}




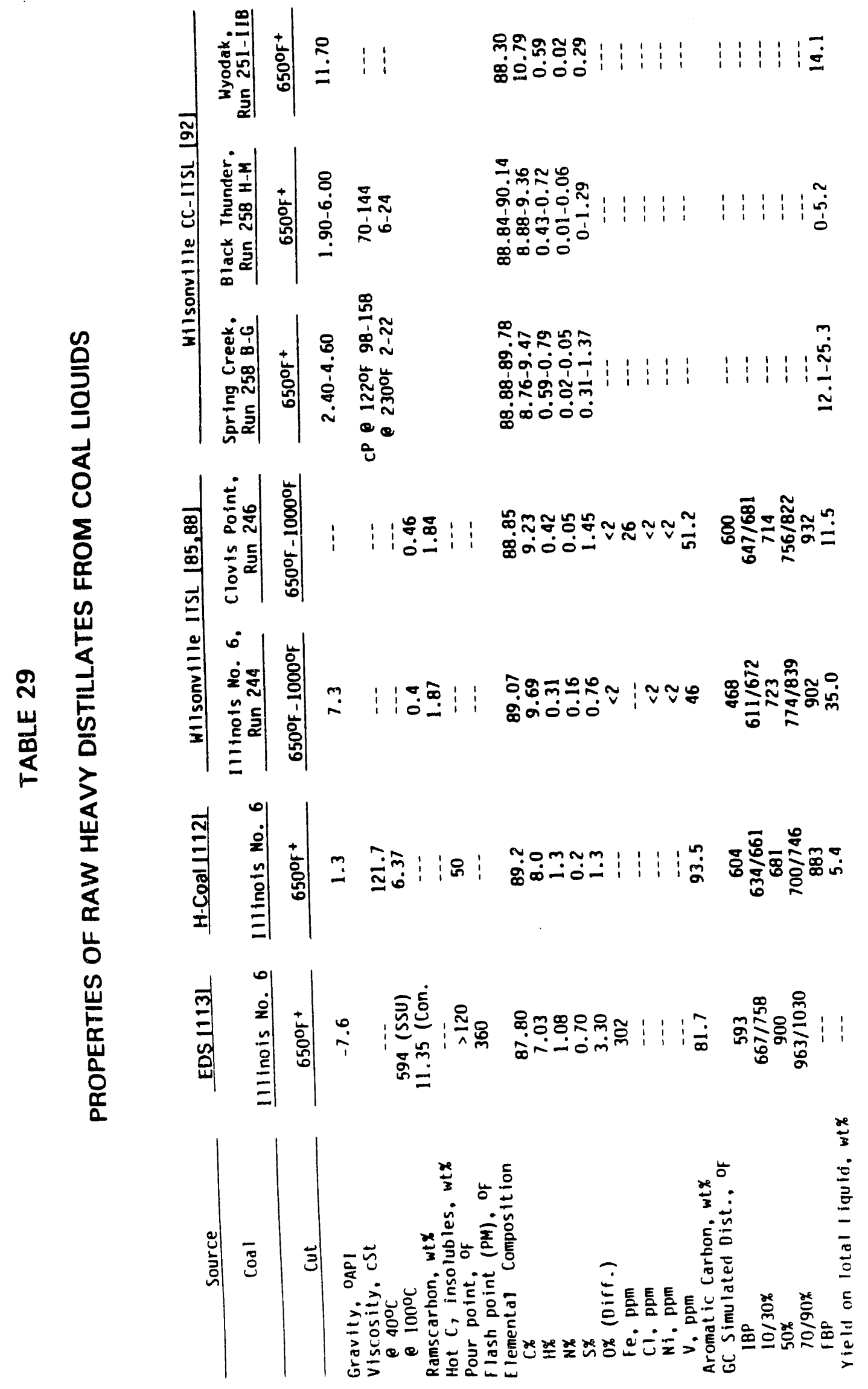


TABLE 30

HYDROCRACKING OF H-COAL GAS OIL [129]

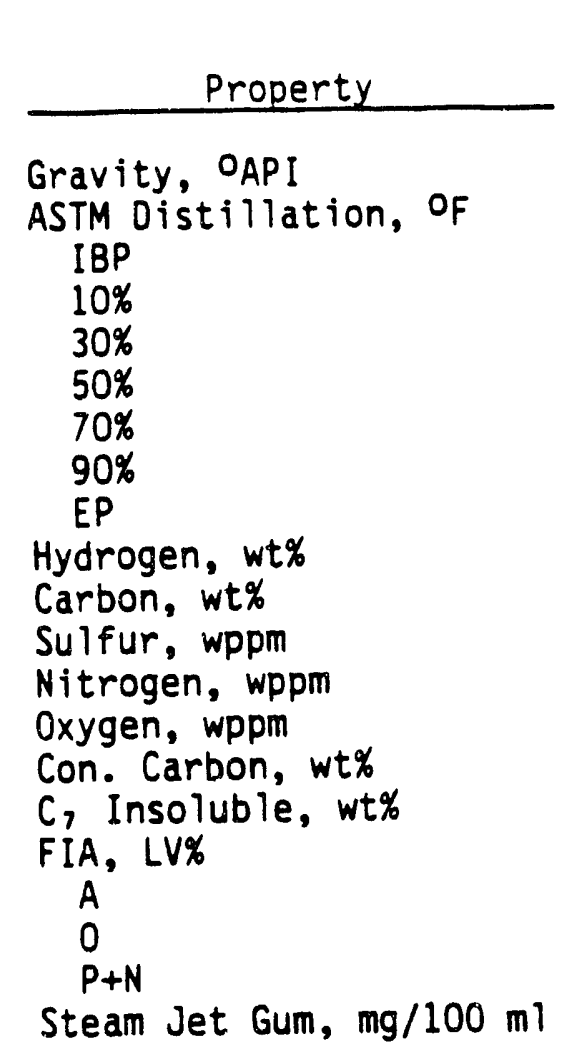

\begin{tabular}{c} 
Feed \\
\hline 10.8 \\
435 \\
505 \\
535 \\
571 \\
627 \\
715 \\
850 \\
9.36 \\
89.32 \\
700 \\
3900 \\
5700 \\
0.08 \\
0.06 \\
85.5 \\
0 \\
14.5 \\
447
\end{tabular}

First-Stage
Product

19.2

315

458

498

530

573

660

748

10.69

88.41

1.4

4.8

530.4

69.7

0

30.3

30.3
Secono-Stage

Product

$49.5-51.0$

$61-70$

143-158

193-204

229-242

280-293

$335-340$

$379-459$
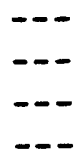

-.-

23.6-28.3

0

71.7-76.4 
TABLE 31

HYDROTREATING TESTS OF COAL LIQUIDS

(Coal liquids listed in increasing order of hydrotreating difficulty) [84]

\begin{tabular}{|c|c|c|c|c|c|c|}
\hline $\begin{array}{l}\text { LHSV } \\
\mathrm{H}_{2} \text { Pressure, psia }\end{array}$ & $\begin{array}{r}0.5 \\
2300\end{array}$ & $\begin{array}{r}1.0 \\
2300\end{array}$ & $\begin{array}{r}1.5 \\
2300\end{array}$ & $\begin{array}{l}1.5 \\
: 800\end{array}$ & $\therefore .50$ & $\begin{array}{l}1.5 \\
900\end{array}$ \\
\hline $\begin{array}{l}\text { Wyodak CTSL B (EP-634OF) } \\
\text { Temperature, OF } \\
\mathrm{H}_{2} \text { Consumption, SCF/B } \\
\text { Product Nitrogen, DPM } \\
\text { Product Aromatics, LV\% }\end{array}$ & $\begin{array}{r}680 \\
775 \\
0.5 \\
3\end{array}$ & $\begin{array}{r}705 \\
725 \\
<0.3 \\
3\end{array}$ & $\begin{array}{r}715 \\
725 \\
<0.3 \\
4\end{array}$ & $\begin{array}{r}715 \\
690 \\
<0.3 \\
6\end{array}$ & $\begin{array}{r}715 \\
450 \\
<0.3 \\
14\end{array}$ & $\begin{array}{r}715 \\
180 \\
<0.3 \\
25\end{array}$ \\
\hline Wyodak $H-C O a l \&\left(E P=603^{\circ} F\right)^{a}$ & & & & & & \\
\hline $\begin{array}{l}\text { Illinois } \mathrm{H} \text {-Coal B } \quad(E P=5890 F) \\
\text { Temperature, OF } \\
\mathrm{H}_{2} \text { Consumption, SCF } / 8 \\
\text { Product Nitrogen, DPm } \\
\text { Product Aromatics, LV\% }\end{array}$ & & $\begin{array}{r}750 \\
2000 \\
<0.3 \\
2\end{array}$ & $\begin{array}{r}750 \\
1950 \\
<0.3 \\
5\end{array}$ & & & \\
\hline
\end{tabular}

Wyodak ITSL B (EP=7310 F) Temperature, OF 683

$\mathrm{H}_{2}$ Consumption, SCF/B $\quad 1650$

Product Nitrogen, Dpm $\quad<0.3$

Product Aromatics, LV\% 14

Wyodak $H$-COal A (EP=7850F)

Temperature, of

$\mathrm{H}_{2}$ Consumption, SCF/B

Product Nitrogen, ppm

Product Aromatics, LV\%

Illinois ITSL $B \quad\left(E P=763^{\circ} \mathrm{F}\right)$

Temperature, ${ }^{\circ} \mathrm{F}$

$\mathrm{H}_{2}$ Consumption, SCF/B

Product Nitrogen, Ppm

Product Aromatics, LV\%

Illinois $\mathrm{H}$-COal A (EP=765\% $)$

Temperature, of

$\mathrm{H}_{2}$ Consumption, SCF/B

Product Nitrogen, ppm

Product Aromatics, LV\%

Wyodak CTSL A (EP=8580F)

Temperature, ${ }^{\circ} \mathrm{F}$

$\mathrm{H}_{2}$ Consumption, SCF/B

Product Nitrogen, PDm

Product Aromatics, LV\%

$750 \quad 750$

1225950

$<0.3<0.3$

313

Illinois ITSL A (EP $\left.=859^{\circ} \mathrm{F}\right)^{\mathrm{a}}$

Wyodak ITSL A (EP=9410F)

Temperature, ${ }^{\circ}$

$\mathrm{H}_{2}$ Consumption, SCF/B

Product Nitrogen, ppm

Product Aromatics, LV\%

710

1600

$<0.2$

10

750

2150

$<0.3$

2

i30

1400

$<0.2$

26

745

950

0.4

38

745

600

58

750

825

0.3

21

$\begin{array}{rrr}750 & 750 & 750 \\ 1600 & 1275 & 825 \\ 0.3 & 10 & 50 \\ 20 & 35 & 45\end{array}$

a Rank estimated from tests at other conditions 1831 . 


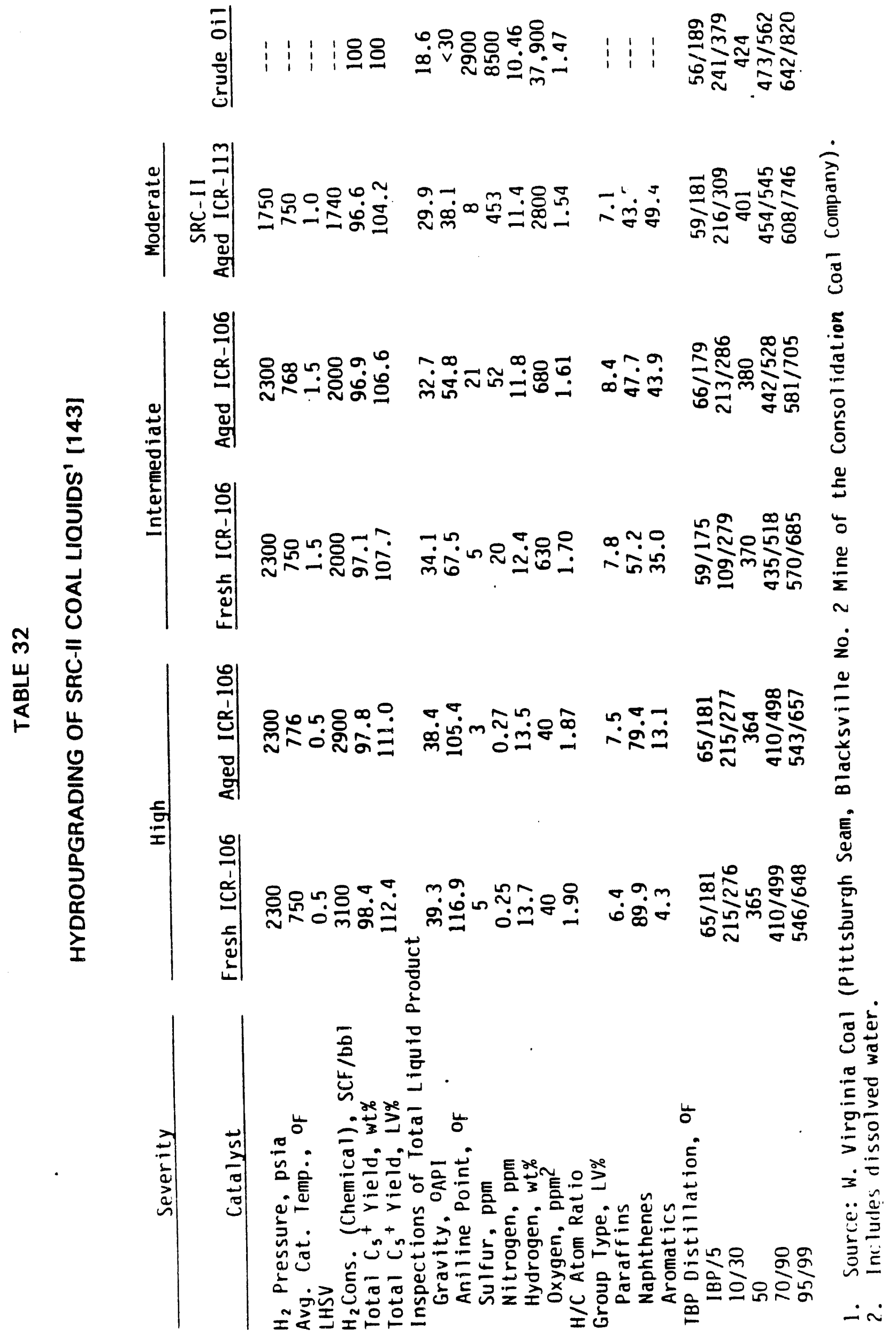


TABLE 33

HIGH SEVERITY HYDROTREATING YIELDS AND HYDROGEN CONSUMPTIONS [104]

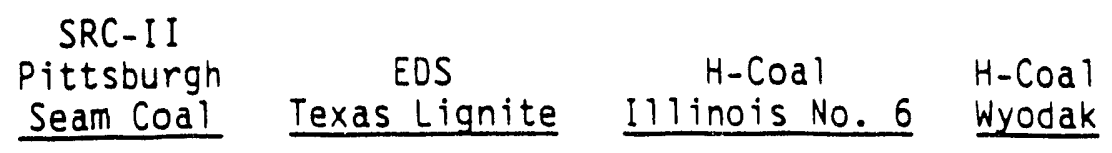

Yields, LV\%

$\mathrm{C}_{5}-180^{\circ} \mathrm{F}$

$180^{\circ} \mathrm{F}-250^{\circ} \mathrm{F}$

$250 F-600{ }^{\circ} F$

Total $C_{5}-600^{\circ} \mathrm{F}$

5

16

$\frac{85}{106}$

10

18

$\frac{73}{101}$

4

10

$18 \quad 19$

$\frac{84}{106} \quad \frac{72}{101}$

Yields for Jet Fuel Production Naphtha, LV\% 25

Jet $A$, LV\%

85

29

21

29

74

88

75

Yields for Diesel Production Naphtha, LV\%

25

Diesel fue $1, L V \%$

87

29

77

21

29

90

77

Hydrogen consumption,

scf/bbl feed

3100

1800

2150

1230

TABLE 34

HIGH SEVERITY HYDROTREATING PRODUCT INSPECTIONS [104]

\begin{tabular}{|c|c|c|c|c|c|}
\hline & $\begin{array}{c}\text { SRC-II } \\
300^{\circ} \mathrm{F}-500^{\circ} \mathrm{F} \\
\end{array}$ & $\begin{array}{l}\text { SRC-II } \\
350^{\circ} \mathrm{F}^{+} \\
\end{array}$ & EDS & $\begin{array}{c}\text { H-Coal } \\
\text { Illinois No. } 6 \\
\end{array}$ & $\begin{array}{l}\text { H-Coal } \\
\text { Wyodak } \\
\end{array}$ \\
\hline $\begin{array}{l}\text { Gravity, OAPI } \\
\text { Boiling Range, of } \\
\text { Aniline Point, of } \\
\text { Freeze Point, of } \\
\text { Pour Point, of } \\
\text { Cloud Point, of } \\
\text { Sulfur, ppm } \\
\text { Nitrogen, ppm } \\
\text { Smoke Point, mm } \\
\text { Cetane Number }\end{array}$ & $\begin{array}{c}34.9 \\
300-500 \\
121 \\
<-94\end{array}$ & $\begin{array}{c}32.8 \\
350+ \\
129 \\
-62 \\
-55\end{array}$ & $\begin{array}{c}35.0 \\
300-600 \\
125 \\
-59 \\
<-80 \\
-72 \\
0.7 \\
0.3 \\
20-23\end{array}$ & $\begin{array}{l}37.8 \\
250+ \\
122 \\
-51\end{array}$ & $\begin{array}{c}39.7 \\
250+ \\
132 \\
-60\end{array}$ \\
\hline
\end{tabular}




\section{TABLE 35}

TYPICAL NAPHTHAS FROM HYDROTREATING OF COAL-DERIVED OILS [83]

\begin{tabular}{|c|c|c|c|}
\hline Feed & $\underline{S R C-I I}$ & $\begin{array}{l}\text { Illinois } \\
\mathrm{H} \text {-Coal }\end{array}$ & $\begin{array}{l}\text { Wyodak } \\
\mathrm{H} \text {-Coal } \\
\end{array}$ \\
\hline $\begin{array}{c}\mathrm{C}_{5}-180^{\circ} \mathrm{F} \text { Naphtha } \\
\text { Gravity, OAPI } \\
\text { Group Type, LV\% } \\
\text { Paraffins } \\
\text { Naphthenes } \\
\text { Aromatics }\end{array}$ & $\begin{array}{r}61 \\
31 \\
64 \\
5\end{array}$ & $\begin{array}{r}36 \\
59 \\
5\end{array}$ & $\begin{array}{r}46 \\
52 \\
2\end{array}$ \\
\hline $\begin{array}{l}\text { 1800F-3500F Naphtha } \\
\text { Gravity, OAPI } \\
\text { Group Type, LV\% } \\
\text { Paraffins } \\
\text { Naphthenes } \\
\text { Aromatics }\end{array}$ & $\begin{array}{r}48 \\
9 \\
78 \\
13\end{array}$ & $\begin{array}{r}47 \\
9 \\
76 \\
15\end{array}$ & $\begin{array}{r}50 \\
18 \\
74 \\
8\end{array}$ \\
\hline
\end{tabular}

TABLE 36

PROPERTIES OF SELECTED NAPHTHAS DERIVED FROM SHALE OIL AND WYODAK H-COAL [83]

\begin{tabular}{|c|c|c|}
\hline & $\begin{array}{l}\text { Hydrotreated } \\
\text { Shale 0il } \\
\end{array}$ & $\begin{array}{l}\text { Hydrotreated } \\
\text { Wyodak H-Coal }\end{array}$ \\
\hline $\begin{array}{l}\mathrm{C}_{5}-180^{\circ} \mathrm{F} \\
\text { Gravity, OAPI }\end{array}$ & 85 & 66 \\
\hline Octane No., F-1 Clear & 70 & 79 \\
\hline $\begin{array}{l}\text { Group Type, LV\% } \\
\text { Paraffins } \\
\text { Naphthenes } \\
\text { Aromatics }\end{array}$ & $\begin{array}{r}90 \\
9 \\
1\end{array}$ & $\begin{array}{r}42 \\
57 \\
1\end{array}$ \\
\hline $\begin{array}{l}i C_{5} / n C_{6} \\
i C_{6} / n C_{6}\end{array}$ & $\begin{array}{l}0.7 \\
1.2\end{array}$ & $\begin{array}{l}0.4 \\
0.6\end{array}$ \\
\hline $\begin{array}{l}1800 \mathrm{~F}-300^{\circ} \mathrm{F} \\
\text { Gravity, OAPI }\end{array}$ & 58 & 50 \\
\hline Octane No., F-1 Clear & 51 & 56 \\
\hline $\begin{array}{l}\text { Group Type, LV\% } \\
\text { Paraffins } \\
\text { Naphthenes } \\
\text { Aromatics }\end{array}$ & $\begin{array}{l}51 \\
39 \\
10\end{array}$ & $\begin{array}{r}18 \\
80 \\
2\end{array}$ \\
\hline
\end{tabular}


PROPERTIES OF NAPHTHA PRODUCTS FROM SRC-II LIQUIDS HYDROTREATED AT INTERMEDIATE AND HIGH SEVERITIES [144]

\author{
$\frac{\text { Severity }}{\text { Catalyst Condition }}$ \\ Inspections, $C_{5}-180^{\circ} \mathrm{F}$ Product \\ Gravity, OAPI \\ Group Type, LV\% \\ Paraffins \\ Naphthenes \\ Aromatics \\ olefins \\ Octane Number \\ F-1 Clear \\ F-2 Clear \\ Inspections, $180^{\circ} \mathrm{F}-300^{\circ} \mathrm{F}$ Product \\ Gravity, OAPI \\ Aniline Point, OF \\ Nitrogen, ppm \\ Oxygen, ppm \\ Group Type, LV\% \\ Paraffins \\ Naphthenes \\ Aromatics \\ Octane Number \\ $\mathrm{F}-1$ Clear \\ F-2 Clear
}

$\frac{\text { High }}{\text { Fresh Aged }} \quad \frac{\text { Intermediate }}{\text { Fresh Aged }}$

\begin{tabular}{cccc}
\hline & & & \\
& & & \\
60.7 & 58.6 & 59.9 & 59.9 \\
31.2 & 26.2 & 30.0 & 32.8 \\
65.4 & 66.3 & 62.3 & 58.0 \\
3.4 & 7.4 & 7.7 & 9.1 \\
& 0.1 & & 0.1 \\
81.1 & 82.2 & 81.5 & 81.1 \\
77.0 & & 77.4 & \\
& & & \\
51.6 & 49.9 & 49.0 & 48.4 \\
108.8 & 96.8 & 87.4 & 79.2 \\
0.1 & 0.1 & 2.1 & 2.0 \\
$<20$ & $<20$ & 280 & 300 \\
7.1 & 10.1 & 10.1 & 11.3 \\
90.1 & 79.5 & 75.8 & 69.3 \\
2.8 & 10.4 & 14.1 & 19.4 \\
66.0 & 68.4 & 69.2 & 72.0 \\
66.0 & 66.9 & 67.3 & 68.5
\end{tabular}




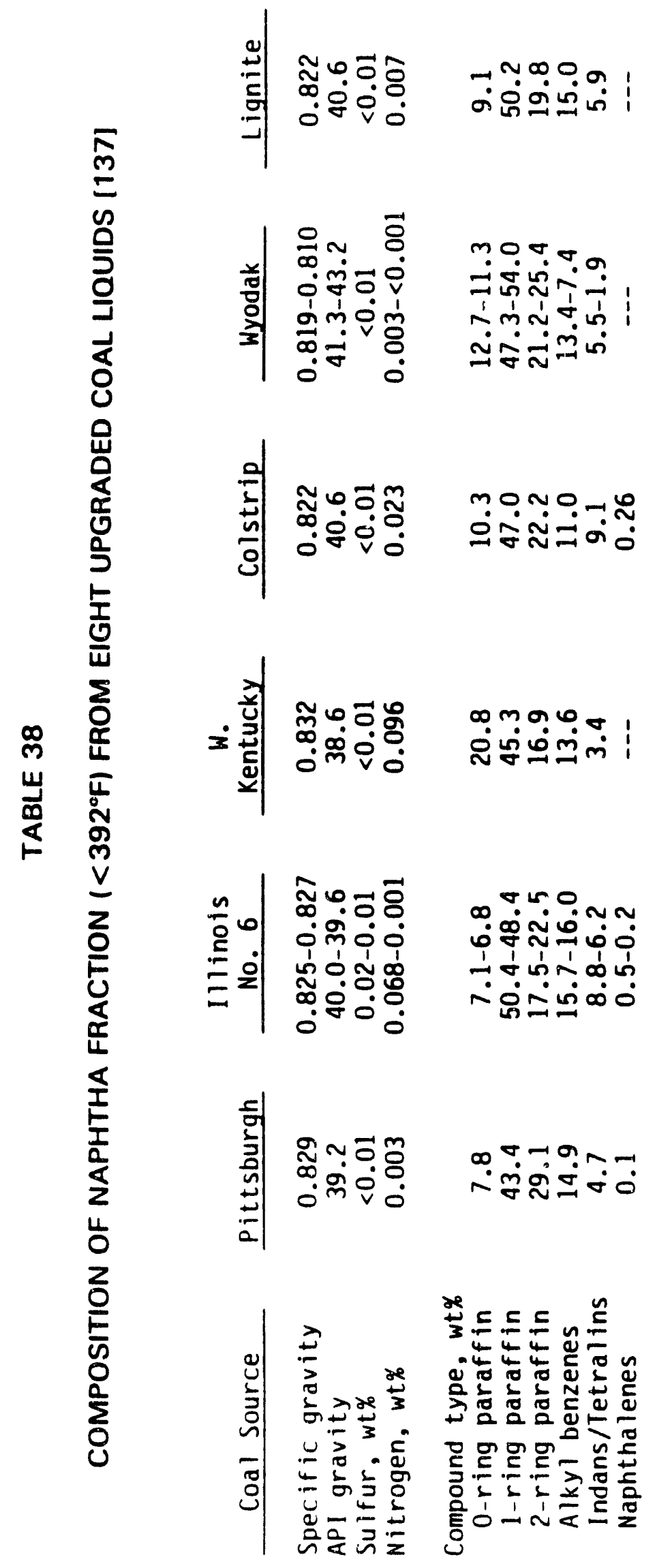




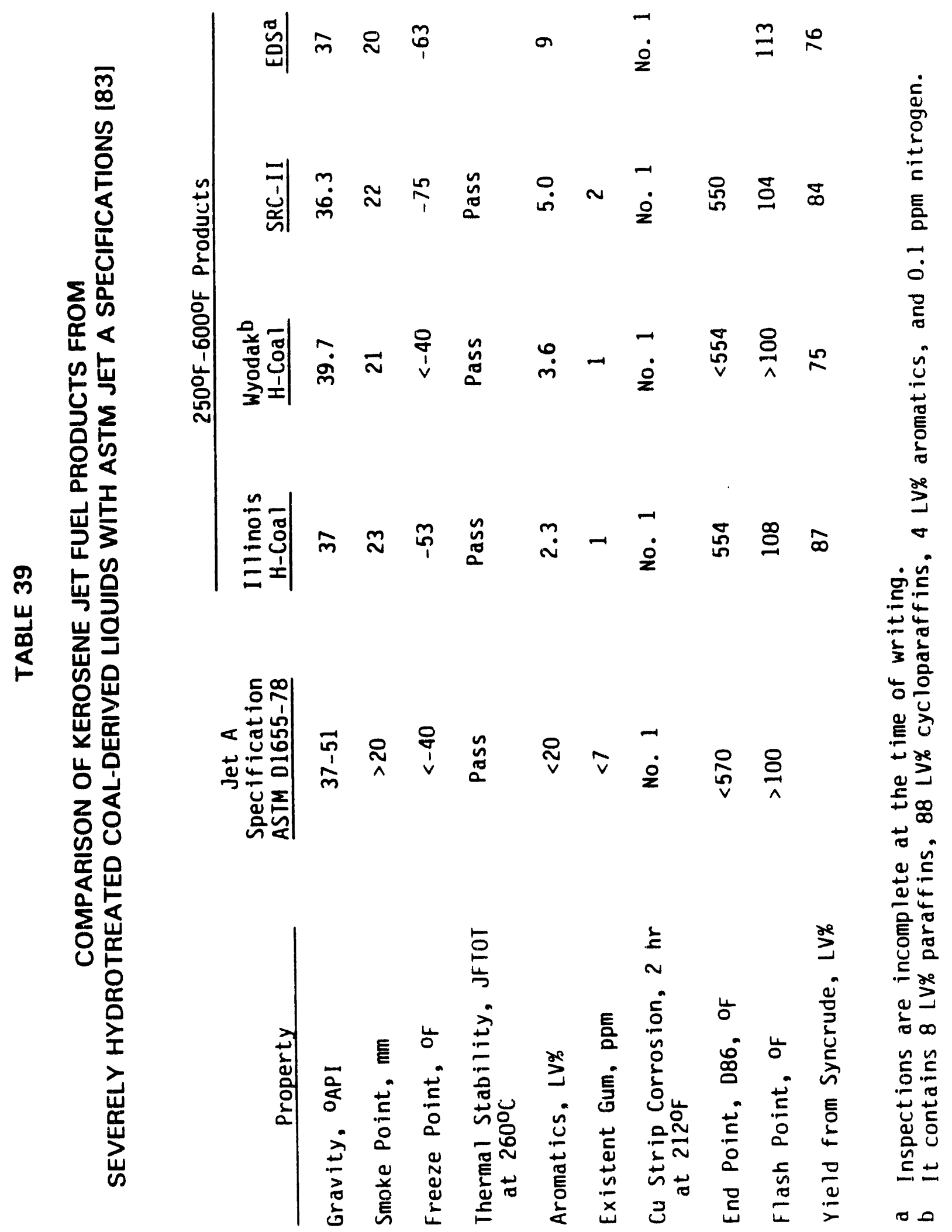



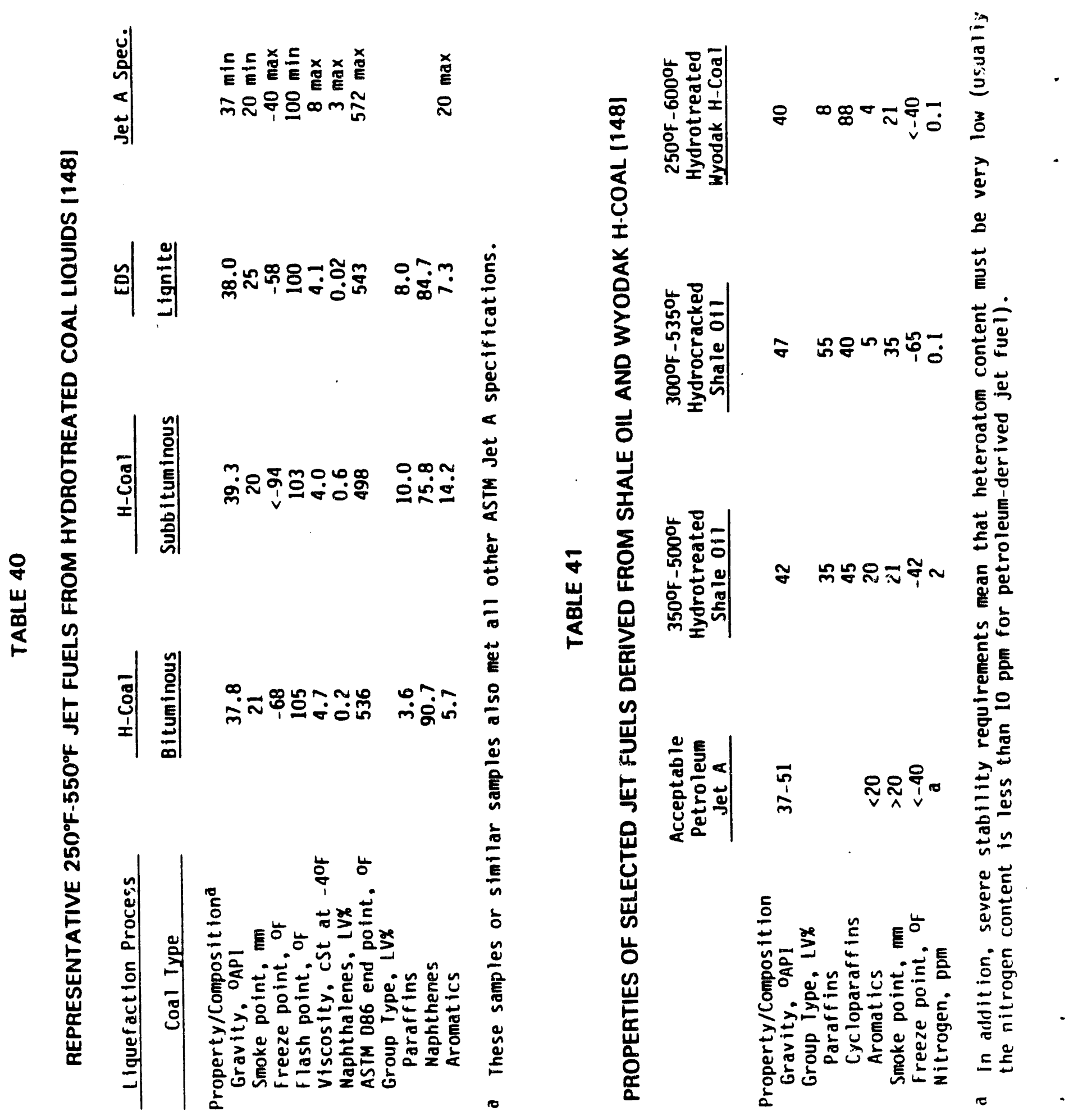


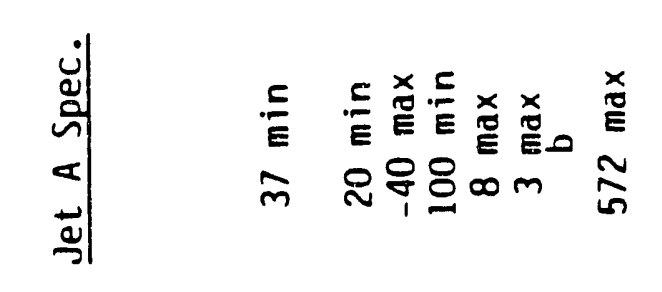

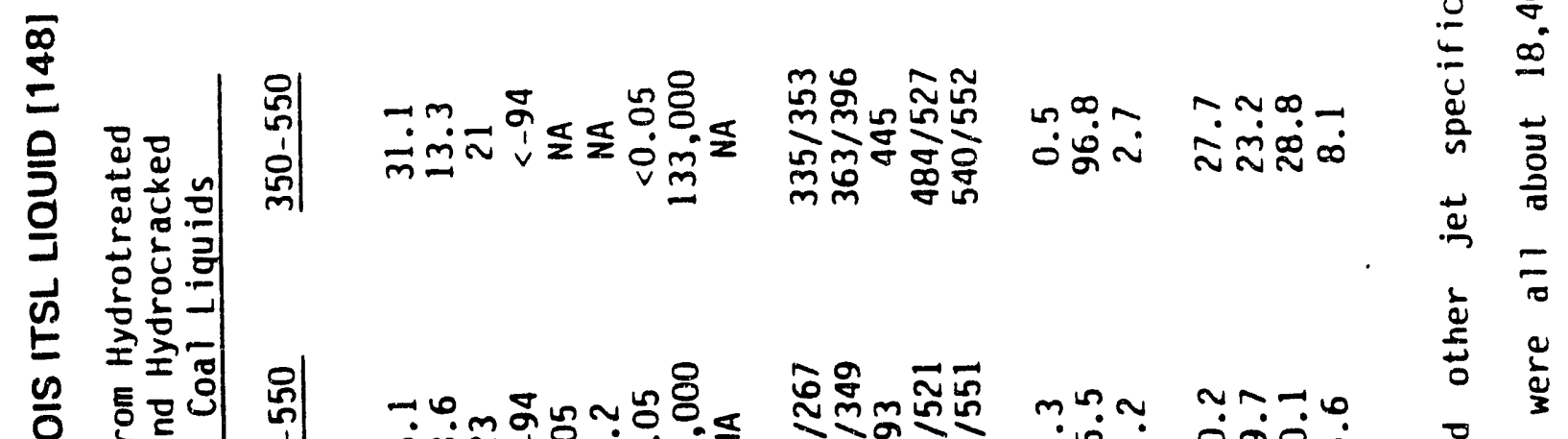

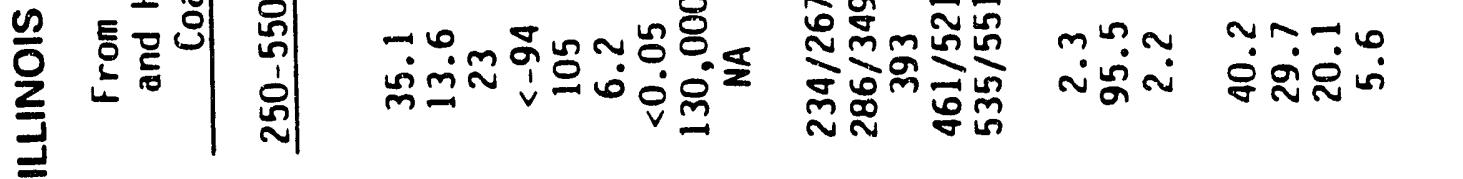
(n)

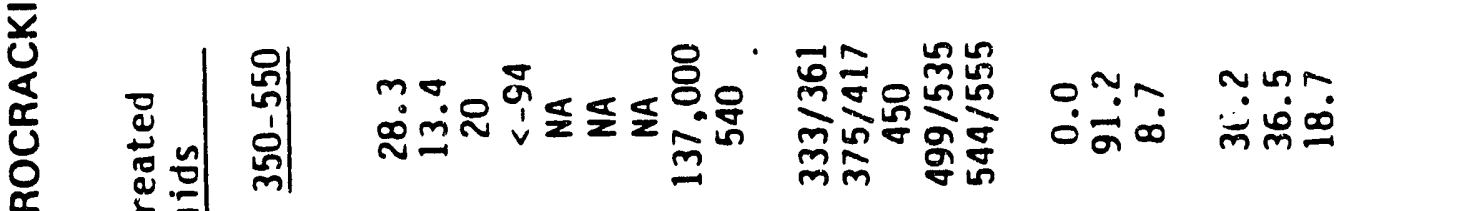

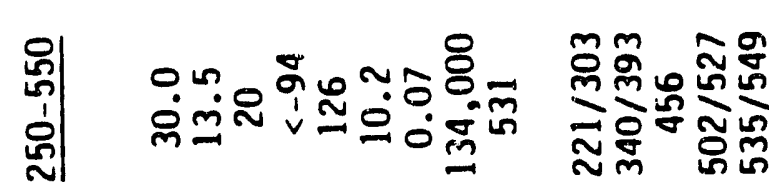

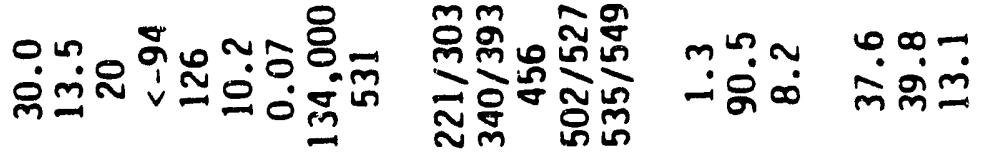

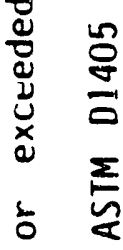

$$
\text { 㟶 }
$$

2

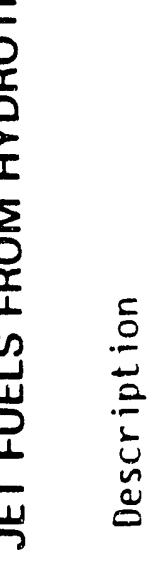




\section{TABLE 43}

\section{DETAILED ANALYSES OF NARROW-BOILING FRACTIONS OF JET FUEL FRCM HYDROTREATED WYODAK ITSL LIQUID [148]}

\begin{tabular}{l} 
Boiling Range, of \\
\hline Inspections \\
\hline Gravity, OAPI \\
Hydrogen, wt\% \\
Smoke point, mm \\
Freeze point, OF \\
Group type, LV\% \\
Total Paraffins \\
Total Naph thenes \\
Total Aromatics \\
Naphthene Distribution \\
$1-$ Ring \\
2-Rings \\
3-Rings \\
Aromatic Distribution \\
1-Ring \\
2-Rings Total \\
1 -Arom. Ring \\
2-Arom. Rings \\
3-Rings Total \\
1-Arom. Ring
\end{tabular}

$400-450$

31.3

13.3

22

3.9

81.4

14.7

34.2

42.7

4.4

10.5

3.3

0.8
$450-500$

500-550

26.5

13.0

15

22.5

12.8

15

$-56$

0.0

0.0

85.2

14.8

85.0

15.0

30.1

36.3

18.8

16.5

29.3

39.2

11.4

12.0

2.4

0.8

1.3

1.0

0.7 


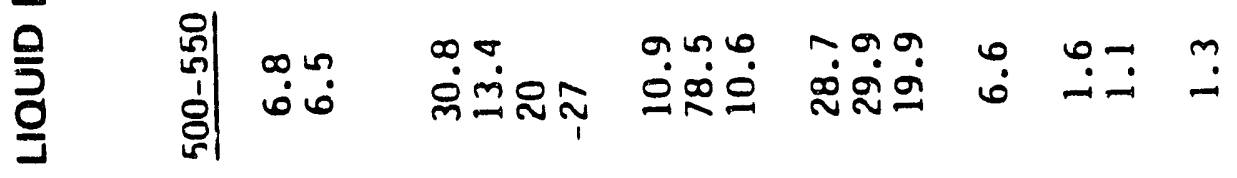

ज़

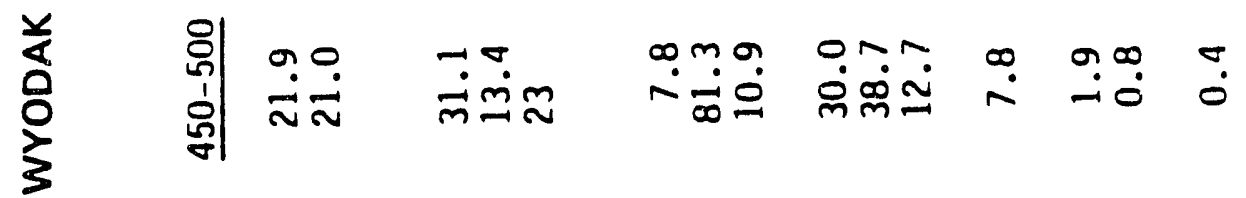

咞

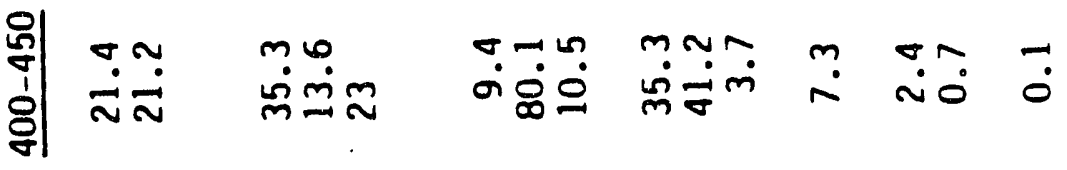

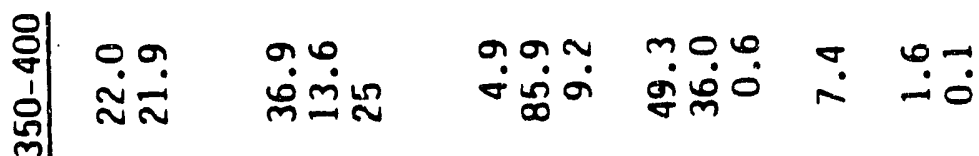

状

뜩

4

鯜

Z

兵

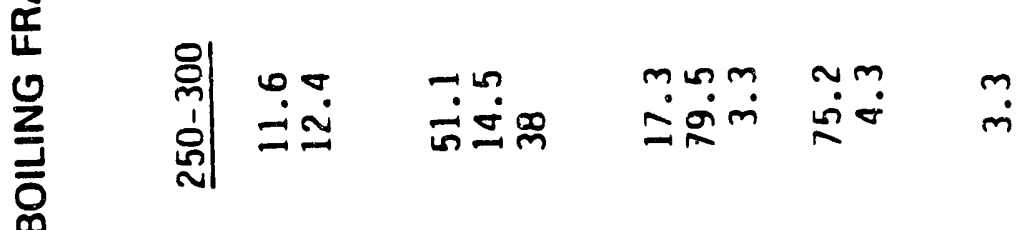

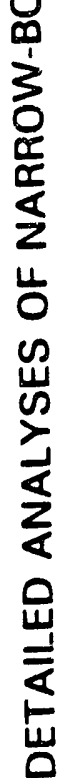

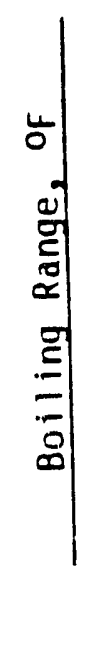

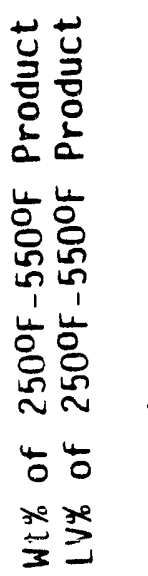

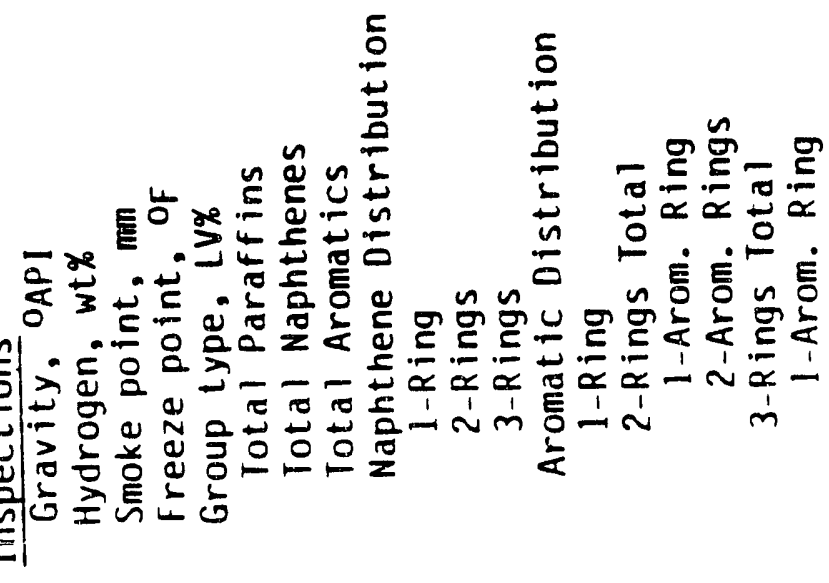




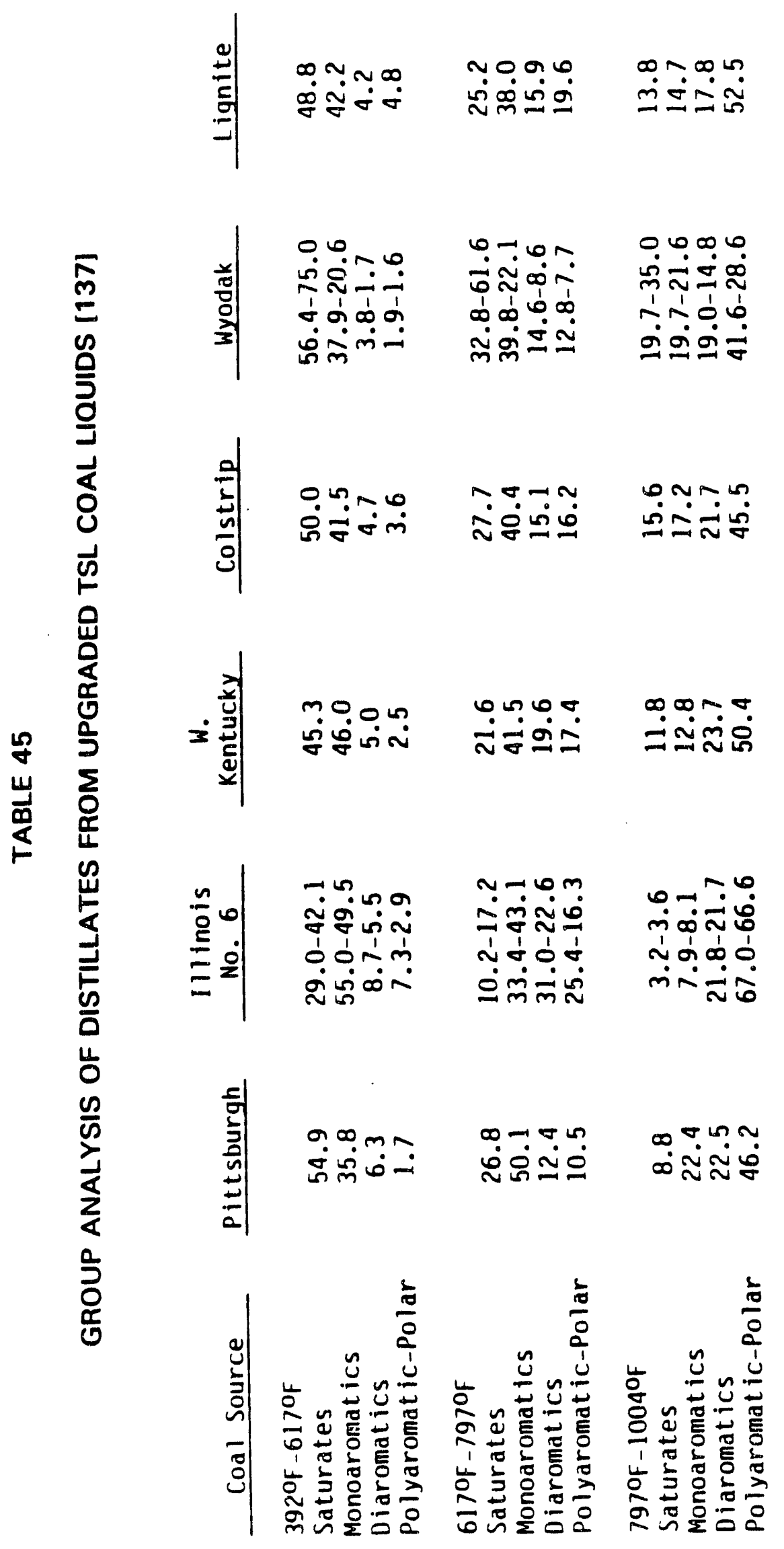




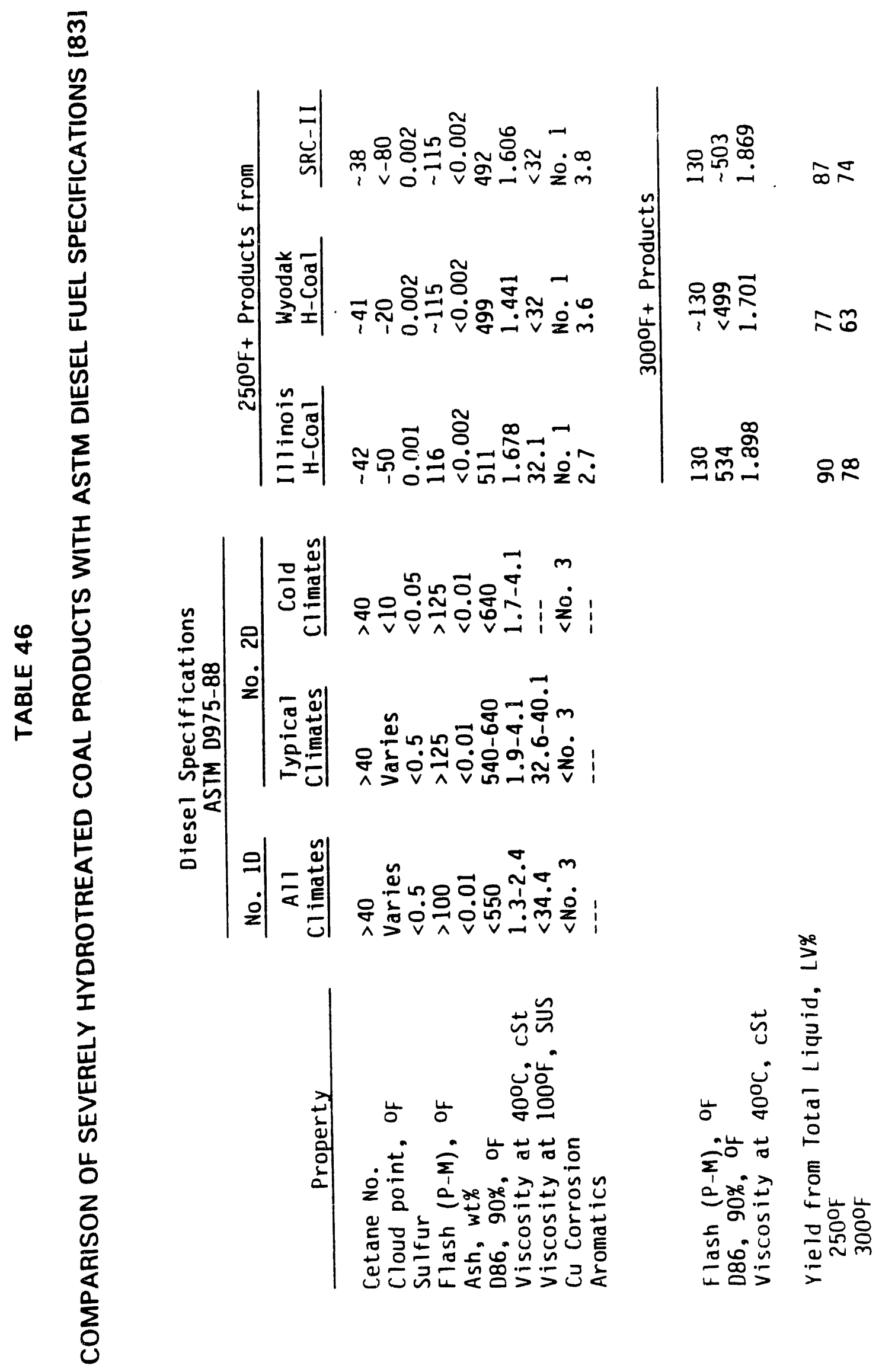




\section{TABLE 47}

\section{PROPERTIES OF SELECTED DIESEL FUELS DERIVED FROM \\ SHALE OIL AND WYODAK H-COAL [83]}

\begin{tabular}{|c|c|c|c|c|}
\hline & $\begin{array}{c}\text { Typical } \\
\text { Diesel } \\
\text { from } \\
\text { Petroleum } \\
\end{array}$ & $\begin{array}{l}350^{\circ} \mathrm{F}-650^{\circ} \mathrm{F} \\
\text { Hydrotreated } \\
\text { Shale 0il } \\
\end{array}$ & $\begin{array}{c}3500 \mathrm{~F}-600 \mathrm{~F} \\
\text { Hydrotreated } \\
\text { Shale 0il } \\
\text { Coker Distillate } \\
\end{array}$ & $\begin{array}{c}300^{\circ} \mathrm{F}+ \\
\text { Hydrotreated } \\
\text { Wyodak } \mathrm{H} \text {-Coa } 1\end{array}$ \\
\hline Gravity, 'API & $>30$ & 38 & 41 & 36 \\
\hline Cetane No. & $>40$ & 46 & 48 & 40 \\
\hline Pour point, of & $<+15$ & -5 & -20 & -45 \\
\hline $\begin{array}{l}\text { Group type, LV\% } \\
\text { Paraffins } \\
\text { Naphthenes } \\
\text { Aromatics }\end{array}$ & . & $\begin{array}{l}37 \\
44 \\
19\end{array}$ & $\begin{array}{l}41 \\
41 \\
18\end{array}$ & $\begin{array}{r}9 \\
89 \\
2\end{array}$ \\
\hline Nitrogen, ppm & & 350 & 350 & $<1$ \\
\hline
\end{tabular}


TABLE 48

PROPERTIES OF $250^{\circ} \mathrm{F}^{+}$FRACTIONS FROM ITSL LIQUIDS

(Hydrotreated with ICR-106 catalyst at 0.5 LHSV, 683 $\left.{ }^{\circ} \mathrm{F}-730^{\circ} \mathrm{F}\right)[132,152]$

\begin{tabular}{l} 
Coal Source \\
\hline Product Inspections \\
Gravity, OAPI \\
Aniline Point, of \\
Smoke Point, mm \\
Cetane Number \\
Pour Point, of \\
Cloud Point, OF \\
Freeze Point, of \\
Flash Point, of \\
Viscosity, CSt at 1040F \\
Group Type, LV\% \\
Paraffins \\
Naphthenes \\
Aromatics \\
Carbon, wt\% \\
Hydrogen, wt\% \\
ASTM D86 Dist., of \\
IBP \\
$10 \%$ \\
$30 \%$ \\
$50 \%$ \\
$70 \%$ \\
$90 \%$ \\
FBP
\end{tabular}

Illinois No. 6

$24.7-25.8$

$126.1-132.1$

$14-15$

$\sim 43$

$<-80$

$<-80$

$<-70$

$---$

$--$

0

$85.2-90.1$

$9.8-14.8$

$86.8-87.3$

$12.7-13.2$

$334-338$

$405-411$

$474-484$

$527-539$

566-576

610-620

659-674
Wyodak

25.2-25.6

$129.6-132.9$

$41.1-43.5$

$<-30$

$+10$

$-26$

185

4.0-4.1

$3.1-5.7$

77.7-81.3

$13.0-19.1$

87.0

13.0

344-351

420-423

510-514

552-563

578-594

612-636

671-694 


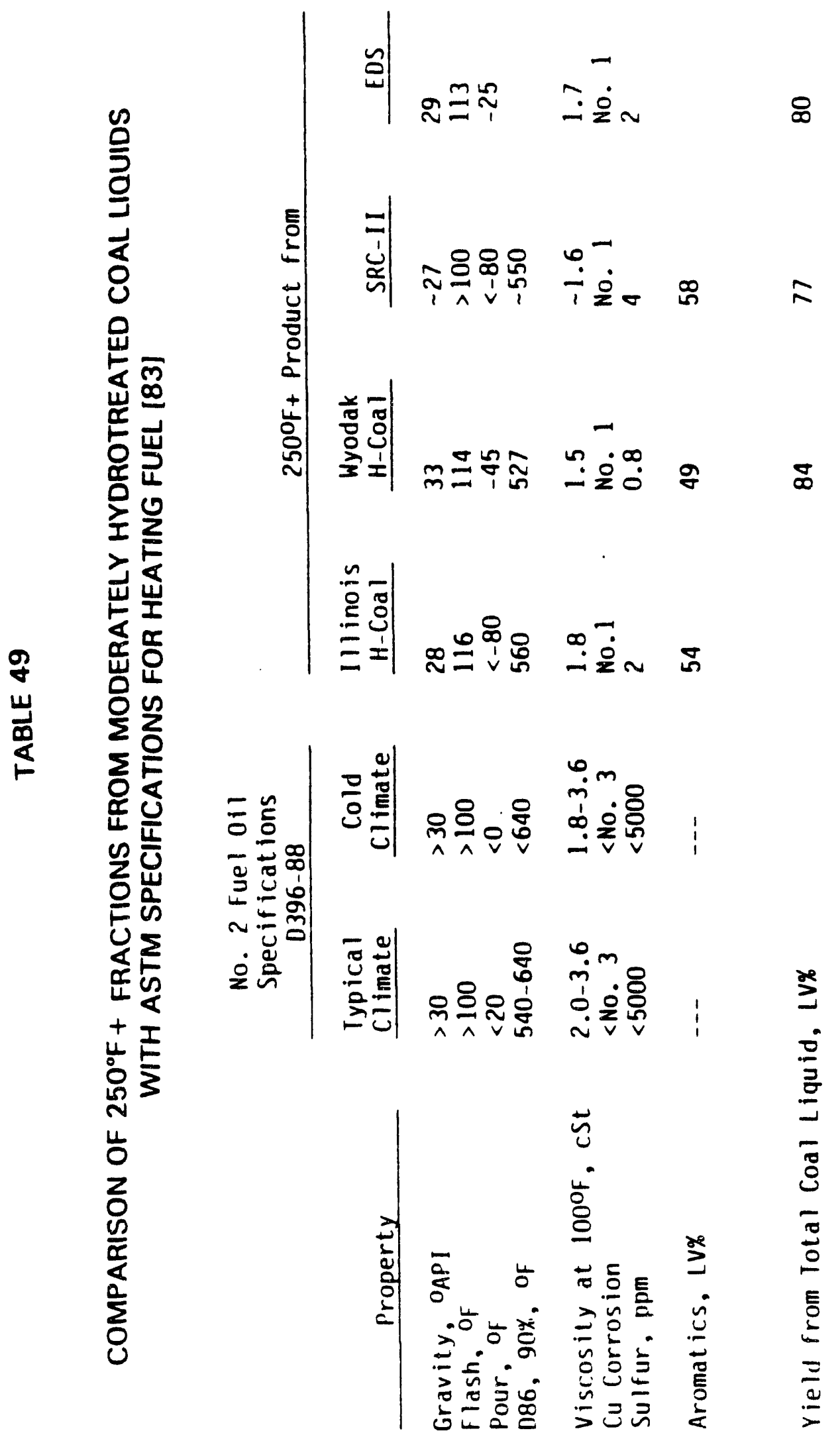




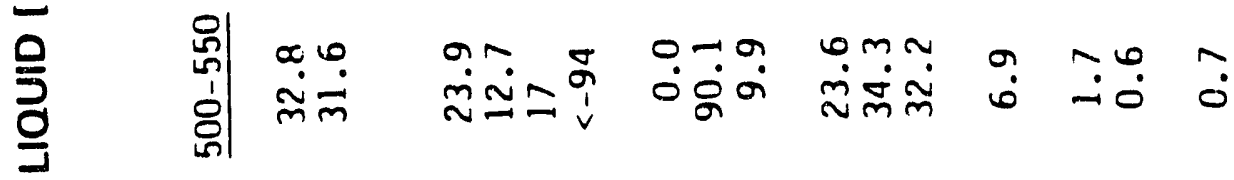

๘

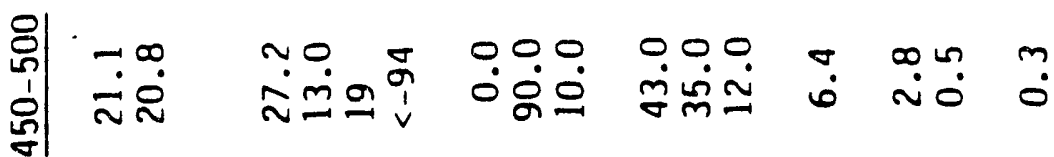

:

辛|

酸|

离

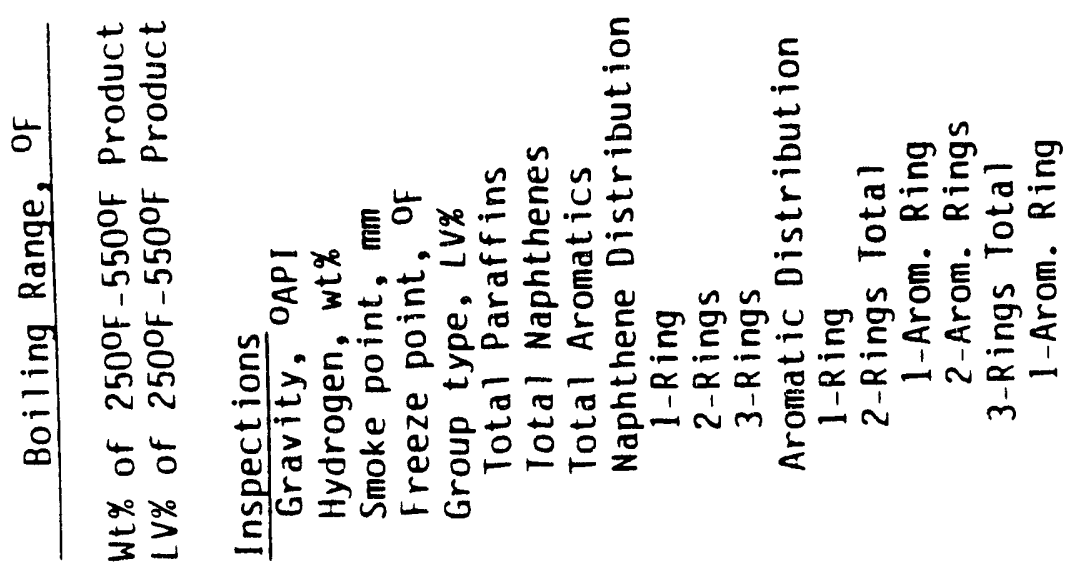




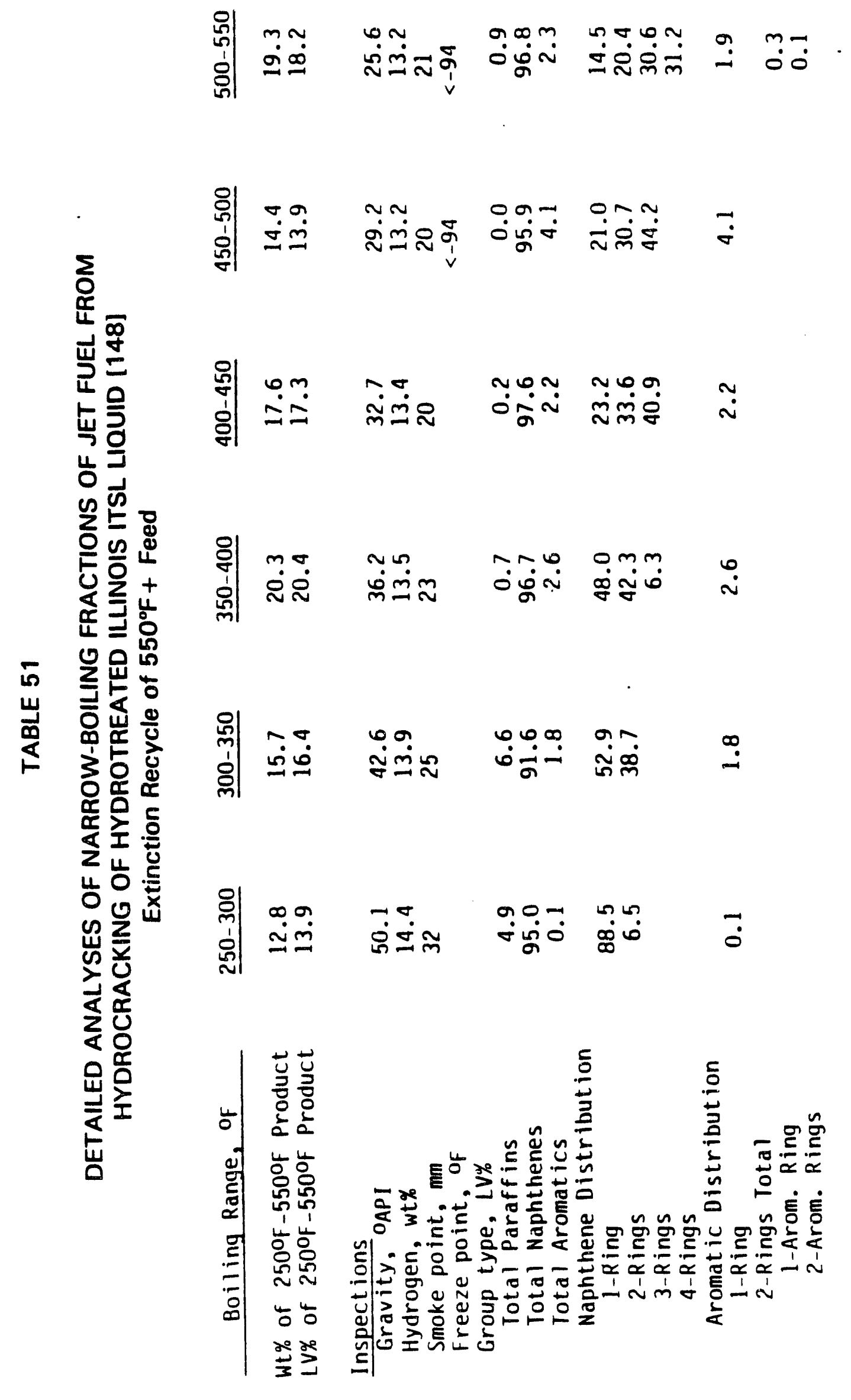


FIGURES 


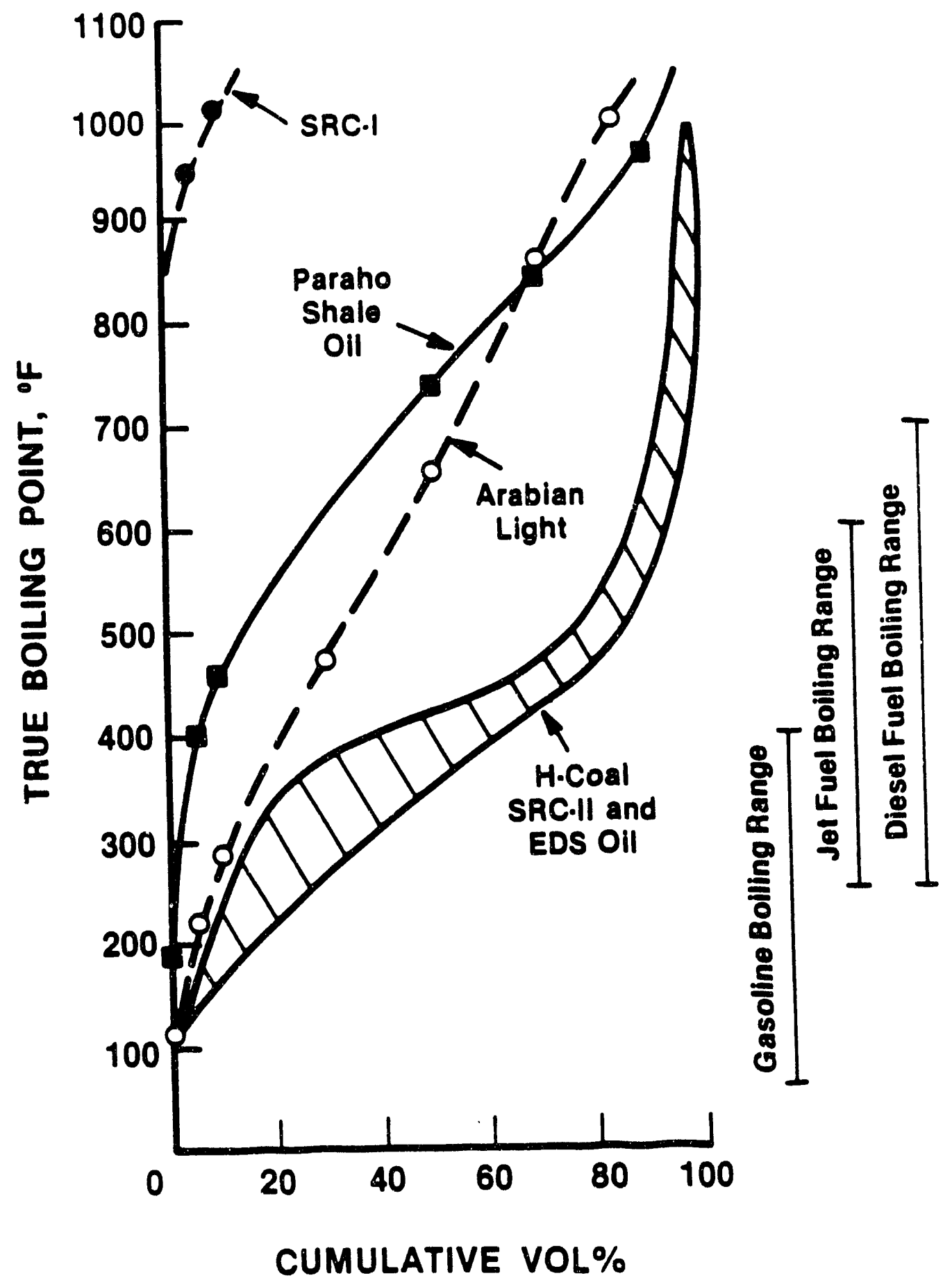

FIGURE 1. TBP DISTILLATIONS OF ARABIAN LIGHT CRUDE, SHALE OIL AND COAL-DERIVED LIQUIDS [83] 


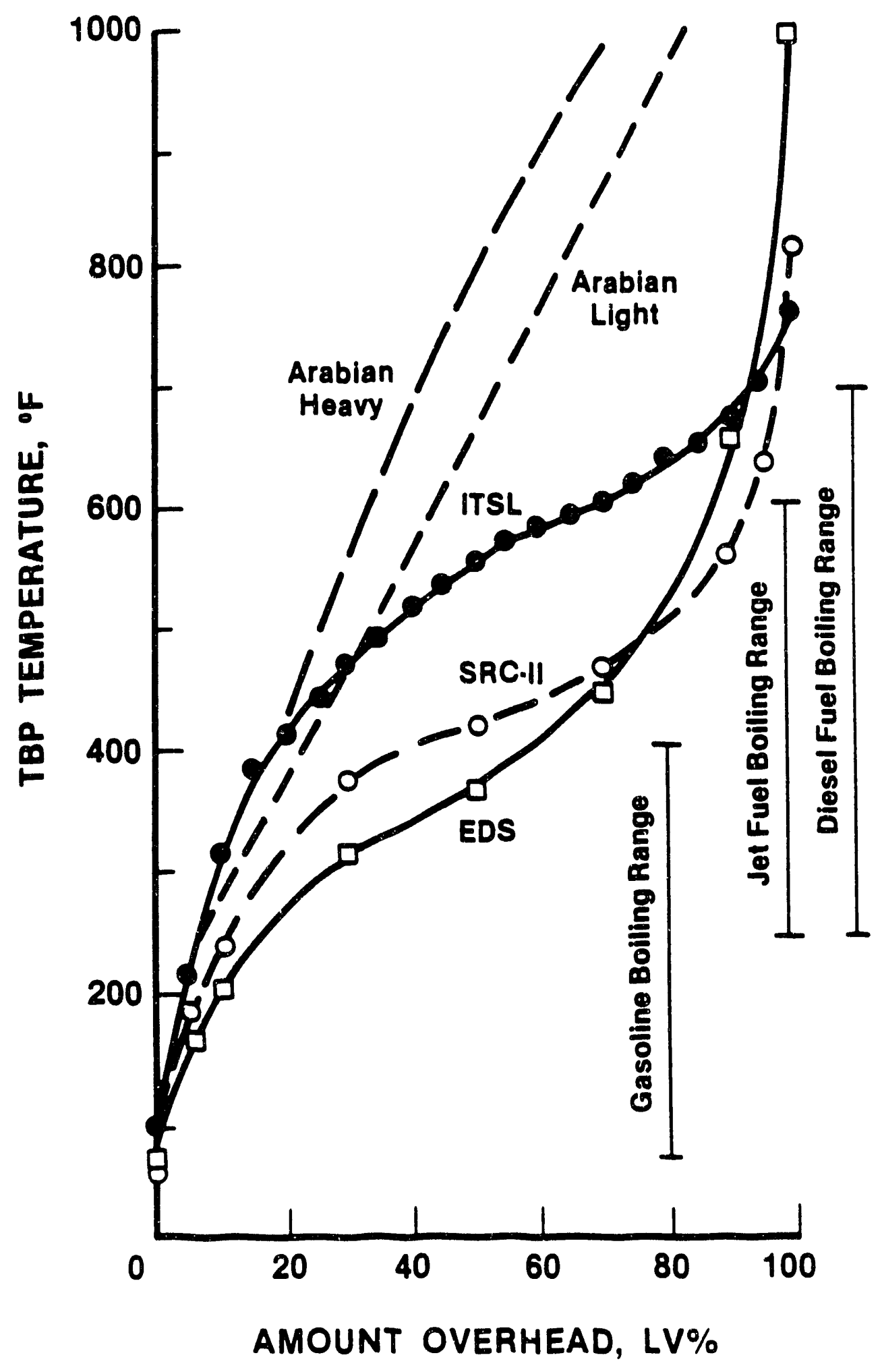

FIGURE 2. TBP DISTILLATIONS OF ARABIAN CRUDES AND COAL.DERIVED LIQUIDS [84] 

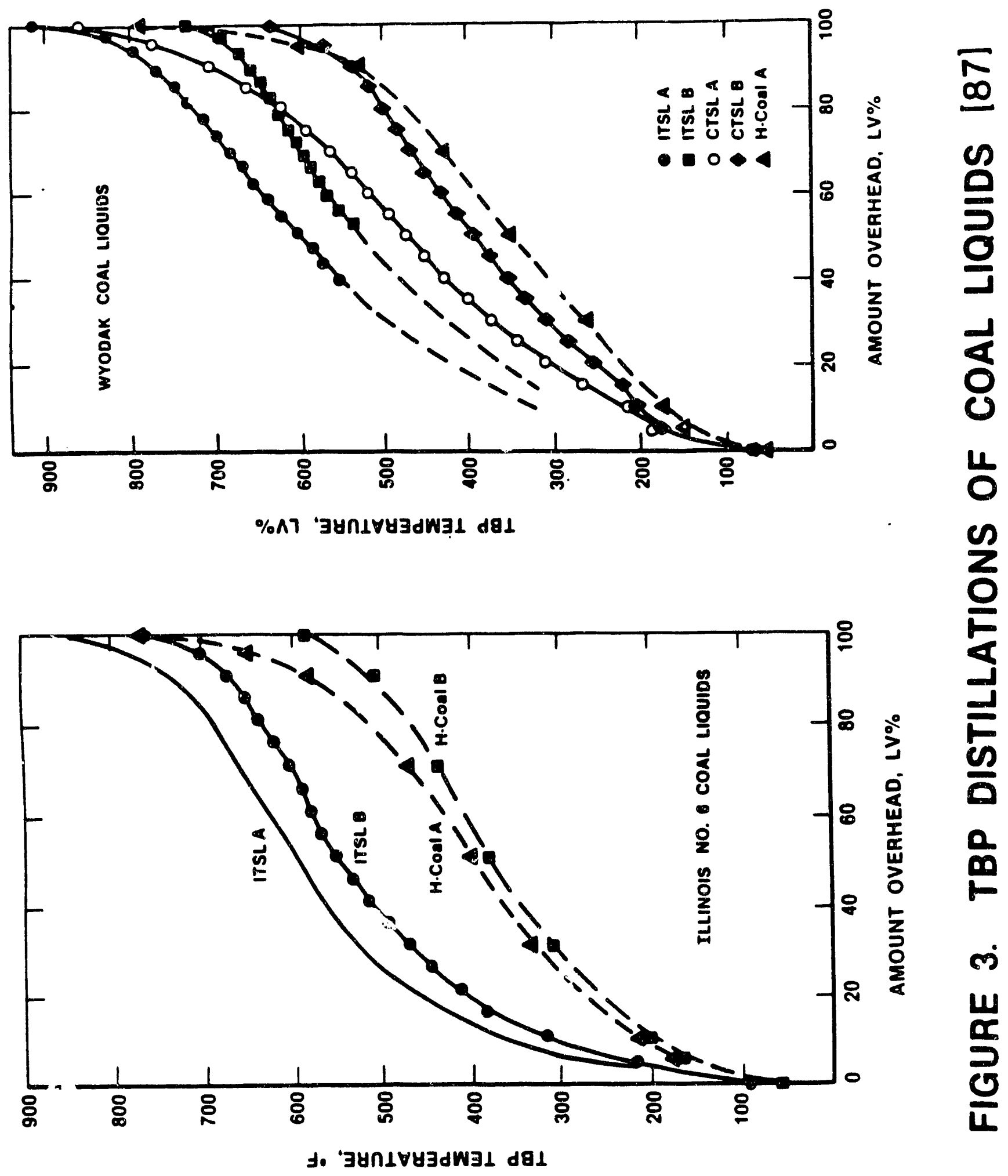


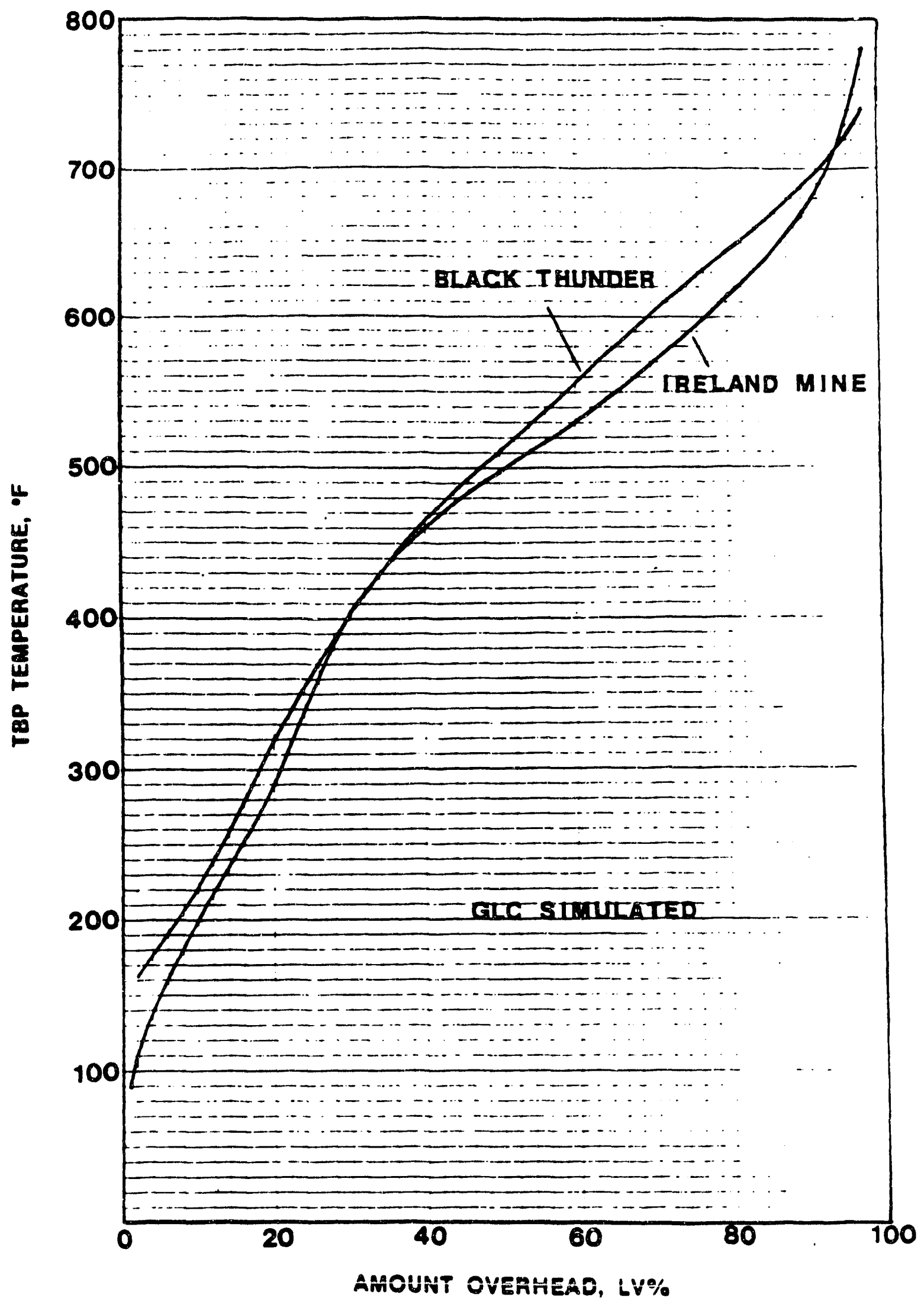

FIGURE 4. TBP DISTILLATIONS OF COAL LIQUIDS 153 


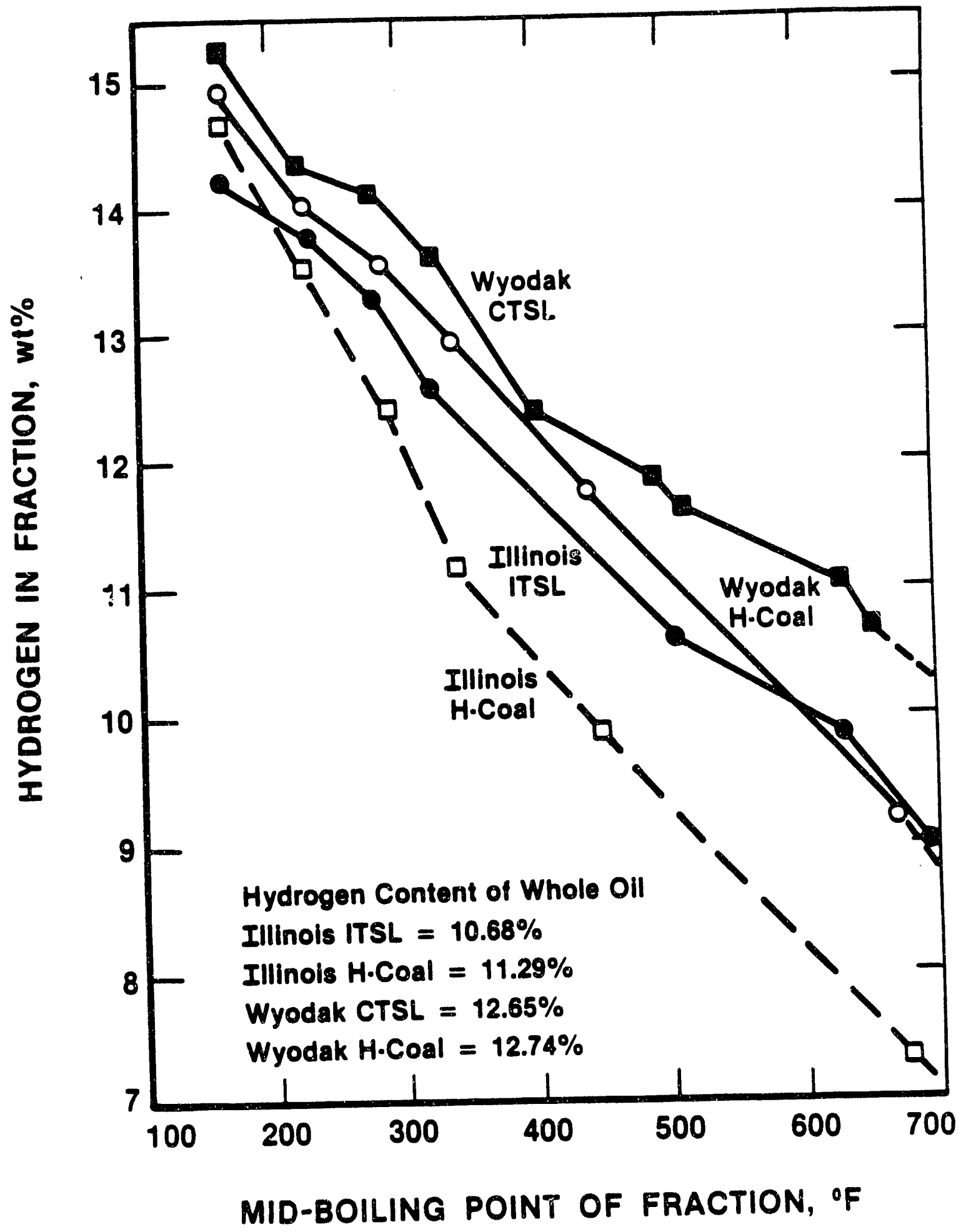

FIGURE 5. HYDROGEN CONTENT OF COAL LIQUID FRACTIONS VS. BOILING RANGE [87] 


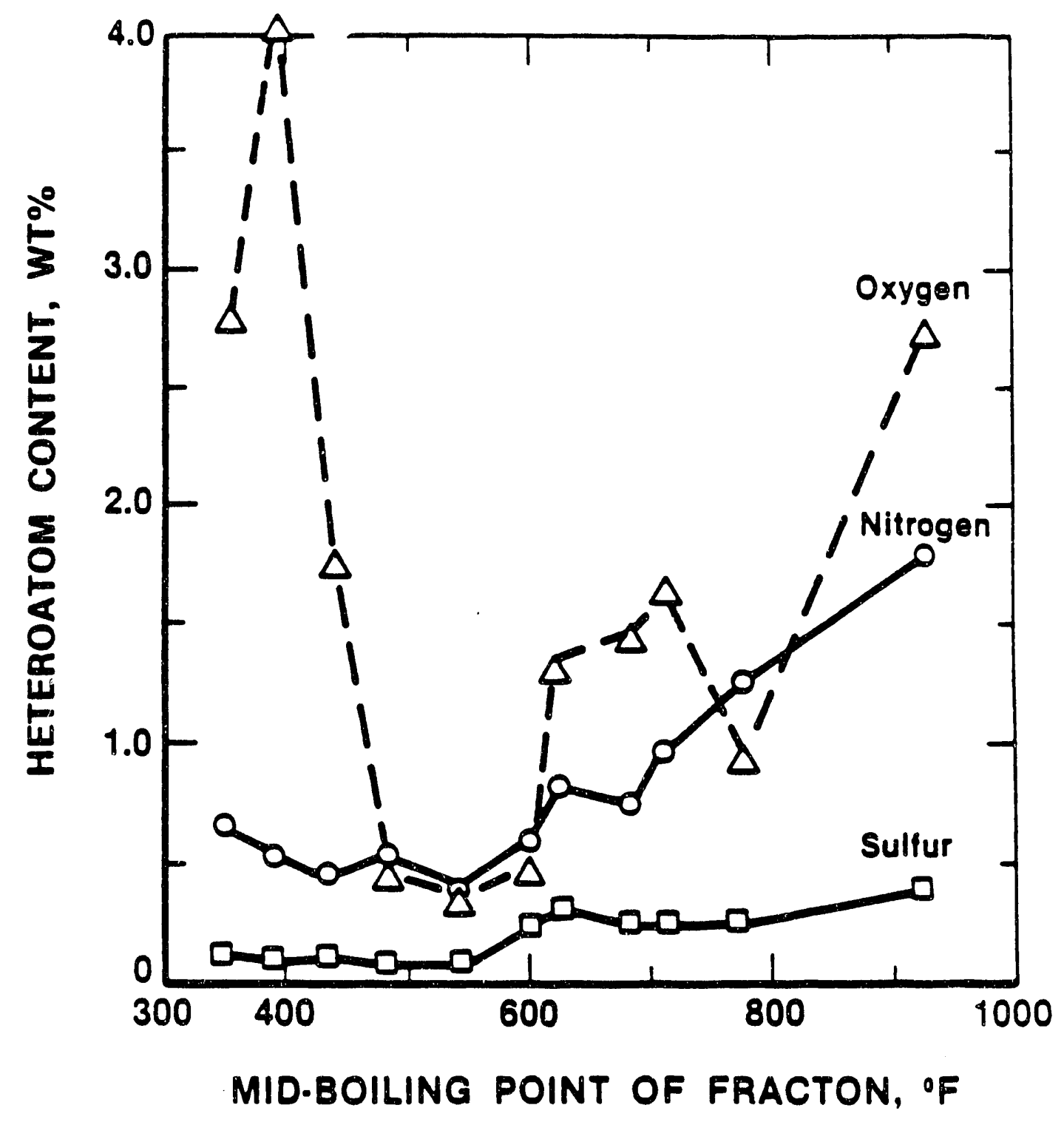

FIGURE 6. DISTRIBUTION OF HETEROATOM CONTENT IN H.COAL FRACTIONS [99] 


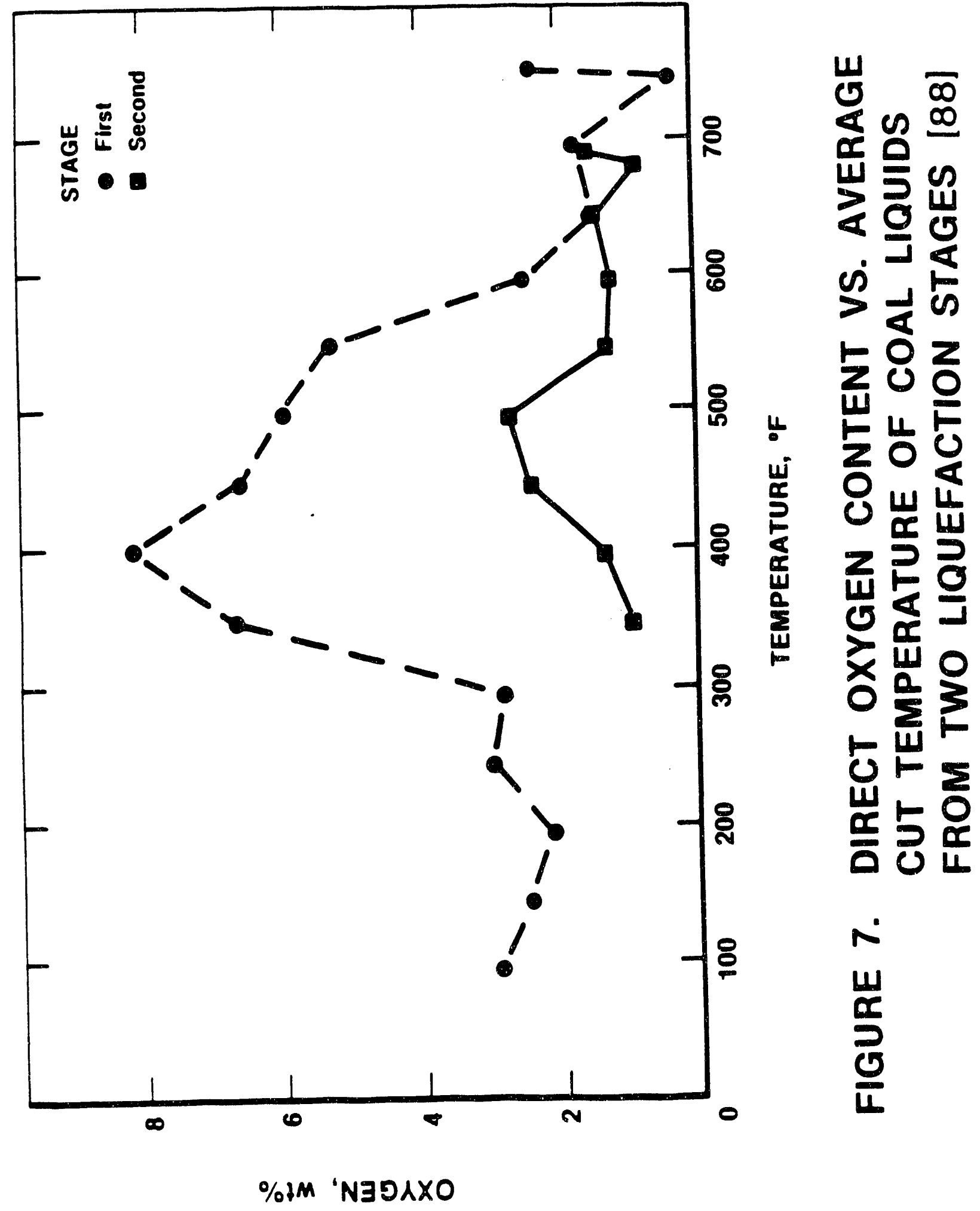




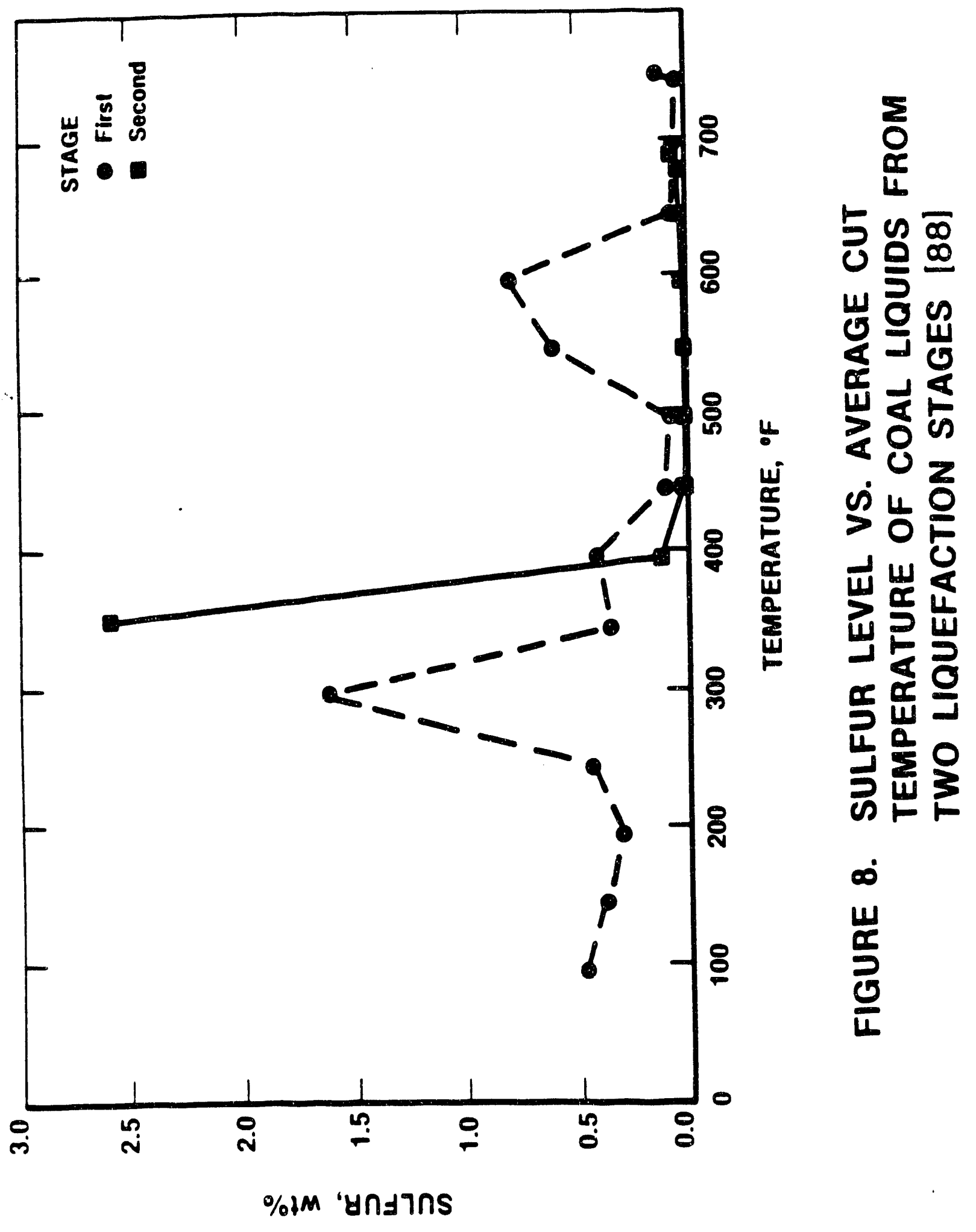




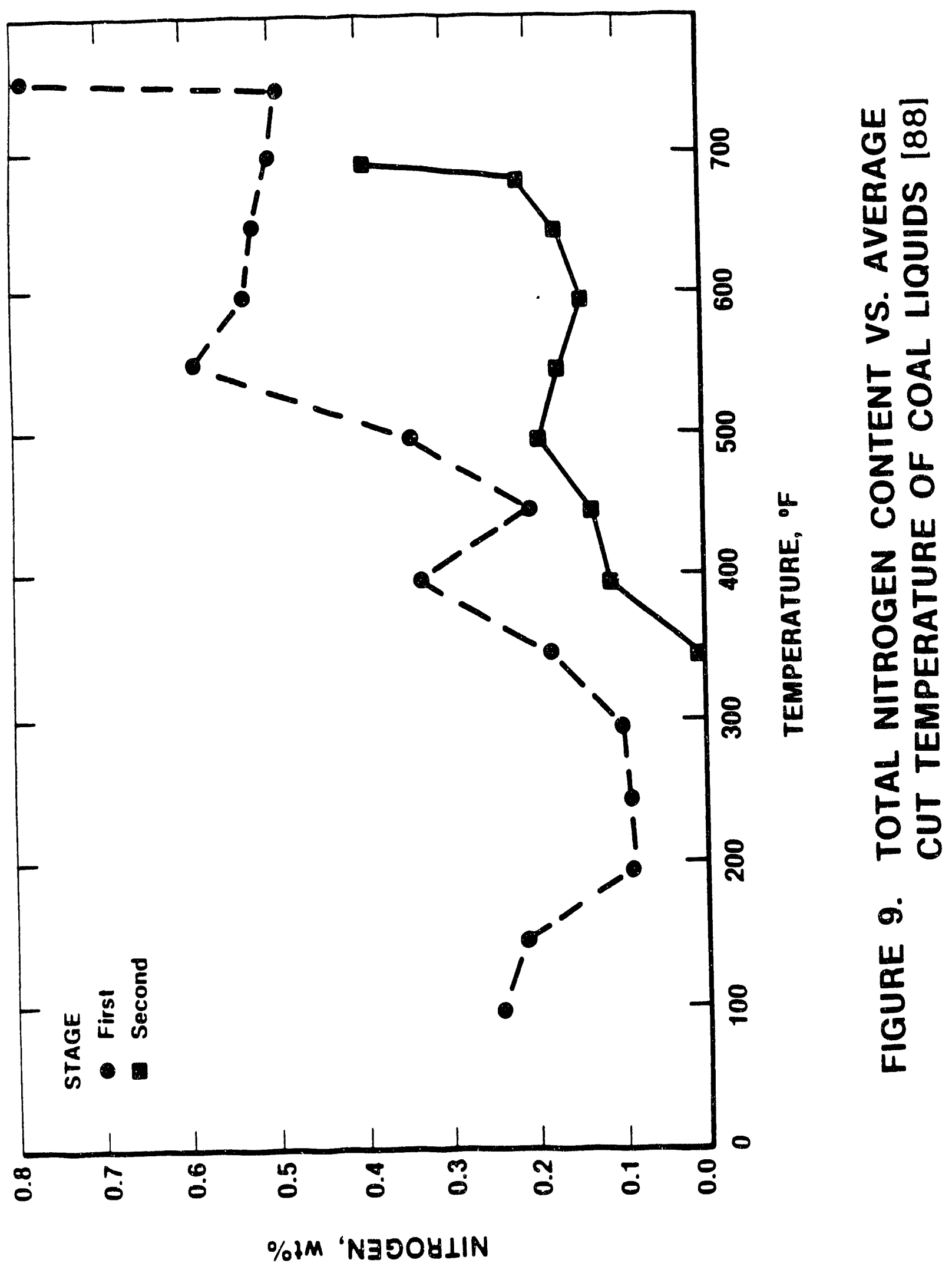




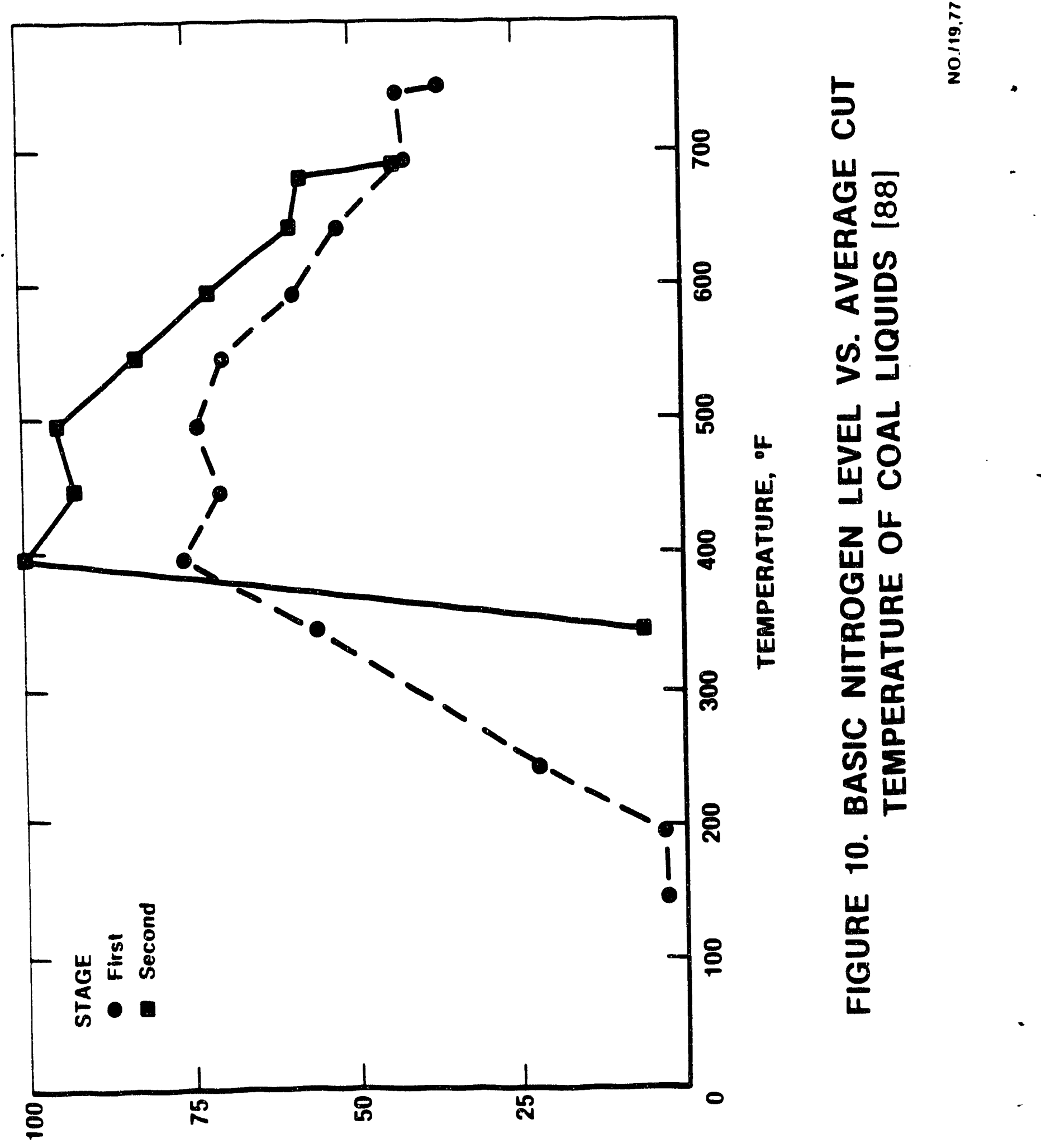

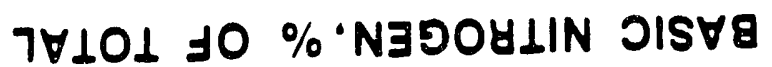




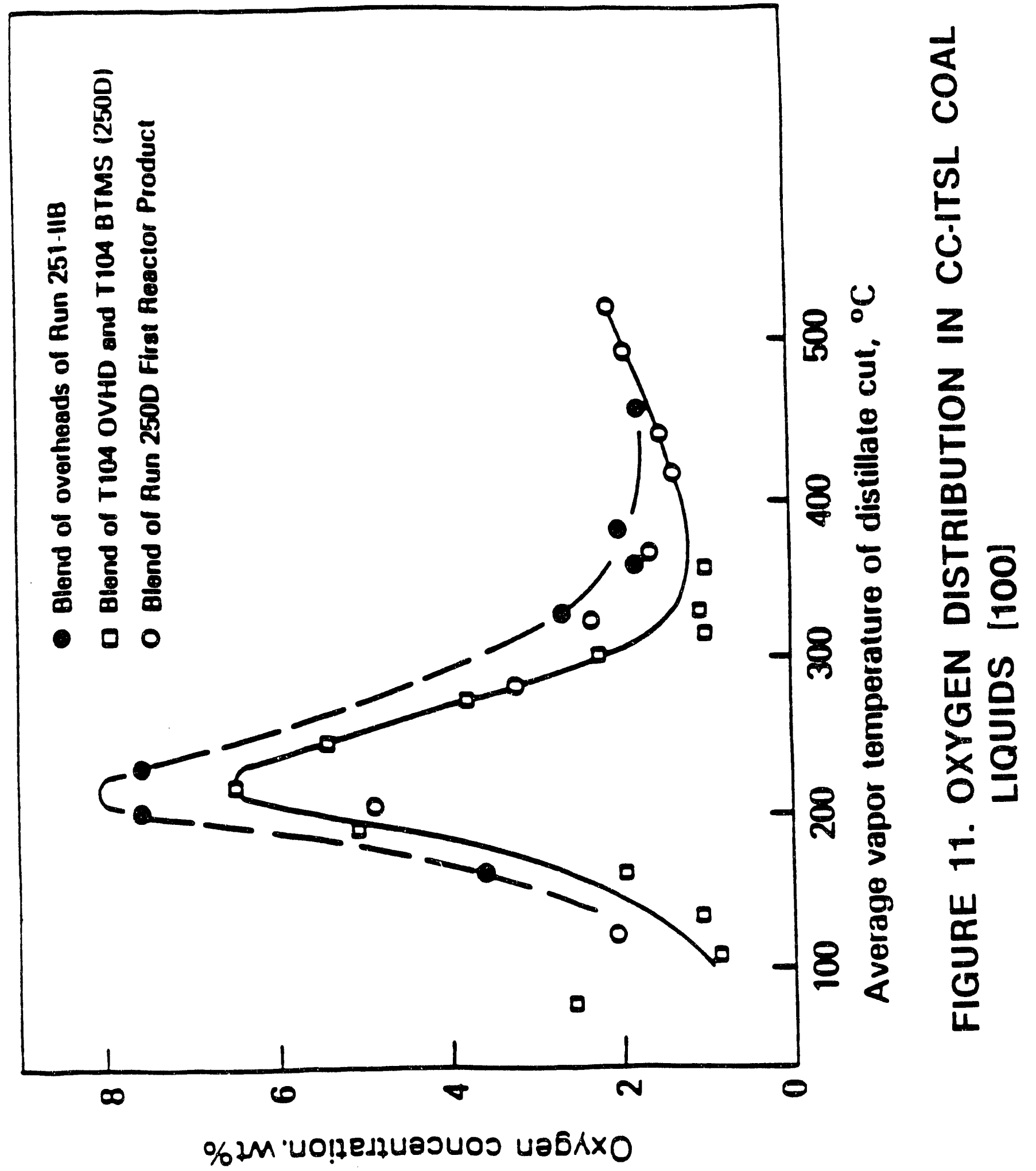




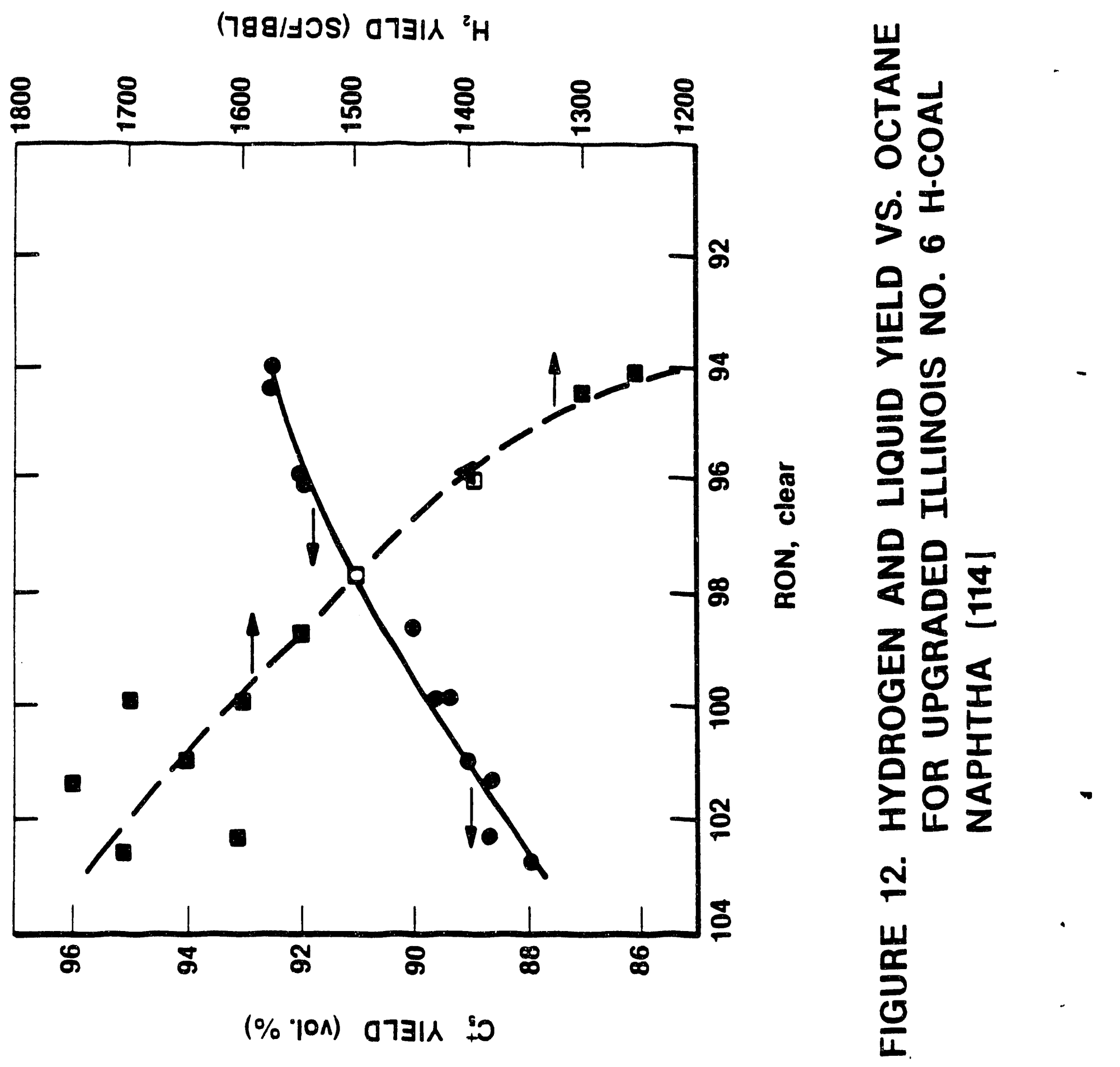


(788/J0S) هา

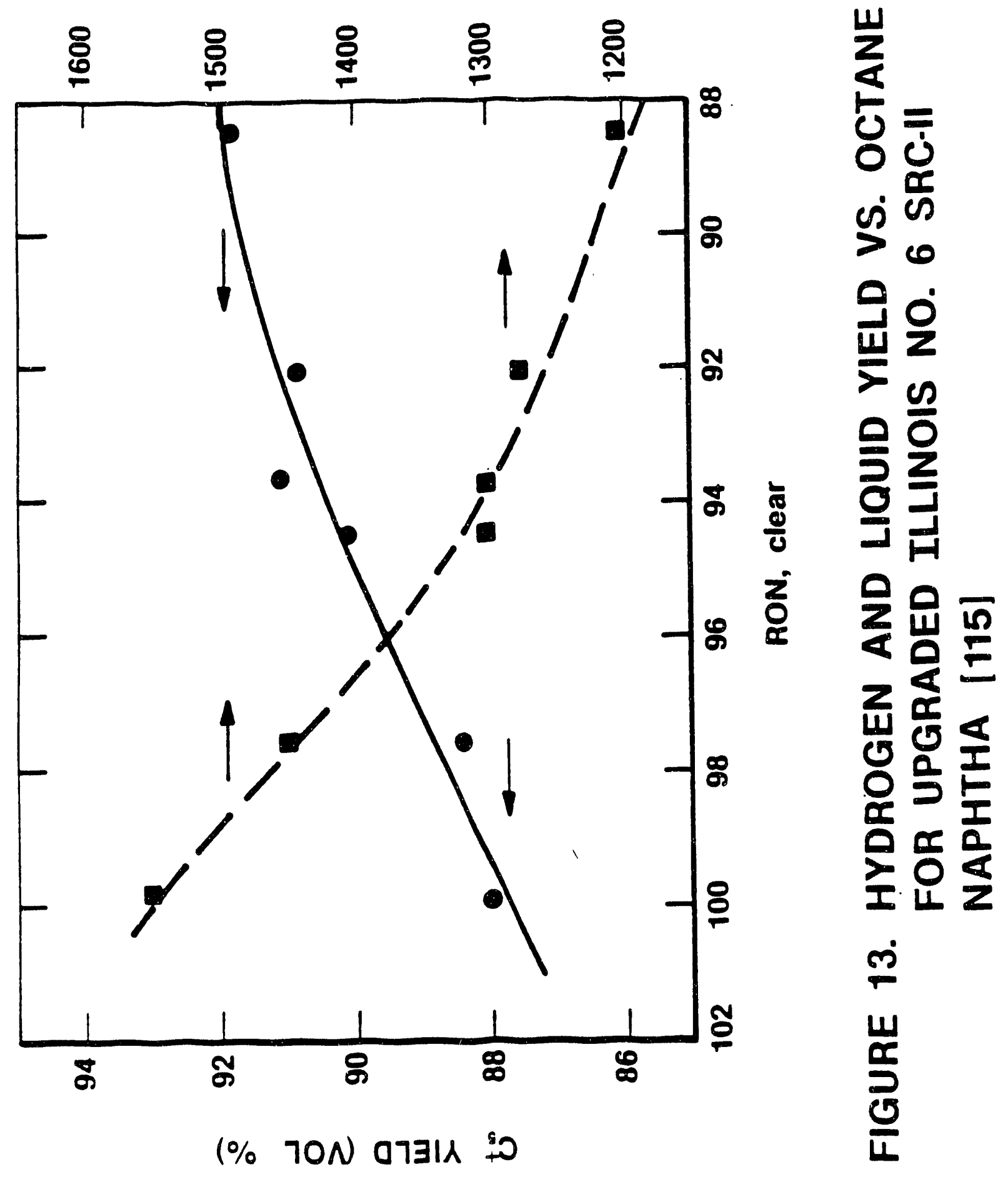




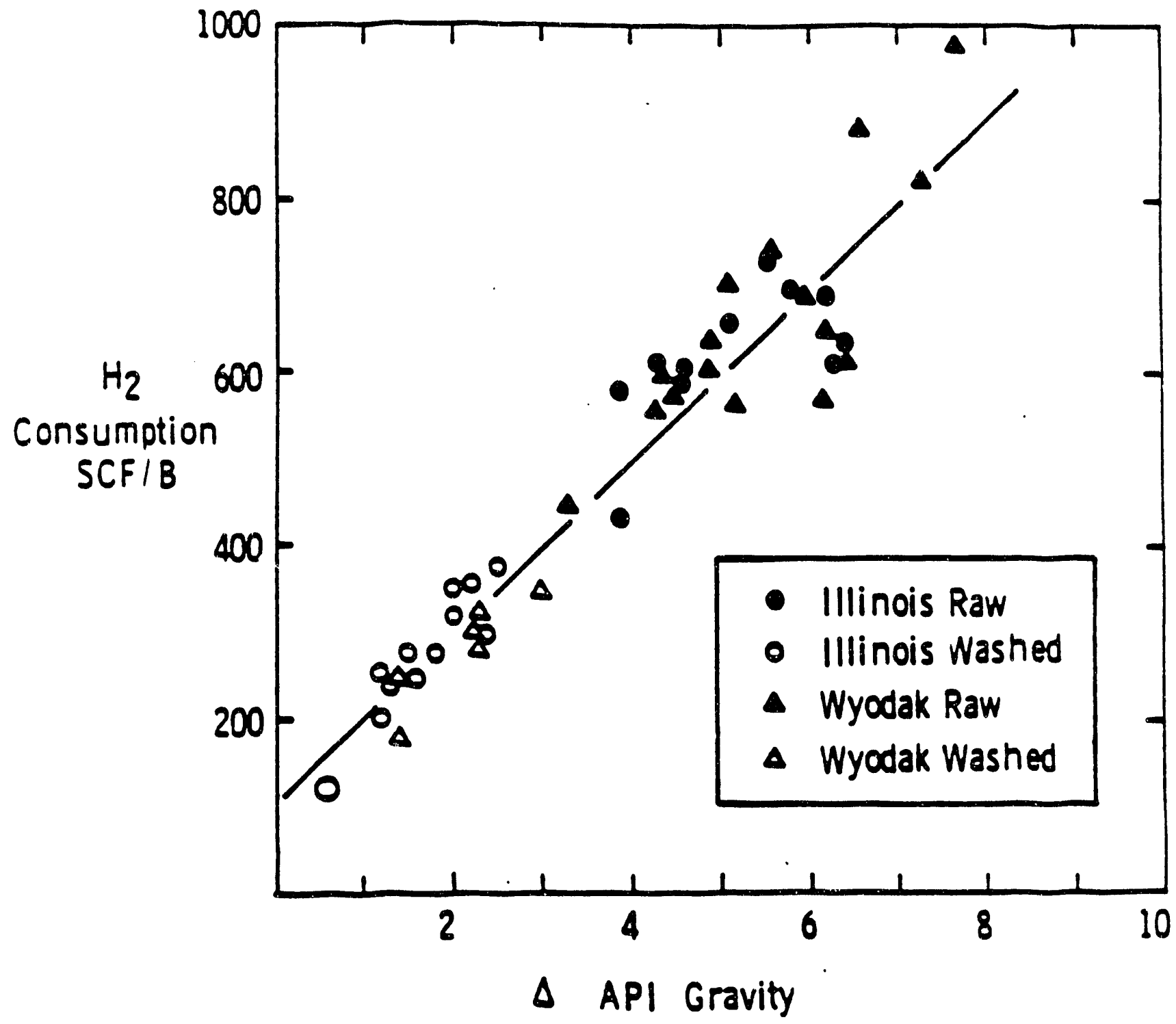

FIGURE 14. HYDROGEN CONSUMPTION VS. EDS NAPHTHA API GRAVITY INCREASE [118] 


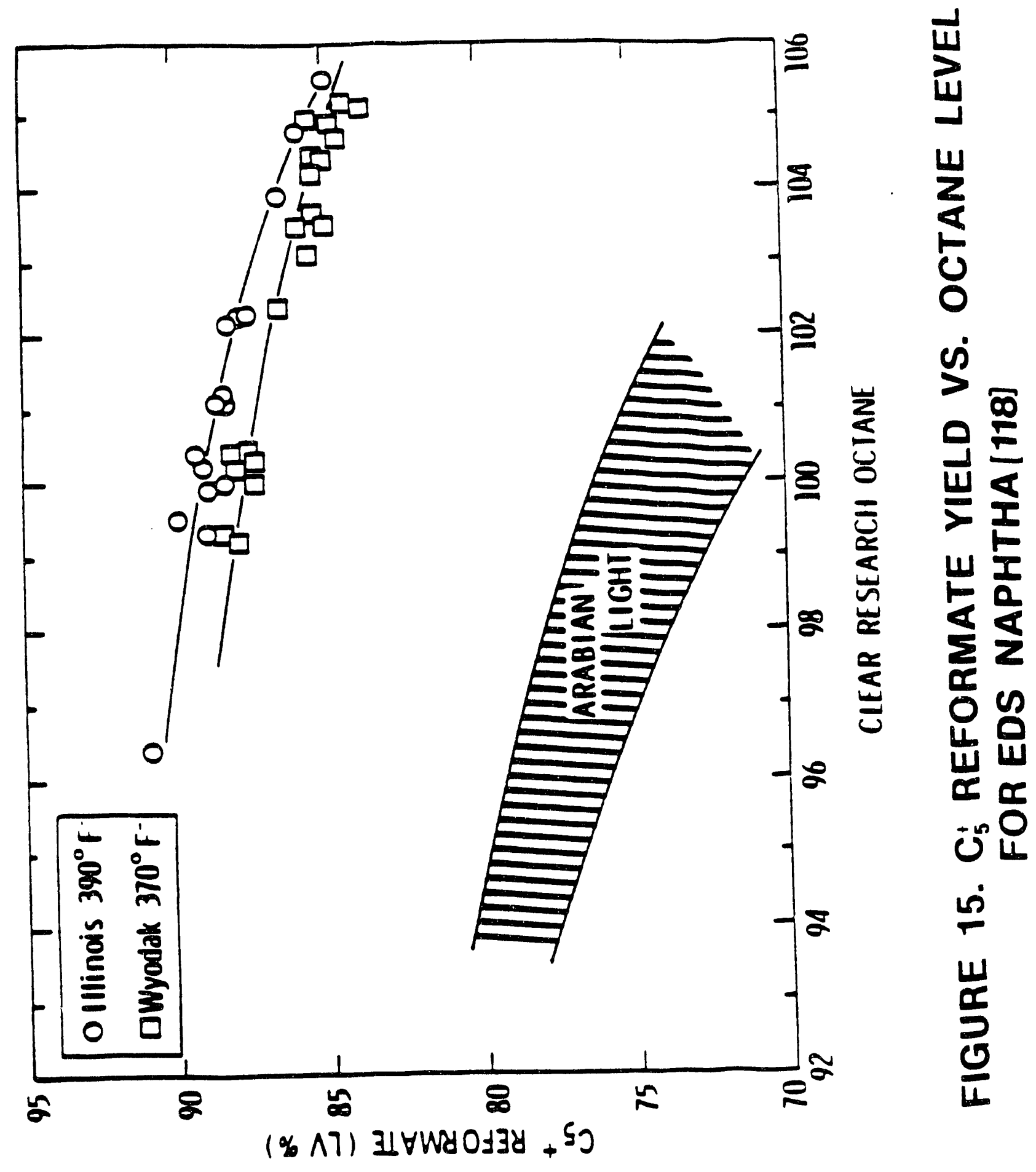




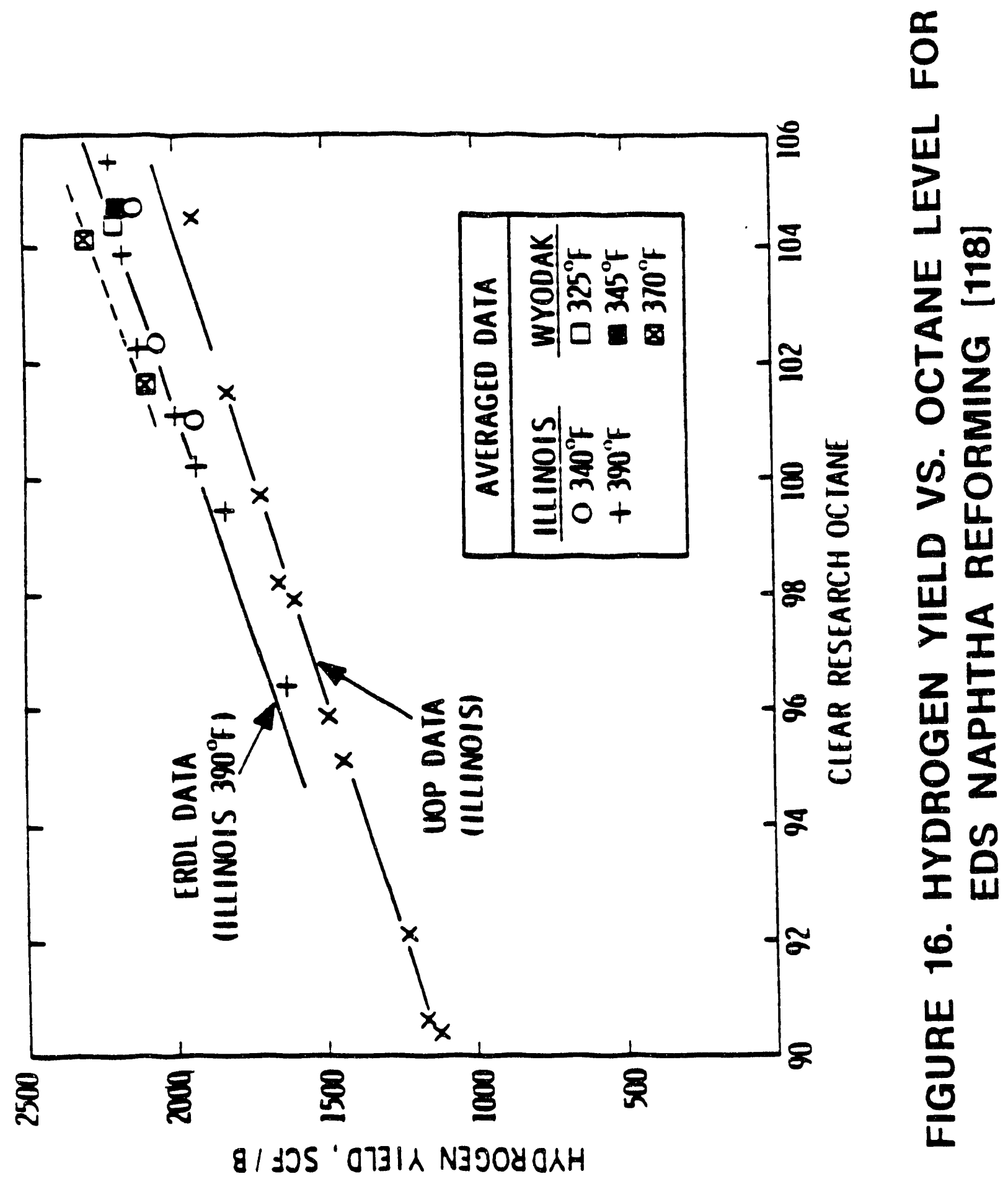




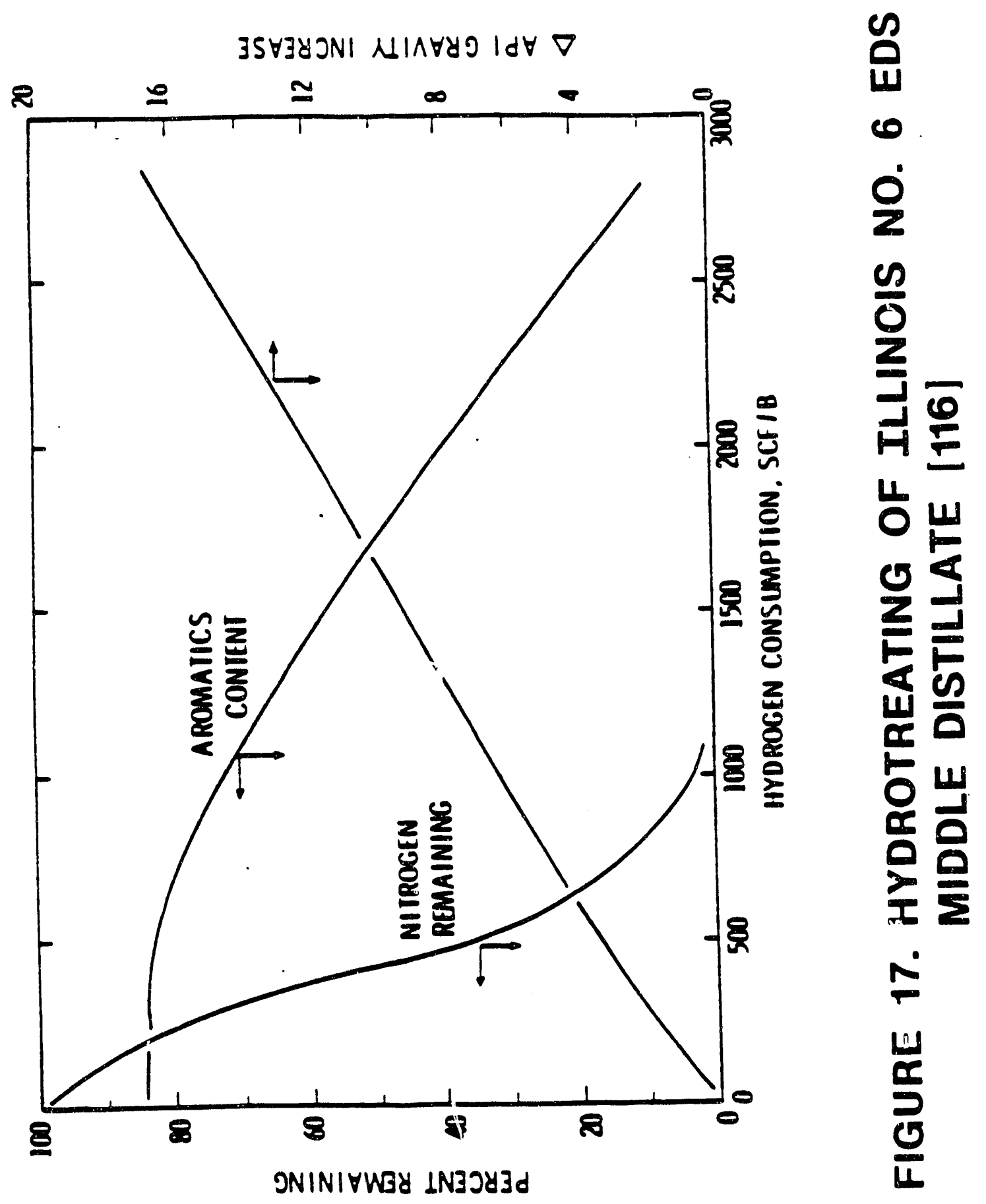



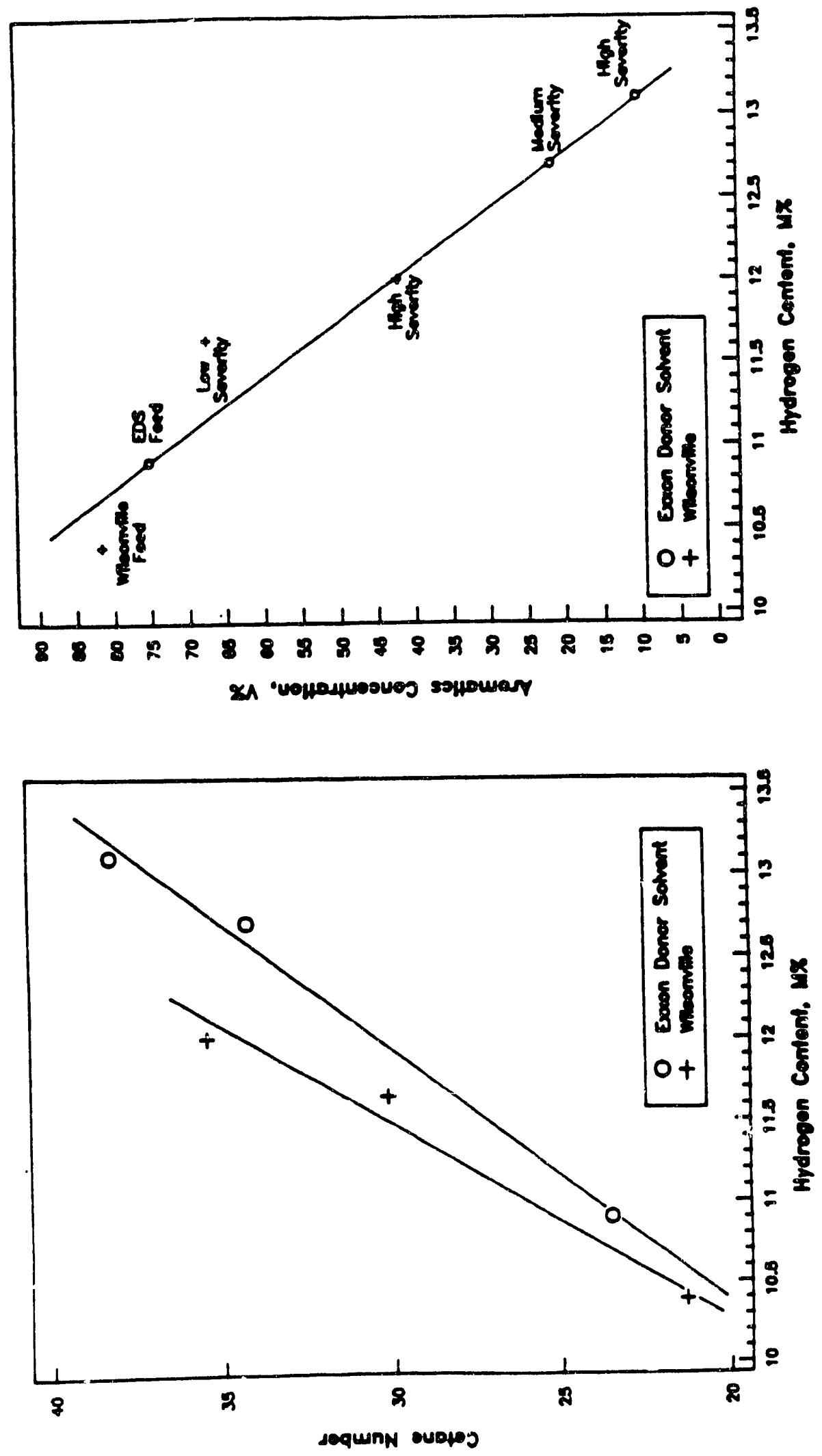

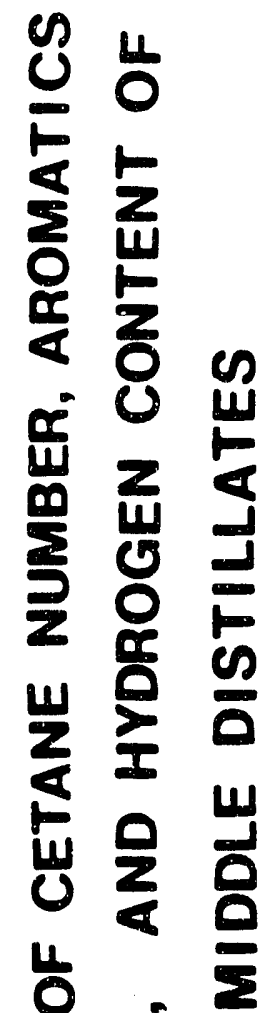

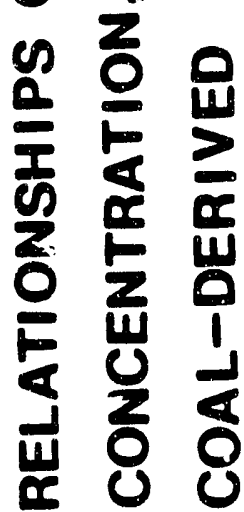

0
$\frac{14}{9}$
$\frac{5}{4}$
$\frac{1}{4}$ 


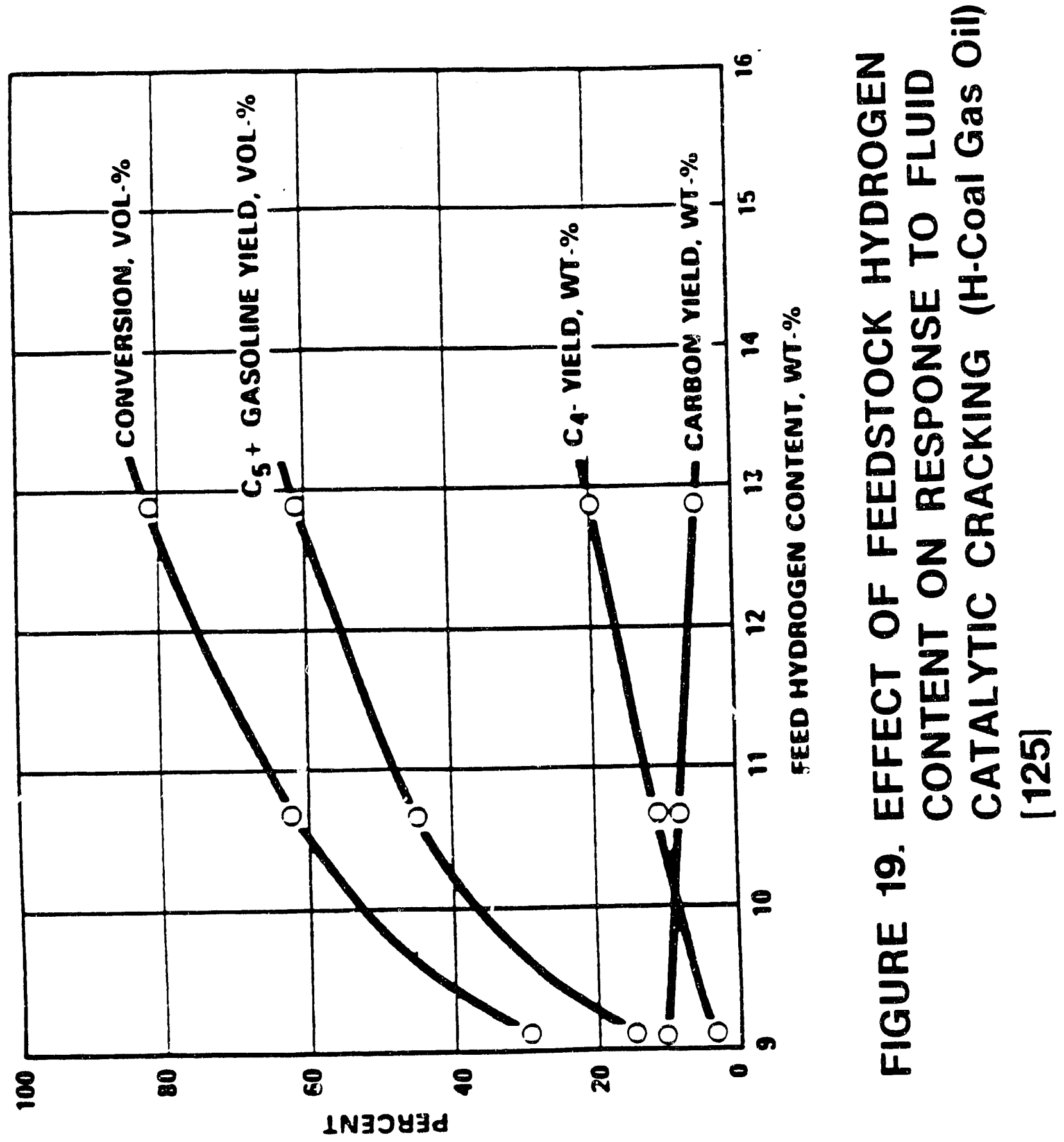




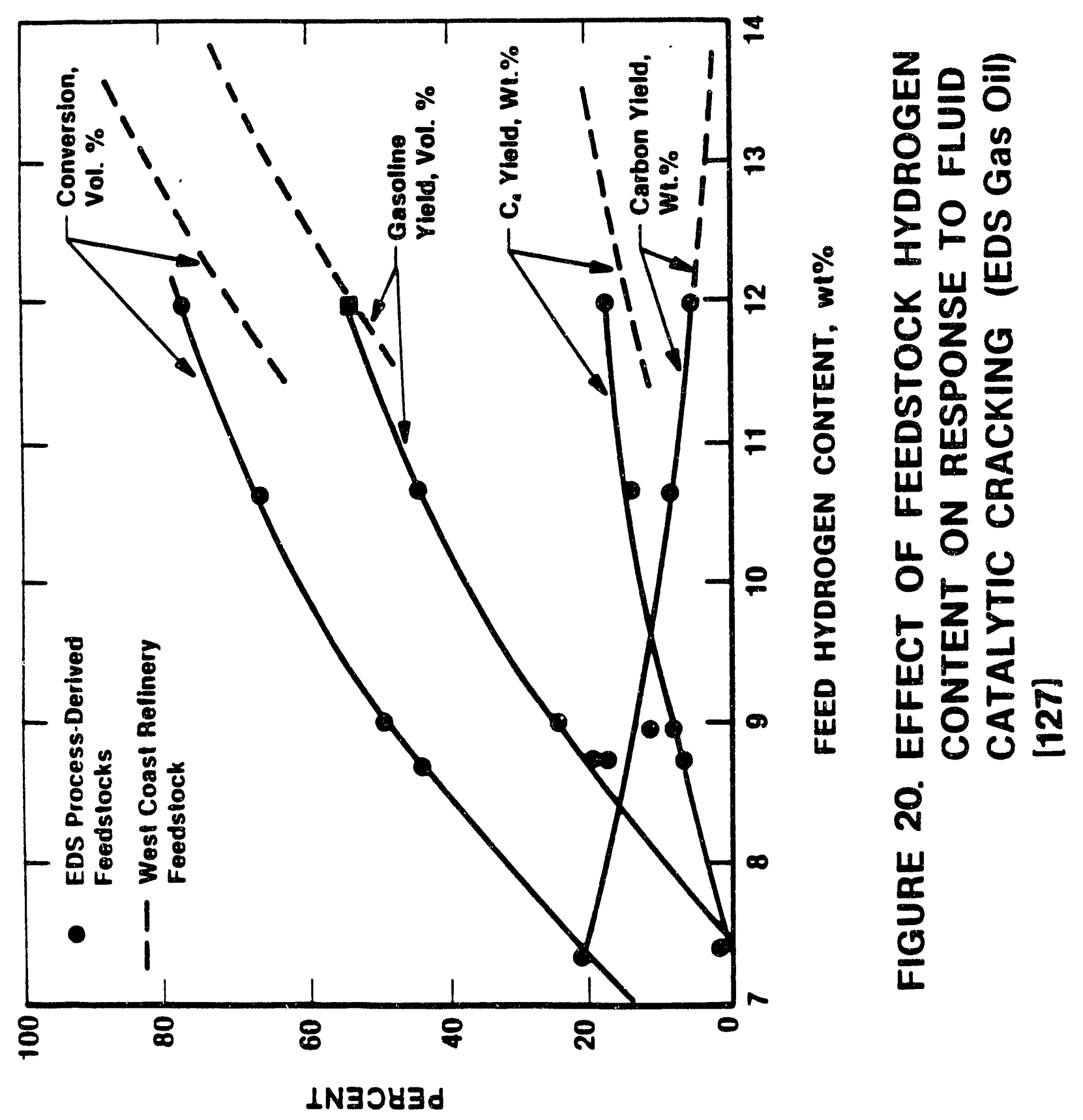




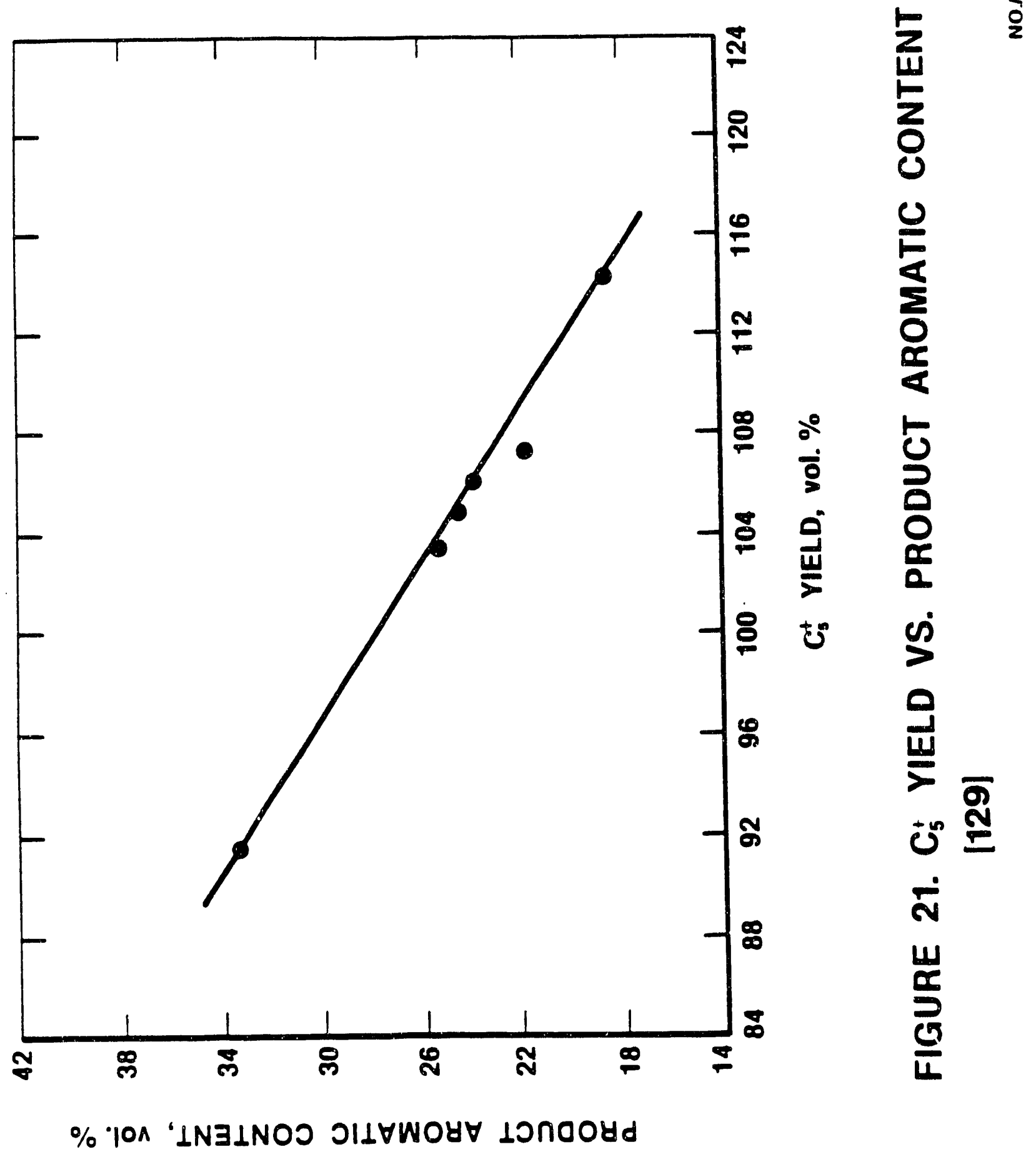




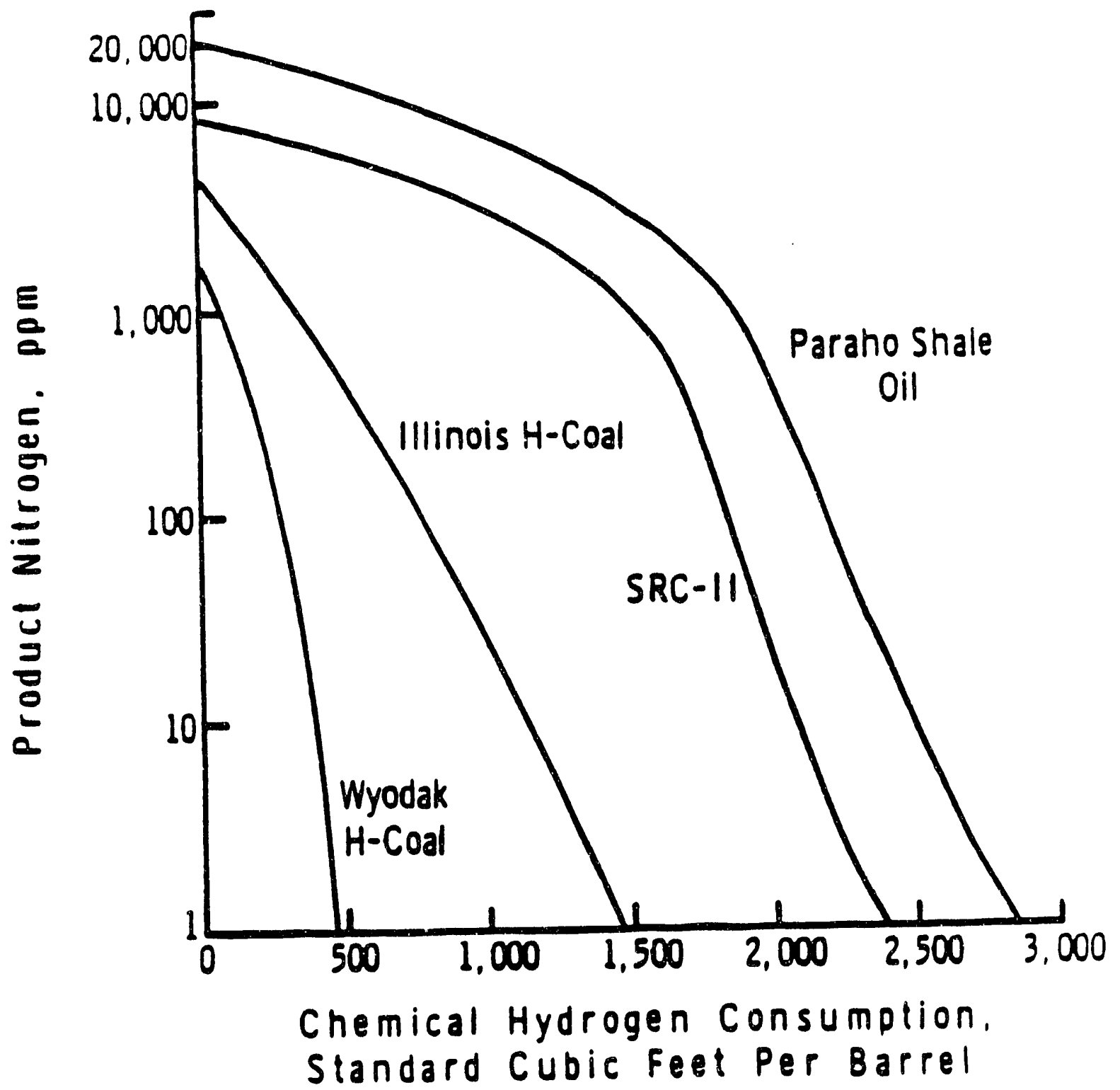

FIGURE 22. PRODUCT NITROGEN VS. HYDROGEN CONSUMPTION FOR COAL LIQUIDS [83] 


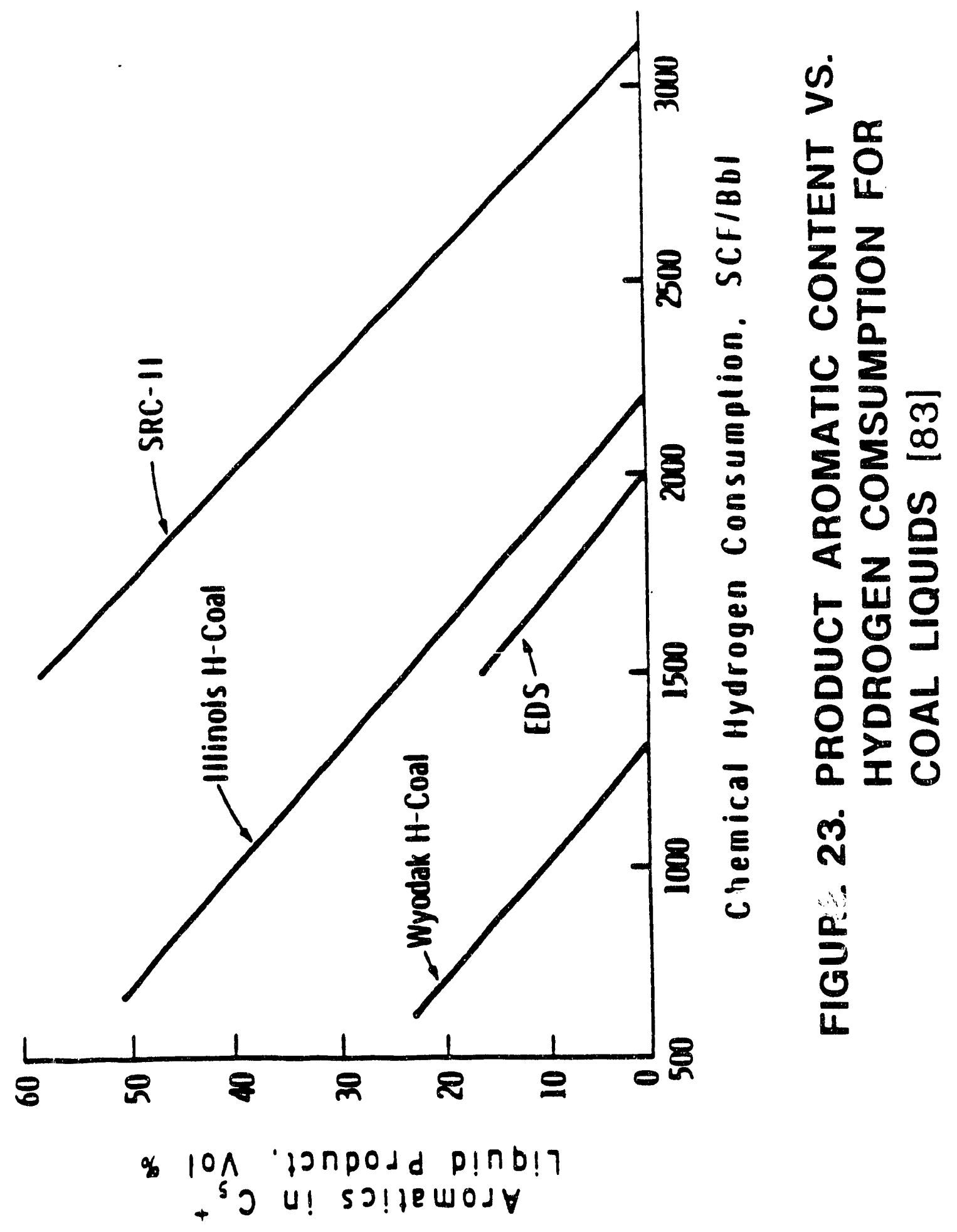




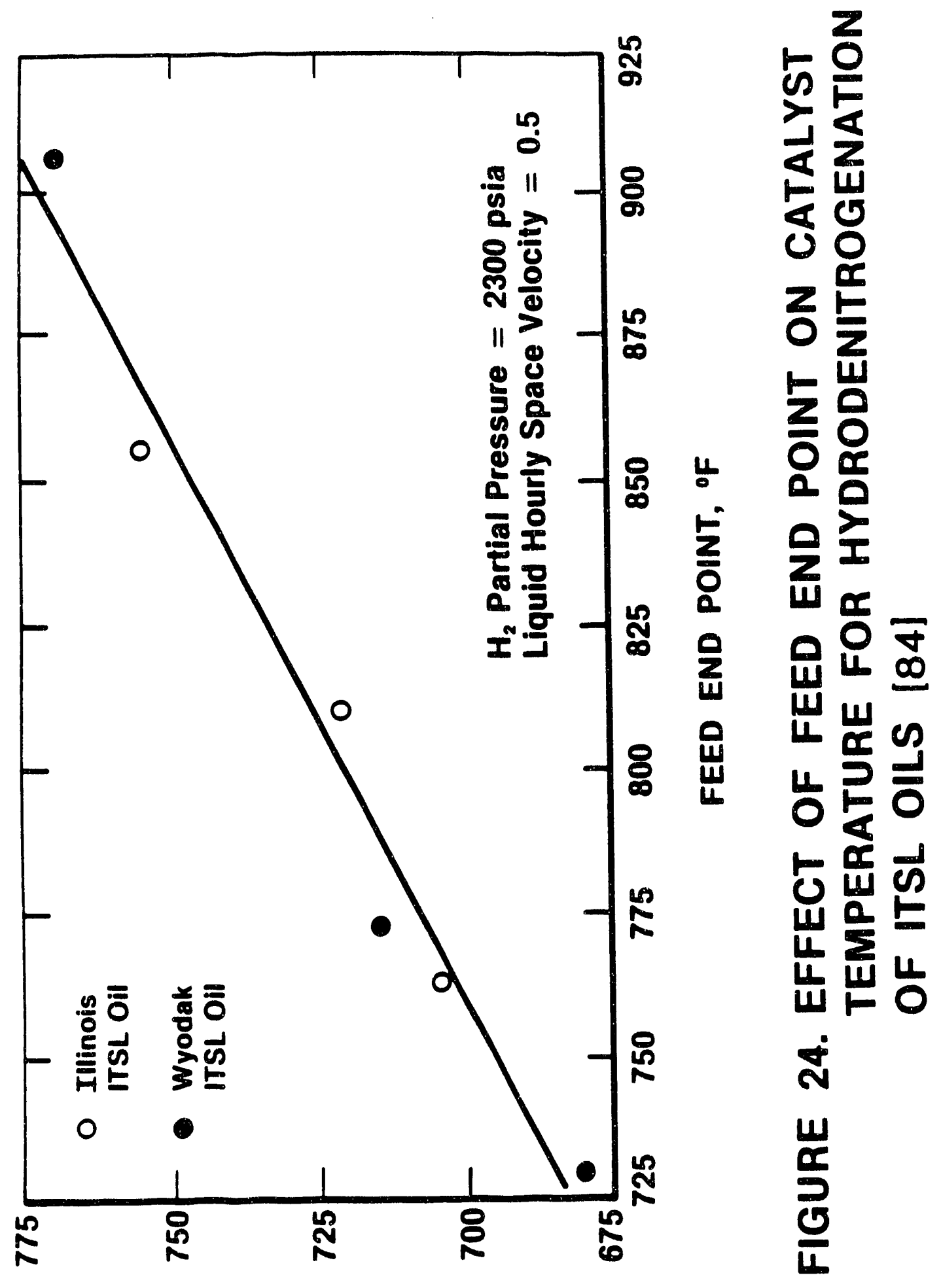

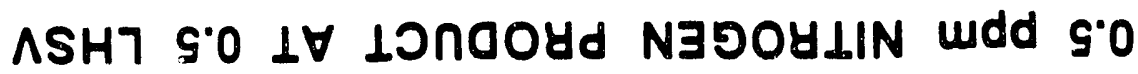
yOJ $\exists \forall n \perp \forall \forall \exists d W \exists \perp \perp S \wedge 7 \forall \perp \forall 0$ $\exists D \forall \forall \exists \wedge \forall$ 


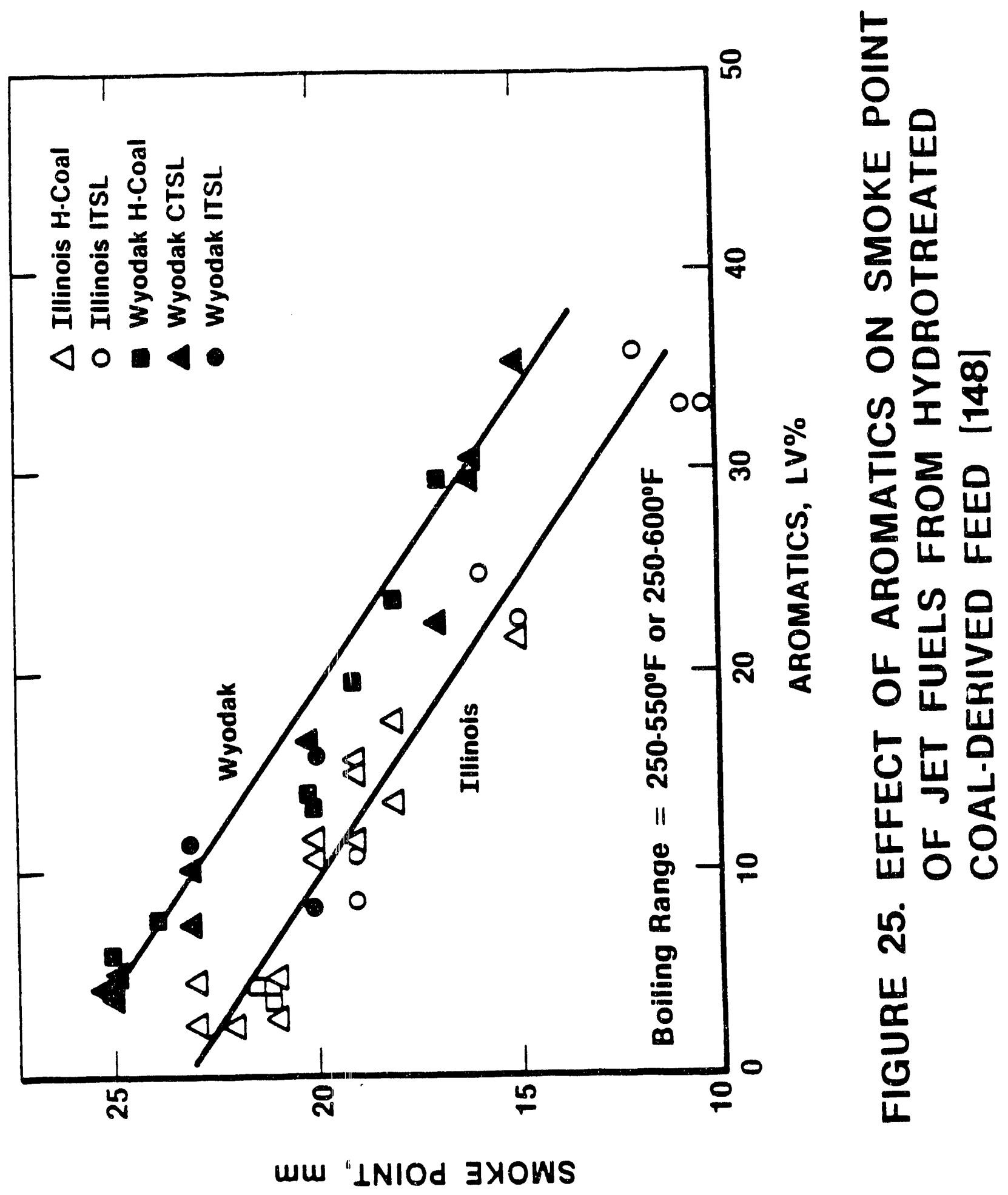



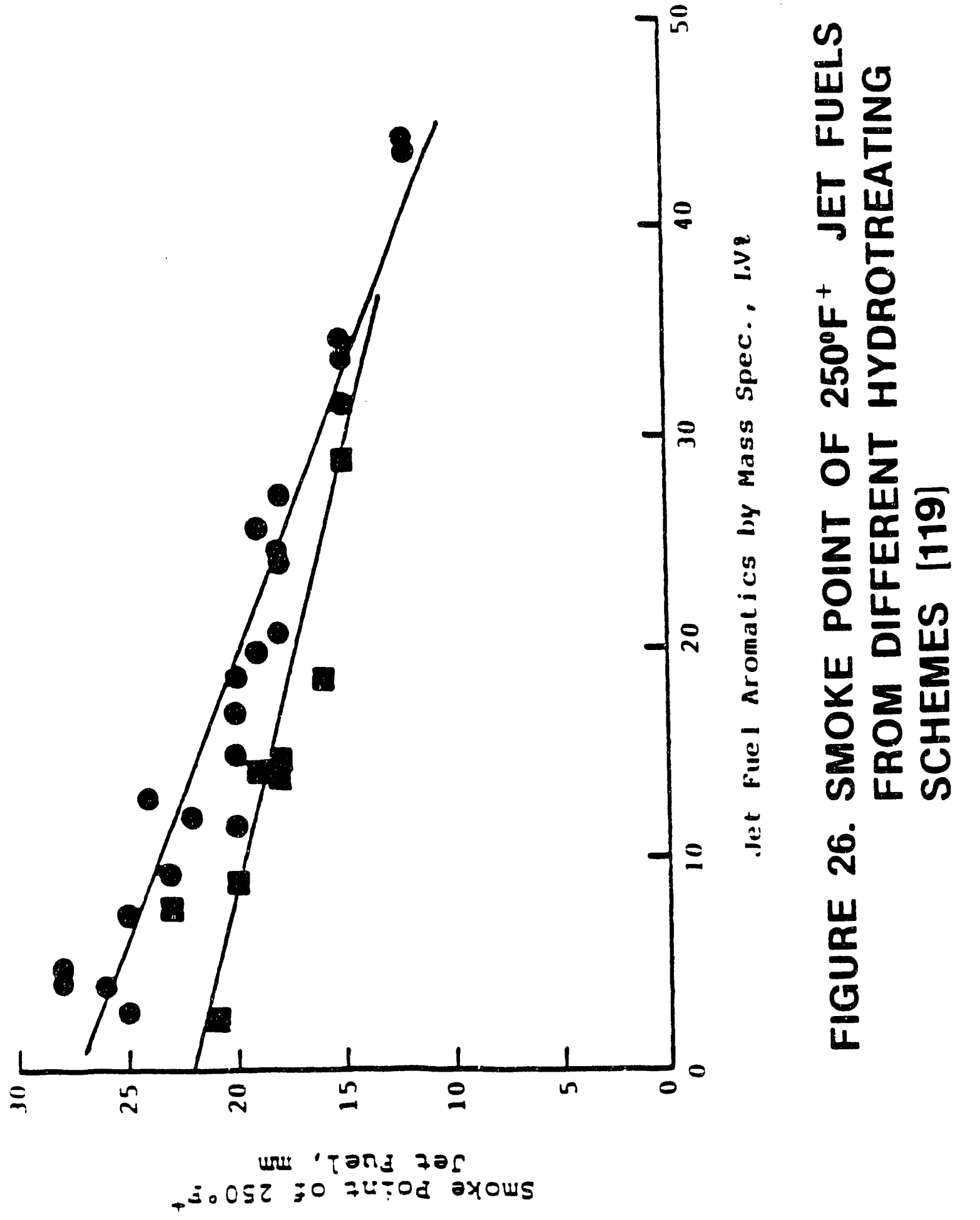

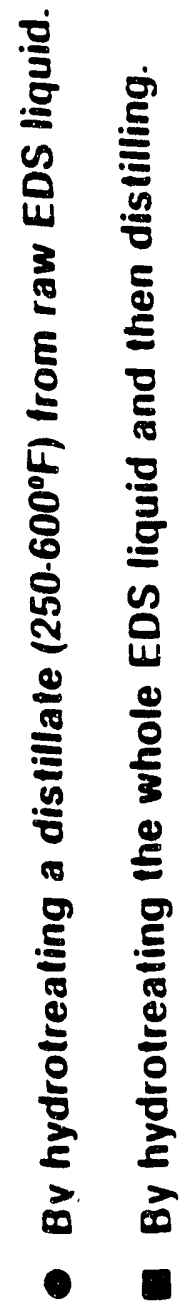




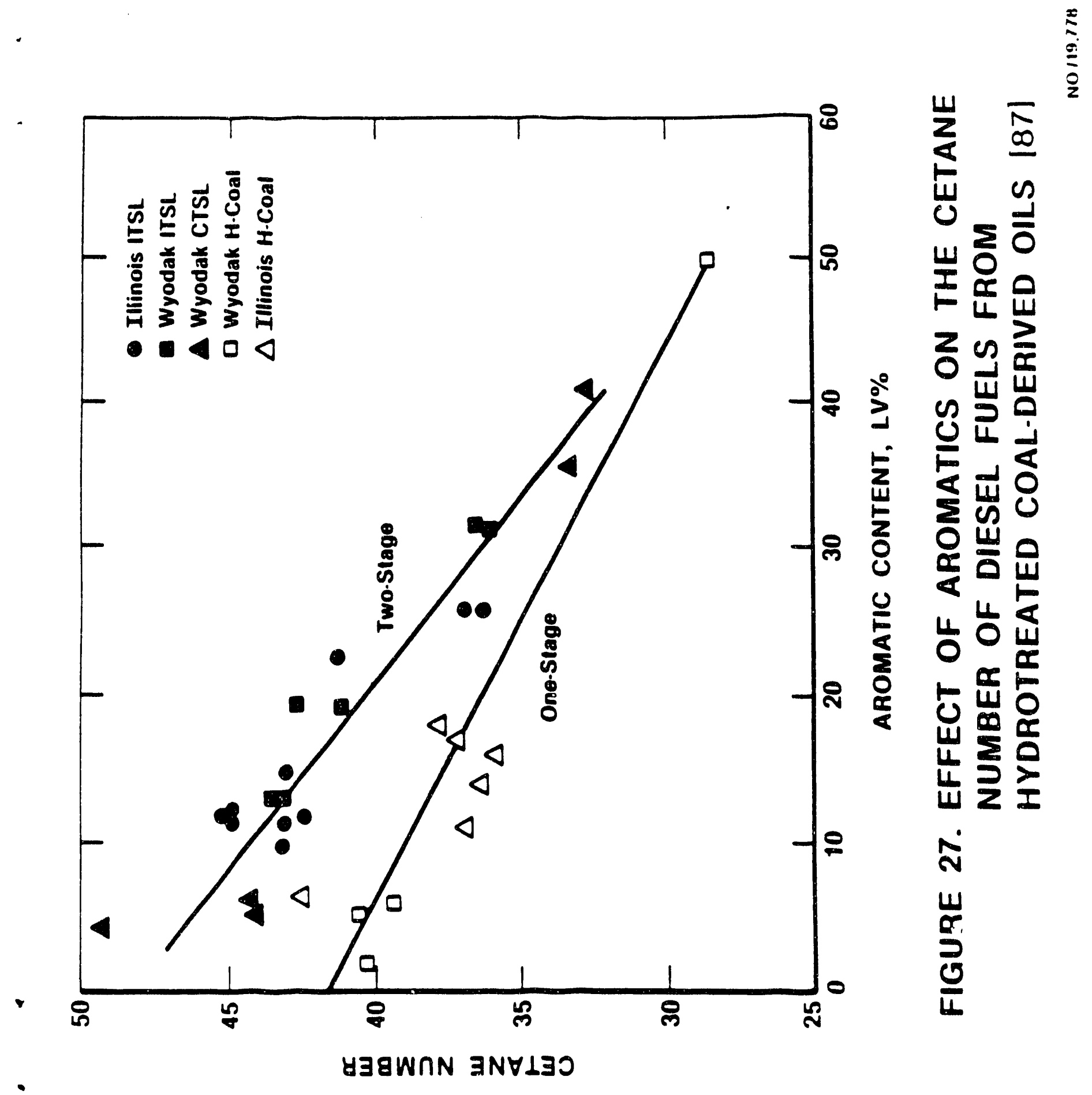




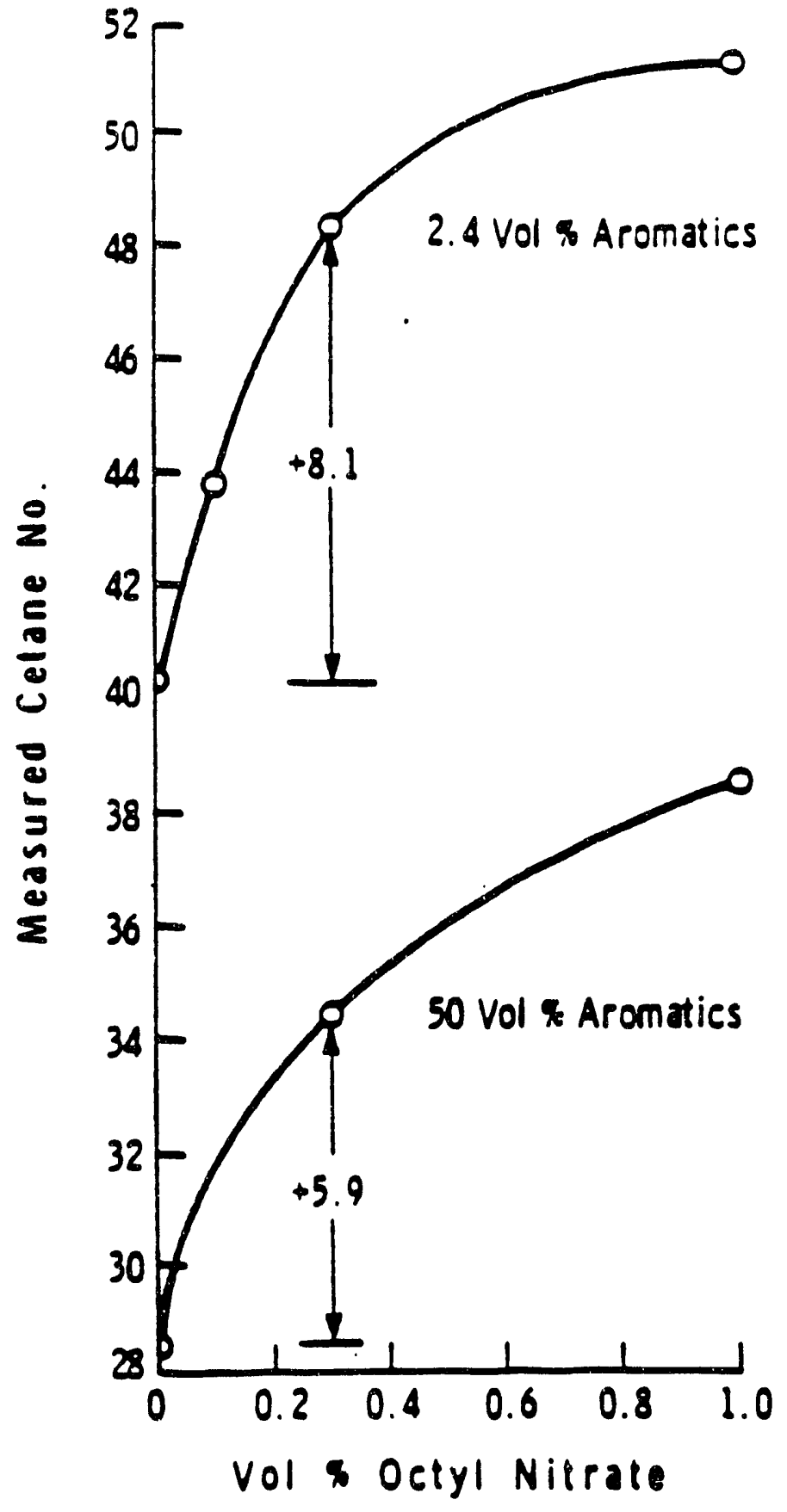

FIGURE 28. EFFECT OF OCTYL NITRATE CETANE NUMBER IMPROVER

ON TWO COAL.DERIVED

DIESEL FUELS [33] 


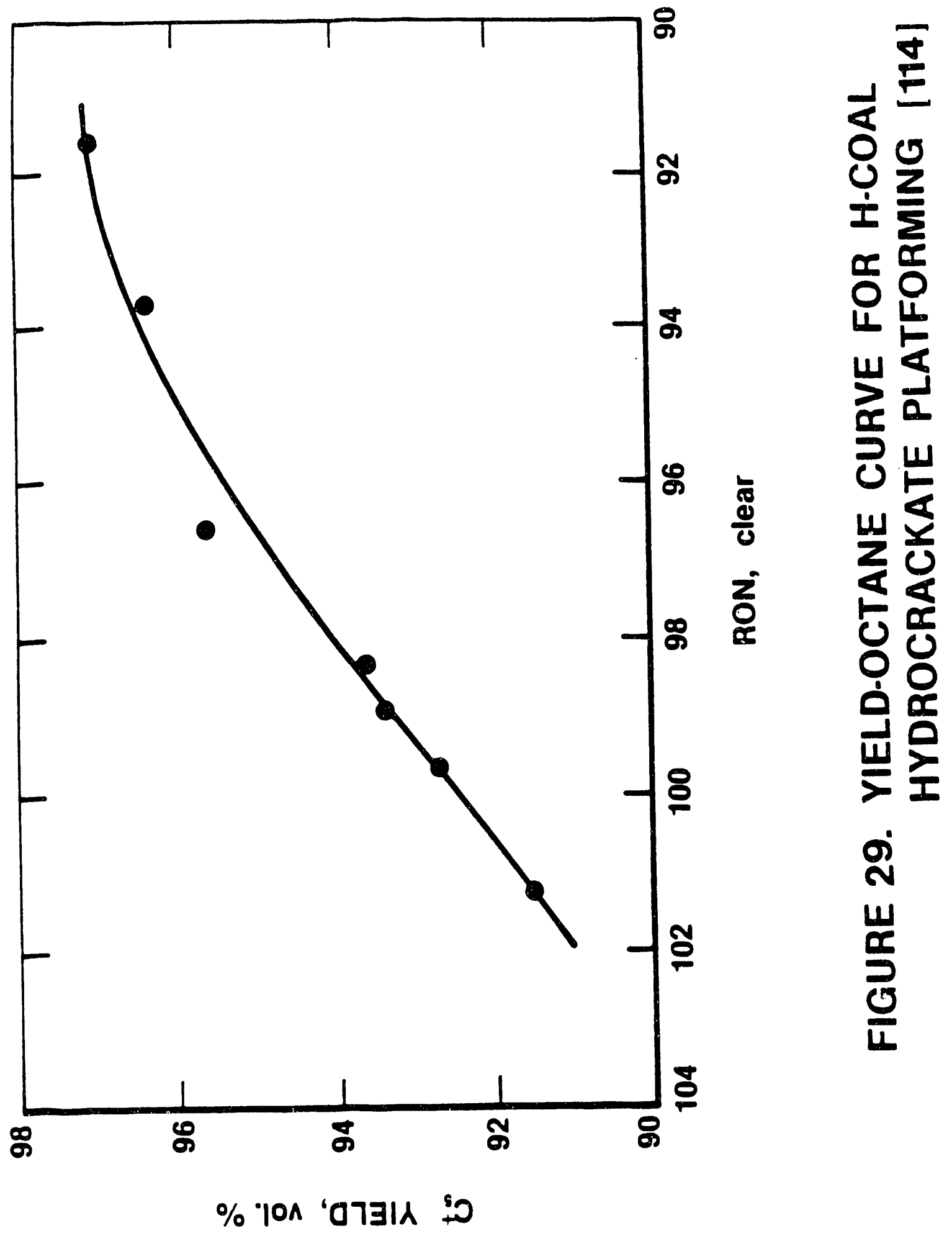



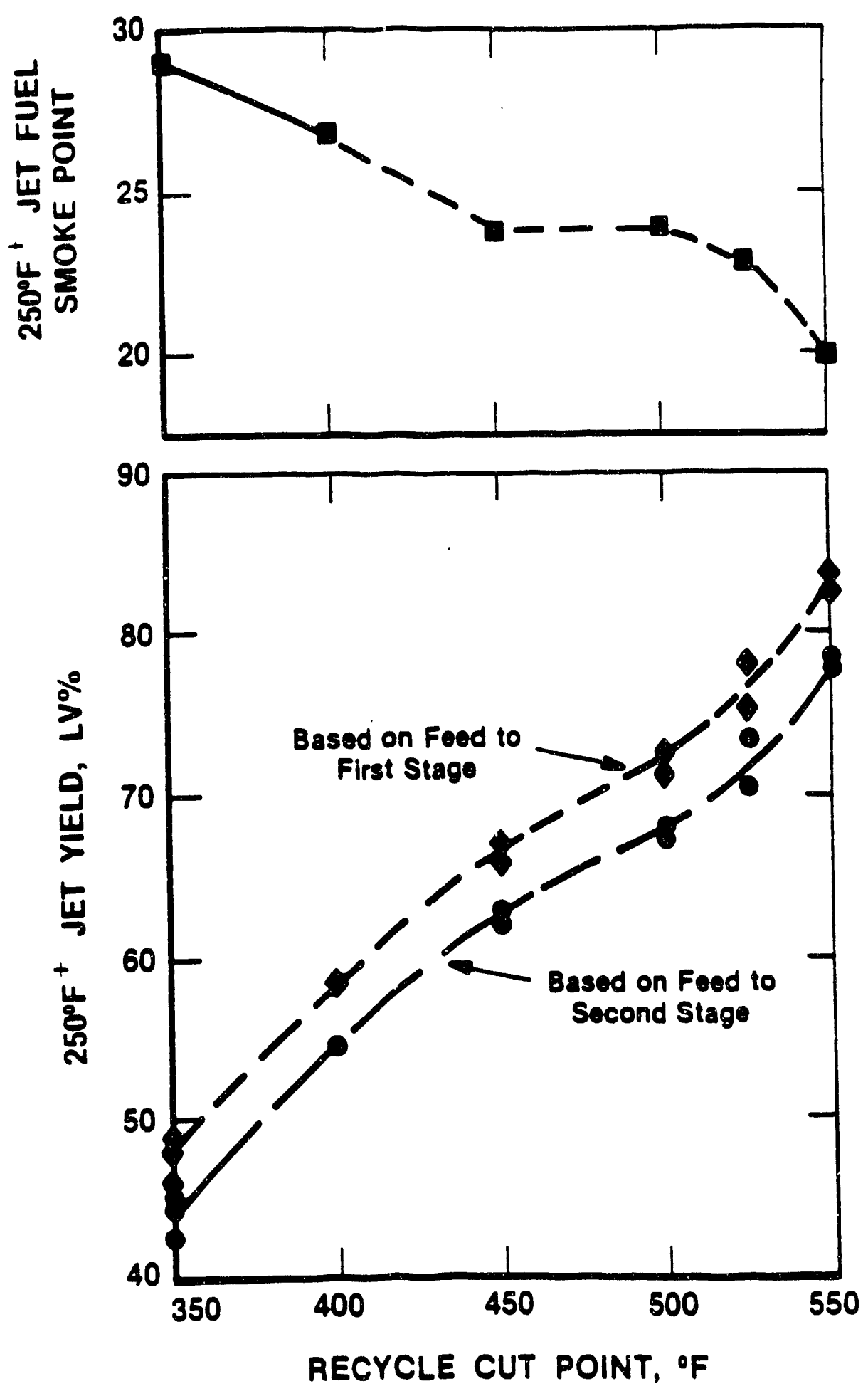

FIGURE 30. HYDROCRACKING OF HYDROTREATED ITSL OIL.EFFECT OF RECYCLE CUT POINT ON YIELD AND SMOKE POINT OF $250^{\circ} \mathrm{F}^{+}$JET FUEL FRACTION [119] 


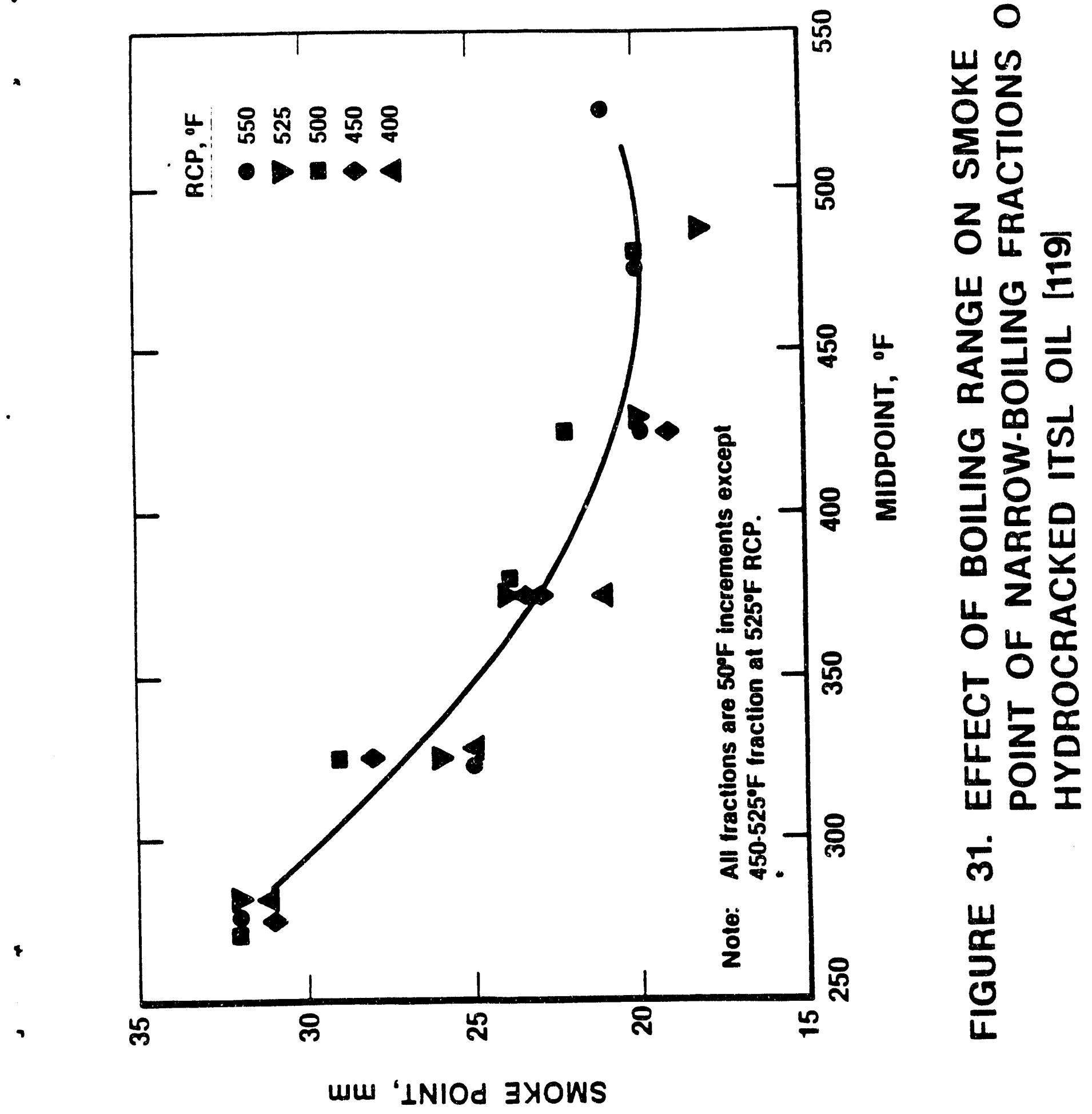

항 


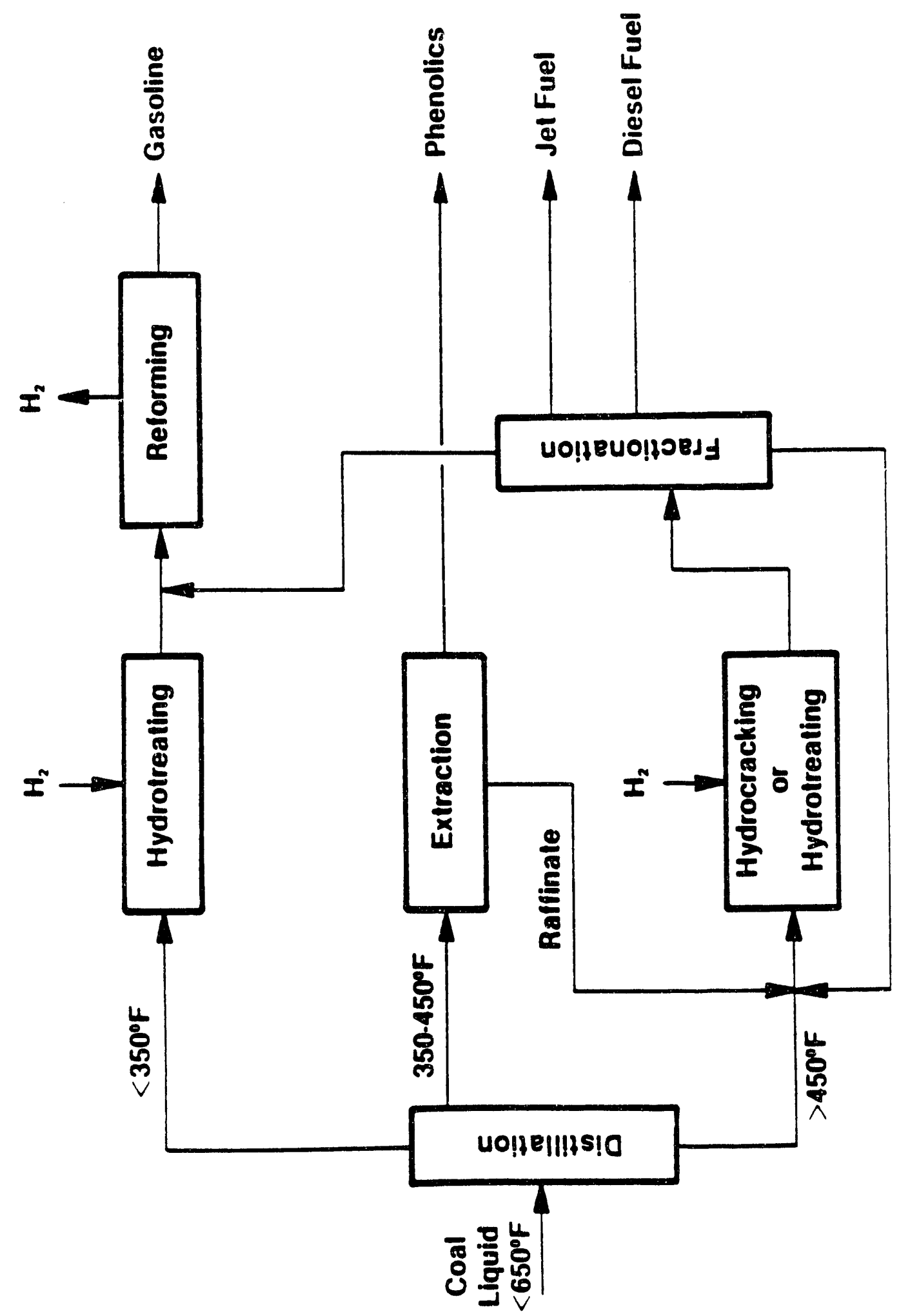

\begin{tabular}{l}
\multirow{2}{*}{} \\
$\frac{2}{2}$
\end{tabular}

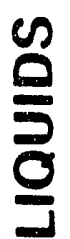

ঠิ

운

$\frac{ \pm}{5}$

$\frac{3}{\frac{3}{2}}$

ก่

$\frac{w}{\frac{\pi}{5}}$

$\checkmark$

$\frac{5}{0}$

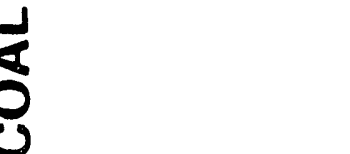

$\frac{1}{3}$ 

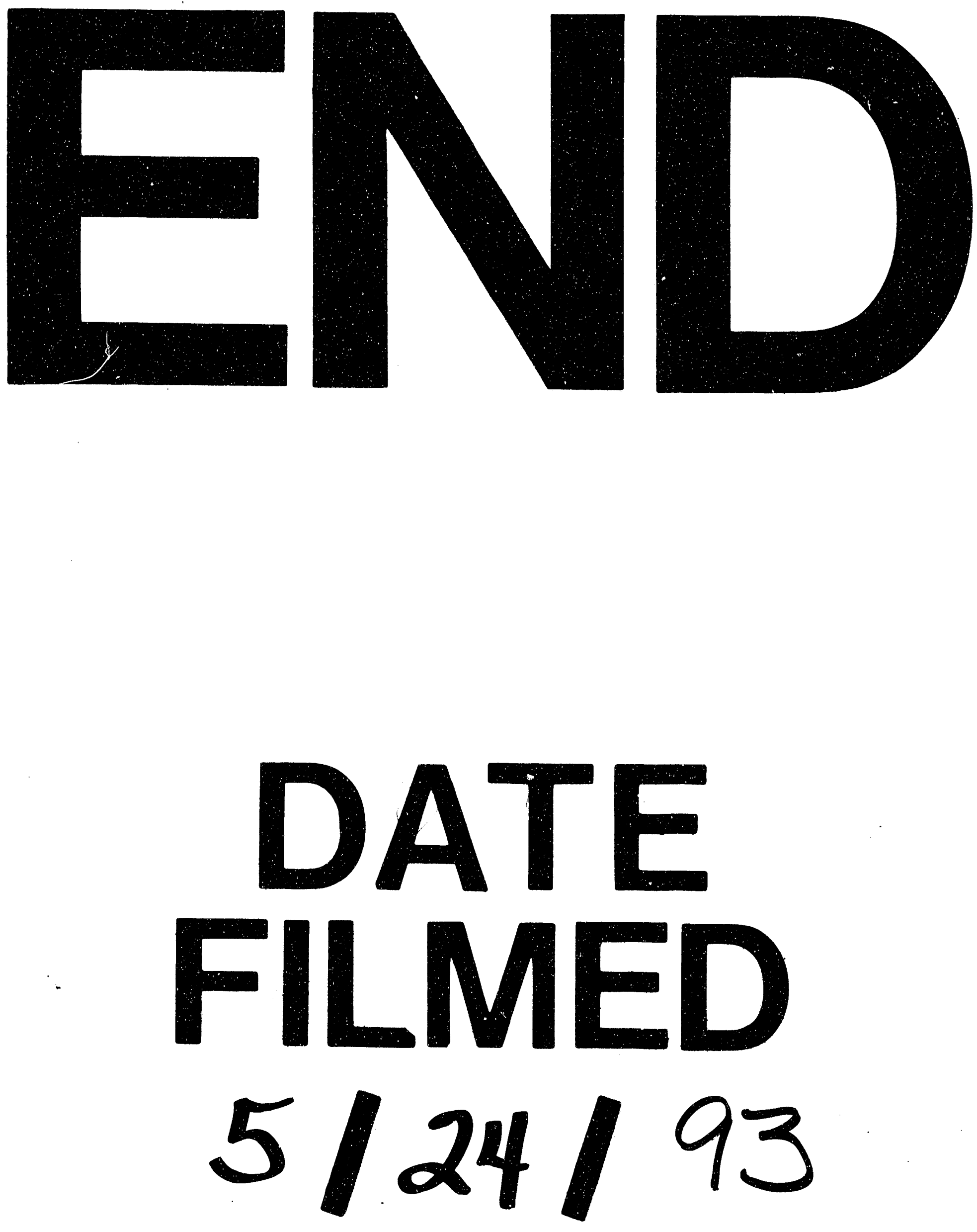

1 
